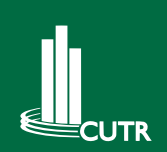

Center for Urban Transportation Research

$$
\begin{gathered}
\text { College of Engineering } \\
\text { University of South Florida } \\
4202 \text { E. Fowler Avenue, CUT100 } \\
\text { Tampa, FL 33620-5375 } \\
\text { (813) } 974-3120, \text { fax (813) } 974-5168
\end{gathered}
$$

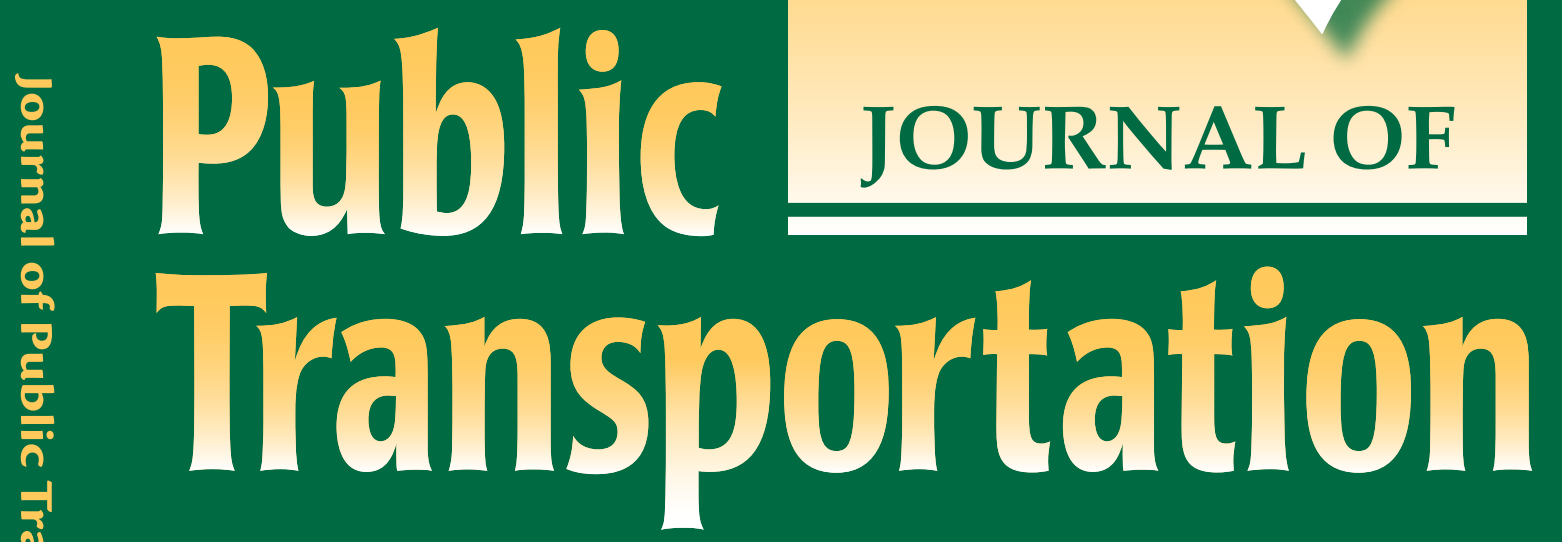

Transportation Management Associations: A Reappraisal -Erik Ferguson

Diagnostic Evaluation of Public Transportation Mode Choice in Addis Ababa - Mintesnot Gebeyehu, Shin-ei Takano

Measuring the Impacts of Employer-based Transportation Demand Management Programs on an Interstate Corridor

- Nevine Labib Georggi, Phil Winters, Sachin Rai, Liren Zhou

Documented Impact of Transportation Demand Management Programs Through the Case Study Method -Sara J. Hendricks, Nevine Labib Georggi

User Perceptions of Private Paratransit Operation in Indonesia

-Tri Basuki Joewono, Hisashi Kubota

- Casual Carpooling-Enhanced

-Kalon L. Kelley

Guaranteed Ride Home Programs: A Study of Program Characteristics, Utilization, and Cost -William B. Menczer

Examining Incentives and Preferential Treatment of Carpools on Managed Lane Facilities - David Ungemah, Ginger Goodin, Casey Dusza, Mark Burris

Employer Perceptions and Implementation of Commute Alternatives Strategies -Kai Zuehlke, Randall Guensler
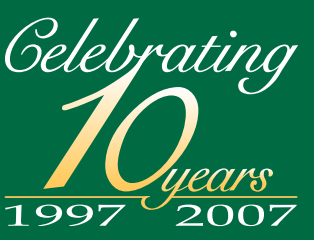


\section{EDITORIAL BOARD}

Robert B. Cervero, Ph.D.

University of California, Berkeley

\section{Chester E. Colby}

E \& J Consulting

Gordon Fielding, Ph.D.

University of California, Irvine

David J. Forkenbrock, Ph.D.

University of lowa

Jose A. Gómez-lbáñez, Ph.D.

Harvard University

Naomi W. Ledé, Ph.D.

Texas Transportation Institute
William W. Millar

American Public Transportation Association

Steven E. Polzin, Ph.D., P.E.

University of South Florida

Sandra Rosenbloom, Ph.D.

University of Arizona

Lawrence Schulman

LS Associates

George Smerk, D.B.A.

Indiana University

Vukan R. Vuchic, Ph.D., P.E.

University of Pennsylvania
The contents of this document reflect the views of the authors, who are responsible for the facts and the accuracy of the information presented herein. This document is disseminated under the sponsorship of the U.S. Department of Transportation, University Research Institute Program, in the interest of information exchange. The U.S. Government assumes no liability for the contents or use thereof
Complimentary subscriptions can be obtained by contacting:

Pam Clark, Assistant to the Editor

Center for Urban Transportation Research (CUTR)

University of South Florida

Fax: $\quad 813 \cdot 974 \cdot 5168$

Email: jpt@cutr.usf.edu

Web: www.nctr.usf.edu/jpt/journal.htm

\section{SUBMISSION OF MANUSCRIPTS}

The Journal of Public Transportation is a quarterly, international journal containing origina research and case studies associated with various forms of public transportation and re lated transportation and policy issues. Topics are approached from a variety of academic disciplines, including economics, engineering, planning, and others, and include policy, methodological, technological, and financial aspects. Emphasis is placed on the identification of innovative solutions to transportation problems.

All articles should be approximately 4,000 words in length (18-20 double-spaced pages). Manuscripts not submitted according to the journal's style will be returned. Submission of the manuscript implies commitment to publish in the journal. Papers previously published or under review by other journals are unacceptable. All articles are subject to peer review. Factor considered in review include validity and significance of information, substantive contribution to the field of public transportation, and clarity and quality of presentation. Copyright is retained by the publisher, and, upon acceptance, contributions will be subject to editoria amendment. Authors will be provided with proofs for approval prior to publication.

All manuscripts must be submitted electronically, double-spaced in Word file format, containing only text and tables. If not created in Word, each table must be submitted separately in Excel format and all charts and graphs must be in Excel format. Each chart and table must have a title and each figure must have a caption. Illustrations and photograph must be submitted separately in an image file format, (i.e., TIF, JPG, Al or EPS), having a minimum $300 \mathrm{dpi}$, and include all sources and written permissions. All supporting materials of a manuscript cannot exceed 4.5" $\times 7$ ", regardless of orientation. However, charts and graph may be submitted for use as spreads, covering two facing pages of an article.

All manuscripts should include sections in the following order, as specified:

Cover Page - title (12 words or less) and complete contact information for all authors First Page of manuscript - title and abstract (up to 150 words)

Main Body - organized under section headings

References - Chicago Manual of Style, author-date format

Biographical Sketch - of each author

Be sure to include the author's complete contact information, including email address, mailing address, telephone, and fax number. Submit manuscripts to the Assistant to the Editor, as indicated above. 


\section{Public \\ JOURNAL OF \\ Transportation}

Volume 10, No. 4, 2007

ISSN 1077-291X

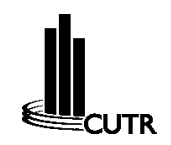

The Journal of Public Transportation is published quarterly by

National Center for Transit Research

Center for Urban Transportation Research

University of South Florida • College of Engineering

4202 East Fowler Avenue, CUT100

Tampa, Florida 33620-5375

Phone: $813 \cdot 974 \cdot 3120$

Fax: $813 \cdot 974 \cdot 5168$

Email: jpt@cutr.usf.edu

Website: www.nctr.usf.edu/jpt/journal.htm

(C) 2007 Center for Urban Transportation Research 



\section{Transportation Management Associations: A Reappraisal}

Diagnostic Evaluation of Public Transportation Mode Choice in Addis Ababa

Measuring the Impacts of Employer-based Transportation Demand Management Programs on an Interstate Corridor

Nevine Labib Georggi, Phil Winters, Sachin Rai, Liren Zhou.

Documented Impact of Transportation Demand Management Programs Through the Case Study Method

Sara J. Hendricks, Nevine Labib Georggi.

User Perceptions of Private Paratransit Operation in Indonesia

Tri Basuki Joewono, Hisashi Kubota

\section{Casual Carpooling-Enhanced}

Kalon L. Kelley

Guaranteed Ride Home Programs: A Study of Program Characteristics, Utilization, and Cost

William B. Menczer.

Examining Incentives and Preferential Treatment of Carpools on Managed Lane Facilities

David Ungemah, Ginger Goodin, Casey Dusza, Mark Burris

Employer Perceptions and Implementation of Commute Alternatives Strategies

Kai Zuehlke, Randall Guensler. 



\title{
Transportation Management Associations: A Reappraisal
}

Erik Ferguson, American University of Sharjah, United Arab Emirates

\begin{abstract}
This article reviews the results of eight national transportation management association (TMA) surveys conducted between 1989 and 2003 using meta-analytical techniques. TMAs became popular as vehicles for dealing with traffic congestion and related problems in the late 1980s. Despite their initial popularity, however, many TMAs struggled in the 1990s, and by 2002 almost half of all TMAs formed in previous years had disappeared. Median TMA annual budgets bottomed out in 1991, but have since rebounded to a new high in 2003. TMAs today are more diverse in terms of organizational structure, offer a wider variety of products and services, and have better financial security. With higher gasoline prices and a heightened awareness of the security issues related to foreign oil dependence, the market for TMA programs and services seems likely to grow, if perhaps at a modest pace, during the foreseeable future.
\end{abstract}

\section{Introduction}

Transportation management associations (TMAs) first appeared on the scene in the late 1970 s or early 1980 s, although it was not until the late 1980 s that these were consistently labeled as such. The boom years of the late 1980s and early 1990s were followed by a time of challenge, during which many formative and operational TMAs ceased to exist. In the mid-1980s, TMAs were viewed by some as a form of panacea, destined to solve not only traffic congestion, but many other societal ills as well (Leinberger and Lockwood 1986). 
Elsewhere, developers, employers, and local governments have created TMAs to find solutions to transportation problems. Besides organizing ridesharing and vanpools, promoting staggered work hours, and lobbying for government-funded capital improvements, some TMAs are expanding their role into childcare, private police, and other services for their geographic areas. It is imaginable that TMAs, born of the traffic-congestion crisis, could mature into an echelon of government well-suited to the realities of our emerging urban villages.

The reality may have been a little harsher than this early testimonial might otherwise suggest, but TMAs continue to persevere, and many are thriving in the first decade of the 21st century. The purpose of this article is to review the historical development of TMAs over the critical period of their first rise to prominence, to shed light on their prospects for growth, change, and innovation in the coming years.

One broadly inclusive definition of a TMA is "an organized group applying carefully selected approaches to facilitating the movement of people and goods within an area" (Hendricks 2004). Individual TMAs may vary in terms of their size and location, organization and management, revenues and expenses, membership and participation, and products and services offered. Alternative TMA labels include transportation management organization (TMO), transportation management initiative (TMI), and transportation management district (TMD), among others, although none of these has achieved the widespread popularity of the TMA acronym. To the extent that these alternative TMA designations represent real differences, TMOs are more action-oriented than TMAs, TMIs refer to TMA start-ups, and TMDs refer to special purpose tax districts and/or operating areas.

\section{Data}

Most of the data used to inform this article derive from eight national TMA studies conducted over a 14-year time period (1989 to 2003). These are the most complete data available on TMA planning, development, and implementation, and the most current as well:

1. 1989: The Association for Commuter Transportation (ACT) compiled its first comprehensive national TMA directory in 1989 (ACT 1989). Ferguson (1990) used these data to show that TMA characteristics varied significantly, depending on who initiated the TMA. 
2. 1990: The Urban Land Institute (ULI) evaluated transportation management through partnerships, with a particular focus on TMAs, between 1986 and 1990 (Dunphy and Lin 1990). Their report focused especially on the evaluation of TMA results, measured in terms of observed changes in travel behavior.

3. 1991: The Georgia Institute of Technology conducted a national TMA survey under a grant from the Urban Mass Transportation Administration in 1991 (Ferguson, Ross, and Meyer 1993). Ferguson (1997a) used these data to show how private sector participation affected and was affected by key TMA characteristics.

4. 1993: Commuter Transportation Services, Inc. (CTS) conducted a national TMA survey in 1993 under the auspices of ACT, focusing on policies and procedures, especially management and personnel issues (CTS 1993). Ferguson and Davidson (1995) compared these national TMA survey results with those from several previous studies.

5. 1995: ACT compiled a new national TMA directory in 1995 (ACT 1995). This directory was a revised and improved version of ACT (1989).

6. 1998: UrbanTrans Consultants, Inc. (UrbanTrans) conducted a national TMA survey under the auspices of ACT in 1998 (UrbanTrans 1998). This survey was a revised version of the one CTS conducted in 1993. The results were summarized in an appendix of ACT (2001).

7. 2002: ETF Associates (ETF) conducted a national TMA internet search in 2002. The purpose of this study was to identify the survival characteristics of all previously identified TMAs.

8. 2003: The Center for Urban Transportation Research (CUTR) at the University of South Florida conducted a national TMA survey under the auspices of ACT in 2003 (Hendricks 2004). This survey was a revised and expanded version of the ones previously conducted in 1993 and 1998.

The 1989 and 1995 data are closely related, as are the 1993, 1998, and 2003 data. The 1990, 1991, and 2002 data are unique unto themselves. The 1995 data have never before been used for scholarly research. Ferguson and Davidson (1995) gave a cursory overview of several previous TMA studies, but focused mainly on comparing the 1991 and 1993 data. Hendricks (2004) compared selected survey results from the 1993, 1998, and 2003 studies. This article seeks to provide a more 
comprehensive overview of survey results from all eight studies using a variety of formal and informal meta-analytical techniques (Hunter 1982).

\section{Organization}

ACT (1989) identified 51 TMAs nationally, of which many presumably were still in the earliest formative stage at the time the directory was compiled. Dunphy and Lin (1990) identified 72 TMAs nationally between 1986 and 1990, of which only 34 were operational at the time. Ferguson, Meyer and Ross (1993) identified 110 TMAs nationally in 1991, of which 64 responded to their survey. CTS (1993) identified 136 TMAs in 1993, of which 51 responded to their survey. ACT (1995) identified 78 TMAs nationally in 1995. UrbanTrans (1998) identified 135 TMAs nationally in 1998, of which 82 responded to their survey. Hendricks (2004) identified 146 TMAs nationally in 2003, of which 97 responded to her survey.

It would appear that the number of TMAs in the United States grew rapidly from 1989 to 1992, but leveled off sometime shortly thereafter. ETF Associates conducted a national search for TMAs in 2002 (ETF 2002), seeking answers to four simple questions:

1. How many TMAs are there?

2. In what year were they formed?

3. In what year were they disbanded (if relevant)?

4. Does the TMA have a website (if it currently exists)?

ETF (2002) identified a total of 137 active TMAs in existence in 2002, of which more than 100 currently maintained their own websites. Although the number of TMAs in existence in 2002 did not rise much above the number previously identified in 1992, it would appear that there were more "fully operational" TMAs in 2002 than in previous years.

ETF (2002) identified a grand total of 249 past and present TMAs based on information derived from various national studies, as well as personal contacts with industry professionals. Of these, 112 TMAs were confirmed no longer to exist. In fact, many of these dissolved TMAs never really got off the ground in the first place, having failed to get past the earliest formative stages of development. This information was difficult but not impossible to ascertain, despite the short institutional memory frequently associated with failed public policy experiments. 
Year of formation was identified for all 249 of the TMAs included in ETF (2002), with multiple data points available in many cases. Four previous studies provided this information for between 34 and 78 TMAs each, yielding a total of 251 data points representing 123 different TMAs (Dunphy and Lin 1990; Ferguson, Ross, and Meyer 1993; ACT 1995; UrbanTrans 1998). Year of formation was identified for an additional 81 TMAs from their websites and/or Internet correspondence. Year of formation was interpolated for the remaining 45 TMAs based on other information. Whereas definitive information was available for the year in which 204 of the 249 TMAs identified by ETF (2002) were formed, the year of dissolution could be identified for only 23 of the 112 TMAs that no longer existed.

National trends in TMA formation are illustrated in Figure 1. As can be seen from this five-year moving average, the peak year for TMA formation was 1990. The number of TMAs formed each year has declined steadily since then, although the number of active TMAs formed each year has remained relatively stable for more than a decade. It would appear that overall stability in the total number of TMAs identified nationally in previous studies dating back to 1993 is the result of two related factors:

1. The number of TMAs formed each year has declined.

2. The number of TMAs disbanded (or which failed to get past the formative stage) has declined even more.

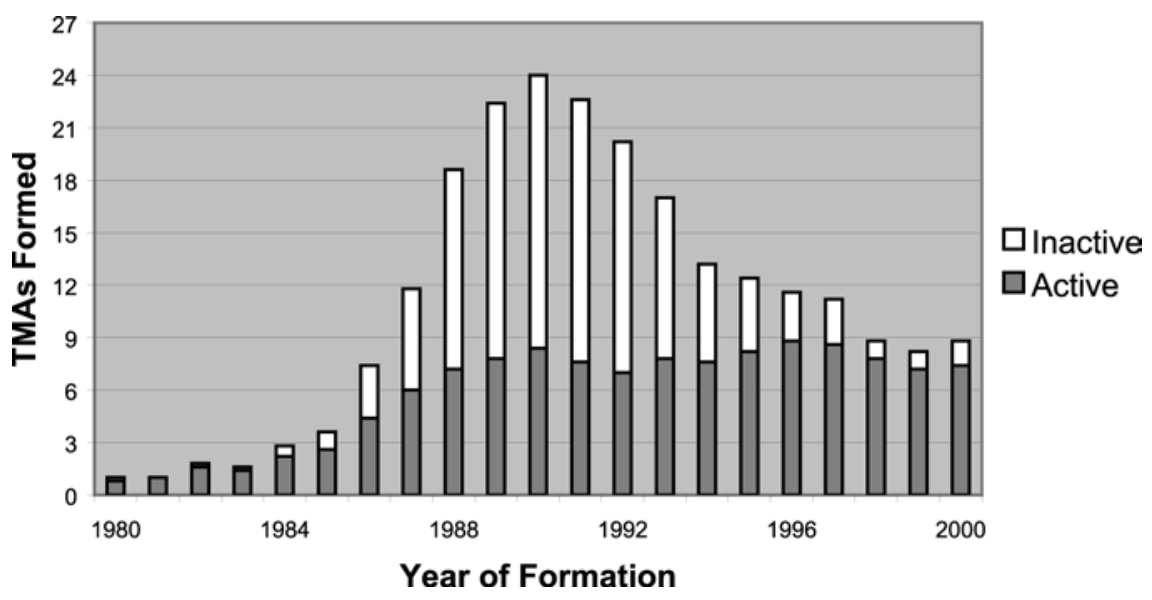

Figure 1. TMA Formation, 1980-2000 
The overall result is stability in the total number of TMAs in existence. This implies that there is still some turnover, but that the rate of turnover has decreased, the average age of TMAs has increased, and the percentage of TMAs that are "fully operational" is higher today than it was 10 or 15 years ago.

TMA formation varies across space as well as time. Western states, especially California, were early leaders in the formation of TMAs (Figure 2). Southern and midwestern states entered the field somewhat later. Although California continues to have more TMAs than any other single state, the regional distribution of TMAs is today more even than at any previous time.

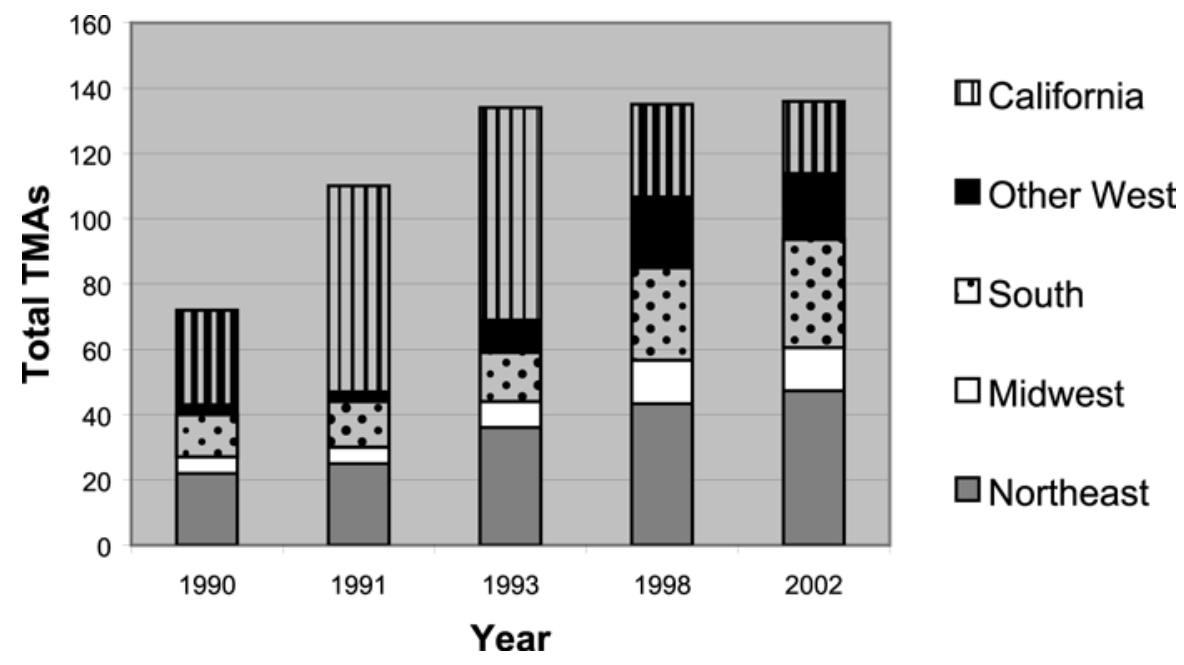

Figure 2. TMA Distribution 1990-2002

TMA formation also varies by metropolitan location. Of the 249 TMAs identified by ETF (2002), 231 (93\%) were located in the 48 standard metropolitan statistical areas with populations exceeding 1,000,000. These same metropolitan areas account for "only" 54 percent of the total U.S. population, demonstrating that TMAs are primarily a phenomenon of large urban areas. Interestingly, of the 18 remaining TMAs located in rural and small urban areas (generally speaking the latter), 13 were still in existence in 2002 , demonstrating that these out-of-the- 
ordinary small urban TMAs had a much stronger likelihood of surviving than did their large urban counterparts.

Older TMAs are significantly more likely than newer ones to use technology creatively (maintain websites, provide online matching, etc.), to be insured against liability damages, and to be incorporated as a nonprofit organization. Older TMAs have slightly larger governing boards with a somewhat higher percentage of voting members as well (UrbanTrans 1998). There are clear advantages to survival for a longer period of time, so one might well ask what caused so many TMAs to fail as innovative public/private partnerships in transportation in the early 1990 s.

\section{Finance}

One possible explanation for the demise of so many TMAs seemingly at the height of their popularity is financing, or the lack thereof. TMAs in 1989 had a median annual budget of $\$ 145,000$, which fell by 1991 to $\$ 120,000$, only to rise again to a new high of more than $\$ 200,000$ in 2003. Adjusted for inflation, TMA financial resources fell in the early 1990s, and were only restored to their 1989 level in 2003 (Figure 3). A large number of TMAs entered the market in the early 1990s, starting out with limited resources, and attempted to build a secure financial base. Many would not succeed.

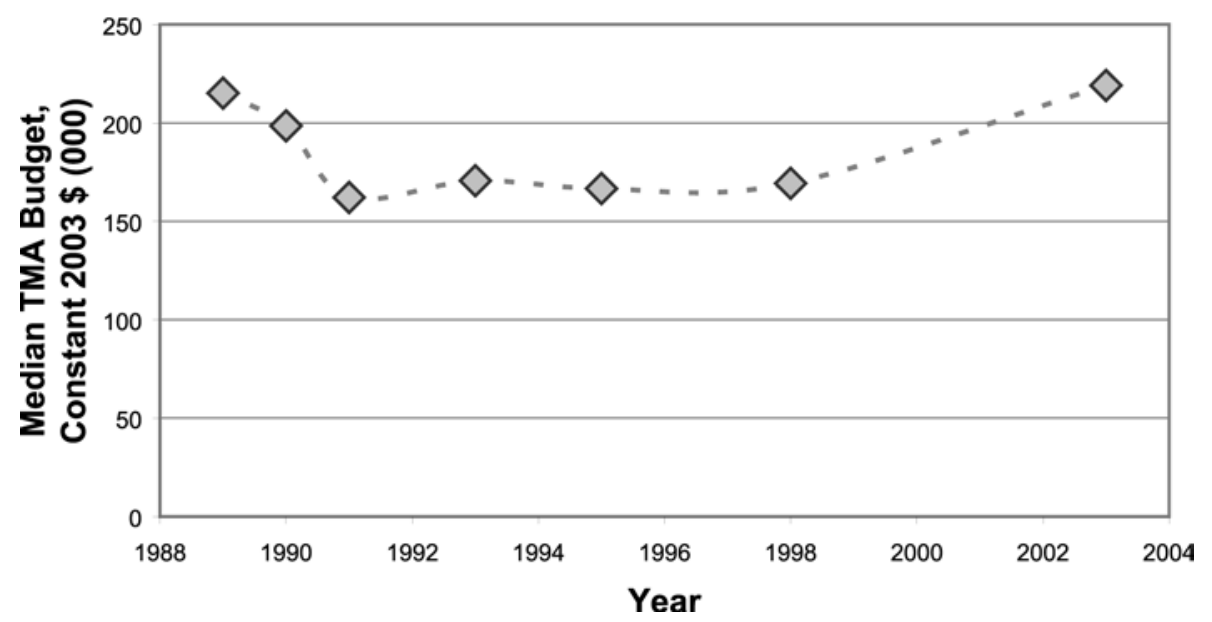

Figure 3. TMA Finance, 1989-2003 
In 1991, TMAs estimated their median annual start-up budget at $\$ 80,000$, their median current budget at $\$ 120,000$, and their median anticipated 1995 budget at $\$ 175,000$ (Ferguson, Ross, and Meyer 1993). The observed increase in TMA budgets between 1991 and 1993 was identified by some as a positive sign (Ferguson and Davidson 1995). The median budget figures for both 1995 and 1998 remained well below those projected in 1991 for 1995, however, suggesting that many TMAs continued to struggle in their efforts to achieve financial security long after the crunch in 1991 had passed. Only in 2003 was there a significant increase in TMA financial resources over previous years, and then only in nominal terms.

California TMAs differed considerably from their counterparts in other states in 1991. California TMAs in 1991 projected that membership dues would increase considerably from 10 percent at start-up to 49 percent in 1995, private grants would increase modestly from 32 percent to 40 percent, while government grants would decline precipitously from 50 percent to only 5 percent. In contrast to these major anticipated changes in California TMA financing, TMAs in other states in 1991 projected that membership dues would increase modestly from 10 percent at start-up to 24 percent in 1995, private grants would fall slightly from 22 percent to 14 percent, and government grants would fall even more slightly from 63 percent to 57 percent (Ferguson, Ross, and Meyer 1993).

Of 66 California TMAs that have been formed at one time or another, only 19 remained active in 2002, producing a rather imposing 71 percent overall failure rate. Only the Midwest joined California with a failure rate exceeding half (53\%). The average failure rate in all other parts of the country was only about 30 percent (ETF 2002). Clearly, it would seem that California TMAs suffered a much higher mortality rate than those located in other parts of the country. To the extent that financial insolvency was a primary factor in the demise of TMAs generally, it would seem that California's approach to TMA financing, eschewing government grants in favor of private grants and voluntary membership dues, may have been at least partially to blame. Many failed California TMA start-ups (as well as some of the more successful ones) were funded initially by Caltrans seed grants that were limited in duration to three years maximum (Diggins and Schreffler 1992).

California TMAs in 1998 received more revenue from membership dues and less from grants than did those in any other region, showing that their 1991 financial objectives were at least partially met. Northeastern and southern TMAs had the most resources in 1998, followed by California TMAs, those in other western states, and those in the Midwest. Northeastern and southern TMAs spent the 
most money on marketing in 1998. Northeastern and California TMAs spent the most money on direct service provision (UrbanTrans 1998).

What is perhaps most interesting about the information presented in Table 1 is that TMAs that derive a higher percentage of their revenues from membership dues would seem to have a much higher propensity to fail as well. California and midwestern TMAs both derive about 40 percent of their revenues from membership dues. Both of these groups of TMAs are underfunded, at least in relation to northeastern and southern TMAs. Both groups have shown a much higher failure rate than those in other parts of the country. Since membership dues have long been touted by industry pundits as the best and most secure form of long-term TMA funding (Dunphy and Lin 1990; Ferguson, Ross, and Meyer 1993; Ferguson and Davidson 1995), this finding is rather surprising, to say the least. It appears that purely voluntary membership organizations and dues often fail to provide sufficient financial stability for long-term TMA survival.

\section{Table 1. TMA Revenues and Expenses by Region, 1998}

\begin{tabular}{|c|c|c|c|c|c|}
\hline Budget Category & Northwest & Midwest & South & $\begin{array}{l}\text { Other } \\
\text { West }\end{array}$ & California \\
\hline Office operations & $\$ 62,185$ & $\$ 81,250$ & $\$ 86,154$ & $\$ 51,073$ & $\$ 49,392$ \\
\hline Marketing amd promotion & $\$ 46,923$ & $\$ 25,625$ & $\$ 53,808$ & $\$ 14,854$ & $\$ 24,658$ \\
\hline Capital services & $\$ 29,107$ & $\$ 417$ & $\$ 1,442$ & $\$ 6,563$ & $\$ 12,100$ \\
\hline Other services & $\$ 32,417$ & $\$ 1,042$ & $\$ 17,404$ & $\$ 9,792$ & $\$ 32,333$ \\
\hline Other & $\$ 28,179$ & $\$ 0$ & $\$ 35,423$ & $\$ 26,052$ & $\$ 22,350$ \\
\hline Total & $\$ \overline{198,810}$ & $\$ 108,333$ & $\$ 194,231$ & $\$ 108,333$ & $\$ 140,833$ \\
\hline \multirow{6}{*}{$\begin{array}{l}\text { Other } \\
\text { Total }\end{array}$} & $\$ 42,932$ & $\$ 42,583$ & $\$ 45,643$ & $\$ 23,973$ & $\$ 62,912$ \\
\hline & $\$ 143,568$ & $\$ 41,417$ & $\$ 110,071$ & $\$ 58,973$ & $\$ 45,890$ \\
\hline & $\$ 11,719$ & $\$ 0$ & $\$ 6,429$ & $\$ 14,732$ & $\$ 809$ \\
\hline & $\$ 4,427$ & $\$ 0$ & $\$ 23,750$ & $\$ 5,357$ & $\$ 11,015$ \\
\hline & $\$ 18,708$ & $\$ 24,333$ & $\$ 6,964$ & $\$ 18,393$ & $\$ 32,316$ \\
\hline & $\$ 221,354$ & $\$ 108,333$ & $\$ 192,857$ & $\$ 121,429$ & $\$ 152,941$ \\
\hline
\end{tabular}




\section{Membership}

Membership in most TMAs is predicated on the interaction between two clearly separate and distinct principles. First, most TMAs serve a specific geographic location, which may include one or more cities, counties, travel corridors, activity centers, and/or an entire metropolitan region, or some significant part thereof. Second, within any given TMA's clearly designated service area boundaries, it may seek to recruit members, volunteers or participants from among land owners, developers, employers, employees, residents, local governments, state agencies, transportation providers, and other potentially interested individuals and organizations in either the public or the private sectors.

Well over 90 percent of all TMAs have membership programs of some type currently in existence. Service area definitions vary considerably by region (Figure 4). Most northeastern TMAs serve regions or multiple jurisdictions. Most southern TMAs serve CBDs or suburban/fringe activity centers. A plurality of midwestern TMAs serve individual cities or single jurisdictions. Western TMAs are the most diversified in terms of service area characteristics (UrbanTrans 1998).

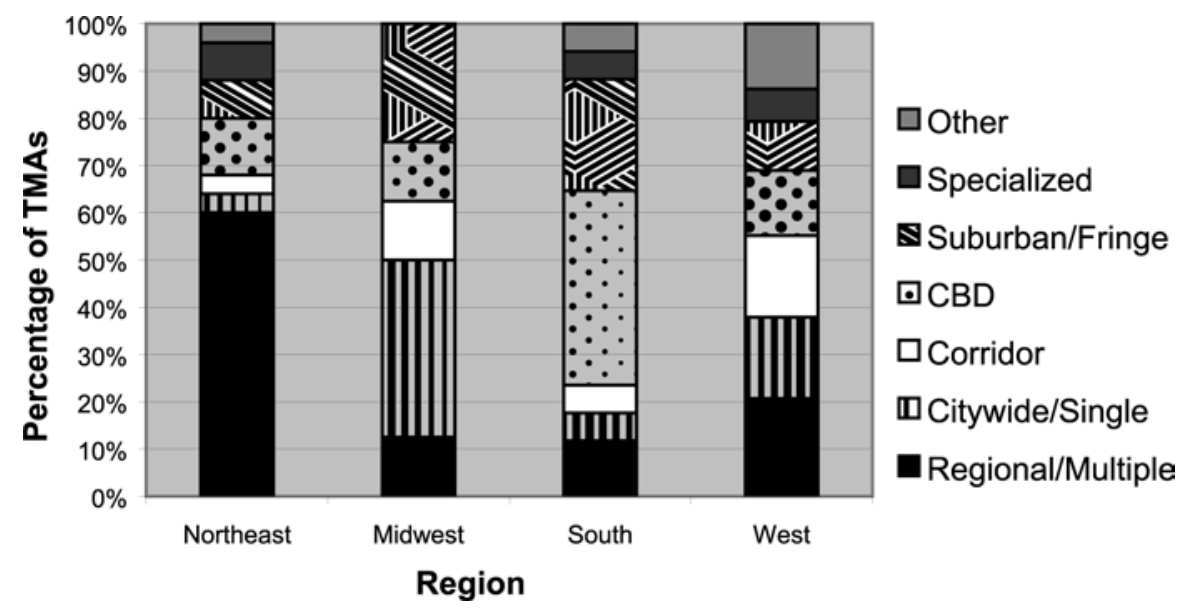

Figure 4. TMA Type by Region, 1998

Despite such obvious differences in service area boundary definitions, there are no major differences in the populations served by TMAs in different parts of the country. The median TMA has 25 corporate members and serves a geographic 
area that encompasses 25,000 commuters nationally. This varies from a high of 36 members and 30,000 commuters in the South to a low of 20 members in the Midwest and 16,600 commuters in the West. Although there are some differences among regions in terms of total TMA membership, such differences do not appear to vary systematically based on either service area boundaries or financial characteristics.

In 1998, 62 percent of all TMA members nationally were businesses, 17 percent government agencies, 8 percent developers, 5 percent nonprofits, and 2 percent residents. These figures varied hardly at all by region. The average TMA reported a net gain of five members in 1998, with only two of 62 respondents admitting to an actual net loss in TMA membership during that year. TMAs in the South claimed the greatest market penetration, with 52 percent of the potential market included within their membership, followed by the West at 36 percent. The Northeast and Midwest lagged behind at 22 percent each (UrbanTrans 1998).

The most popular TMA recruitment strategy in 1998 was peer-to-peer contact, which basically entailed using current members to recruit new ones in the private sector (73\%), followed by personal letters from the TMA executive director (66\%), brochures (56\%), cold calls (44\%), and governmental or contractual mandates (16\%) of one kind or another. The single most effective technique in 1998 was peer-to-peer contacts (43\%), followed by mandates (30\%), letters (13\%) and anything else (14\%). Clearly, mandates were underutilized as a recruitment device in 1998, based on their reported effectiveness (UrbanTrans 1998).

It would appear that membership is rising for almost all TMAs, at least among those choosing to participate in the 1998 national study. TMA membership does not seem to relate to either TMA finance or the propensity of TMAs to succeed or fail, however, at least not in any observably systematic fashion. This suggests that TMA membership, at least by itself, cannot explain either TMA financial success or the survivability of TMAs. This once again seems strange and unexpected, requiring further thought and analysis.

\section{Services}

Membership has its benefits, and it is these benefits that determine the desirability of membership, which is the propensity of individuals or firms to join organizations as members, to maintain their organizational membership in good standing, and to pay their membership dues on a regular and timely basis, if and as required 
for the continuation of both their membership and any of its associated benefits. In the case of nonprofit organizations, the question of membership benefits can at times become somewhat more obscure to public view. Is membership in a TMA a form of profit-making activity, a charitable contribution to society, a necessary adjunct to other related decisions (such as the location of economic activities across both time and space), all of the above, or none of the above?

TMAs may choose to provide specific programs and services to their members, to nonmembers located within their designated service area boundaries, or to others located outside their service area boundaries on a special or case-by-case basis (Ferguson 1997a). TMAs may choose to provide particular programs and services directly, indirectly through brokerage or referral, or not at all. TMAs may chose to provide programs and services at cost, at a higher price than cost (as a private firm does to generate profits, or simply to cover indirect overhead in the case of nonprofit organizations), at a lower price than cost (a form of subsidy), at no cost (free of charge, although one could argue that membership dues broadly cover all or at least a portion of related costs), or even at negative cost (in the form of a cash payment, voucher, or other financial instrument that exceeds the out-of-pocket cost to the commuter or other designated beneficiary of the program and/or service).

Member services may be distinguished in terms of pricing policy as loss leaders (subsidies), nonprofit (break even), or income producing (profit centers). Most nonprofits, including most TMAs, base their pricing schedules on a cost or subsidy basis, ignoring overhead, treating office and administration expenses as a sunk cost. Subsidies paid to corporate members and their employees are a tangible benefit of TMA membership, a return on the investment of membership fees that have already been paid. Subsidies paid to nonmembers and their employees are nominally free, but may come with strings attached, such as the expectation of future membership, and are thus linked to marketing and recruitment efforts. Subsidies paid to firms and employees outside the designated TMA service area boundary typically include no future expectations whatsoever, and are thus essentially a form of charity (Table 2).

Prices higher than market rates (or the TMA's cost basis, whichever is higher) are a form of profit taking, although in the case of indirectly provided services there may be some basis for a modest mark-up to cover TMA costs related to brokerage or referral services, similar to those imposed by travel agencies, for example. Some products and services may not be available at all, either because the TMA does not provide these services, or more generally because these are not provided, are 


\section{Table 2. TMA Services by Membership, Location, and Fee or Charge}

\begin{tabular}{|l|l|l|l|l|l|l|}
\hline & \multicolumn{2}{|c|}{ Members } & \multicolumn{2}{c|}{ Non-Members } & Outside Service Area \\
\hline Fee or Charge & Direct & Indirect & Direct & Indirect & Direct & Indirect \\
\hline $\begin{array}{l}\text { Not available } \\
\text { (at any price) }\end{array}$ & Not offered & Unavailable & Excluded & Unavailable & Excluded & Unavailable \\
Higher price & Profit & Mark-up & Profit & Mark-up & Profit & Mark-up \\
$\begin{array}{l}\text { Market price } \\
\text { (or cost basis) }\end{array}$ & Market & Broker & Market & Referral & Market & Referral \\
$\begin{array}{l}\text { Lower price } \\
\text { Free (no charge) }\end{array}$ & Subsidy & Subsidy & Marketing & Marketing & Charity & Charity \\
$\begin{array}{l}\text { Negative price } \\
\text { (cash bonus) }\end{array}$ & Incentive & Inclusive & Marketing & Marketing & Charity & Charity \\
\hline
\end{tabular}

not suitable, or are not relevant to the local service area. Membership-based TMAs need not offer any of their products and services to either nonmembers or firms and employees outside their designated service area. If and when TMAs do offer benefits of any kind to nonmembers, it is not necessary for them to employ the same pricing policy. A TMA may exclude any nonmember from receiving a product or service that is available to members, or to offer such products and services to nonmembers at a higher price.

The only previous national study to consider direct versus indirect TMA services offered was the 1991 Georgia Tech study (Figure 5). The most common type of TMA service offered in 1991 was information (e.g., carpool, vanpool, and transit information). The least likely was on-site services, which includes childcare, banking, etc. With the exception of on-site services, which were relatively uncommon in 1991, all services were offered indirectly by between 15 percent and 27 percent of responding TMAs, a limited range of variability that suggests TMAs were more limited by the availability of selections than selective in their choice of indirect services to offer.

The 1993 CTS, 1998 UrbanTrans and 2003 CUTR surveys each included a set of related questions about the availability of TMA services to TMA members (regardless of price) and to nonmembers (with or without a nonmember price surcharge). The use of TMA services as a marketing tool (provided to nonmembers at the same price as members) has increased gradually from 38 percent in 1993 to 40 percent in 1998 and 43 percent in 2003. The use of price surcharges to exclude 


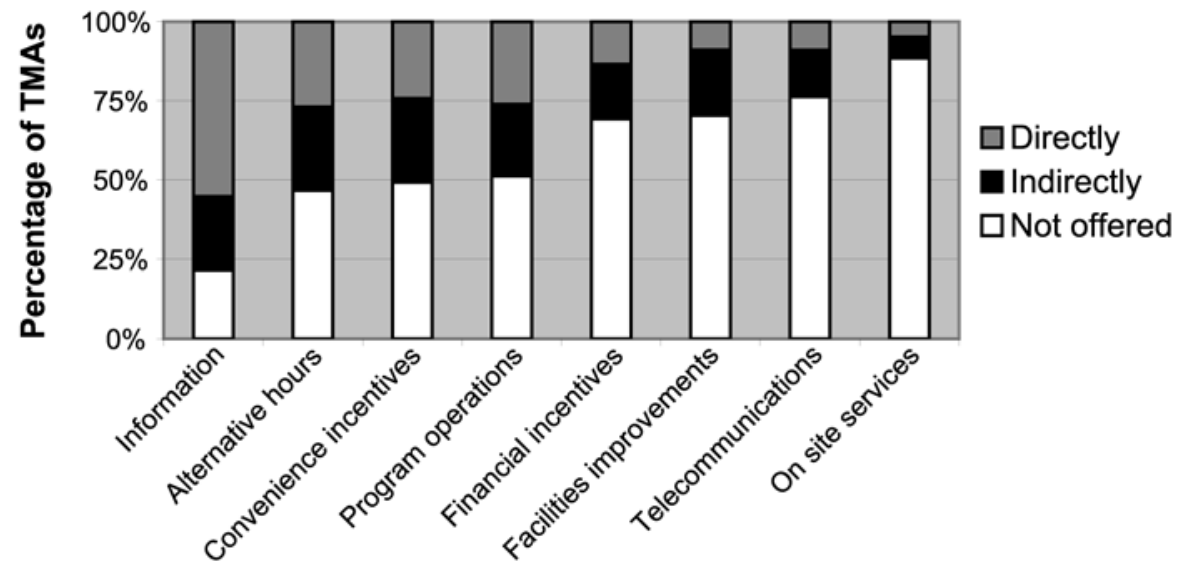

Services Offered

Figure 5. TMA Services, 1991

nonmembers from TMA services (a negative enticement to join the TMA) has fallen from 29 percent in 1993 to 10 percent in 1998 and 6 percent in 2003.

The number of TMA services included in each successive ACT survey has grown, and the labels in many cases have changed, sometimes expanding, sometimes contracting, the definition of the specific service in question. Four general types of TMA services are included in all three national ACT TMA surveys. These include marketing and public relations, employer services, commuter services, and parking services.

Marketing and public relations include regional and local advocacy and promotional materials and events. These services have declined in importance relatively speaking in recent years, but continue to be among the most popular offered by TMAs (Table 3). Employer services include ETC training, trip reduction plan preparation, site design assistance, and employee surveys. These services have declined slightly as well, with a new service, tax benefit assistance, emerging as the most popular among these in 2003. Commuter services have expanded over the years, increasing in both number and relative popularity between 1993 and 2003. Parking services are the least common type of TMA service, and declined slightly between 1998 and 2003. 







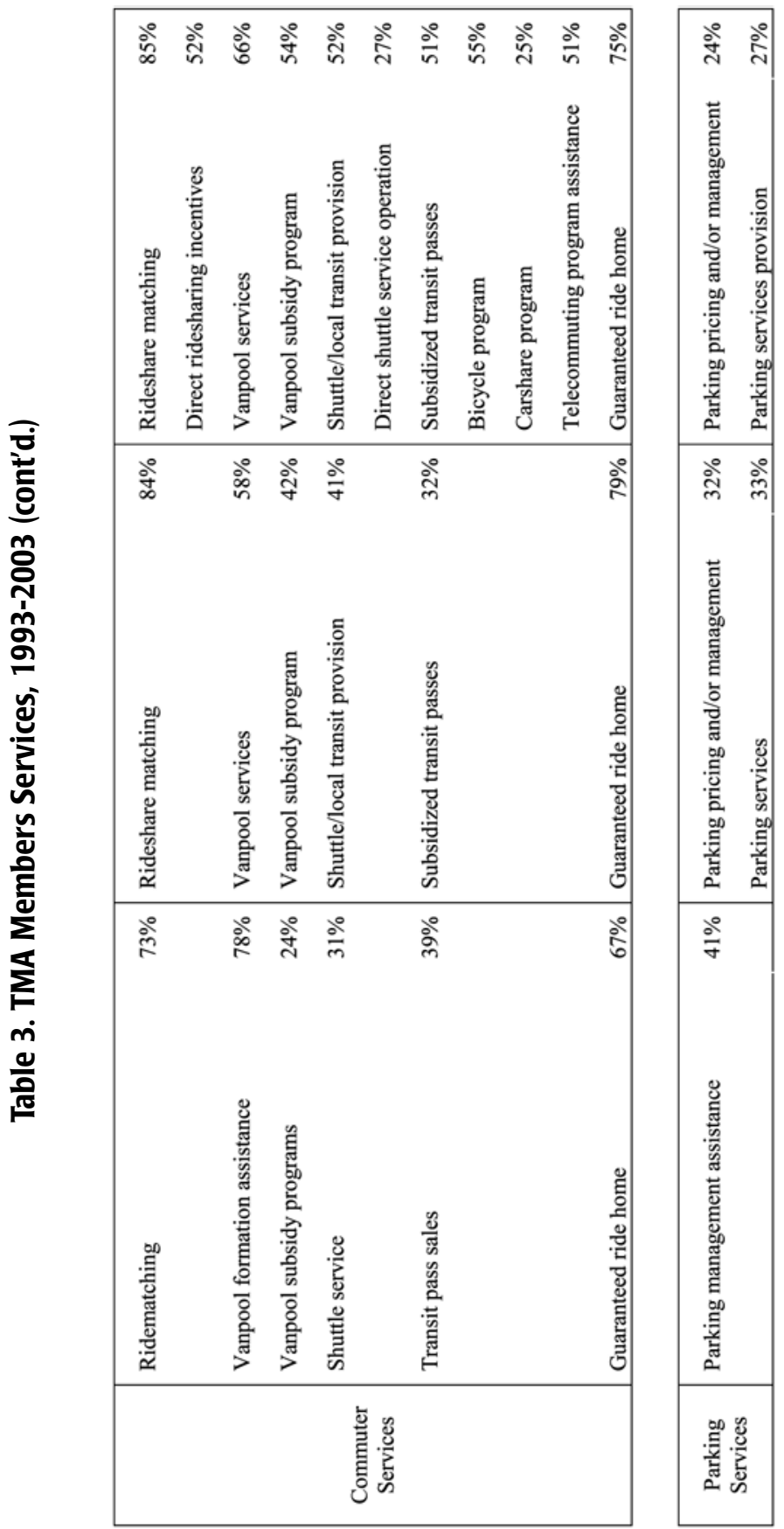




\section{Personnel}

Another possible explanation for the poor financial performance of TMAs in the 1990s might be inadequate staff or inappropriate hiring decisions. In 1998, the average TMA had 2.0 full-time employees, 0.8 part-time employees, and 0.3 contract employees, for a total of 3.1 employees. The median TMA had only 1 full-time employee, 1 part-time employee, and no contract employees, for a total of just 2 staff, 1 of these being part time. Clearly, TMAs are not overstaffed. The average "value added" of the median TMA employee is $\$ 75,000$ per year, which is not unreasonable given the extent to which TMAs contract out for staff, products, and/or services.

In 1998, 33 percent of all TMA executive directors indicated their professional background was in transportation, followed by marketing (16\%), administrative (12\%), public relations (11\%), planning (11\%), and nonprofit or government management (11\%). This would seem to be an appropriate mix to manage publicprivate partnerships in transportation. In 1998, the most common TMA executive director educational backgrounds included public service (13\%), planning (12\%), education (11\%), marketing (9\%), public relations ( $9 \%)$, transportation (8\%), and a rather large contingent in the "other" category (22\%). Executive director educational backgrounds were more diverse than professional backgrounds, with less specific emphasis on transportation. This is a reflection of the educational system in the United States and indeed the entire world, which only began to pay serious attention to transportation as an academic subject and professional training issue in the last few decades (Figure 6).

In 1998, as TMA staff size increased, so too did the average qualifications of those hired to do the job. While 38 percent of 1-person TMA staff were contract employees and 50 percent of 2-person TMA staff worked part-time, fully 72 percent of all 3- or more person TMA staff were full-time employees. As TMA staff size increased, so too did each of the following critical parameters:

- The percentage of TMAs that contracted out for specific services, had written personnel policies, and conducted annual employee reviews

- The executive director's average level of education, annual salary, years of service with the TMA, and overall years of experience in TDM

- The number of employee benefits offered (especially paid holidays, seminar and conference attendance, professional membership dues, and medical, dental, life and vision insurance) 


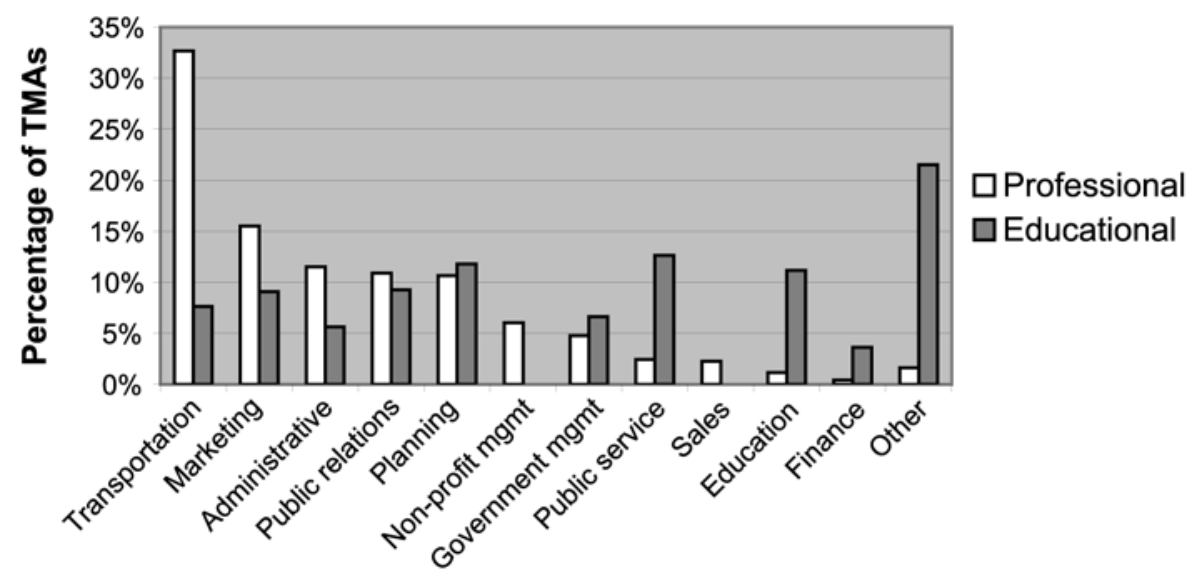

Executive Director Background

Figure 6. TMA Leadership, 1998

It would seem that TMA personnel have suitable backgrounds for the work they are engaged in. Further, the level of professional expectations and rewards both increase as the number of TMA employees increase. Thus, it would seem that TMA growing pains are not associated with either insufficient staff or inadequate staff preparation.

\section{Evaluation}

An evaluation of TMA performance may contribute to a better understanding of past, present, and future expectations. TMA evaluation has been the subject of intense scrutiny in the past (Dunphy and Lin 1990), and may once again become a topic of research interest in the future. TMA evaluation may take place at several different levels of analysis, using diverse information sources, to serve a multiplicity of goals and objectives. Some people seem to expect TMAs to perform congestion mitigation miracles on shoestring budgets (see Ferguson, Ross, and Meyer 1993), while others think TMAs do not require any evaluation at all (see Ferguson and Davidson 1995). The answer presumably lies somewhere in between.

TMA evaluation criteria may include one or more of the following general types of performance measures (ACT 2001): 
1. Corporate leadership and involvement

2. Suitability of goals and objectives

3. Development and deployment of strategic plan

4. Financial management systems

5. Degree of external visibility

6. Effectiveness of programs

7. Measures of commuter and member satisfaction

8. Other (completely open-ended, tailored to the specific needs and requirements of individual TMA boards, members, clientele, etc.)

These are organized from the most general to the most specific. The first five are all internalized performance measures, which relate to the way the TMA sees itself in the broader context of urban travel markets, regional transportation policy, and corporate client concerns. The sixth and seventh are those most often found in external reviews of TMA performance as an objective evaluation outcome. Clearly, TMA evaluation is mainly, although not entirely exclusively, a subjectively experienced phenomenon, at least from the TMA industry perspective.

In 1989, only 14 percent of 51 responding TMAs indicated they had any experience with evaluation of any kind (ACT 1989). Dunphy and Lin (1990) devoted much of their attention to measuring TMA performance, with mixed results. Their relatively few examples of drive-alone rates and peak-period congestion in suburban activity centers with and without TMAs are good indicators of how a TMA evaluation ought to be done, but rather poor examples of TMA performance in practice. This is mainly because most TMAs were not yet operational at the time the ULI study was conducted.

In 1991, the performance indicators most commonly felt to be appropriate by TMAs in terms of their own evaluation criteria were (1) changes in employee mode of travel (89\%) and (2) changes in the number of vehicle trips made (80\%). In 1991, 18 percent of 60 responding TMAs had completed, 17 percent were conducting, 10 percent had proposed, and 55 percent had not performed any type of evaluation within the last three years (Ferguson, Ross, and Meyer 1993).

Most TMA evaluations in 1991 were conducted externally (73\%). The most common TMA auditors included government agencies (68\%), private consultants (37\%), and universities (16\%). In 1991, more than half (54\%) of responding TMAs indicated they intended to conduct at least one evaluation within the next three 
years, while 36 percent did not intend to conduct any evaluations within the next five years. Nonetheless, 47 percent of all responding TMAs in 1991 reported that annual evaluations were the best approach, at least under ideal circumstances. These results reinforce the notion that TMA evaluation is potentially controversial, possibly even a divisive issue within the TMA community itself.

In 1993, 54 percent of responding TMAs provided at least one example of an evaluation product, while 25 percent provided two or more such examples (CTS 1993). Clearly, as time passed, more TMA evaluations were being performed. ACT (1995) included text describing three different qualitative aspects of program evaluation, including the following:

1. Monitoring and enforcement

2. Successes to date

3. Reports and publications

No analysis was performed on any of these items in 1995, nor were specific results from any of these references either confirmed or denied through external validation. In the 1998 national TMA survey, for the first time no questions of any kind were included on the subject of TMA evaluation (UrbanTrans 1998). Clearly, there is a dearth of recent information on measurable performance indicators for TMA programs, services, and related activities.

Ferguson (1997a) provides two concrete examples of TMAs that achieved measurable changes in employee mode split among commuters within their designated service areas, but quantitative results such as these remain relatively scarce within the TMA community. One should recall, however, that the median TMA serves 25,000 commuters on an annual budget of $\$ 150,000$, which yields just $\$ 6$ per commuter per year. Even assuming that only the employees of TMA members are served, the median TMA still has only $\$ 18$ annually per employee to spend on modifying travel behavior, reducing traffic congestion, and improving air quality. This is a quite modest sum to work with. For TMAs to produce measurable results, one might conclude that greater financial and staff resources than these would be required.

This depends entirely on the performance measure used to evaluate TMA productivity. Reducing traffic congestion in an urban environment is an expensive proposition, even when it falls into the "low cost" category. Recruiting TMA members and encouraging alternative forms of transportation is less costly than reducing traffic congestion. Increasing people's awareness of alternatives is the least costly 
of all, though it may not be associated with measurable changes in local or regional transportation system performance.

\section{Expectations}

As previously demonstrated, much of the confusion over TMA performance in relation to external expectations is due to variations, not so much in financial resources or staff commitments, but rather much broader social and organizational goals and objectives. There are in fact almost as many different types of TMAs as there are TMAs themselves, since each is described uniquely by the individual circumstances that led to its creation in the first place. Nonetheless, it is possible to discern several broad categories of endeavor within the TMA domain, based primarily on service type rather than service area or boundary definitions, for example. These different levels of TMA service may include some or all of the following:

1. Promoter: Advocacy, marketing, and promotions

2. Broker: Brokerage and referral services

3. Provider: Direct provider of corporate and/or commuter services, focusing on the exchange of information and other more tangible incentives

4. Owner/operator: Facility and equipment manager, e.g. parking, vanpools, shuttle, etc.

The first type listed is the most common among TMAs today, the last perhaps least common. Many TMAs provide a range of services covering more than one of these categories. It may be that some or all of these service delivery options operate on a hierarchical or sequential basis, with those listed above required for those below to become fully operational, but this hypothesis has yet to be tested on real data, which at present do not exist for that purpose.

As TMA products and services grow increasingly more sophisticated, their cost may be expected to rise, and demands for adequate performance monitoring and evaluation will increase correspondingly. TMAs that focus their efforts primarily on promotional activities may not have much of an impact on commuter travel markets, other than as a form of emergency back-up, with some additional appeal as a vehicle for improved public relations.

There may be some hope yet for more tangible TMA results. Ferguson (1997b) developed a model of carpooling as a function of average fleet fuel economy, real 
gasoline prices, and a trend variable representing demographic changes in society. When this model is applied to more recent national data, it suggests that carpooling may have done slightly better than expected in the 1990s, even if there was a slight decline in carpooling mode split overall between 1990 and 2000 (Figure 7). Even more dramatic, the rapid rise in driving alone that occurred in both previous decades did not materialize in the 1990s (Figure 8).

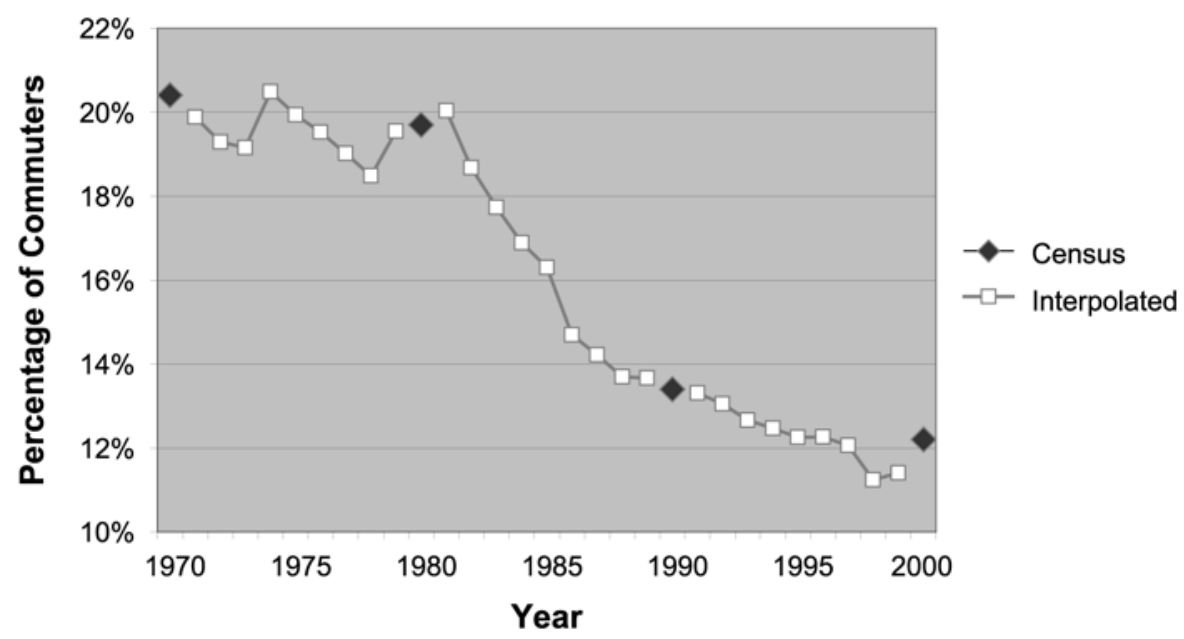

Figure 7. National Trends in Carpooling, 1970-2000

The large declines in transit use and walking observed in previous decades were not repeated in the 1990s (U.S. Census Bureau 2000). It thus appears that something happened in the 1990s that did not occur in either the 1970s or 1980s before it.

Washington State, which currently possesses the only mandatory statewide commute trip reduction ordinance in the country, actually saw a slight decline from 73.9 percent driving alone to work in 1990 to 73.3 percent in 2000. King County, which includes the City of Seattle, saw a much larger decline from 71.4 percent driving alone in 1990 to 68.7 percent in 2000, a 3.7 percent shift from driving alone to work into alternative modes of travel. 


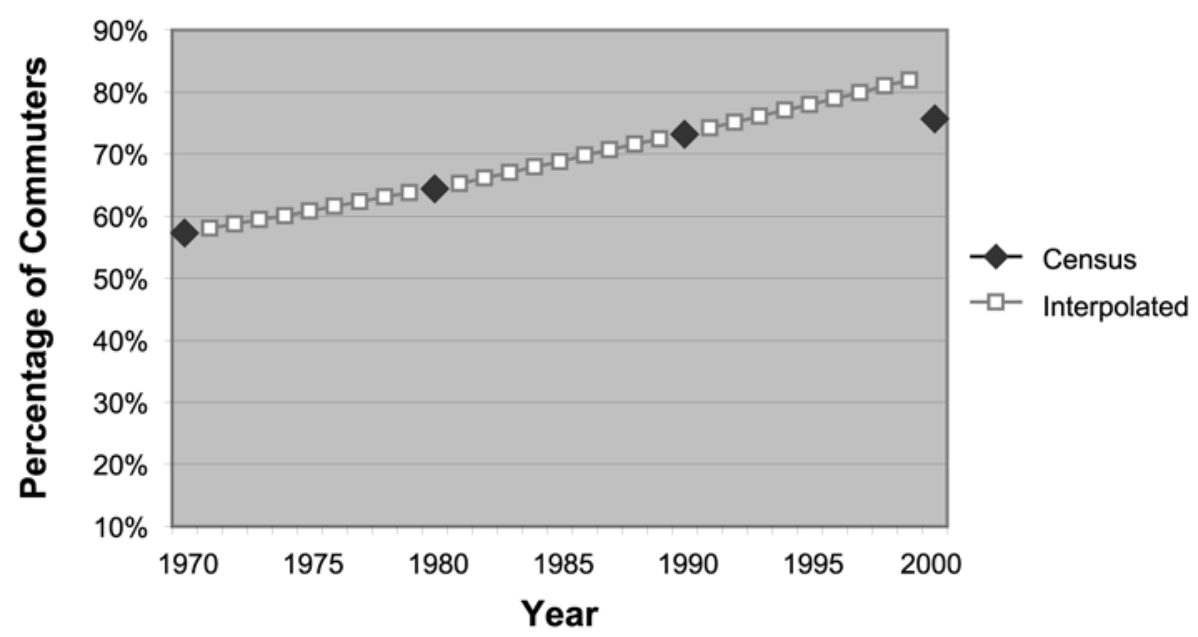

Figure 8. National Trends in Driving Alone, 1970-2000

While one cannot attribute any of Washington State's success in commute trip reduction specifically to the performance of individual TMAs, there are a number of these in Washington State, most formed within the last 10 years. These results do suggest that TDM can work on a large regional scale, at least under some circumstances. TMAs may be one of the institutional mechanisms needed to implement more efficient and effective TDM programs in the future.

\section{Conclusions}

TMAs have evolved considerably over the last 25 years. Initially conceived as public/private partnerships formed on a voluntary basis to advocate on behalf of local stakeholders to alleviate traffic congestion in rapidly growing transportation corridors and suburban activity centers, TMAs today have diversified into a broader range of institutional forms serving a wider range of organizational interests.

After a shake-out in the 1990s, the number of TMAs nationally is rising slowly but steadily. TMAs have access to more financial resources today, promising greater long-term stability and viability. TMAs are more widely and evenly spread out across the nation, although their primary focus continues to be large metropolitan areas and their environs. TMAs in recent years have concentrated more on provid- 
ing services directly to commuters, and less on indirect services though employers and regional advocacy.

TMAs are an integral part of regional TDM programs in many urban areas of the United States, as well as an increasing number of cities in other parts of the world (Hendricks 2004). TMAs are unlikely to grow into an alternative form of governmental entity, as predicted by Leinberger and Lockwood in 1986, however, these highly innovative organizations are likely to maintain an important role as niche TDM service providers in a global economy, or "flat world," increasingly dominated by large urban agglomerations, which is where TMAs seem to thrive best.

\section{Acknowledgements}

The author would like to thank Diane Davidson, David Ungemah, and Sara Hendricks for access to data and/or results from the 1993, 1998, and 2003 national TMA studies. The author would also like to thank Chris Park, Rebecca Garrison, Malaika Rivers, Rhonda Abell, and many other members of the ACT TMA Council for their assistance in identifying current information on national TMA activities. Finally, the author would like to thank several anonymous TMA liaisons at metropolitan planning organizations, regional transit agencies, and state departments of transportation in the United States and abroad for their help in identifying relevant information on the formation of TMAs within their respective jurisdictions.

\section{References}

Association for Commuter Transportation. 1989. TMA directory. 2nd ed. Washington, DC: ACT.

Association for Commuter Transportation. 1995. TMA directory. 3rd ed. Washington, DC: ACT.

Association for Commuter Transportation. 2001. TMA handbook. 2nd ed. Denver, CO: ACT.

Commuter Transportation Services. 1993. 1993 TMA policies and procedures survey. Los Angeles, CA: CTS.

Diggins, L., and E. N. Schreffler. 1992. Status report on transportation management association development in California. Transportation Research Record 1346: 53-61. 
Dunphy, R. T., and B. C. Lin. 1990. Transportation management through partnerships. Washington, DC: Urban Land Institute.

ETF Associates. 2002. TMA Internet search. Unpublished data based on comprehensive telephone interviews, broadcast e-mails, and exhaustive web searches. Atlanta, GA: ETF.

Ferguson, E. 1990. Transportation demand management: planning, development and implementation. Journal of the American Planning Association 56(4): 442-456.

Ferguson, E. 1997a. Privatization as choice probability, policy process and program outcome: The case of transportation management associations. Transportation Research A 31(5): 353-364.

Ferguson, E. 1997b. The rise and fall of the American carpool: 1970-90. Transportation 24(4): 349-376.

Ferguson, E., and D. Davidson. 1995. Transportation management associations: An update. Transportation Quarterly 49(1): 45-60.

Ferguson, E., M. Meyer, and C. Ross. 1993. Transportation management associations. Transportation Quarterly 47(2): 207-219.

Hendricks, S. J. 2004. Results of the 2003 TMA survey. Tampa, FL: Center for Urban Transportation Research.

Hunter, J. E. 1982. Meta analysis. Beverly Hills, CA: Sage.

Leinberger, Christopher B., and Charles Lockwood. 1986. How business is reshaping America. The Atlantic Monthly 258(4): 43-52.

U.S. Census Bureau. 2000. 2000 census of population and housing, journey to work statistics. Washington, DC: U.S. Census Bureau.

UrbanTrans Consultants. 1998. 1998 TMA operational survey. Denver, CO: UrbanTrans.

\section{About the Author}

ERIK FerGUSON (eferguson@aus.edu) teaches transportation planning, urban economics, and research methods at the American University of Sharjah. He coined the term "transportation demand management" while working for Commuter Transportation Services, Inc. in Los Angeles in 1984. He has written extensively on 
the subjects of transportation demand management in general and transportation management associations in particular. His current research interests include parking planning by design and the art and science of public policy decision making. 


\title{
Diagnostic Evaluation of Public Transportation Mode Choice in Addis Ababa
}

\author{
Mintesnot Gebeyehu and Shin-ei Takano \\ Hokkaido University, Sapporo, Japan
}

\begin{abstract}
The major modes of public transportation in the city of Addis Ababa are buses and taxis. There is no rail transit within the city. The existing public transportation is of a low quality because of the limited number of buses and taxis, poor management, and bad behavior of drivers. Despite these prevailing problems, efforts to make an empirical study of the city's urban transportation are insignificant. This research attempts to develop an ordered logit model to examine citizens' perceptions of the bus condition, as a determining factor for their choice of bus transportation, and to develop a binary logit model to analyze traveler choice behavior. A diagnostic analysis is undertaken based on the two models. The result shows that citizens' perceptions of the three chosen bus condition aspects (fare, convenience, and frequency) have a significant influence on public transport mode choice.
\end{abstract}

\section{Introduction}

Mobility in the developing world is often characterized by travel demand that far exceeds supply (Darido 2003). The city of Addis Ababa is not an exception to this reality. Demand for urban public transport services is growing in the same way as in other third-world cities (Jacobs et al. 1986). Public transportation is an important element in day-to-day activities in Addis Ababa because (1) it is a relatively 
affordable means of transportation, (2) infrastructure is not sufficient to promote private vehicle ownership, and (3) it promotes reduction of environmental pollution and traffic accidents. Even though the role of public transportation is noteworthy, the service provision is not good enough as the demand is much greater than the supply. As the population and the number of passengers increase, service should be expected to grow. This is not practically true in the city because of financial and managerial constraints. Despite prevailing problems, efforts to make an empirical study of the transportation in the city are insignificant.

Several analytical methods have been developed to examine the mode choice behavior of travelers. The influence of socioeconomic issues and mode-related variables are examined using discrete choice analysis. Traveler modal choice is generally explained by three basic factors: characteristics of the journey (e.g., length, time of day, and purpose), the socioeconomic characteristics of the traveler, and the transport system (Thamizh Arasan et al. 1996). Other literature identifies added characteristics of the trip itself, land use and urban design (Racca and Ratledge 2004). The most common methods of mode choice analysis are binary and multinomial logit models (Ghareib 1996; Mintesnot and Takano 2005a; Yamamoto et al. 2000; Thamizh Arasan et al. 1996). No literature documents the application of ordered models for mode choice as choice does not lend itself to ranking responses. It is choosing one mode over the other. Other issues like seat belt usage and injury analysis are analyzed using an ordered logit model for the dependent variables of ranking response (Hamad and Easa 1998; Wang and Kockelman 2005). However, travelers' mode choice is not only dependent on their socioeconomic backgrounds. Their perception of the mode also plays a significant role in affecting their choice. Because the public transportation alternatives in Addis Ababa are limited to only two modes, making perception analysis is essential in addition to the widely used mode choice model. Perception responses have ranking nature, so they could be analyzed using ordinal models. Using perception analysis, this study attempts to provide an improved modeling of the mode choice. Unlike previous studies on mode choice, this study uses the ordered logit model with four ordered levels of perceptions on three mode-related aspects (fare, convenience, and frequency); the result is then be used as an input for the mode choice model.

\section{Methodology and Objectives}

The research approach implemented in this study involved data collection, analysis of bus company data, and modeling travelers' perception on bus transportation 
and its influence on public transport mode choice using logit models. A survey was undertaken in September 2004 to understand better the respondents' attitudes on bus service. The study's objective is to analyze the public transport modal choice behavior of residents and their perception on bus condition parameters as a determining factor in their bus choice. In this study an ordered logit model is developed to examine citizens' perceptions on bus conditions, in addition to the widely used binary logit model, which is developed for public transport mode choice analysis.

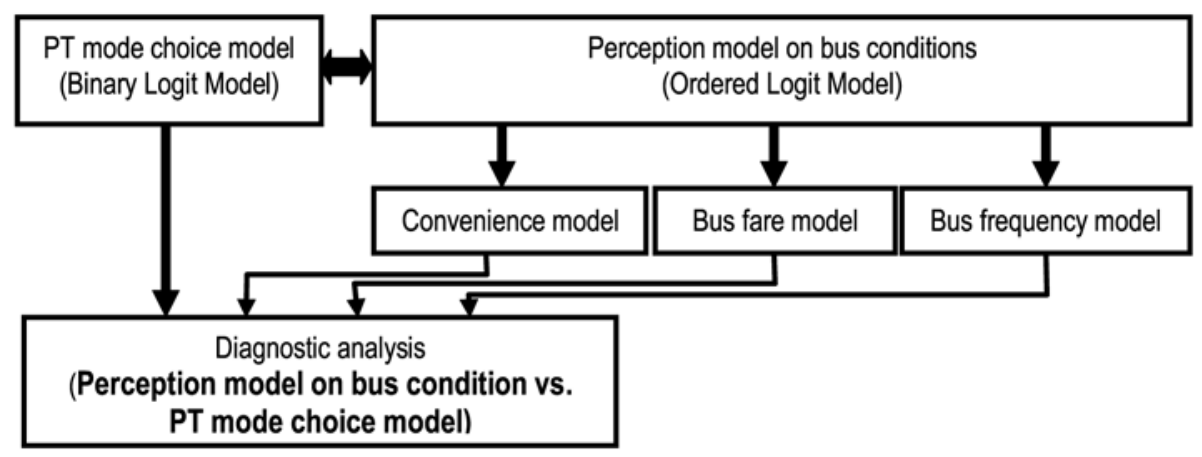

\section{Figure 1. Framework of the Proposed Models}

\section{Background}

Addis Ababa, the capital city of the Federal Democratic Republic of Ethiopia, is located in the center of the country. Established in 1886, the city has experienced several planning changes that have influenced its physical and social growth. The area of Addis Ababa is 530.14 square kilometers. Its current population is about 2.57 million (2005 estimate), about 3.9 percent of the population of Ethiopia. It also represents about 26 percent of the urban population of Ethiopia. Addis Ababa has an aggregate population density of 4,847.8 persons per square kilometer. Public transport in the city consists of conventional bus services provided by the publicly owned Anbessa City Bus Enterprise, taxis operated by the private sector, and buses used exclusively for the employees of large government and private companies. The role of bicycles in urban transport is insignificant (World Bank African Region Scoping Study 2002). The road network of Addis Ababa is limited in extent and right of way. Its capacity is low, on-street parking is prevalent, and 
the pavement condition is deteriorating. Despite a large volume of pedestrians, there are no walkways over a large length (63\%) of the roadway network. This is a major concern because it contributes to the increased pedestrian involvement in traffic accidents (10,189 accidents occurred in 2004 [Ethiopian Roads Authority 2005]).

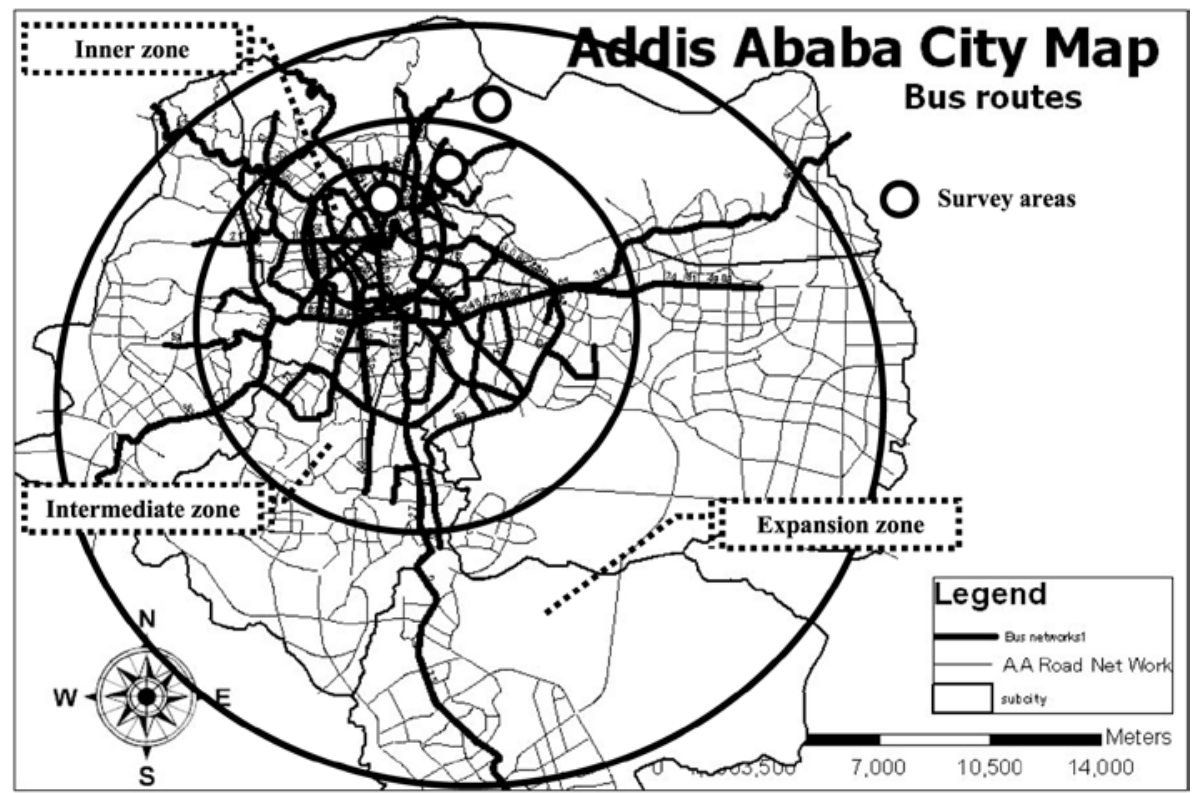

Figure 2. City of Addis Ababa

\section{Overview of Public Transportation}

In the city of Addis Ababa, the dominant public transportation modes are city buses and taxis. Although buses have 30 seats each, they have a carrying capacity of 100 people in a crowded situation. Taxis have a carrying capacity from four (small taxis) to 12 persons (large taxis). There is no rail transit within the city. Car ownership among residents is very low, so the majority depend on buses and taxis for their day-to-day mobility. Walking is the main means of transportation for a number of residents. Unlike other cities in the country, bicycle use is insignificant because of topographic inconveniences. 
Buses provide 40 percent of the public transport in the city; taxis account for 60 percent (Ethiopian Roads Authority 2005). The city is currently experiencing horizontal growth, but the bus service has not exhibited growth proportionate enough to accommodate this increase. Analysis results of the transit availability indices show that only the city center is being served by the existing bus networks while urban expansion areas have low transit availability (Mintesnot and Takano 2006). Taxis experience many operating constraints, including bad driver behavior, excessive fares, and high accident rates. This study examines the existing situation as an input for future public transport development and improvement programs.

\section{Buses}

Only one bus company, Anbessa City Bus Enterprise, operates in the city. The company is mandated to provide public transport services to the city and the surrounding areas. It operates a fleet of 524 conventional buses, with an average vehicle age of six years, and provides scheduled services along 93 routes as well as nonstop rapid (express) services. An additional 0.1 Ethiopian birr per trip (1USD $=8.8$ Ethiopian birr) is charged for express services. The basic bus service has a system of flat fares for the route with a range varying according to distance. There are about 1400 bus stops, 16 service check stations, and 3 main bus terminals. The Anbessa City Bus Enterprise, which is subsidized by the city council, moves around 40 percent of all public transport passengers. The absence of an up-to-date structure in the bus company, shortage of finance, and reduction of the subsidy from the government are the biggest challenges for the service. The lack of welldefined performance parameters to evaluate the operational efficiency of the bus company is also a constraint for development. The prospects are the year-to-year increase in the number of bus users (Anbessa City Bus Enterprise 2004; Mintesnot and Takano 2005b; SEMALY Public Transport Consultants 2001). Spatial analysis of the bus network coverage shows that only the city center, which is where commercial activities are abundant, boasts high bus network availability. Areas with low or no bus network availability are in localities where the city is exhibiting trends in urban expansion and where residential developments are underway. According to the recent structural synthesis map, prepared by the Addis Ababa Master Plan Revision Office, those sections are strategic areas for city expansion development (Office of the Revision of Addis Ababa Master Plan 2002). 


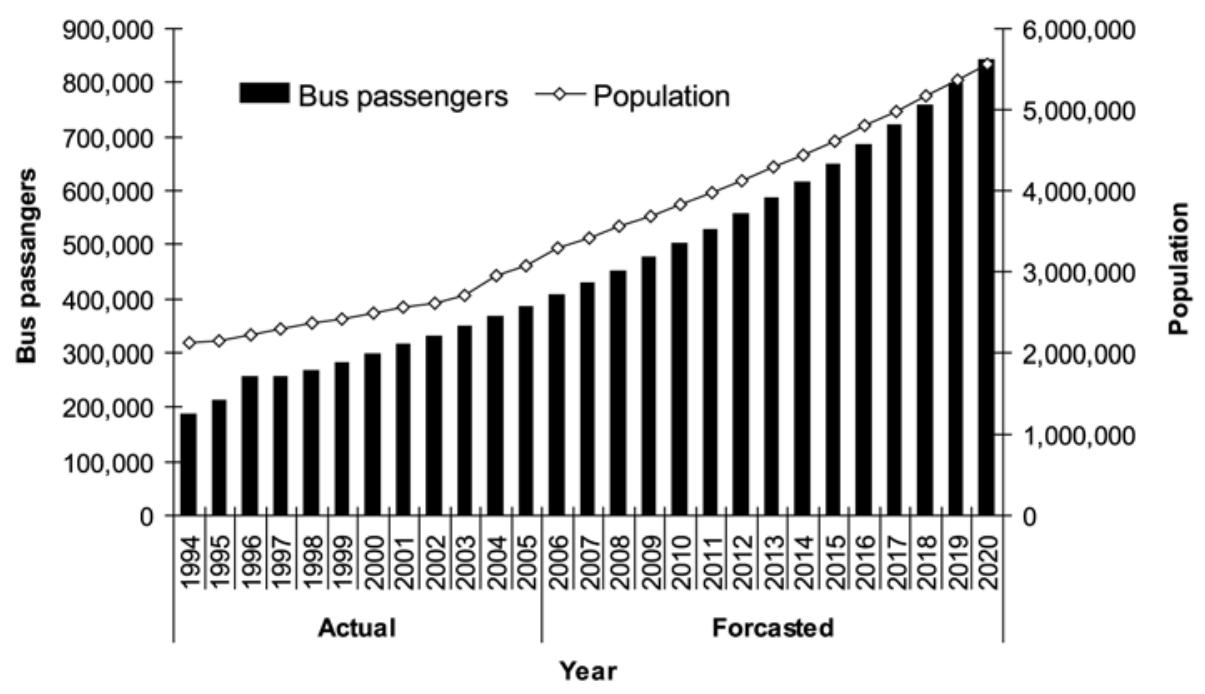

Source: The Bus Company and Central Statistics Authority.

\section{Figure 3. Population and Bus Passenger Growth}

\section{Taxis}

Of the 14,083 taxis operating in Addis Ababa in 2005, 12,283 had 12 seats and 1,800 were small taxis with 4 seats. Of the total number of taxis, only 11,806 were inspected and registered by the Addis Ababa Transport Authority through March 2005. Public transport service is highly dependant on taxis as a mode despite high fares (taxis are an expensive means of transportation when compared to buses), which are not affordable, particularly for the low-income group (i.e., the urban poor). Taxis, which are operated by the private sector, usually run on fixed routes even if they are not highly enforced by the government (unlike that of the bus). Taxi speeds are affected by frequent stopping for loading and unloading. Some unpublished documents reveal that, when compared, the carrying capacity of taxis to city buses is eight to nine times less. Inadequate vehicles, loading extra passengers, and bad behavior of taxi drivers and their assistants make taxi transport difficult. 
Table 1. Registered and Inspected Taxis for 1999-2005

\begin{tabular}{lcc} 
Year & Registered Taxis & Growth Rate (\%) \\
\hline $1999-2000$ & 8266 & - \\
$2000-2001$ & 8847 & 7.0 \\
$2001-2002$ & 9910 & 12.0 \\
$2002-2003$ & 9930 & 0.2 \\
$2003-2004$ & 9262 & -6.7 \\
$2004-2005$ & 11806 & 27.5 \\
Average & 8.0 & \\
\hline
\end{tabular}

Source: Addis Ababa Transport Authority, 2005.



Figure 4. Buses in Addis Ababa 


\section{Figure 5. Taxis in Addis Ababa}

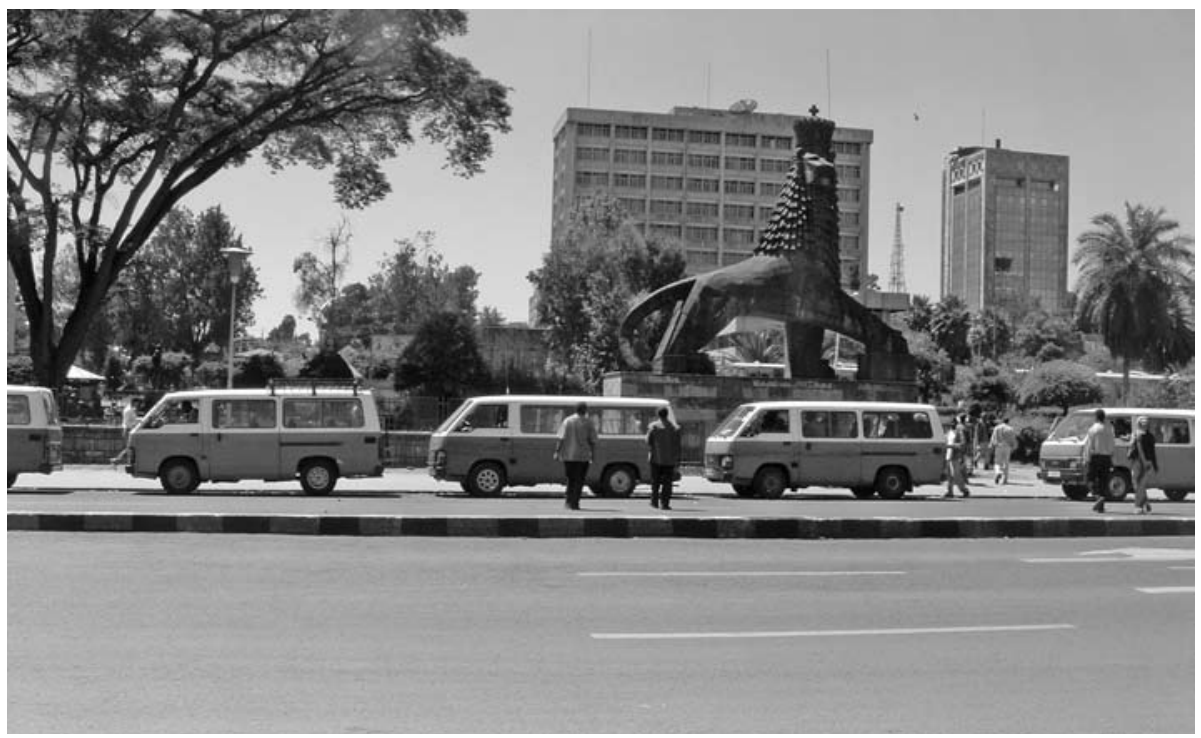

\section{Data Description}

\section{Socioeconomic Characteristics of Respondents}

To determine the city's public transportation condition and the effectiveness of implementing the proposed models, a sample survey of residents was undertaken in September 2004. The survey questionnaire addressed socioeconomic variables, demographic characteristics, travel patterns, mode attributes, satisfaction variables, and bus condition data. A door-to-door survey of 750 respondents from three categories of society (innercity residents, those living in intermediate zones, and expansion area [periphery] residents) was performed. Innercity residents are those living in and around the central business districts; periphery residents are those living in the expansion urban edges; and intermediate residents are those living in the middle of the two mentioned locations.

According to the general analysis results of the survey, 64 percent of the respondents use bus as their typical mode of transportation, 18 percent use taxis as their major mode of transportation, and 12 percent walk. The remaining respondents preferred other modes of transportation like private car. The bicycle is not considered a mode of transportation in the city due to inconvenient topography. The 
Ethiopian Road Authority in 2005 stated that walking enjoys the largest share of overall trips, if all short-distance trips are included. As to the socioeconomic and demographic characteristics of the respondents, 58 percent are male and 42 percent are female. Their income varies from low (below 100 Ethiopian birr) to high (above 2000 Ethiopian birr). However, the majority have an income within the range of 100 to 300 Ethiopian birr. Thus, the majority of the respondents are in the low-income group. In terms of jobs, 35 percent of the respondents are public company employees and 19 percent are private company employees. In addition, 24 percent run their own small businesses, 8 percent are students, and the remaining 14 percent are unemployed. More than 90 percent of the respondents do not own a car and/or have a driver's license. Family size ranges from 1 to 11, with average household size being 5.08. Work is the main purpose for trips, followed by educational activities. The zonal variation study on mode choice showed that periphery area residents are more dependent on bus transportation than inner and intermediate zone residents. Innercity residents are the dominant taxi users.

\section{Attitudinal Data on Public Transport Conditions}

The survey addressed three bus condition parameters-bus fare, bus convenience (boarding, in-bus crowd, bus steps and chair convenience etc.), and bus frequency. The majority of those surveyed responded that bus is less costly when compared with other modes of transportation. Of 733 respondents, 44 percent replied that bus is strongly preferable, 47 percent said preferable, 7 percent and 2 percent said it is less preferable and nonpreferable, respectively, where fare is concerned. In terms of convenience, most respondents said bus is not convenient, or it is less convenient, when compared with other modes of transportation. Very few respondents noted that bus is a convenient mode of transportation in the city. A high number of respondents reported that bus frequency is good, even though a significant number of respondents said the bus has low and very low frequency. Only a few answered that bus has very high frequency (see Figure 7). Taxi is a less preferable mode of transportation when fare is considered. Taxis are an expensive mode of transport in the city, and are not affordable for the urban poor who account for the majority of the population. The respondents, however, believe that taxi is preferable in terms of convenience because there is no considerable intaxi crowd when compared with buses. Concerning frequency/delay parameters, taxis function better than buses as they have frequent services, which is attributed to the competition among taxi drivers to increase daily revenue despite the effect of loading and unloading on the speed of the journey. 


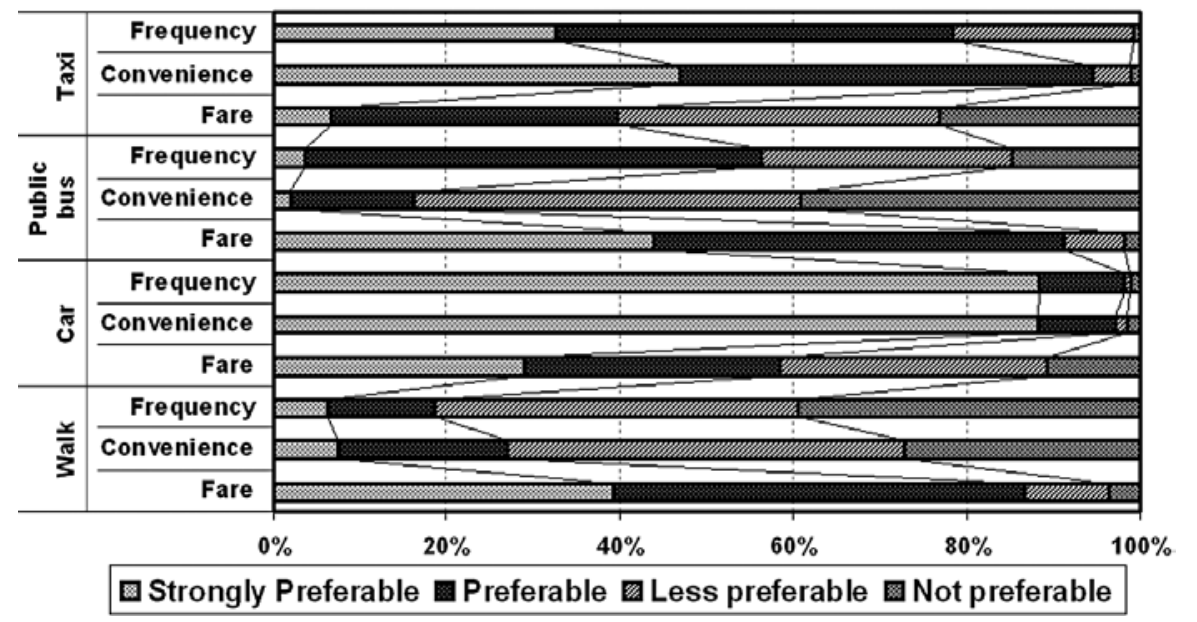

\section{Figure 6. Attitude Toward Different Modes}

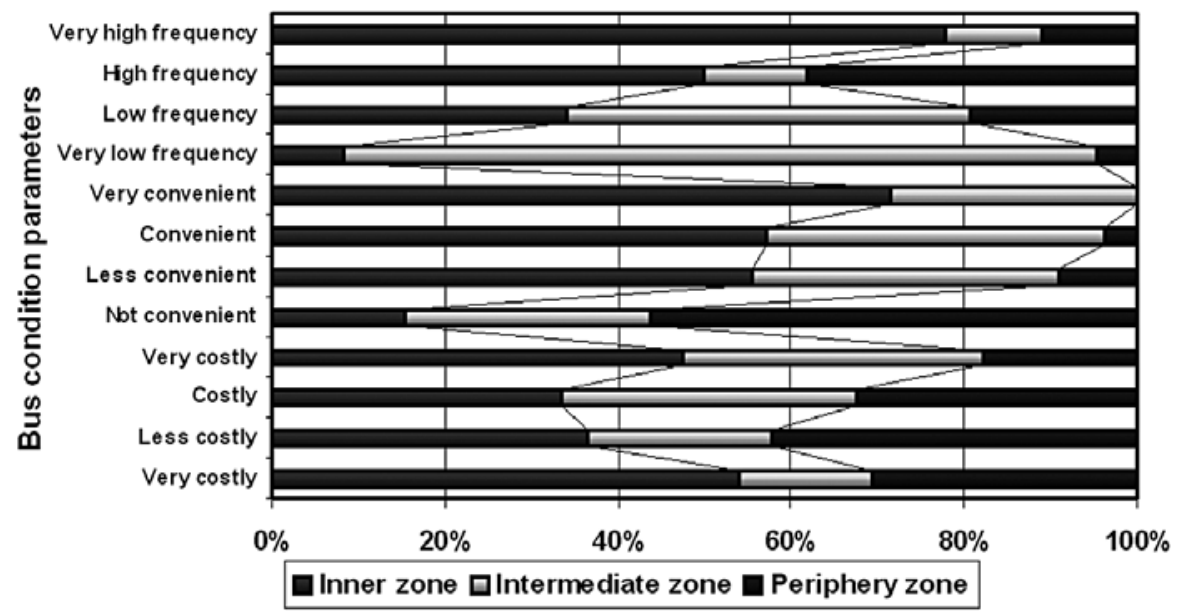

Figure 7. Attitude Toward Bus Service 


\section{Model Structure}

Two models were formulated in this study: an ordered logit model and a binary logit model. The ordered logit model is used to examine the influencing factors affecting citizens' perceptions on bus service conditions, and, in turn, affecting choice of mode. The binary logit model is used to estimate the likelihood of the public transportation mode choice with the dependent variable being the public transportation mode, which gets 1 if the mode is bus and 0 if it is taxi. The two models are discussed in more detail below.

\section{Citizens' Perceptions Model on Bus Conditions: Ordered Logit Model}

Some multinomial choice variables are inherently ordered. Although the outcome is discrete, the multinomial logit or probit models would fail to account for the ordinal nature of the dependent variable (Green 2000). An ordered logit model is able to treat variables with a ranking order. Modeling citizens' perceptions on current bus conditions is based on the ranked responses of a survey with three parameters (bus fare, bus convenience, and bus frequency). Suppose that the values of $Y$ represent an ordering of items. For example, let $Y_{i}$ be the outcome of a bus condition test of observation $i$ for the three evaluation parameters, coded like

$$
Y_{i}=\left\{\begin{array}{l}
0: \text { very costly/not convenient/very low bus frequency } \\
1: \text { costly/less convenient/low bus frequency } \\
2: \text { less costly/convenient/high bus frequency } \\
3: \text { not costly/very convenient/very high bus frequency }
\end{array}\right.
$$

$Y$ is not a quantity but a ranking, nevertheless a larger value of $Y$ means more, or better. In this case there exists a known natural number $m$ such that

$$
P\left[Y_{i} \in\{0,1,2 \ldots m\}\right]=1
$$

This type of data is usually modeled via a latent (unobserved) variable model:

$$
Y^{*}{ }_{i}=\alpha+\beta_{i}{ }^{\prime} X_{i}+\varepsilon
$$

Where:

$Y^{*} \quad$ equals a latent (unobserved) measure of bus condition faced by the respondent 
$X \quad$ is a vector of explanatory variables describing the age, sex, and bus waiting time etc.

$\alpha, \beta^{\prime} \quad$ represents a vector of parameters to be estimated

$\varepsilon \quad$ denotes a random error term (assumed to follow a standard normal dis tribution for probit model or logistic distribution for logit model). In this study, the logistic distribution is followed.

The observed and coded discrete bus condition variable, $\mathrm{Y}_{i}$ is determined from the model as follows (e.g., for the bus fare model):

$$
Y i=\left\{\begin{array}{l}
0 \rightarrow \text { Very costly if } Y_{i}^{*} \leq 0 \\
1 \rightarrow \text { Costly if } 0<Y_{i}^{*} \leq \mu_{1} \\
2 \rightarrow \text { Less } \cos \text { tly if } \mu_{1}<Y_{i}^{*} \leq \mu_{2} \\
3 \rightarrow \text { Not } \cos \text { tly if } Y_{i}^{*}>\mu_{2}
\end{array}\right\}
$$

Where:

$\mu_{\mathrm{i}} \quad$ represent thresholds to be estimated along with the parameter vector $\beta$

The following figure illustrates the correspondence between the latent (unobserved) and coded (observed) bus condition variable:

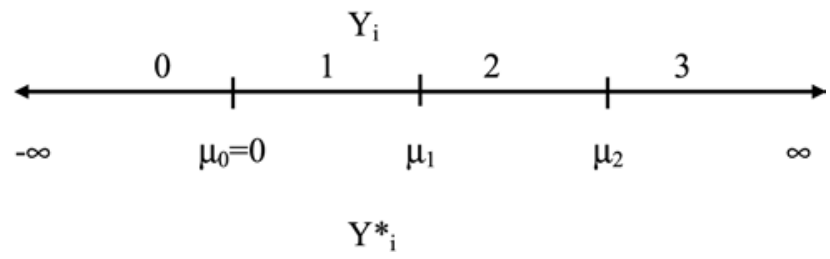

The probability associated with the coded responses of an ordered probability model is as follows:

$$
\operatorname{Pr}\left(Y_{i}=j\right)=\operatorname{Pr}\left(\mu_{j-1}<Y^{*}{ }_{i} \leq \mu_{i}\right)=\operatorname{Pr}\left(\mu_{j-1}<\left[\alpha+\beta_{i}{ }^{\prime} X_{i}+\varepsilon\right] \leq \mu_{i}\right)
$$

As the random error $\varepsilon$ should be distributed, the function will be

$$
\operatorname{Pr}\left(Y_{i}=j\right)=\operatorname{Pr}\left(\mu_{i-1}<Y^{*}{ }_{i} \leq \mu_{j}\right)=F\left(\mu_{i}-\alpha-\beta_{i}{ }^{\prime} X_{i}\right)-F\left(\mu_{j-I^{-}} \alpha-\beta_{i}{ }^{\prime} X_{i}\right)
$$


In ordered logit, $\mathrm{F}(\mathrm{x})$ is specified as the logistic distribution function, i.e.

$$
F(x)=\exp (x) /[1+\exp (x)]
$$

\section{Public Transport Mode Choice Model: Binary Logit Model}

Choice models are widely used in economic, marketing, transportation, and other fields to represent the choice of one among a set of mutually exclusive alternatives. Several models have been developed to analyze transportation choice behavior, which is the key aspect of the demand analysis. This study aimed to model the mode choice behavior of public transport users using the binomial logit model. When travelers are faced with two dominant alternatives, the situation will be termed as a binary choice case. The derivation of any binary choice model is conceptually straightforward, in that the probability of alternative $i$ being chosen can be easily solved.

Consequently, the probability that $j$ is chosen is equal to $[1-P(i)]$. The general form of the binomial logit model is

$$
\operatorname{Prob}\left[Y_{i}=1 \mid b u s\right]=\operatorname{Exp}\left(\alpha+\Sigma \beta_{i} x_{i}\right) /\left[1+\operatorname{Exp}\left(\alpha+\Sigma \beta_{i} x_{i}\right)\right]
$$

The model application is based on the utility theory, which assumes that the decision-maker's preference for an alternative is captured by a value called utility (U). The decision-maker selects the alternative in the choice set with the highest utility

$$
U\left(\text { alternative 1) }=\beta_{I} x_{1}\right.
$$

Where:

$\beta_{1} \quad$ is the coefficient associated with the alternative

$\mathrm{x}_{1} \quad$ is the variables value

$\alpha \quad$ is the constant estimated by the model (Green 1998)

This model is developed in this study to analyze the mode choice behavior of public transportation users. 


\section{Empirical Analyses}

\section{Dependent and Independent Variable Design}

For the ordered logit model, the dependent variable is taken as ranking responses on bus condition parameters. The independent variables keep heterogeneity by comprising the socioeconomic attributes and the attributes related to the mode. As stated earlier, the dependent variable for the binary logit model is the mode of public transportation chosen by the respondents. The major modes of public transportation are bus and taxi. Walking is excluded as the respondents are not using it for long trips. As a binomial logit model has the best output, the data is organized in such a way that the probability of bus choice over taxi is made. The probability estimate of the ordered logit model is also included among the independent variables for the mode choice model. The descriptive analysis of the independent values is given in Table 2 .

Table 2. Descriptive Statistics:

Dependent and Independent Variables for the Two Models

\begin{tabular}{|l|r|r|r|r|l|l|}
\hline Variable & \multicolumn{1}{|c|}{ Mean } & \multicolumn{1}{c|}{ Std. Dev } & \multicolumn{1}{c|}{ Min. } & \multicolumn{1}{c|}{ Max. } & \multicolumn{1}{c|}{ Unit } & \multicolumn{1}{c|}{$\boldsymbol{N}$} \\
\hline Mode: 1 if bus and 0 taxi & 0.788 & 0.409 & 0 & 1 & Binary & 674 \\
\hline Bus condition in terms of fare $(0,1,2,3)$ & 2.332 & 0.687 & 0 & 3 & Ordered & 674 \\
\hline Bus condition in terms of convenience $(0,1,2,3)$ & 0.752 & 0.741 & 0 & 3 & Ordered & 674 \\
\hline Bus condition in terms of bus frequency $(0,1,2,3)$ & 1.436 & 0.784 & 0 & 3 & Ordered & 674 \\
\hline Zone: 0 if inner, 1 if intermediate, 2 if peripheral & 0.923 & 0.803 & 0 & 2 & Ordered & 674 \\
\hline Age & 40.864 & 14.491 & 15 & 85 & Continuous & 674 \\
\hline Sex: 1 if male, 0 if female & 0.568 & 0.496 & 0 & 1 & Binary & 674 \\
\hline $\begin{array}{l}\text { Occupation: } 1 \text { if public and private employee and } \\
\text { student; 0 otherwise }\end{array}$ & 0.605 & 0.489 & 0 & 1 & Binary & 674 \\
\hline Monthly income & 488.72 & 374.751 & 60 & 3140 & ETH. BIRR & 674 \\
\hline Family size & 5.064 & 1.885 & 1 & 11 & Continuous & 674 \\
\hline $\begin{array}{l}\text { Trip purpose: } 1 \text { if work, education, and business; } \\
\text { 0 otherwise }\end{array}$ & 0.780 & 0.414 & 0 & 1 & Binary & 674 \\
\hline Travel time & 45.967 & 21.760 & 4 & 180 & Continuous & 674 \\
\hline Waiting time & 26.169 & 15.880 & 3 & 120 & Continuous & 674 \\
\hline $\begin{array}{l}\text { Fare (differential of taxi and bus fares for the } \\
\text { specified distance) }\end{array}$ & 74.169 & 25.045 & 35 & 125 & ETH Cents ${ }^{2}$ & 674 \\
\hline No. of bus connections & 2.613 & 1.075 & 1 & 6 & Continuous & 674 \\
\hline
\end{tabular}

\footnotetext{
$11 \mathrm{USD}=8.8 \mathrm{ETH}$ birr

21 ETH birr $=100$ ETH cents
} 


\section{Modeling Results: Ordered Logit Model}

The perception model on bus condition is estimated based on three aspects of the existing bus condition as discussed below.

\section{Bus Fare Model}

Results of the bus fare model showed that all the selected parameters have significance on citizens' perceptions of the bus fare conditions. When the residence of respondents is in the periphery zone, their perception is that bus is costly. As understood from the histogram of mode choice vs. zonal variations, the majority of bus users are living in the periphery area and their trip is characterized by a long travel time. Therefore, they have high transport expenses and regard bus as costly. Likewise, as age increases, so does the perception that bus is a costly mode of transportation. Male respondents think the bus is not a costly mode of transport, whereas females think the opposite. Since housewives are economically dependent on males, the transportation cost is likely more expensive for them so they are more likely to perceive the transportation cost as being expensive. Respondents who work do not perceive bus as costly. When monthly income increases, respondents feel that bus is not costly. However, increase in family size, bus fare, bus travel time, and bus waiting time make respondents perceive the bus as an expensive mode of transportation. The higher the number of bus connections or transfers, the more likely the bus would be more costly.

\section{Bus Convenience Model}

According to the ordered logit result of the convenience model, all the chosen factors (socioeconomic as well as mode attributes) have a significant effect (positive or negative) on citizens' perceptions of bus convenience, as the t-value is above the acceptable value. As age increases, the probability of perceiving bus service as inconvenient grows. It is the same for other attributes like monthly income, family size, number of bus transfers, bus travel time, and bus waiting time. The existing bus service is not convenient for elderly people because there are no priority seats or other policy incentives. A policy option that would provide suitable public transport service for the elderly is needed. Bus waiting time is also an indication of the need to improve bus stops and increase bus frequency. A longer travel time increases inconvenience, as there are chained trips. Male respondents and those who work perceive that the existing bus service is convenient because the bus is their preferable mode of transportation for their daily home-to-work trips. Most workers have too low of an income to afford another mode of transportation. Bus users think that bus service is convenient. As the bus fare increases, respondents 
suppose that the bus is convenient because for a long travel time the bus is a relatively affordable means of transportation.

\section{Bus Frequency Model}

Many of the attributes in the bus frequency model are not statistically significant because of the small t-value. However, all the results are presented in Table 3 to show the tendency of significance from the positive and negative signs of the coefficients. Four factors influence respondent's perceptions on the bus frequency: sex, number of bus connections, bus travel time, and bus waiting time. Since waiting time is explained by the frequency, it is not surprising that the $t$-value is a big value. Male respondents believe the bus is less frequent because of the longer waiting time they experience. Most females use buses for shopping purposes and not on a daily basis. When the number of bus transfer increases, respondents think the bus frequency condition is not good, where as an increase in in-bus time results in the perception of good bus frequency.

\section{Table 3. Ordered Logit Result for Bus Service Parameters}

\begin{tabular}{|c|c|c|c|c|c|c|}
\hline & \multicolumn{2}{|c|}{ Bus Fare Model } & \multicolumn{2}{|c|}{ Bus Convenience Model } & \multicolumn{2}{|c|}{ Bus Frequency Model } \\
\hline Independent variables & $\beta$ & t-ratio & $\beta$ & t-ratio & $\beta$ & t-ratio \\
\hline Constant & 2.1953 & 6.949 & 0.4879 & 1.535 & 2.1299 & 7.323 \\
\hline Mode & 0.4514 & 3.199 & 0.3781 & 2.751 & -0.1319 & -1.091 \\
\hline Zone & -0.2789 & -3.396 & -0.8679 & -9.69 & -0.1182 & -1.414 \\
\hline Age & -0.0060 & -1.624 & -0.0073 & -1.887 & -0.0045 & -1.294 \\
\hline Sex & 0.1098 & 1.920 & 0.1557 & 1.853 & -0.3036 & -3.026 \\
\hline Occupation & 0.1924 & 1.818 & 0.0787 & 2.692 & -0.0463 & -0.448 \\
\hline Monthly income & 0.0003 & 1.758 & -0.0001 & -1.891 & -0.0002 & -1.275 \\
\hline Family size & -0.0290 & -2.201 & -0.0260 & -1.680 & 0.0222 & 0.932 \\
\hline Waiting time & -0.0066 & -2.402 & -0.0095 & -1.669 & -0.0189 & -3.693 \\
\hline Travel time & -0.0097 & -2.497 & -0.0068 & -1.595 & -0.0062 & -1.687 \\
\hline Trip purpose & 0.0489 & 2.401 & -0.1331 & -1.896 & 0.0591 & 0.432 \\
\hline $\begin{array}{l}\text { Fare (differential of taxi and bus } \\
\text { fares for the specified distance) }\end{array}$ & -0.0002 & -2.112 & 0.0040 & 1.95 & -0.0024 & -1.236 \\
\hline No. of bus connections & -0.0723 & -1.595 & -0.0476 & -1.603 & -0.1854 & -4.316 \\
\hline \multicolumn{7}{|l|}{ Threshold values } \\
\hline$\mu(1)$ & 0.7841 & 6.509 & 1.4865 & 20.607 & 0.9571 & 15.628 \\
\hline$\mu(2)$ & 2.3551 & 17.464 & 2.7850 & 18.798 & 3.0252 & 25.955 \\
\hline No. of observations & & 674 & & 674 & & 674 \\
\hline Log likelihood function & & -631.5265 & & -611.8053 & & -707.1415 \\
\hline Restricted log likelihood & & -657.6018 & & -715.5172 & & -739.0919 \\
\hline Chi-squared & & 52.15059 & & 207.4238 & & 63.90071 \\
\hline Degrees of freedom & & 12 & & 12 & & 12 \\
\hline Significance level & & .05 & & .05 & & .05 \\
\hline
\end{tabular}




\section{Modeling Results: Binary Logit Model}

The estimated results of the public transport choice are given in Table 4. According to the logic result for choosing buses over taxi, all categories of the selected independent variables have a significant effect on choice. Periphery zone dwellers exhibit a high tendency for choosing bus over taxi because buses are an affordable means of transportation for long trips. In the innercity, trips tend to be short, so using a taxi could be seen as a reasonable option. However, for the urban poor living in the urban expansion area, buses are an indispensable choice because of the affordability issue. The probability of choosing bus decreases when age increases. This is due to the elderly tending to shift to other modes of transportation, as buses are crowded and are inconvenient to board. No policies or technical support exist to encourage the elderly to use the bus. Even the design of the high steps on the bus is not friendly to the elderly. Females tend to use buses more often than males, because females have spare time to wait for a bus as their destinations are not time restricted (predominantly shopping trips). Another significant factor is monthly income. When monthly income increases, the tendency of using a bus decreases (Figure 8). When residents' incomes increase, they look for a more convenient, although more costly, mode of transportation like taxi or private cars as the level of affordability has grown for them. Family size is another factor for bus choice. The larger the family, the higher the probability of choosing buses because other modes are unaffordable. Attributes related to mode also affect the

\section{Table 4. Binary Logit Result for Choosing Buses over Taxi}

\begin{tabular}{|l|r|r|}
\hline & \multicolumn{1}{|c|}{$\boldsymbol{\beta}$} & \multicolumn{1}{c|}{-ratio } \\
\hline Constant & -0.5162 & -2.6094 \\
\hline Zone: 0 if inner, 1 if intermediate, 2 if peripheral & 2.5439 & 9.1435 \\
\hline Age: Continuous value & -0.0210 & -1.9804 \\
\hline Sex: 1 if male, 0 if female & -0.1059 & -2.3663 \\
\hline Occupation: 1 if public and private company employee, and student; 0 otherwise & 0.4548 & 1.5819 \\
\hline Monthly income: Continuous value & -0.0023 & -6.4858 \\
\hline Family size: Continuous value & 0.0773 & 1.9901 \\
\hline Waiting time: Continuous value (differential of bus and taxi waiting time) & -0.1731 & -7.4338 \\
\hline Travel time: Continuous value & 0.0126 & 1.9204 \\
\hline Trip purpose: 1 if work, education, and business; 0 otherwise & 0.5966 & 1.4100 \\
\hline Fare: Continuous value (differential of taxi and bus fares for the specified distance) & -0.0032 & -1.6587 \\
\hline No. of bus transfers: Continuous value & -0.5733 & -4.2663 \\
\hline Dependent variable: Mode & & \\
Number of observations: 674 & & \\
Log likelihood function: -197.8537 & & \\
Restricted log likelihood: -348.3317 & & \\
Chi-squared: 300.9560 & & \\
Degrees of freedom: 11 & & \\
Significance level: 0.05 & & \\
Predicted outcome: $82.7 \%$ & & \\
\hline
\end{tabular}


probability of choosing a bus. When bus waiting time increases, there is higher probability for choosing a taxi. Therefore, bus frequency is the most important factor in determining residents' public transportation mode choice. Long travel time makes residents choose bus, as it is difficult to afford longer trips by taxi. The overall results showed that residents have a strong dependency on bus despite the low level of service. Besides, perception estimates impact mode choice.

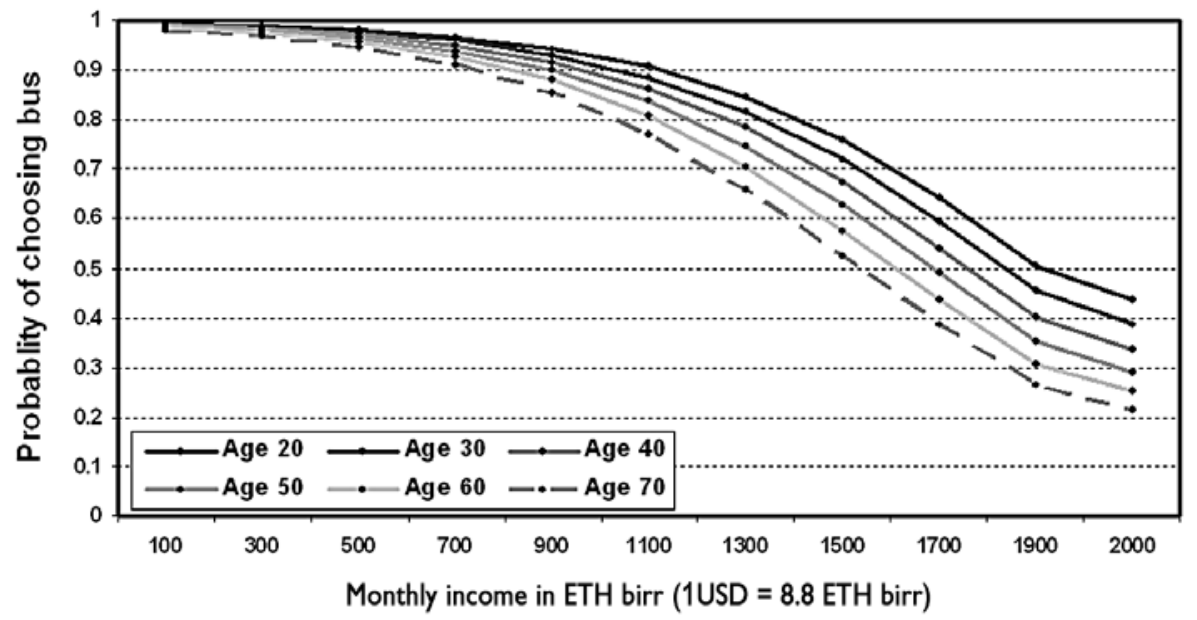

Figure 8. Probability of Bus Choice in Terms of Income and Age

\section{Discussion on Diagnostic Results}

In the previous sections, the factors that affect residents' choices of public transportation were analyzed by developing two probability models: the ordered logit model and the binary logit model. In addition, the relationship of independent variables in the two models is examined using a diagnostic approach as indicated in Table 5.

Periphery zone residents, who are public or private company employees with a larger family size, have a higher tendency of choosing bus over taxi. The positive sign with the distance variable is consistent with the choice of bus for long trips. Elderly people, male respondents, and residents with a higher monthly income are less likely to choose bus as their preferred public transportation mode. For the bus fare aspect, elderly females who are unemployed (or housewives), have a low monthly income, and have a large family size perceive the existing bus trans- 


\section{Table 5. Diagnostic Results of Mode Choice and Perception Models on Bus Condition}

\begin{tabular}{|c|c|c|c|c|}
\hline \multirow{2}{*}{ Parameters } & \multirow{2}{*}{$\begin{array}{l}\text { Binary Logit Model } \\
\text { (PT mode choice) }\end{array}$} & \multicolumn{3}{|c|}{ Ordered Logit Model (perception model on bus condition) } \\
\hline & & Cost (bus fare) & Convenient & Bus Frequency \\
\hline Zone & + & - & - & $\mathrm{NA}^{2}$ \\
\hline Age & - & - & - & NA \\
\hline Sex & - & + & + & - \\
\hline Occupation & + & + & + & NA \\
\hline Monthly income & - & + & - & NA \\
\hline Family size & + & - & - & NA \\
\hline Travel time & + & - & - & - \\
\hline Waiting time & - & - & - & - \\
\hline Trip purpose & + & + & - & + \\
\hline Fare & + & - & + & +1 \\
\hline \multicolumn{5}{|c|}{$\begin{array}{l}+ \text { and -signs show the independent variable's functional relation with the dependent variable. } \\
2 \text { NA: Parameters that are not applicable beca use they are statistically insignificant (very low t-value). }\end{array}$} \\
\hline $\begin{array}{l}\text { Socioeconomic } \\
\text { Parameters }\end{array}$ & \multicolumn{4}{|l|}{ Diagnosis } \\
\hline Place of residence & \multicolumn{4}{|c|}{$\begin{array}{l}\text { Periphery area residents choose bus because their trips are longer than inner zone residents' } \\
\text { trips. They perceive that bus is a costly and inconvenient mode of transportation. }\end{array}$} \\
\hline Gender issue & \multicolumn{4}{|c|}{$\begin{array}{l}\text { Male respondents do not choose bus despite bus being an affordable means of transportation fo } \\
\text { their daily work trip. They perceive low bus frequency as decreasing their probability of choosing } \\
\text { bus. }\end{array}$} \\
\hline Age & \multicolumn{4}{|c|}{$\begin{array}{l}\text { Elderly do not choose bus because of crowding and boarding inconveniences. Their attitude } \\
\text { toward bus fare as well as its convenience shows that they are not satisfied with the existing bus } \\
\text { service. }\end{array}$} \\
\hline $\begin{array}{l}\text { Income vs. public } \\
\text { transportation fare }\end{array}$ & \multicolumn{4}{|c|}{$\begin{array}{l}\text { Low-income groups choose bus because it is a cheaper mode of transportation. As taxi fare } \\
\text { increases (longer trips), the probability of choosing bus increases. High-income groups think tha } \\
\text { bus is not convenient and has very low frequency. They do not choose bus because they can } \\
\text { afford taxi and/or private car. }\end{array}$} \\
\hline Family size & \multicolumn{4}{|c|}{$\begin{array}{l}\text { Families of a larger size choose bus yet they consider bus a costly and inconvenient mode of } \\
\text { transport. Affordability is a question as the family size increases. }\end{array}$} \\
\hline Bus users & \multicolumn{4}{|c|}{ Bus users perceive that bus is not costly. However, they think that bus has very low frequency. } \\
\hline $\begin{array}{l}\text { Origin-destination } \\
\text { distance }\end{array}$ & \multicolumn{4}{|c|}{$\begin{array}{l}\text { The longer the trip distances, the higher the probability of choosing bus. Bus is the preferable } \\
\text { mode of transportation for long trips. }\end{array}$} \\
\hline Waiting time & \multicolumn{4}{|c|}{$\begin{array}{l}\text { High waiting time reduces the probability of choosing bus. The probability of perceiving bus as a } \\
\text { costly and inconvenient mode increases with an increase of the waiting time. }\end{array}$} \\
\hline Chained trips & \multicolumn{4}{|c|}{$\begin{array}{l}\text { When the number of bus transfers increases, bus is perceived as a costly, inconvenient, and } \\
\text { nonfrequent mode of transportation. }\end{array}$} \\
\hline
\end{tabular}

portation as costly. When the convenience aspect is considered, the same group perceives bus as an inconvenient mode of public transport except for the monthly income parameter. Those who have a higher monthly income perceive bus as an inconvenient mode of public transportation. In addition, the longer distances, shorter waiting times, and cheaper bus prices increase the probability of choosing bus and enhance the perception of bus convenience. Low bus frequency (long waiting time) and high fares increase the probability of perceiving bus as a costly 
and inconvenient mode of public transport. The ordered model results show that periphery residents are not satisfied with the bus condition. Even if bus is the affordable means of transportation, it is still difficult for the urban poor living in the urban expansion area to afford. One of the reasons they perceive bus as a costly mode is the very limited bus networks in the periphery area, thus forcing them to pay for a more expensive mode of transportation like a taxi. Bus service is not convenient for periphery residents, as there is longer travel time and very low bus service coverage (Figures 9 and 10). According to the results of the ordered logit model, the number of bus transfers is one of the independent parameters that influences residents' perceptions on bus condition. The number of bus transfers has a negative sign for the three dependent variable parameters. This shows that residents are not satisfied with the bus linkages.

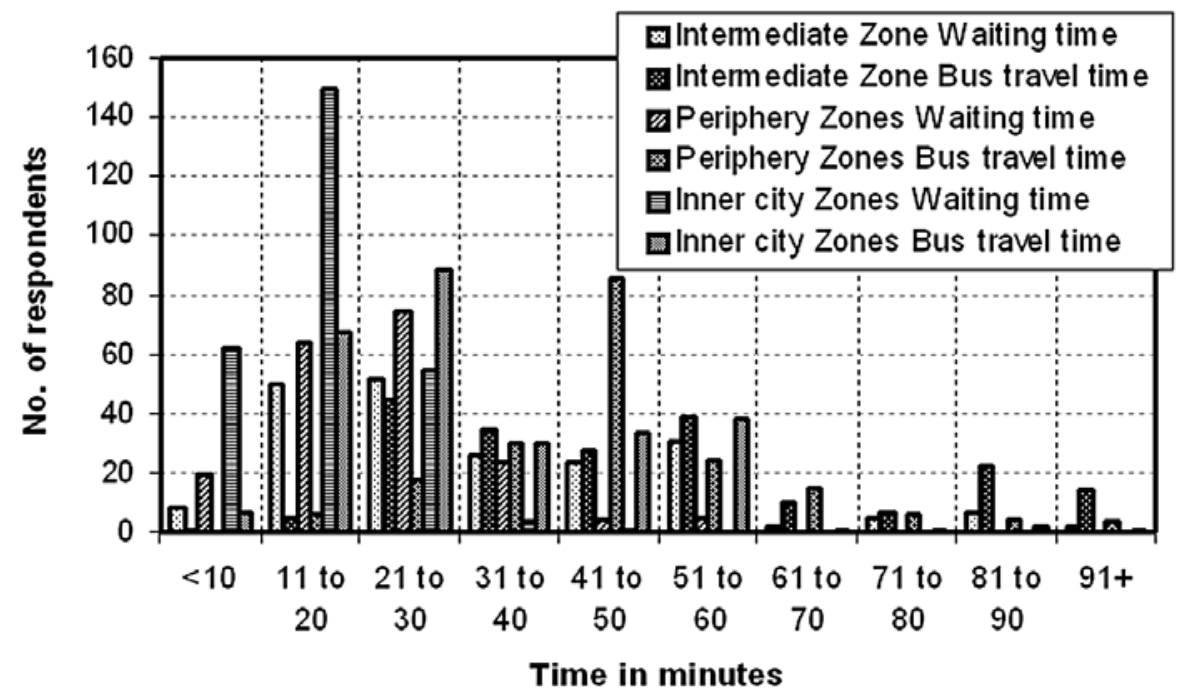

Figure 9. Bus Waiting and Travel Time in Different Zones 

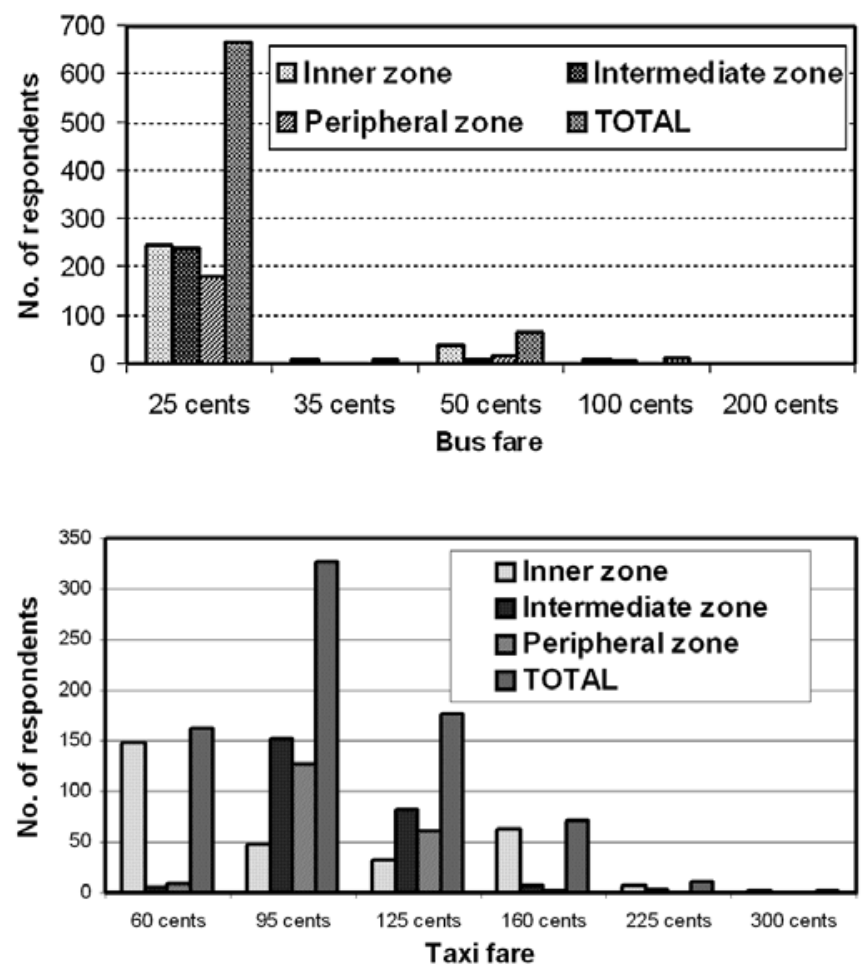

\section{Figure 10. The Relationship Between Public Transportation Fare and Zones}

\section{Conclusions}

This study presents a diagnostic analysis of the existing public transport situation in Addis Ababa. A binary logit model was assessed for the public transportation mode choice analysis; and an ordered logit model is implemented to analyze the ranking responses of citizens' perceptions on the condition of the current bus service. In addition to the widely used mode choice model, the newly developed ordered logit model result is useful to make a further analysis of the bus condition aspects influencing bus transportation choices. In a situation with limited alternatives, such an approach would explain better the respondents' choice characteristics.

The analysis results showed that socioeconomic as well as public transport moderelated parameters have a significant negative or positive influence on the mode 
choice and the respondents' perceptions of the bus service condition. Based on the results and further analysis and considerations, the strategic plan, policy indications, and physical solutions could be drawn as an effort to improve the existing public transport services. Spatial expansion of bus service, improving bus frequency conditions, and strengthening the bus linkage with respect to the land use are among the policy intervention areas.

\section{References}

Anbessa City Bus Enterprise. 2004. 2004-2005 yearly report, Addis Ababa (written in Amharic).

Darido, Georges B. 2003. Regulation of road-based public transportation and strategies for the developing world. Transportation Research Record 1835, TRB National Research Council, Washington DC, pp. 66-73.

Ethiopian Roads Authority (ERA). 2005. Urban transport study and preparation of pilot project for Addis Ababa. Consulting Engineering Services (India) Private Limited and SABA Engineering Private Limited Company, Addis Ababa, Ethiopia.

Ghareib, Ahmed Hamdy. 1996. Evaluation of logit and probit models in modechoice situation. Journal of Transportation Engineering 122, 4: 282-290.

Greene, William H. 1998. LIMDEP version 7.0 users manual. Econometric Software, Inc.

Greene, William H. 2000. Econometric analysis, 4th ed. Prentice-Hall, Inc.

Hamed, Mohammad M., and Said M. Easa. 1998. Ordered probability modeling of seat belt usage. Journal of Transportation Engineering 124, 3.

Jacobs, G. D., D.A.C., Maunder, and P.R. Fouracre. 1986. Characteristics of conventional public transport services in third world cities. Traffic Engineering and Control 27, 12: 6-11.

Mintesnot, G., and S. Takano. 2005a. Modeling the relationship between seasonal constraints and modal choice characteristics of high school students in snowy regions. Journal of Eastern Asia Society of Transportation Studies 6: 1844-1857. 
Mintesnot, G., and S. Takano. 2005b. Citizen's attitude, existing challenges and prospects of bus transportation in the city of Addis Ababa, Ethiopia. Proceedings of Japanese Society of Civil Engineers 60.

Mintesnot, G., and S. Takano. 2006. Application of logical planning model for public transportation improvement programs in the city of Addis Ababa. Studies in Regional Science. Journal of JSRSAI 36: 663-682.

Office of the Revision of Addis Ababa Master Plan (ORAAMP). 2002. Project proposal for Addis Ababa transport sector, Addis Ababa, Ethiopia.

Racca, David P., and Edward C. Ratledge. 2004. Project Report for "Factors That Affect and/or Can Alter Mode Choice." Delaware Transport Institute and State of Delaware Department of Transport.

SEMALY Public Transport Consultants. 2001. Comments about prospective mass transport system in Addis Ababa City, Addis Ababa, Ethiopia.

Thamizh Arasan, V., V. R. Rangaraju, and K. V. Krishna Rao. 1996. Trip characteristics of travelers without vehicles. Journal of Transportation Engineering 122, 1: 76-81

Wang, Xiaokun, and Kara M. Kockelman. 2005. Occupant injury severity using a hetroscedastic ordered logit model: Distinguishing the effects of vehicle weight and type. Transportation Research Board Annual Conference, Washington DC.

World Bank African Region Scoping Study. 2002. Urban mobility in three cities, Addis Ababa, Dar es Salam, Nairobi. SSATP Working Paper 70.

Yamamoto, Toshiyuki, Satoshi Fujii, Ryuichi Kitamura, and Hiroshi Yoshida. 2000. Analysis of time allocation, departure time, and route choice behavior under congestion pricing. Journal of Transport Research Board 1725: 95-101.

\section{About the Authors}

Mintesnot GebeyehU (mintesnot@gmail.com) is a Ph.D. student at Hokkaido University, Department of Urban and Environmental Engineering. He holds a master's degree in urban engineering and planning from Hokkaido University. His research focuses on urban land-use planning and public transportation planning and policy. 
SHIN-EI TAKANO (shey@eng.hokudai.ac.jp) is an associate professor of transportation planning and construction management at Hokkaido University, Department of Urban and Environmental Engineering. His research focuses on public transportation planning, construction management, and tourism transport management. He has participated in many national and local transportation projects and has reviewed several research papers for refereed journals. 


\section{Measuring the Impacts of Employer-based Transportation Demand Management Programs on an Interstate Corridor}

Nevine Labib Georggi, Phil Winters, Sachin Rai, and Liren Zhou Center for Urban Transportation Research, University of South Florida

\section{Abstract}

This article is based on a study that analyzed the impacts of employer-based transportation demand management (TDM) strategies and the performance of a transportation system. The study simulated the effects of the Washington State Commute Trip Reduction (CTR) programs implemented by 189 employers on an 8.6-mile segment of $1-5$ in the Seattle downtown area. This comprehensive dataset included before/after employer trip reduction plans and the origins/destinations of nearly 63,000 commuters working for those 189 employers. The current performance of the selected network was compared to that of a scenario with reduced vehicle trips due to CTR programs added back onto the network. The hypothesis of the research was that a widescale adoption of employer-based strategies is likely to have a measurable difference on the performance of a transportation system. The analysis found the reduction in AM peak delay due to TDM programs implemented in the study area was 152,489 vehicle-minutes and 17,297 vehicle-miles of travel. Savings in PMpeak delay were 169,486 vehicle-minutes and 14,510 vehicle-miles were reduced. Fuel saved in the AM and PM peaks were 3,489 and 4,314 gallons, respectively. Some segments and periods saw significant improvement. The study proved that compre- 
hensive TDM programs could have a significant impact on the operation of a major Interstate corridor.

\section{Introduction}

Traffic congestion continues to affect the quality of life in the United States. According to the Texas Transportation Institute's (TTI) 2005 Annual Urban Mobility Report, "Despite a slow growth in jobs and travel in 2003, congestion caused 3.7 billion hours of travel delay and 2.3 billion gallons of wasted fuel, an increase of 79 million hours and 69 million gallons from 2002 to a total cost of more than $\$ 63$ billion" (Schrank and Lomax 2005). These impressive numbers directly correlate to degradation of transportation system efficiency and performance. In recognition of the challenges facing communities, Schrank and Lomax recommend a balanced approach including-beginning to "plan and design major capacity increasing projects, plans or policy changes while immediately relieving critical bottlenecks and aggressively pursuing operations improvements and demand management options that are available." One of the questions that quickly arises is what can transportation demand management (TDM) contribute.

Numerous case studies assessing the impacts of TDM report significant changes in travel behavior and vehicle miles of travel or vehicle trips reduced (VTR) but not the performance effects on any particular corridor. At the University of California's Los Angeles campus, transit ridership for commuting to campus increased by 56 percent during the first year promotion of an unlimited access pass program, and solo driving fell by 20 percent. Since the pass program reduced the demand for parking by at least 1,020 spaces, the reduction in parking demand was worth $\$ 32.1$ million (1,020 spaces $\times \$ 31,500$ per space; Brown 2003).

The U.S. General Services Administration (GSA) estimates that 80 percent of federal agencies adopt alternate work schedules such as telework or compressed workweek (GSA 2005). From 2003 to 2004 the number of teleworkers increased 37 percent $(102,921$ to 140,694$)$. The number of employees teleworking as a percentage of those eligible to telework (41\%) increased from 14 percent in 2003 to 19 percent in 2004. Thirty-eight agencies (46\%) reported that more than 25 percent of their workforce participated in telework during 2004. Not considering other alternatives, such as compressed workweek or flex hours that remove vehicle trips off the peak hours of congestion, these hard numbers are a result of only one strategy, teleworking, that totally eliminated vehicle trips from the road. 
If these thousands of government workers were to join in daily peak-hour traffic, then levels of transportation system congestion, air quality, lost time, vehicle miles traveled (VMT), and fuel consumption would dramatically worsen. In 2004, South Florida Commuter Services, the regional commuter assistance program that serves Miami-Dade, Broward, and Palm Beach Counties in South Florida, reported 2.2 million vehicle trips and 57,660,000 VMT reduced due to its ridematching and vanpool programs (Hagelin and Perone 2004).

The scale of the employer-based programs is another issue. Though the programs may, in total, substantially reduce VMT, the reductions are likely to be spread geographically and temporally so the "observed" impact may be difficult to recognize. However, substantial investments have shown significant overall impacts. The state of Washington invested $\$ 2.7$ million in CTR programs in 2005. This investment, combined with those of local jurisdiction partners and participating employers, provided significant benefits for the state's citizens that were quantified as follows in the annual report (Commute Trip Reduction Task Force 2005):

- at least \$24 million in reduced cost of delay in the Puget Sound region (calculated using 2003 data)

- savings of $\$ 13.7$ million in fuel costs for employees commuting to CTR worksites based on driving fewer miles

- reduction of 3,700 tons of criteria pollutants including carbon monoxide, volatile organic compounds, and oxides of nitrogen

- reduction of the equivalent of 74,200 tons of carbon dioxide

For traffic operations and transportation planners, the question is how do these impressive reductions change the performance of the traffic network? There is no recognized process for performance measurement that captures the actual impacts of employer-based TDM programs on a transportation system. This research study combined two common goals of transportation agencies: relieving congestion and increasing the efficiency of the transportation system. By monitoring, evaluating, and communicating TDM strategies and their combined impacts on the roadway system, planners, traffic operations staff, TDM professionals, decision makers, and elected officials can be "on the same page" choosing to combine and compare all the available cost-effective measures to reduce congestion. 


\section{Literature Review}

In reviewing different performance measurement efforts on the state level, the Florida Commuter Assistance Program (CAP) evaluation measures included (CUTR 1999):

- number of commuters requesting assistance

- number of commuters switching modes

- number of vans in service (where applicable)

- number of vehicle trips eliminated

- vehicle miles eliminated

- employer contacts

- parking spots saved/parking needs reduced

- commuter costs saved

- major accomplishments

- gasoline saved

- emissions reduced

- information materials distributed

- special events

- media/community relations

It seems logical that CAP's results would correlate to improvements in transportation system efficiency and performance. What remains to be done is translating these measures of effectiveness (MOEs) into measurable congestion improvements on a traffic system.

There is a similar challenge in addressing how to relate the impact of worksite trip reduction programs on the transportation system as well as on the worksite level. For example, the CTR program in Washington State has used a variety of methods to help communicate the impacts in its biennial reports to the state legislature (CTR Task Force 2005). In 1999, a lane-mileage reduction method was used to estimate low-cost additional roadway capacity and reduced trip times for motorists and freight that had resulted from removing vehicles trips due to CTR. In 2001, WSDOT used change in travel delay. In 2003, the agency used a method developed by TTI for its 2003 Annual Urban Mobility Report (Schrank and Lomax 2003). This methodology estimated the levels of congestion on roadways in major metropolitan areas throughout the country. 
TTI's 2003 report used a new methodology to estimate the delay reduction from five congestion remedies: ramp metering, incident management, signal coordination, public transportation, and high occupancy vehicle (HOV) lanes. These analysis techniques are experimental but provide a context for understanding the significance and value of travel delay reduction. TTI estimated that the total (morning and evening) annual delay reduction in 2003 for changes in commute choices at CTR sites was 1.84 million hours and valued the savings at \$24 million each year. In addition, fuel savings from less stop-and-go traffic amounted to an estimated 3.6 million gallons - worth more than $\$ 5.8$ million per year to commuters. The TTI methodology for estimating delay and speed for various congestion mitigation strategies is based on a macroscopic approach. Travel delay is estimated from vehicle traffic per lane and traffic speed equations. The fundamental challenge is to assess the bearings of TDM programs on the traffic system and to quantify speed, delay, and travel time after TDM programs are applied.

The research study addressed this challenge by using a microscopic simulation model, CORSIM, to evaluate the impacts of employer-based programs from the WSDOT CTR database on a segment of Seattle's downtown I-5 corridor. The implications of the research can be instrumental in developing strategies that increase transportation system efficiency, particularly by reducing delays and bottlenecks during peak hours without added construction costs.

The process begins with the selection of pertinent performance measures. On the national level, the National Transportation Operations Coalition (NTOC) Action Team on Performance Measurement was assembled to define and document "a few good measures" for transportation operations performance measurement (NTOC 2005). With the guidance of an oversight team comprised of transportation professionals and state and local government representatives, specific measures focused on the following issue areas:

- nonrecurring congestion (e.g., traffic incident management)

- recurring congestion (e.g., arterial management, traffic signal timing)

- system-wide performance (e.g., travel time, reliability, congestion)

The oversight team identified performance measures within each of these areas. These measures, listed below, were defined as commonly acceptable and important among a range of jurisdictions and agencies. NTOC recommended standardizing these performance measures. This research study utilized several of these 
measures (underlined in the list below), in addition to other MOEs, including vehicle miles reduced, fuel savings, and vehicle emission reduction to communicate the impacts of TDM on the transportation system.

- customer satisfaction

- spatial extent of congestion (lane miles)

- temporal extent of congestion (hours of congestion)

- incident duration (median minutes per incident)

- nonrecurring delay (vehicle-hours)

- recurring delay (vehicle-hours)

- average speed (miles per hour)

- person throughput (minutes)

- vehicle throughput (vehicle per hour)

- travel time-link (minutes per trip)

- travel time-reliability (buffer time in minutes)

- travel time-trip (minutes per trip)

\section{Research Methodology}

The literature review revealed the gap between methodologies used to evaluate the effectiveness of employer-based TDM strategies at worksites and common measures used to evaluate the performance of the transportation system. The research study addressed this gap by developing a methodology that will help TDM professionals communicate the effectiveness of employer-based programs in terms of commonly used transportation performance measures, including delay in vehicle-hours and seconds per vehicle, average speed in miles per hour ( $\mathrm{mph}$ ), spatial and temporal extent of congestion, in addition to fuel consumption in gallons and emissions in grams/mile. The hypothesis of the research was that a widescale adoption of employer-based strategies is likely to have a measurable impact on the performance of a transportation system.

The methodology was to simulate the impacts of employer-based programs affecting a segment of a corridor to compare traffic performance with and without TDM programs. The steps summarized below were followed: 
1. A traffic network with documented data of employer-based TDM programs in its surroundings was selected.

2. Worksites utilizing TDM programs within the impact area were inventoried.

3. Time period for the analysis was defined.

4. Data including worksite information, types of employer-based TDM strategies practiced, employee participation, and employee commute travel behavior were collected.

5. VTR at each worksite were calculated.

6. VTR were then distributed (pairs of origin-destination trips) on the traffic network.

7. The distributed trips were then assigned onto network links based on the shortest path between origins and destinations.

8. The already-calibrated microsimulation model was run with existing volumes (Scenario A: with TDM).

9. VTR (from step 7) were added to existing traffic counts on network links (Scenario B: without TDM).

10. Scenarios A and B were run and data from output files were analyzed to compare the scenarios.

\section{Employer-based TDM Programs Data}

In 1991, the Washington State Legislature passed the CTR law (RCW 70.94.521551) to reduce traffic congestion, air pollution, and petroleum consumption through employer-based programs that reduce peak-hour, single-occupant vehicle (SOV) commute trips in the states' nine most populous counties. The CTR program works with employers to encourage workers to commute without driving alone every day and encourages transportation service providers to expand the opportunities available to employees for commuting in ways other than driving alone. The results of these efforts are demonstrated in the daily choices made by more than 560,000 employees at the 1,114 worksites participating in the program. CTR employers submit an annual report and a program description form to report on TDM programs implemented. CTR employers are also required to survey employee commute behavior every two years to measure progress toward their CTR goals. The employer annual report and employee biennial survey form two 
databases that provide detailed data on the employers' TDM performance and employees' travel behavior. The data are detailed, comprehensive, and certified as correct for each employer. Information contained in the annual employer report includes:

- worksite description

- employee information

- program promotion information, including list of CTR programs implemented or promoted by the employer

- worksite characteristics

- worksite parking information and parking management

- financial incentive and subsidies

- site amenities

- work schedule policy

- other programs' availability [e.g., guaranteed ride home (GRH), internal match, fleet vehicle, etc.]

Information contained in the individual employee survey includes:

- work schedule

- commute trip mode split

- compressed workweek schedule

- teleworking schedule

- travel distance

- job title

- home zip code

\section{Traffic Network Data}

The study corridor was selected in the vicinity of a high concentration of CTR-participating employers where quality data are regularly collected. The Washington State CTR program database for the year 2003 was studied to establish the geographical concentration of participating employers. The database provided the list of cities and zip codes with high numbers of employers/employees participating in 
TDM programs. The WSDOT long-range plans were studied to determine where DOT has identified problem areas and planned future improvements.

Based on these factors, $1-5$ in downtown Seattle was selected as the transportation corridor for this study. Figure 1 shows worksite locations on and around the 1-5 study area. The area consists of 8.6 miles of I-5 from NE 45th Street in the north to Corson Avenue in the south. The 67 lane-miles of interstate consist of 16 onramps and 19 off-ramps. Other major roadways in the area were I-90, SR 520, and SR 99. The $1-5$ reversible express lanes were not considered in the analysis as they provided limited entrance to and egress from the study area or provided access to HOV lanes only. The total volumes of the three-hour AM peak between 6:00 AM and 9:00 AM were 22,500 and 19,900 vehicles for the northbound and southbound 1-5, respectively, for the year 2004. The three-hour PM-peak volumes between 3:00 PM and 6:00 PM were 19,800 and 20,600 vehicles for northbound and southbound



Figure 1. Employer Worksites in Study Area of I-5 
1-5, respectively. The study area had 189 employers participating in CTR programs, affecting 62,947 employees.

\section{Traffic Analysis Tool: CORSIM}

CORSIM, a stochastic microsimulation model, has been used by practitioners and researchers for the past 30 years to simulate and conduct various transportation-related evaluations. CORSIM assigns random numbers to drivers, vehicle characteristics, and decision-making processes simulating the randomness of the actual traffic conditions. The model has different driver types, depending on the aggressiveness of driving, various vehicle types, and vehicle fleets, depending on the acceleration capability, weight, and size of vehicles. All proportions of these driver types and vehicle types can be adjusted to simulate the existing driver and vehicle mix. Several calibration parameters can be modified to adjust the model for the existing traffic conditions. These parameters include mean start-up delay at ramp meters, incident rubbernecking factors, car-following sensitivity factors, lane change gap acceptance dynamics, and factors affecting discretionary lane changes.

The CORSIM network model files for the AM- and PM-peak periods were obtained from the WSDOT with traffic volume data for the year 2004. The network files were already calibrated by WSDOT to represent the traffic conditions that exist on the field. The volumes were provided in 19 time intervals of 15 minutes each from 5:30 AM to 10:15 AM for the AM peak and from 3:00 PM to 7:45 PM for the PM peak. The transportation network consists of nodes and links in the CORSIM network file where nodes are intersections, location of exits on interstate, or location of merge-on interstates; and links are actual roadways between two nodes. An 8.6-mile segment of the $1-5$ corridor was divided into 49 links in CORSIM to simulate the changes in the roadway geometry, add/drop lanes, or ramps on the Interstate.

\section{The Analysis}

\section{Trip Reduction Estimation, Distribution, and Assignment}

Since the CTR employee biennial survey is conducted after the CTR program is implemented, it is assumed for this study that individual employee commute travel behavior information in the survey is the scenario with TDM. However, 
since the implementation of TDM programs vary across the employers, the definition of with TDM was not consistent. In other words, the scenario with TDM for one employer may differ from another. It is possible to define the scenario with TDM assuming all target employers implement the same level of TDM program. The shortcoming of this assumption would be the lack of the corresponding employee commute travel behavior data. The reality is that employers comply with the same CTR law in various degrees.

While TDM is a broad application of different strategies aimed at reducing and/or eliminating SOVs, for the purposes of this research, these strategies are combined into four different groups and only the impact of these groups will be evaluated (Table 1).

\section{Table 1. Combined Groups of TDM Strategies for Scenarios A and B}

\begin{tabular}{|l|l|l|l|l|}
\hline Group & \multicolumn{1}{|c|}{ Strategies } & \multicolumn{1}{|c|}{ Purposes } & \multicolumn{1}{|c|}{$\begin{array}{l}\text { Scenario A } \\
\text { With TDM }\end{array}$} & \multicolumn{1}{|c|}{$\begin{array}{l}\text { Wcenario B } \\
\text { Without TDM }\end{array}$} \\
\hline A & $\begin{array}{l}\text { Alternative } \\
\text { work } \\
\text { schedules }\end{array}$ & CWW and telecommuting. & $\begin{array}{l}\text { This group of strategies } \\
\text { functions to reduce } \\
\text { person trips. }\end{array}$ & $\begin{array}{l}\text { Employees are not } \\
\text { allowed to } \\
\text { telecommute or } \\
\text { participate in CWW. }\end{array}$ \\
\hline B & $\begin{array}{l}\text { Employer } \\
\text { TDM support } \\
\text { strategies }\end{array}$ & $\begin{array}{l}\text { Nonmonetary promotions to encourage use of } \\
\text { alternative modes. These include rideshare } \\
\text { matching services, vanpool formation } \\
\text { assistance, onsite transit information and/or } \\
\text { pass sales, ETCs, and guaranteed ride home. }\end{array}$ & $\begin{array}{l}\text { This group of strategies } \\
\text { functions to reduce } \\
\text { drive-alone trips by } \\
\text { encouraging employee } \\
\text { taking alternative } \\
\text { modes. }\end{array}$ & $\begin{array}{l}\text { Employers do not assist } \\
\text { in any way to } \\
\text { encourage modes } \\
\text { other than SOV. }\end{array}$ \\
\hline C & $\begin{array}{l}\text { Travel cost } \\
\text { changes }\end{array}$ & $\begin{array}{l}\text { Measures such as imposition of parking fees, } \\
\text { differential rates or discounts for carpool or } \\
\text { vanpool parking, transit fare subsidies }\end{array}$ & $\begin{array}{l}\text { This group of strategies } \\
\text { functions to reduce } \\
\text { SOVs by increasing } \\
\text { SOV costs or } \\
\text { decreasing that of } \\
\text { alternative modes. }\end{array}$ & $\begin{array}{l}\text { There is no financial } \\
\text { subsidy for any } \\
\text { alternative mode and } \\
\text { SOV or other mode } \\
\text { parking is free. }\end{array}$ \\
\hline D & $\begin{array}{l}\text { Flexible work } \\
\text { hours }\end{array}$ & $\begin{array}{l}\text { A relaxation in the official daily hours of } \\
\text { business allows employees the flexibility to } \\
\text { adjust their personal work schedules to either } \\
\text { come early/leave early, or come late/leave late } \\
\text { to avoid the most congested portion of daily } \\
\text { commute periods. }\end{array}$ & $\begin{array}{l}\text { This group functions } \\
\text { to shift vehicle trips } \\
\text { out of peak period. }\end{array}$ & $\begin{array}{l}\text { Employees are not } \\
\text { allowed to work on } \\
\text { flexible workhour } \\
\text { schedules. }\end{array}$ \\
\hline
\end{tabular}

While the assumptions of without TDM for the first three groups of TDM strategies are straightforward and consistent with the general understanding of TDM, the assumption for travel cost changes is debatable. The travel cost changes strategies include measures such as imposition of parking fees, differential rates, or discounts for carpool or vanpool parking, and financial incentives or subsidies 
to alternative modes. The differential rates or discounts for carpool or vanpool parking and the financial subsidies to alternative modes are inarguably considered direct results of TDM but there is disagreement on the imposition of parking fees as part of TDM strategies in this specific case study. The major concern is that, no matter if with TDM or without TDM, free parking does not widely exist, especially in Seattle's downtown area.

The assumption of free parking for individual employees only means employees do not have out-of-pocket cost for parking; it may be free for the employer. In other words, it assumes that the imposition of parking fees by the employer on individual employees has a direct impact on their commute model choice. Employees park either in an employer-provided parking facility or in a facility that is not provided by the employer. The employer-provided facility included employer-leased parking space or employer-owned space. In both case, if it is free for the employee, it is not for the employer. Free parking in the parking space that is not provided by the employer means the employee either receives a financial subsidy from the employer to cover the parking cost or enjoys free public parking space. The public parking space that is free for both the employee and employer is a rare situation. According to the 2003 Washington State CTR employer annual report, 50.8 percent of employers charge for SOV parking, 31.2 percent charge for carpool parking, and 11.1 percent charge for vanpool parking.

If only differential rates or discounts for carpool or vanpool parking and financial incentives or subsidies to alternative modes were taken into account, based on the TDM reduced vehicle-trip calculation procedure, the average percentage of vehicle-trip reduction is $\mathbf{1 1 . 3}$ percent. Compared with the original 14.2 percent, it suggests the impact of the imposition of parking fees accounts for a 3 percent reduction in vehicle trips.

The process of estimating VTR was developed based on the COMMUTER model (U.S. Environmental Protection Agency 2005). The impact of each group of strategies is evaluated separately using different methods:

- The impact of alternative work hours is evaluated by adding participants of telecommuting and CWW back to SOVs, then calculating the revised person trips.

- Employer TDM support programs are analyzed using relational factors in look-up tables, along with a normalization procedure applied to the adjusted 
shares to ensure that changes are proportionate across the available alternatives and final choices do not exceed 100 percent.

- Travel cost changes strategies are analyzed through the more rigorous logit pivot-point procedure.

- The impact of flexible work hours is evaluated by estimating the number of vehicle trips shifted out of the peak period due to the program.

The results included changes in traffic flow at each ramp and the ramp ID for each reduced trip if using the $1-5$ portion of the study area. To use CORSIM in evaluating the impacts of TDM, a course of action was developed to calculate changes in traffic flow due to the implementation of a TDM program for each entry and exit ramp of the I-5 study area based on the Washington State CTR database. A methodology was developed to estimate the volume of VTR by TDM, programs implemented at each worksite within the study area can be summarized as follows:

- The percentage of non-SOV trips from each origin (home) to all destinations (worksites) was calculated based on the CTR employee survey data.

- Each reduced trip at an employer site was distributed between worksite and home traffic zones pairs based on the assumption that VTRs were derived from the non-SOV trips.

- Based on the 2000 Tiger/Line road census data, a transportation network of five counties including King, Island, Snohomish, Kitsap, and Pierce was created to find the shortest path for each home-worksite pair and to assign the reduced traffic onto network links based on the all-or-nothing traffic assignment approach.

Table 2 provides selected statistics of the data input into CORSIM. While the average change in traffic flow on $1-5$ ramps is about 4 percent, the distribution of the change is not even. At the AM-peak period, work trips flow from north and south to the downtown area. The biggest flow change for the on-ramps is more than 10 percent and for the off-ramps is almost 50 percent. The average change in traffic flow change for the off-ramps at the downtown area is more than 30 percent.

At the PM-peak period, commuters going home from the downtown area are traveling to both north and south ends. Traffic flow changes at both south and north ends for the on-ramps and the off-ramps in the downtown area are signifcant. The biggest flow changes for off-ramps and on-ramps are more than 10 and 55 percent, respectively. The average change in traffic flow for the on-ramps at the downtown area is more than 20 percent. 
Table 2. Selected CORSIM Inputs

\begin{tabular}{|l|l|l|}
\hline Total Number of Worksite & \multicolumn{2}{|l|}{189} \\
\hline Total number of affected employees working 6am-9am & \multicolumn{2}{|l|}{} \\
\hline Total number of reduced vehicle trips & 5,149 \\
\hline Average percentage of TDM vehicle-trip reduction & $14.2 \%$ & \multicolumn{1}{|l|}{} \\
\hline & \multicolumn{1}{|l|}{} \\
\hline Average share of SOV & With TDM & Without TDM \\
\hline Average share of transit & $56.9 \%$ & $64.5 \%$ \\
\hline Total number of person trips & $28.1 \%$ & $20.4 \%$ \\
\hline Total number of vehicle trips & 54,459 & 54,997 \\
\hline & 34,860 & 40,009 \\
\hline Total number of reduced vehicle trips for I-5 & AM-Peak Period & PM-Peak Period \\
\hline Total I-5 ramp traffic flow & 4,142 & 3,815 \\
\hline Average percentage of I-5 ramp traffic flow change & 99,648 & 109,437 \\
\hline
\end{tabular}

\section{Performance Measures}

The findings showed a significant reduction in recurring delay, a reduction in spatial and temporal extent of congestion, and lesser emissions due to TDM programs. In addition, TDM programs resulted in fuel savings, VMT reduction, and an increase in the average speed of the corridor. These results indicate that TDM had significant impact on the performance of the transportation corridor. The following sections detail the definition of each performance measure and the analysis results.

Recurring Delay. Recurring delay is the cumulative delay encountered by all the vehicles on a section of roadway during a predefined period. Delay is calculated as the actual time taken by a vehicle to traverse a section of roadway minus the time it would have taken if it were traveling at free-flow speed. Figures 2 and 3 compare the $A M$ recurring delay for the scenario with TDM versus the scenario without TDM for NB I-5 and SB 1-5, respectively. 




$\rightarrow$ Scenario A (with TDM) $\leftarrow$ Scenario B (without TDM)

Figure 2. AM Recurring Delay on NB I-5

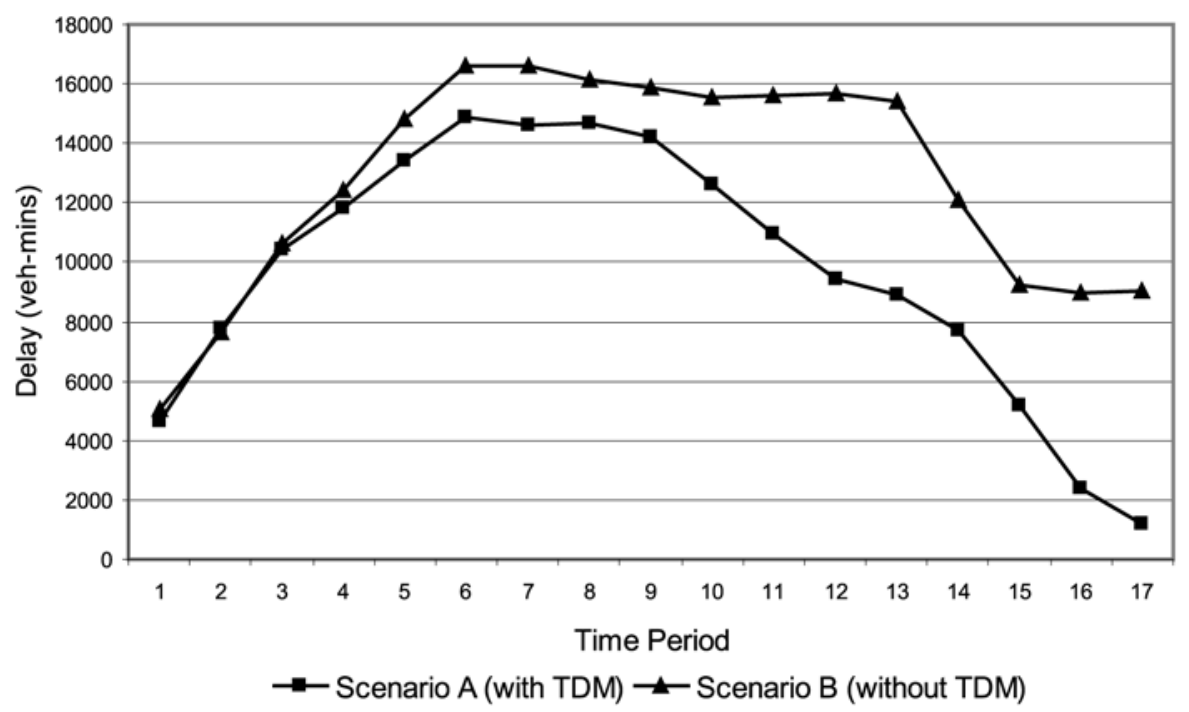

Figure 3. AM Recurring Delay on SB I-5 
Figures 4 and 5 compare the PM recurring delay for the scenario with TDM versus the scenario without TDM for NB I-5 and SB I-5, respectively.

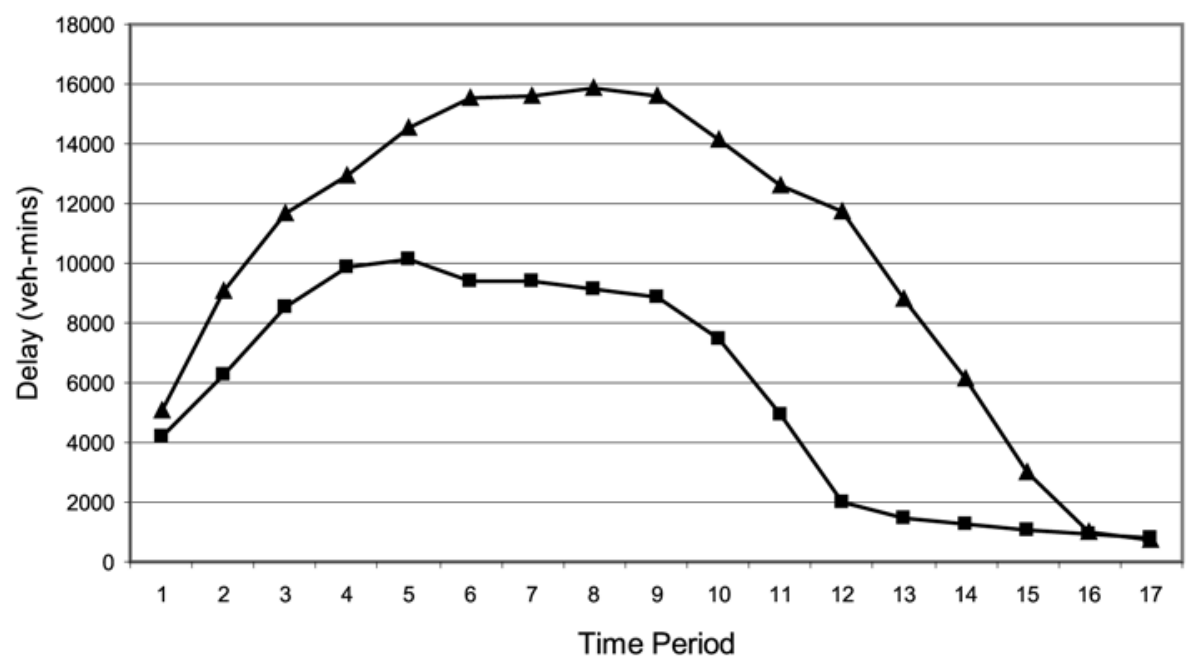

$\rightarrow-$ Scenario A (with TDM) $\longleftarrow$ Scenario B (without TDM)

Figure 4. PM Recurring Delay on NB I-5

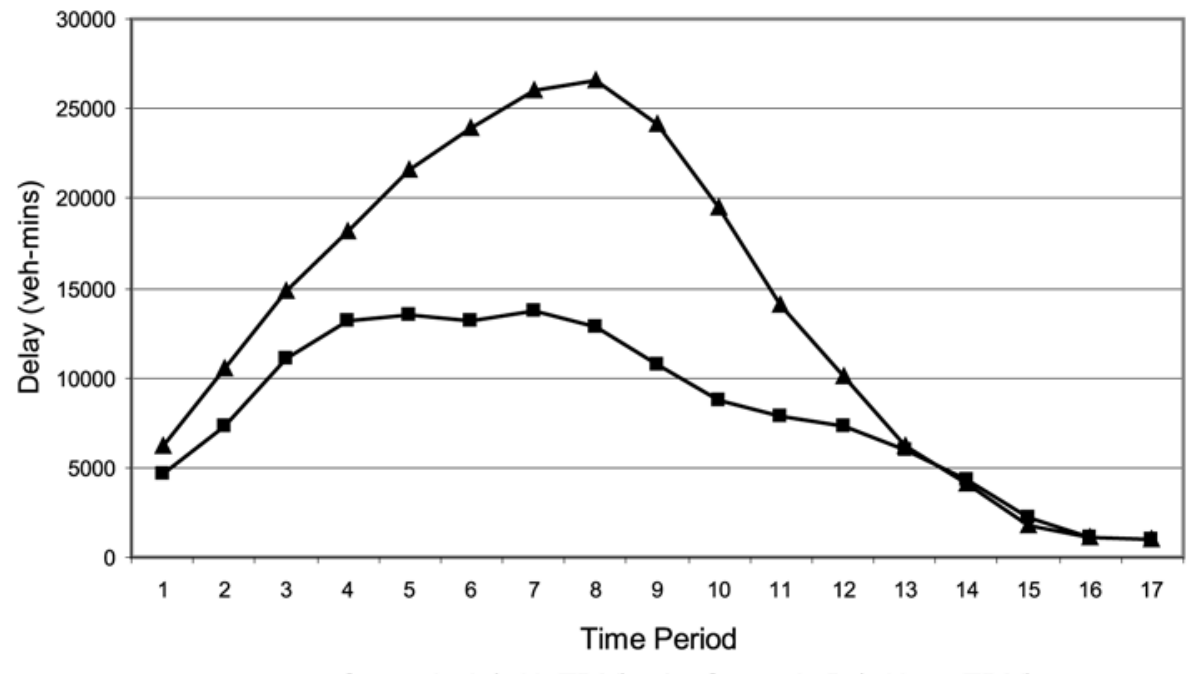

$\rightarrow-$ Scenario A (with TDM) $\longleftarrow$ Scenario B (without TDM)

Figure 5. PM Recurring Delay on SB I-5 
The increase in delay in the scenario without TDM was significant for the entire PM periods, except for the last 15-minute interval on NB and the last 45 minutes on the SB. The without TDM scenario had more recurring delay of 169,486 vehicle minutes during PM period and 152,489 vehicle minutes during the AM period, compared to the scenario with TDM.

Spatial Extent of Congestion on the Corridor. The spatial extent of congestion is the length of roadway within a predefined area and period for which the average travel times are 30 percent longer than the unconstrained travel time. Unconstrained travel time is the time it takes for a motorist to traverse a roadway section when traveling at the free-flow speed of $65 \mathrm{mph}$. If the travel speed were $50 \mathrm{mph}$ or lower, it would take 30 percent longer to travel the same distance when compared with a speed of $65 \mathrm{mph}$. Spatial congestion was measured in lane-miles of the network with speeds lower than the corresponding congested speed. The travel time on a link during a particular time period was calculated to determine the level of congestion on the network. The lane-miles of congested links were added to determine the total lane-miles of congestion on the network during a particular period.

The cumulative spatial congestion for AM-peak periods increased from 442.7 lanemiles in the scenario with TDM to 544.4 lane-miles in the scenario without TDM, where it took 30 percent longer or more than unconstrained travel time. The spatial congestion cumulative for all the periods increased from 324.2 lane-miles for scenario A to 467.1 lane-miles for scenario $B$ during the PM periods, where it took 30 percent longer or more than unconstrained travel time (see Table 3 ).

Temporal Extent of Congestion on the Corridor. The temporal extent of congestion is the "time duration" during which more than 20 percent of the roadway sections in a predefined area are congested as defined by "spatial extent of congestion." One period is considered as the "time duration"; therefore, if 20 percent of the network is congested for a particular period, that particular time period is considered congested. During the AM peak, the temporal extent of congestion increased by 31 percent in the scenario without TDM, as compared to that with TDM at the level of congestion of 30 percent longer or more than the unconstrained travel time (see Table 4). 
Table 3. Spatial Extent of Congestion

\begin{tabular}{|c|c|c|c|c|c|c|c|}
\hline \multicolumn{8}{|c|}{ Spatial Congestion - Lane Miles } \\
\hline \multicolumn{4}{|c|}{ AM-Peak Period } & \multicolumn{4}{|c|}{ PM-Peak Period } \\
\hline From & To & $\begin{array}{l}\text { With } \\
\text { TDM }\end{array}$ & $\begin{array}{c}\text { Without } \\
\text { TDM }\end{array}$ & From & To & $\begin{array}{l}\text { With } \\
\text { TDM }\end{array}$ & $\begin{array}{l}\text { Without } \\
\text { TDM }\end{array}$ \\
\hline $6: 00$ & $6: 15$ & 21.0 & 21.0 & $3: 00$ & $3: 15$ & 12.4 & 22.3 \\
\hline $6: 15$ & $6: 30$ & 32.5 & 29.4 & $3: 15$ & $3: 30$ & 22.8 & 27.4 \\
\hline 6:30 & $6: 45$ & 34.9 & 35.5 & $3: 30$ & $3: 45$ & 29.8 & 32.9 \\
\hline $6: 45$ & 7:00 & 35.5 & 36.2 & $3: 45$ & $4: 00$ & 27.4 & 33.9 \\
\hline $7: 00$ & $7: 15$ & 36.4 & 37.5 & 4:00 & $4: 15$ & 35.2 & 44.5 \\
\hline $7: 15$ & $7: 30$ & 35.4 & 34.8 & $4: 15$ & $4: 30$ & 29.8 & 43.5 \\
\hline $7: 30$ & $7: 45$ & 36.4 & 34.2 & $4: 30$ & $4: 45$ & 32.1 & 45.0 \\
\hline $7: 45$ & $8: 00$ & 34.2 & 34.2 & $4: 45$ & $5: 00$ & 31.6 & 45.0 \\
\hline $8: 00$ & $8: 15$ & 32.7 & 32.7 & $5: 00$ & $5: 15$ & 23.8 & 41.3 \\
\hline $8: 15$ & $8: 30$ & 30.8 & 34.2 & $5: 15$ & $5: 30$ & 20.7 & 33.3 \\
\hline $8: 30$ & $8: 45$ & 31.9 & 34.2 & $5: 30$ & $5: 45$ & 19.0 & 31.1 \\
\hline $8: 45$ & $9: 00$ & 29.7 & 34.2 & $5: 45$ & $6: 00$ & 13.6 & 24.5 \\
\hline 9:00 & $9: 15$ & 19.2 & 34.2 & $6: 00$ & $6: 15$ & 13.0 & 22.1 \\
\hline $9: 15$ & $9: 30$ & 14.1 & 32.3 & $6: 15$ & $6: 30$ & 6.3 & 10.9 \\
\hline $9: 30$ & $9: 45$ & 12.0 & 29.7 & $6: 30$ & $6: 45$ & 5.4 & 8.0 \\
\hline $9: 45$ & $10: 00$ & 5.4 & 27.9 & $6: 45$ & $7: 00$ & 0.7 & 0.7 \\
\hline $10: 00$ & $10: 15$ & 0.7 & 22.0 & $7: 00$ & $7: 15$ & 0.7 & 0.7 \\
\hline \multicolumn{2}{|l|}{ Total } & 442.7 & 544.4 & \multicolumn{2}{|l|}{ Total } & 324.2 & 467.1 \\
\hline \multicolumn{3}{|c|}{$\%$ increase } & $23 \%$ & \multicolumn{3}{|c|}{$\%$ increase } & $44 \%$ \\
\hline
\end{tabular}


Table 4. Temporal Extent of Congestion

\begin{tabular}{|c|c|c|c|c|c|c|c|}
\hline \multicolumn{8}{|c|}{ Temporal Congestion-Vehicle Minutes } \\
\hline \multicolumn{4}{|c|}{ AM-Peak Period } & \multicolumn{4}{|c|}{ PM-Peak Period } \\
\hline From & To & $\begin{array}{l}\text { With } \\
\text { TDM }\end{array}$ & $\begin{array}{l}\text { Without } \\
\text { TDM }\end{array}$ & From & To & $\begin{array}{l}\text { With } \\
\text { TDM }\end{array}$ & $\begin{array}{c}\text { Without } \\
\text { TDM }\end{array}$ \\
\hline 6:00 & 6:15 & 15.0 & 15.0 & 3:00 & 3:15 & 0.0 & 15.0 \\
\hline $6: 15$ & 6:30 & 15.0 & 15.0 & $3: 15$ & $3: 30$ & 15.0 & 15.0 \\
\hline $6: 30$ & $6: 45$ & 15.0 & 15.0 & $3: 30$ & $3: 45$ & 15.0 & 15.0 \\
\hline $6: 45$ & 7:00 & 15.0 & 15.0 & $3: 45$ & 4:00 & 15.0 & 15.0 \\
\hline 7:00 & 7:15 & 15.0 & 15.0 & 4:00 & 4:15 & 15.0 & 15.0 \\
\hline $7: 15$ & $7: 30$ & 15.0 & 15.0 & $4: 15$ & $4: 30$ & 15.0 & 15.0 \\
\hline $7: 30$ & $7: 45$ & 15.0 & 15.0 & $4: 30$ & $4: 45$ & 15.0 & 15.0 \\
\hline $7: 45$ & $8: 00$ & 15.0 & 15.0 & $4: 45$ & $5: 00$ & 15.0 & 15.0 \\
\hline $8: 00$ & $8: 15$ & 15.0 & 15.0 & $5: 00$ & $5: 15$ & 15.0 & 15.0 \\
\hline $8: 15$ & $8: 30$ & 15.0 & 15.0 & $5: 15$ & $5: 30$ & 15.0 & 15.0 \\
\hline $8: 30$ & $8: 45$ & 15.0 & 15.0 & $5: 30$ & $5: 45$ & 15.0 & 15.0 \\
\hline $8: 45$ & $9: 00$ & 15.0 & 15.0 & $5: 45$ & $6: 00$ & 0.0 & 15.0 \\
\hline 9:00 & 9:15 & 15.0 & 15.0 & $6: 00$ & $6: 15$ & 0.0 & 15.0 \\
\hline $9: 15$ & $9: 30$ & 0.0 & 15.0 & $6: 15$ & $6: 30$ & 0.0 & 0.0 \\
\hline $9: 30$ & $9: 45$ & 0.0 & 15.0 & $6: 30$ & $6: 45$ & 0.0 & 0.0 \\
\hline $9: 45$ & $10: 00$ & 0.0 & 15.0 & $6: 45$ & $7: 00$ & 0.0 & 0.0 \\
\hline $10: 00$ & $10: 15$ & 0.0 & 15.0 & 7:00 & $7: 15$ & 0.0 & 0.0 \\
\hline \multicolumn{2}{|l|}{ Total } & 195.0 & 225.0 & \multicolumn{2}{|l|}{ Total } & 324.2 & 467.1 \\
\hline \multicolumn{3}{|c|}{$\%$ increase } & $31 \%$ & \multicolumn{3}{|c|}{$\%$ increase } & $30 \%$ \\
\hline
\end{tabular}


Average Speed. The average speed for the corridor was calculated for each of the 17 periods. Figure 6 shows the average speed of the network for AM period for the scenario with TDM versus the scenario without TDM. The average speed is lower for all periods for the scenario without TDM, and the difference between the average speeds is more significant from 8:30 AM onwards. The difference in average speed ranges from $2 \mathrm{mph}$ to $19 \mathrm{mph}$ for different periods.



\section{Figure 6. Average Corridor Speed during AM Peak}

Figure 7 shows the average speed of the corridor for the PM period for the scenario with TDM versus the scenario without TDM. The average speed is higher for the scenario with TDM for all periods. The difference in the average speed is more significant between 4:00 PM and 6:00 PM. The difference in average corridor speed varies from 11 to $0 \mathrm{mph}$. 


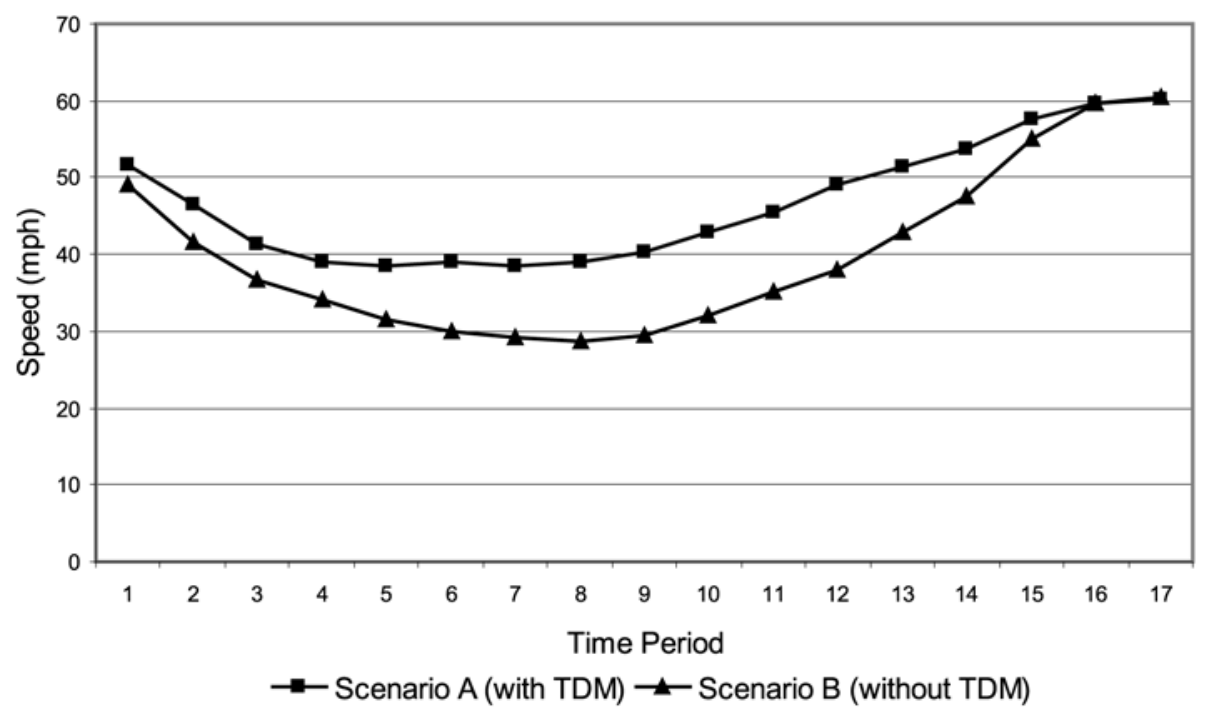

Figure 7. Average Corridor Speed during PM Peak

Fuel Consumption and Emissions. CORSIM provides fuel consumption and emissions statistics for each vehicle on the network. These statistics are accumulated for each period of the analysis. Figures 8 and 9 show the fuel consumption for both scenarios for AM period and PM period, respectively. During the AM period, the scenario without TDM had significantly more fuel consumption for periods after 8:00 AM as compared to that with TDM. During the PM period, this difference in fuel consumption occurred between 4:00 PM to 6:00 PM. The scenario without TDM had 3,489 gallons of excess fuel consumption during AM period and 4,314 gallons during the PM period. 


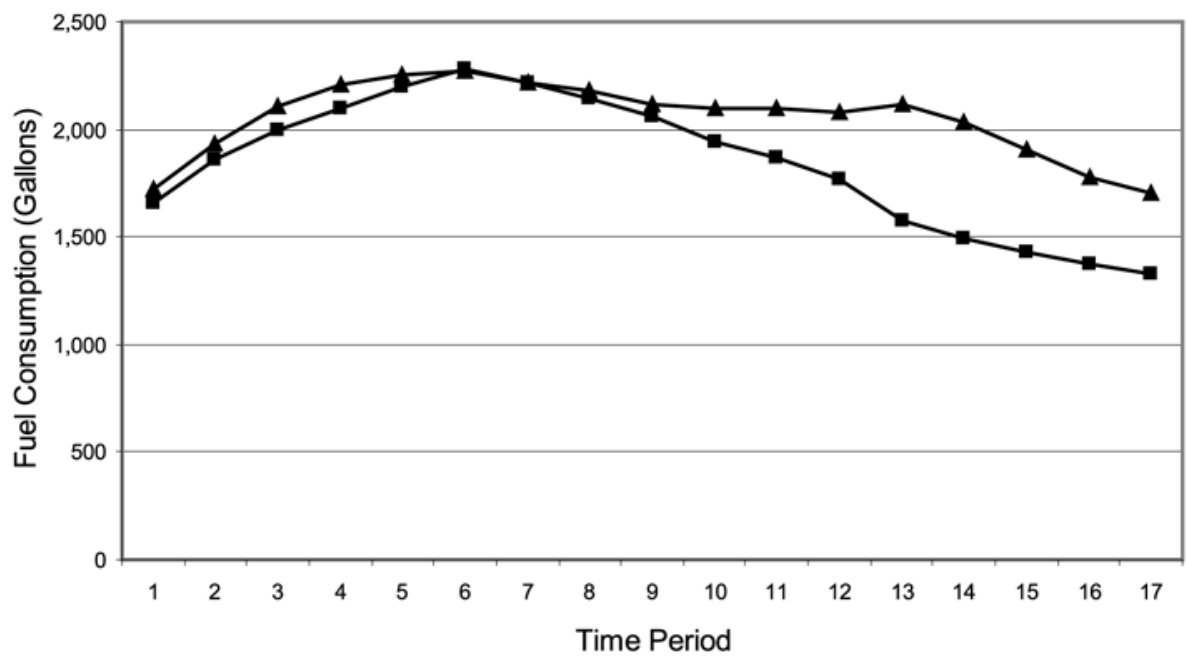

$\rightarrow-$ Scenario A (with TDM) $\longleftarrow$ Scenario B (without TDM)

Figure 8. Fuel Consumption during AM Peak

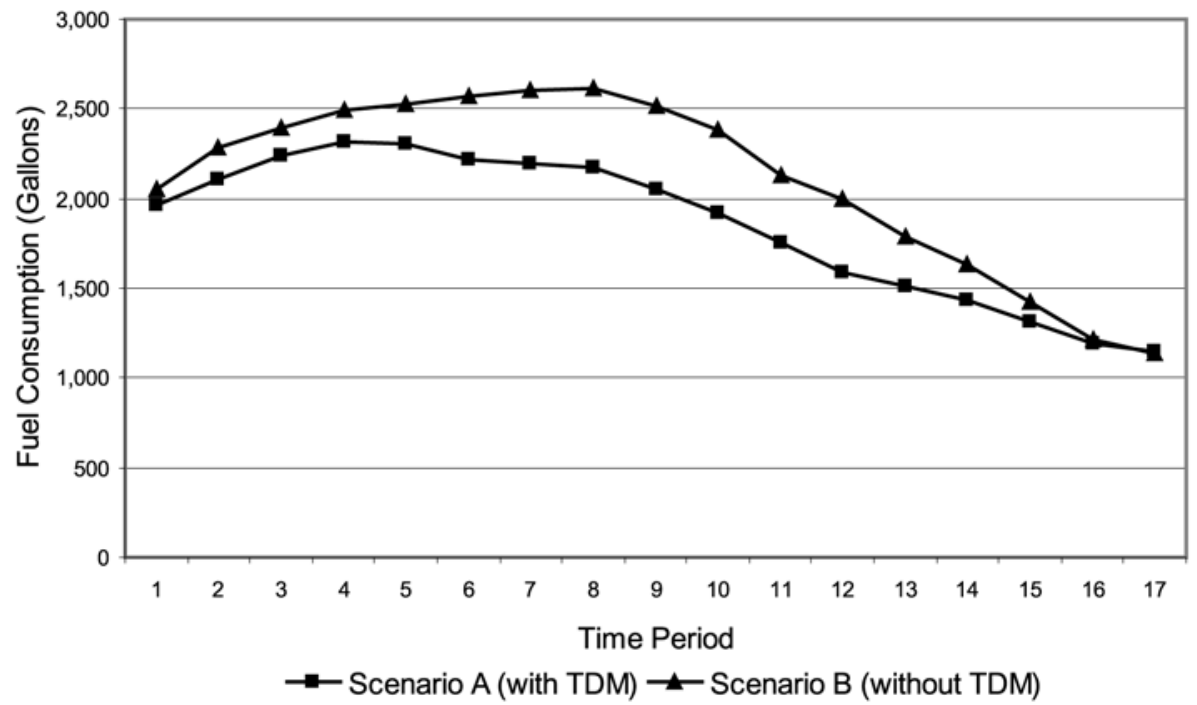

Figure 9. Fuel Consumption during PM Peak 
CORSIM provides hydrocarbons ( $\mathrm{HC})$, carbon monoxide (CO), and oxides of nitrogen (NOx) emission statistics for each vehicle on the network. These values were compared for the scenario with TDM versus the scenario without TDM, as seen in Tables 5 and 6 for AM period and PM period, respectively. Table 5 shows an increase in $\mathrm{HC}$ emissions by 10.3 percent, $\mathrm{CO}$ emissions by 9.6 percent, and NO emissions by 8.9 percent for the scenario without TDM as compared to with TDM during the AM period.

Table 5. Emissions during AM Peak

\begin{tabular}{|l|c|c|c|c|}
\hline Pollutant & $\begin{array}{c}\text { With } \\
\text { TDM }\end{array}$ & $\begin{array}{c}\text { Without } \\
\text { TDM }\end{array}$ & $\begin{array}{c}\text { Added } \\
\text { Emissions }\end{array}$ & $\begin{array}{c}\text { Percentage } \\
\text { Increase }\end{array}$ \\
\hline HC emissions (Kg) & 159.0 & 175.4 & 16.4 & 10.3 \\
\hline CO emissions $(\mathrm{Kg})$ & 11563.5 & 12672.7 & 1109.2 & 9.6 \\
\hline NOx emissions $(\mathrm{Kg})$ & 608.6 & 662.9 & 54.3 & 8.9 \\
\hline
\end{tabular}

Table 6 shows an increase in HC emissions by $21.7 \mathrm{~kg}$, CO emissions by $1,545.1 \mathrm{~kg}$, and NO emissions by $67.9 \mathrm{~kg}$ for the scenario without TDM as compared to that with TDM during the PM period.

Table 6. Emissions during PM Peak

\begin{tabular}{|l|c|c|c|c|}
\hline Pollutant & $\begin{array}{c}\text { With } \\
\text { TDM }\end{array}$ & $\begin{array}{c}\text { Without } \\
\text { TDM }\end{array}$ & $\begin{array}{c}\text { Added } \\
\text { Emissions }\end{array}$ & $\begin{array}{c}\text { Percentage } \\
\text { Increase }\end{array}$ \\
\hline HC emissions $(\mathrm{Kg})$ & 165.4 & 187.1 & 21.7 & 13.1 \\
\hline CO emissions $(\mathrm{Kg})$ & 12170.8 & 13715.9 & 1545.1 & 12.7 \\
\hline NO emissions $(\mathrm{Kg})$ & 625.2 & 693.1 & 67.9 & 10.9 \\
\hline
\end{tabular}

\section{Conclusions}

The employer-based CTR programs in the Seattle area had a significant impact on traffic congestion, travel delay, fuel savings, and emissions. Savings in delay amounted to 152,489 and 169,486 vehicle-minutes for the AM and PM periods, respectively. There was a reduction of 101.7 lane-miles of spatial congestion in the AM peak and 142.9 lane-miles in the PM peak. A significant congestion reduction of 60 and 45 minutes for the AM and PM peaks, respectively, was observed from 
the CORSIM output files. The average speed increased by up to $19 \mathrm{mph}$ for the AM and up to $11 \mathrm{mph}$ for the PM peak. VMT reductions ranged from 17,297 vehiclemiles in the $A M$ peak to 14,511 vehicle-miles in the PM peak. Fuel savings of 3,489 gallons during the $A M$ peak period and 4,314 gallons during the $P M$ periods were direct results of TDM programs. HC emissions reductions of 16.4 and 21.7 kilograms for the AM and PM peak, respectively, are a considerable improvement to air quality, as are emissions reduction of 1,109 and 1,545 kilograms of $\mathrm{CO}$ for the AM and PM peak, respectively.

The research study combined two common goals of transportation agencies: reducing traffic congestion and improving the efficiency of the existing transportation system. By monitoring, evaluating, and communicating TDM strategies and their combined impacts on the roadway system, planners, traffic operations staff, TDM professionals, decision makers, and elected officials can be talking the same language when comparing available cost-effective measures to reduce congestion with a focus on performance, not a given solution.

The research used the language of traffic operations professionals to communicate the impacts of TDM strategies. In the future, data can be collected by intelligent transportation systems (ITS) to help improve the methodology of assessing the impacts on TDM on the total system, not just a corridor. Since ITS is systematically used for dynamic data collection, it can be utilized in before- and after-TDM evaluations.

Furthermore, the impacts of TDM programs were measured using the performance measures indicated by the NTOC performance measure initiative. This aids in communicating the impacts of TDM programs to traffic operations professionals and decision makers.

With respect to future research, this study sets a foundation for work on:

- development of national standards for measuring the performance of TDM that integrate with other transportation systems measures

- development of cost/benefit analysis of TDM programs to communities and businesses

- measuring the impact of TDM programs on freeways, arterials, and surface streets

- analyzing the additive or multiplicative effects of combining different TDM strategies with appropriate ITS applications locally and regionally 
Another area for future research is the synergistic effects of TDM and ITS strategies. For example, on a given corridor, are the effects of implementing a 511 system with HOV lanes equal to the sum of the individual effects of each application or does combining these strategies have a multiplicative effect that could result in larger or smaller impacts?

\section{References}

Brown, Jeffrey, Daniel Baldwin Hess, and D. Shoup. 2003. Fare-free public transit at universities: An evaluation. Journal of Planning Education and Research 23 (1), 69-82. University of California-Berkeley, CA.

Center for Urban Transportation Research, University of South Florida. 1999. Commuter Assistance Program evaluation manual. Florida Department of Transportation. http://www.nctr.usf.edu/clearinghouse/pdf/capman\%20rev\%202.pdf.

Commute Trip Reduction Task Force. 2005. Report to the Washington State Legislature. Accessed February 13, 2007 at http://www.wsdot.wa.gov/NR/ rdonlyres/172087A9-85D1-416B-86C4-33281C7BDE68/0/CTR_Report_ 05.pdf.

General Administration Services (GAO). 2005. The status of telework in the federal government. http://www.telework.gov/documents/tw_rpt05/status-intro. asp.

Hagelin, Christopher, and Jennifer Perone. 2005. 2004 Evaluation of South Florida Commuter Services. Center for Urban Transportation Research. University of South Florida (July).

National Transportation Operations Coalition. 2005. Performance measure initiative final report (July). Accessed August 2006 at http://www.ntoctalks.com/ ntoc/ntoc_final_report.pdf.

Schrank, D., and T. Lomax. 2005. Annual urban mobility report. College Station, TX: Texas Transportation Institute.

Schrank, D., and T. Lomax. 2003. Annual urban mobility report. College Station, TX: Texas Transportation Institute.

United States Environmental Protection Agency. 2005. Commuter model v2.0 user manual. Accessed June 2006 at http://www.epa.gov/otaq/stateresources/ policy/transp/commuter/commuter-v20.zip. 


\section{About the Authors}

NeVine Labib GeorGgi (georggi@cutr.usf.edu) joined CUTR in 1993 as CUTR Resource and Information Center Coordinator. As a research associate in the Transportation Demand Management Team, she investigates the impacts of employerbased policies and programs on the transportation system. Currently, Ms. Georggi is researching impacts of ITS applications in collecting travel data, providing travelers with pertinent feedback to reduce drive-alone use, and enhancing the transit rider experience. She is also researching impacts of employing new technology, in advanced public transportation systems and advanced traveler information systems, on travel behavior.

Over the past 18 years, Ms. Georggi has also participated in designing ITS planning and integration guidebooks for the state of Florida, alcohol-related safety research, travel behavior, travel-related statistical analysis, trip generation models, transportation survey design and analysis, project development and environmental studies, web-interfaced searchable solution database, and transportation resource information center. She holds an M.S.C.E. from the University of South Florida (2000) and a B.S.C.E. from Cairo University (1984).

PhILIP L. WinTers (winters@cutr.usf.edu) joined CUTR as TDM program director in 1993. He has more than 25 years of experience with TDM research, planning, operations, training, and evaluation. Prior to joining CUTR, he worked in corporate relocation and TDM consulting, and directed a regional nonprofit TDM program in Virginia. Among his program's recent accomplishments are the development of the Transportation Management Association Handbook, Vanpool Pricing and Financing Guide, and Worksite Trip Reduction Model and Manual. He manages the National TDM and Telework Clearinghouse, and cohosts the "Learn More. Travel Less" netconference series in partnership with the Association for Commuter Transportation (ACT), which has connected as many as 150 attendees in 15 locations at one time. He also created the TRANSP-TDM listserv, which has more than 1,000 subscribers.

Mr. Winters is a member of the Transportation Research Board's Committee on Transportation Demand, past editor of ACT's TDM Review for five years, and member of the Institute of Transportation Engineers' Transportation Planning Council Executive Committee. 
SACHIN RAJ (rai@cutr.usf.edu) joined CUTR as research associate in March 2005. Mr. Rai has been involved in research related to traffic simulation, traffic operations and safety, and intelligent transportation systems. He has worked on the development of transit signal priority, control strategies, and modeling tools. He has used traffic simulation to develop a model for evaluation of corridors based on traffic, geometric, and transit parameters that affect transit priority. Other areas of his research include traffic signal operations and adaptive traffic control and traffic.

He is actively involved with the Institute of Transportation Engineer (ITE) intelligent traffic signals operations committee. He holds a master of science degree in civil engineering from Michigan State University and a bachelor of technology degree in civil engineering from Institute of Engineering and Technology, India.

LIREN ZHOU (Izhou@cutr.usf.edu) joined CUTR as a graduate research assistant in 2004. He is currently pursuing his Ph.D. in transportation planning and modeling in the Department of Civil and Environmental Engineering at the University of South Florida (USF). Prior to joining CUTR, he worked as a transportation planner at Gannett Fleming, Inc., in Florida and as a mechanical engineer in China. He is an associate member of ITE. He holds a M.S. in civil engineering from USF. 
Journal of Public Transportation, Vol. 10, No. 4, 2007 


\title{
Documented Impact of Transportation Demand Management Programs Through the Case Study Method
}

\author{
Sara J. Hendricks and Nevine Labib Georggi \\ Center for Urban Transportation Research, University of South Florida
}

\begin{abstract}
What are the internal and external conditions of a work site that influence the success of its commuter choice program, aside from the trip-reducing services and incentives themselves? This article shares the results of two studies that used a more rigorous case study method for discerning the relative influence of conditions within and outside of the control of a work site. It also discusses the useful application and elements of the case study method as well as the location for finding properly documented case studies that describe successful programs. Recommendations are developed for work sites to implement commuter choice programs for TDM marketing professionals to identify receptive work-site candidates and for TDM researchers to investigate further using the case study method. By understanding the relative importance of various conditions, TDM professionals, employers, and employee transportation coordinators are better equipped to exert influence on factors within their control to develop more effective programs.
\end{abstract}




\section{Introduction}

A common transportation goal of urbanized areas is to reduce traffic congestion during a.m. and p.m. weekday peak hours. Programs that apply transportation demand (TDM) management strategies to individual employment work sites are one potentially effective response that has been used in urban areas throughout the United States over the last 25 years. Participating employers have offered programs and incentives to employees of work sites located in congested areas and who commute during times of peak traffic congestion. The programs are designed to persuade commuting employees to switch to a different travel mode other than single occupant vehicle (SOV), or to change travel time to outside the peak period, telecommute, decrease trip making, or decrease distance traveled.

Transportation professionals, program funding agencies, and employers want to know the level of effectiveness of these programs. TDM marketing specialists charged with promoting the creation of TDM programs need reliable information about how successful programs can be duplicated at other work sites and what factors contribute to TDM program success.

While numerous programs exist across the nation, the most abundant information includes traffic problem characterizations and simple descriptions of efforts undertaken. Many programs have not collected baseline information about prior commuting characteristics to compare against travel behavior after program implementation. Many programs have not measured program results or adequately tracked progress over time but instead provide only a "snapshot" writeup of program characteristics for one point in time. Often there is an inadequate demonstration of the causal link between the program and the results. Other programs may track data that are inadequate indicators of program effectiveness. There are many preconceived notions that arise from anecdotal information, not based upon any sound evidence, about what conditions are ideal for successful programs. For example, common guidance calls for establishing a work-site commuter choice program administered from the human resources department. This advice originated from observations about what many organizations have already done in the past rather than any evidence that human resources departments have special qualities for directing commuter choice programs. Another commonly held belief is that employee transportation coordinators (ETC) with charismatic personalities will be able to persuade commuters to alter their travel behavior. In addition to the limited usefulness of anecdotal information, the good quality program information that does exist is usually not shared but archived 
separately at each program source. The data are not gathered in one known place where they can be easily accessed and used by others.

The availability of properly documented TDM program results is critical to knowing what strategies work effectively and how to improve existing programs. Positive results provide justification for TDM program funding and can convince other employers to start programs of their own.

\section{Background}

Two events helped shape the focus of the research described in this article. First, the 2001 Association for Commuter Transportation (ACT) End-of-Year Survey indicated that the number one desire of TDM professionals was the provision of information on TDM-oriented statistics and case studies. The second event was the development of the Work Site Trip Reduction Model and Manual (WTRM; Winters and Perez 2004) by the Center for Urban Transportation Research (CUTR). The WTRM is a tool for TDM professionals to use for refining the effectiveness of commuter choice programs. Using a neural network built with thousands of "before" and "after" plans from employers, the model quantifies the change in average vehicle ridership (AVR) as a result of applying various combinations of commuter choice program elements. AVR is the number of people transported to a work site for every 100 vehicles. A surprising finding of the WTRM was that the commuter choice program incentives themselves directly explain only about 18 percent of the variance in effectiveness between one program and another. Our research question then became: "What is it that makes work-site trip reduction programs effective? What circumstances explain the other 82 percent?" By using employee data aggregated to the employer level, the WTRM method captures the many complex social and institutional influences that determine whether a commuter choice program is successful. However, this method does not separate out and make known what these influences are.

Both the need for a TDM case study database and unanswered questions about what other circumstances besides commuter choice program elements explain program effectiveness provided reasons to use a more rigorous case study method in two research studies, both funded by the National Center for Transit Research with sponsorship from the Florida Department of Transportation. Some large datasets containing multiyear performance data for work-site commuter choice programs also became available. The Washington State Department of Transpor- 
tation Commute Trip Reduction Program offered the use of its data for more than 1,300 work sites, starting with baseline data as early as 1993 and performance data as late as 2003. Both research studies discussed in this article used the Washington State dataset.

\section{The Case Study Method}

There are at least two meanings to the term "case study" as well as two very different outcome expectations. In the first meaning, as is commonly used in the TDM field, case studies are brief anecdotes of usually successful programs. TDM practitioners want to use case studies to be able to say that if organization A takes a particular action that yields a certain effect, then organization $B$ can take the same action and expect the same effect. Typically what happens is that organization B will (rightly) claim that the experience of organization $A$ does not apply because of various differences between organizations $A$ and $B$. The utility of case studies is limited by this, with ever-growing requests for more case studies that better mirror the conditions of organization $\mathrm{B}$. The mirrored conditions are never close enough in similarity to create confidence that some action will yield the intended result.

The second meaning of case study is adapted from the social sciences. The foundation for a sound case study approach was articulated by Robert K. Yin of COSMOS Corporation in the early 1980s. This approach was adopted by the United States General Accounting Office (GAO) (United States General Accounting Office 1990), Program Evaluation and Methodology Division. ${ }^{1}$ Properly conceived case studies are a research method for attempting valid inferences from events outside the laboratory. In a lab, researchers can control for other variables to pinpoint the effect of a particular condition on the outcome. However, many study topics cannot be duplicated in a lab. These include complex human situations like work-site trip-reduction programs. In response, the case study method is applied for the purpose of examining the relationship between circumstances and outcome.

The case study method is one of several forms of inquiry used to collect and analyze empirical evidence (accumulated through observation). These also include surveys, experiments, archival analyses, and histories. All these methods can be used for exploratory, descriptive, and explanatory purposes. As outlined by Yin, case studies are used, as opposed to other research methods, when three general conditions are met: we want to learn how or why something is happening, the 
investigator has little control over events, and the focus is on contemporary events within circumstances that affect the outcome of those events (context). These conditions generally describe the circumstances under which researchers attempt to study work-site trip reduction programs.

Yin offers a definition of a case study as a research strategy. "A case study is an empirical inquiry that investigates a contemporary phenomenon within its real life context; when the boundaries between phenomenon and context are not clearly evident; and in which multiple sources of evidence are used" (Yin 1981). The GAO uses a close variation of this definition. The purpose behind multiple sources of evidence is that a hypothesis supported by one source of evidence is consistently reinforced (or disputed) by other independent information sources.

This second, more rigorous meaning of case study also has its own separate expectation as to outcome. Yin points out that one cannot use even the best executed case study to generalize to another population, such as organizations $A$ and $B$ (we also cannot generalize to another population based on one scientific experiment). However, we can generalize to a theoretical proposition or "rule of thumb." This is useful because attempting to apply the proposition will require one to acknowledge the influence of a unique context on the particular outcome.

There are several types of case studies, two of which are of interest to the topic of this article. An explanatory case study approach demonstrates a causal relationship between some variable and an outcome. An exploratory case study approach is more commonly used in the early stages of a subject under study. Often there are multiple variables of likely influence and not enough is known to define a more specific hypothesis confidently. Important to the case study process is the identification of explanations that rival a specified hypothesis. Thus, it is important to acknowledge and consider any other possible causes of the outcome under study, regardless of whether it supports the hypothesis. Efforts are made to search for evidence that supports the rival explanations as well as evidence that eliminates them from consideration.

In the development of a case study, there are clearly defined steps including the development of a research question, the articulation of a hypothesis, the selection of the type of case study best suited to the purpose of the researcher, development of the research design, data collection planning and implementation, analysis, and the reporting of findings. These steps were used in the two studies examining commuter choice programs in anticipation that in the long term the findings will be more robust, reliable, and useful in application. 


\section{The Relative Importance of Work-Site Culture}

The first of the two research studies using the case study method, "Commuter Choice Program Case Study Development and Analysis" (Hendricks and Joshi 2004), looked at work-site "organizational culture" as characterized by theorist Joanne Martin (Martin 2002) to determine if internal culture has some impact on trip reduction program success. Internal culture is an expansive topic and the research needed a more manageable focus within the practical constraints of the study. In response, researchers chose to study the impact of the designated "internal champion" or ETC as the assumed key representative of internal work-site culture within the context of the trip reduction program. A literature review had found that little research had been done on the topic of internal culture and ETCs in the past 10 years since Chen et al. (1995), Lopez-Aqueres (1993), and Wachs and Giuliano (1992).

Because little is known about the effect of organizational culture on travel behavior, investigators started with an exploratory case study approach rather than an explanatory case study approach. They began with the general hunch that the effectiveness of a work-site trip reduction program does depend on organizational culture. For efficacy, the investigators attempted to "disprove the null hypothesis"; that is, to find at least one work site that has demonstrated that the success of its trip reduction program did indeed depend on the work-site's organizational culture. The research design was based on an attempt to control for both internal and external factors to isolate the effects of management culture. This was done by selecting the individual work site as the unit of study and selecting a group of work sites located where there was comparability of external factors, including population and employment densities, alternative transportation services and amenities, parking availability, and local regulatory environment. The work sites were also selected based on likeness of internal factors, including similarity of North American Industry Classification System code and number of employees. The goal was to select a group of very similar work sites, half of which were having the most successful trip reduction performance compared against the other half having the least successful trip reduction performance. Among work sites that are similar in every respect except trip reduction performance, can we see a relationship between organizational culture and trip reduction program effectiveness? The research design also incorporated anonymity of the participants and the identities of the organizations that agreed to participate to enable all participants to talk with candor about the sensitive subject of organizational culture. 
A data collection plan was developed to incorporate the use of multiple independent sources of evidence. This creates opportunities to detect both consistencies and inconsistencies among the information explaining the effects of the trip reduction program. Sources included the extensive comparable descriptive data and trip reduction program and performance data for the work sites as collected by WSDOT, written policies and marketing materials used by the work sites, information from in-depth interviews with both ETCs and their direct supervisors, and a survey of demographic information. Additionally, a battery of feedback instruments was administered to ETCs and their supervisors by consultants with expertise in organizational effectiveness. The case study analysis of the information, including an effort to identify rival explanations (e.g., trip reduction effectiveness was explained by factors other than organizational culture), found evidence that the null hypothesis is true only sometimes. A hierarchy emerged about the level of importance of some external and internal factors. The analysis provided evidence to suggest that the organizational culture in some work sites did influence the outcome of their trip reduction programs but such influence may be overcome by other factors. For example, the organizational culture of a work site to influence trip reduction effectiveness is generally less powerful than the influence of the income level of work-site employees. Also, organizational culture and employee income level are both generally less powerful than the effect of access to high quality public transportation alternatives. Additionally, case study analysis found that the influence of the ETC is less powerful than and contingent on top and middle management support. Management support and an effective ETC are less important for a successful commuter choice program if the work site is located in an area with access to high quality public transportation alternatives and the work site employs lower income staff who must choose transportation cost savings over time savings and convenience. However, management support and an effective ETC are necessary for a successful work-site trip reduction program if the work site is not located in an area with access to high quality transportation alternatives.

With regard to the characteristics of the ETC, research results based on both the interviews and the results of the feedback instruments suggested that the ideal skill sets and personality qualities of the ETC depend on the level of maturity of the commuter choice program. For example, a new commuter choice program sponsored by a supportive yet laissez-faire top management may require a decisive ETC with leadership and problem-solving skills. An organization with a more mature commuter choice program, in which the right combination of programs, services, and incentives are already in place, may benefit most from an ETC with 
high organizational and administrative skills. Charismatic ETCs with strong interpersonal skills may be most needed and successful in commuter choice programs in which the services require outreach and "selling." A more detailed discussion of the role of the ETC is summarized in Hendricks (2005).

To review, the common anecdotes about trip reduction programs have limited use because they often lack context as well as reliable information about baseline conditions and program results. If results are reported, anecdotes may fall short of attempting to explore the possible reasons for program results.

\section{How Can This Case Study be Made Stronger? SunBank's Parking Program}

SunBank and the Downtown Orlando Transportation Management Association (DOTMA) work together to decrease the parking demand for SunBank's employees. Because only half of the roughly 1,000 employees are able to find parking in the SunBank Center garage, the DOTMA offers several TDM incentives. One program allows certain employees, including carpoolers and persons with disabilities to be placed on a waiting list for a reserved parking space in the SunBank Center garage. Once the space becomes available, SunBank pays nearly 40 percent of the employee's parking fee, including tax. Another program, the Centroplex Park ' $n$ Ride, encourages employees to park in a nearby garage that is connected to the SunBank Center via a free shuttle bus. As an added incentive to rideshare and conserve energy, SunBank offers to pay the parking fees for those employees who carpool to the Centroplex garage, but only pays 50 percent of the fees for those employees who drive alone. Source: Angela Gallogly, SunBank, Phone interview.

Reprinted from the "Commute Alternatives Systems Handbook," Center for Urban Transportation Research, University of South Florida, 1996.

The case study method described in this article differs from anecdotes in that researchers were able to reliably identify work sites with varying levels of trip reduction program performance to examine not only by comparing existing "before" (baseline performance) and "after" (program results) data, but also by identifying those work sites with programs that had a clear trend in program performance over time that were not likely due to chance or some temporary unusual 
circumstance. Unlike anecdotes, this case study method started with a research question and the formulation of a particular hypothesis, or hunch, describing an expected relationship between trip reduction program success and an influential factor. Researchers collected information from as many sources as possible and looked for relationships in the data as well as inconsistencies that may support or refute the hypothesis. Use of the case study method yielded evidence about the relationship among internal and external factors of a work site that would not have been apparent from the less complete information of an anecdote. Finally, unlike anecdotal information that is commonly used to try to persuade organization $B$ to adopt a trip reduction program similar to that of organization $A$, the expectation for use of the case study results is to discern the evidence for an apparent rule of thumb, then determine whether to apply the rule with caution to organization $B$, recognizing both the present constraints and potential opportunities afforded by organization B's unique internal and external context.

The Commuter Choice study used a more rigorous case study method for the purpose of sorting out the influence of organizational culture relative to its context. The second study, "National Smart Transportation Archive Researcher (NSTAR)," by Georggi et al. (2006), also applied the case study method but with two other purposes. The first purpose was to create an online updatable, easily searchable database of case studies documenting the impacts of TDM strategies and to begin to populate the database with case studies that supply information to enable users to make inferences with better confidence. These case studies would be for use by transportation professionals as well as those charged with developing and implementing TDM programs for work sites or other applications. Commuter choice program information and trip reduction data from more than 100 carefully selected work sites were compiled by researchers, now located on the Help Desk of the National TDM and Telework Clearinghouse, found at http://www.nctr.usf. edu/clearinghouse. These case studies are not anonymous, but include the identities of the organizations and their contact information so that TDM professionals can pursue further information. The second purpose of the NSTAR study was to provide an in-depth examination of 12 carefully selected work sites from the Help Desk, also using an exploratory case study approach. In the Commuter Choice study, we found evidence to suggest that the external condition of access to public transportation alternatives has more sway in the outcome of a trip reduction program than internal conditions of the work site. In the NSTAR study, we ask if this is always the case. Our research question is: "How important are internal work-site conditions relative to external conditions?" The hypothesis researchers 
wanted to test was "Internal work-site conditions can overcome adverse or unsupportive external conditions if the trip reduction program is explicitly supported by work-site management and the nature of the business also supports program success." The goal was to disprove the null hypothesis by finding at least one trip reduction program that demonstrates that internal conditions can overcome adverse external conditions. Disproving the null hypothesis would lend support to the proposition that work-site trip reduction programs can be successful in reducing SOV mode share, vehicle trips, and reducing VMT under the typically adverse conditions found in many urban areas of the United States.

Adverse external conditions include underdeveloped public alternative transportation options that compete poorly with SOV travel, sprawling land development patterns, abundant public parking, the lack of severe traffic congestion, and (relatively) low fuel prices. Supportive internal work-site conditions could be active in nature, such as management that demonstrably encourages trip reduction activities. Supportive internal conditions could also be passive in nature, meaning that the work site may not be consciously conducting trip reduction programs but its business activities have no intrinsic operational conflict with trip reduction activities. An example of this might be a work site that uses telework for business purposes. An operational conflict might be a business that relies on staff to travel to the offices of clients on less than one day's notice.

The research design for the NSTAR study was simplified so that other transportation professionals working on time constraints could borrow elements from this process to strengthen their case study information. The ultimate goal is to improve case study information available to the profession and encourage transportation professionals to share their information with others through submittal of data to help build case studies on the Help Desk.

The first main question that the NSTAR study addressed was to identify which work-site trip reduction programs that researchers can confidently agree demonstrate effective program results. The Help Desk archive includes 56 work sites from Washington State. The data that document their programs were selected from 1,300 work sites that participate in the Washington State Commute Trip Reduction Program. Selection of these work sites was based on a series of progressively applied criteria, including availability of data for the most recent years, availability of data spanning at least five survey periods, having a negative slope for the trend line of vehicle miles traveled (VMT), with R square greater than 0.5 , and having a negative slope for the trend line of SOV mode share, with R square greater than 0.5 . 
Having an R square greater than 0.5 means a greater level of confidence that the decrease in SOV mode share and VMT over time was not due to chance.

In addition to the development of the Help Desk case study database and the collection of case studies that confidently demonstrate effectiveness, the research design also included a more in-depth examination of 12 of the 56 outstanding work-site trip reduction programs. The 12 programs were self-selected based on ETCs willing to participate in the study. With each of the 12 work sites, researchers gathered multiple sources of evidence by conducting a brief survey, an extensive telephone interview with the ETC, and a request for any office policies, internal organization website information, brochures, and other information provided to employees about trip reduction activities, and any data that the work site collects and reports to its host municipality or other regulatory authority. Unlike the Commuter Choice study, where the aim was to compare differences in organizational culture of work sites with successful trip reduction programs to work sites with less successful trip reduction programs, the aim of the NSTAR study was to solicit the participation of work sites with a success story to tell and summarize the main internal and external factors that appeared responsible for that success. In the NSTAR study, work sites were not selected based on similar external factors but rather simply finding work sites with the best performance. As a result, examples of commute choice programs were identified that thrive in varied settings and land development patterns, including rural areas, suburban locations, and central business districts. It was found that while urban settings generally offer more commuter options, no land development pattern was shown to be absolutely necessary.

The detailed 12 case study write-ups can be found in the Best Practices Guide, located at $h t t p: / / w w w . n c t r . u s f . e d u / p d f / 77604 . p d f$. The narratives include an interpretation of the information and point out characteristics of the following.

- land use configuration of surrounding area

- public parking availability

- traffic conditions

- availability of outside support

- commuter assistance program characteristics

- conditions internal to the work site

- work site accessibility to public transit/regional accessibility 
- physical facilities

- employee characteristics

- nature of business

- organizational culture

- ETC

- graphs of change in average VMT per one-way commute

- graphs of change in percentage of employees traveling by SOVs

For example, Figures 1 and 2 illustrate the performance trends for one work site, Acordia Northwest, Inc. Figure 1 shows that the drive-alone mode share of employees decreased from 43 percent in 1993 to just 9 percent in 2003. Figure 2 indicates that AVMs traveled per employee for a one-way commute trip decreased from 7.6 miles in 1993 to 2.8 miles in 2003.

The NSTAR study sought to disprove the null hypothesis by finding at least one trip reduction program that demonstrates that internal conditions can overcome adverse external conditions, as typically found in urban areas in the United States. It is important to note that the 12 work sites were all located in an area under mandatory trip reduction requirements, which one could argue is the most supportive rather than adverse external condition for trip reduction program success. However, making trip reduction mandatory implies an environment in which some degree of difficulty and effort is required to reduce trips, otherwise a sufficient number of work sites would be reducing trips voluntarily. There is also a difference between demonstrating good faith compliance with the law and implementing a trip reduction program that achieves sustained successful results. More work sites achieve compliance but less work sites achieve program effectiveness. Case study analysis provided insight into how businesses approach the mandate. Instead of business benefits or the desire to abide by "green" business practices, the regulatory requirements did provide the primary motivation for most organizations to take action to ensure legal compliance. However, characteristics of organizational culture further determined if management believes, "If we have to do a trip reduction program, we are going to do it right and make a best effort." 


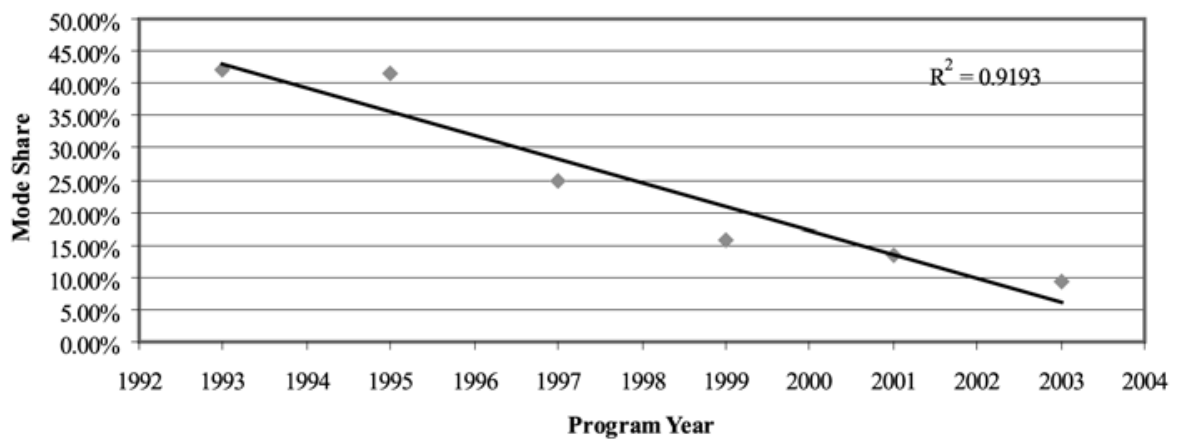

Figure 1. Percentage of Driving Alone Commuting Trip

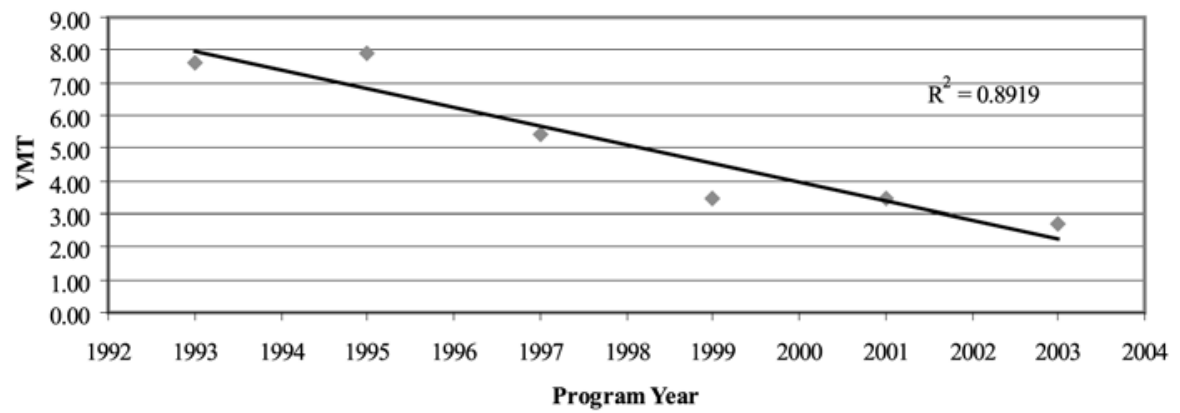

Figure 2. Vehicle Miles Traveled

\section{Presence of Supportive Management}

An analysis of the collected data and information suggested several relationships. In a mandatory regulatory environment, alignment of the nature of the business with the commute trip reduction program is not always necessary but always helpful. Where the intrinsic nature of the business might not support program success, such as a business requiring a location where public transit is not available, the presence of supportive management can still overcome external adversity to result in a successful trip reduction program. Results also found no relationship between the department in which the commuter choice program was implemented and program success. Programs can be run successfully from a number of departments, such as human resources, parking and security, payroll and benefits, 
or the office of the executive assistant, and the greater decider of success is that the staff tasked with implementing the program is sincerely interested in the program and is confident in the benefits of commuter choices. Results pointed to no specific type of administrative program oversight that is better as long as it is supportive. For example, some work sites with successful commuter choice programs are centrally managed by a remote headquarters office, while others are managed at the individual work site.

While limiting parking and leveling the playing field for parking perqs across all tiers in a work-site hierarchy sends powerful signals to employees to use transportation alternatives, study results found that some successful commuter choice programs can also tolerate some free parking. It is recognized that even superior transit service does not match the time savings and door-to-door service of driving one's own vehicle. For those organizations in which it is a business imperative to recruit the highest skilled employees, free parking is sometimes a necessary perq, and will not undermine a strong commuter choice program if the perq is applied with care. For example, one hospital that provides comprehensive commuter choice services to its employees also offers free and convenient parking to its doctors.

\section{The Intrinsic Nature of the Business}

Alternatively, in the absence of supportive management, work-site trip reduction program success might simply be due only to the intrinsic nature of the business rather than any conscious effort on the part of management and staff. Examples of this might include a lower- or moderate-income workforce that is more price sensitive to travel alternatives, or an organization that achieves business efficiencies through telework strategies.

Looking closer for other indicators that represent the intrinsic nature of businesses, no results were found to indicate that work-site commuter choice program performance was linked to work-site industry type or size. In addition, no results were found to indicate that any employee type is necessary to commuter choice program success. The case studies demonstrated that successful commute trip reduction programs serve diverse workforces, such as blue-collar unionized employees and white-collar professionals. 


\section{Recommendations for Action}

\section{For TDM Marketing Professionals}

The Commuter Choice study provided some insights for TDM professionals who want to focus marketing efforts on more receptive organizations. They should target organizations that have some combination of the following attributes:

- work-site location has access to good quality transit

- large support staff for whom cost of transportation is more important than time savings and convenience

- most of the affected employees remain in an office setting during the workday

- most of the affected employees usually work routine predictable hours

- business motivations of work sites to support trip reduction activities beyond regulatory compliance, including organizations that:

- generate environmental hazards, and also may search for ways to demonstrate to the public that they are good stewards of the environment

- want an image that they are "green," progressive, or that they are motivated by "doing what is right"

- have short-term transportation benefits that would enhance employee recruitment and retention

- feel a responsibility to take a leadership role and set the standard for positive action (primarily government)

- are exploring long-term profitability within the context of environmental, social, and financial sustainability practices

TDM marketing professionals may also want to evaluate the usefulness of case study information for demonstrating the causes of trip reduction program outcomes. Based on the NSTAR study, the checklist given in Figure 3 provides an outline for evaluation. Few case studies contain all this information, but the more reliable information, the better. 
Identification of information source

Credible source

Multiple independent sources of information that show consistency

Contact information for the source

Recently updated

Measurements of travel behavior prior to TDM strategy implementation (baseline)

Measurements of travel behavior after TDM strategy implementation

Continued periodic measurements of travel behavior over time (performance trend)

Monitoring of baseline and travel behavior change of same individuals

Detailed information about work-site characteristics

TDM program characteristics

Changes

Employee characteristics

Changes

External environment

Changes

__ Regulatory

Changes

Physical

Changes

Services

Changes

Economic

Changes

Other

Changes

Selection of performance indicators that adequately reflect goals and purposes of stakeholders

Performance indicators that are properly measured

Interpretation of the data

Addresses relationship between TDM strategy and any resulting change in travel behavior Describes other possible causes of changes in travel behavior (rival explanations)

Provides a balanced presentation (what works, what has not worked)

\section{Figure 3. Checklist of TDM Case Study Quality}

\section{For Work Sites}

Several actions for improving work-site commuter choice programs were identified from the results of both case study research projects, as summarized below.

1. Locate the work site with high quality transportation alternatives. Locate near other important offices, institutions, and retail that are complementary 
to the business instead of acres of parking lots and garages that isolate your business from customers.

2. Provide political support to the local transit agency by telling local elected officials that businesses want public transit service for their employees.

3. Offer a transit subsidy and other incentives to employees.

4. Select an ETC that is managerial level with direct communications access to top management decision-makers and has influence on decisions relating to the trip reduction program budget.

5. Incorporate activities of the trip reduction program into the job description of the selected ETC and allocate a realistic amount of time to their execution.

6. Make explicit in the guiding principles the role that the trip reduction program plays in the organization, so that trip reduction and promoting commute alternatives become part of the organizational culture.

7. Consider removing any parking subsidies or related perks to those higher in the organization or at least offer the same parking subsidy to everyone regardless of position in the organization.

\section{For TDM Researchers}

The case studies for both research projects described above used employee data aggregated to the employer level. As a result, reductions in SOV mode share or reductions in VMT are net reductions across all employees of a work site. An advantage of the aggregated data is that it protects the privacy of individual employees. A disadvantage of the aggregated data is that researchers are unable to track the change in travel behavior of individuals over time. In the future, with the informed consent of employees who agree to participate in travel behavior research, combined with emerging technologies for collecting detailed travel behavior data of individuals, we can gain better insight into the reasons why people travel as they do as well as stronger evidence of the impact of trip reduction programs relative to other contextual factors that influence travel behavior.

The NSTAR study found that in a mandatory regulatory environment, alignment of the intrinsic nature of the business with the commute trip reduction program is not necessary but helpful. For future research, a hypothesis could be that in a voluntary environment, the converse is true: An alignment of the intrinsic nature of the business is necessary for the business to involve itself with commute trip reduction program activities. The evolution of business practices to incorporate 
environmental, financial, and social sustainability objectives for long-term profitability may further recognize employee travel as part of these considerations.

\section{Conclusions}

The NSTAR study provided evidence to disprove the null hypothesis by evaluating 56 case studies in which VMT and SOV decreased over time and for which the R square value indicated a high level of confidence that these decreases were not random. These work sites were subject to varying degrees of adverse external conditions associated with underdeveloped transit systems, sprawling land development, abundant parking, the lack of severe traffic congestion, and (relatively) low fuel prices. However, the hypothesis that "Internal work site conditions can overcome adverse or unsupportive external conditions if the trip reduction program is explicitly supported by work site management and the nature of the business also supports program success" is likely overspecified. Examples were found in which trip reduction program effectiveness can be achieved with either management support or a naturally aligned business. Furthermore, no factors were found to be always absolutely necessary, unless in the absence of others.

Each work site is a case study in shades of gray, in which the importance of a factor depends not only on its magnitude or intensity but also its presence in combination with other factors. With regard to management support of trip reduction programs, the results demonstrate the adage, "Where there's a will, there's a way" but also that there is great leeway in how a work site can assemble a program to achieve effectiveness. TDM professionals can stimulate creativity and encourage effective results by describing the variety of strategies for achieving performance, then giving the work site the latitude to craft its unique approach to achieve a performance target.

\section{Endnote}

${ }^{1}$ After 2002, the name for the U.S. General Accounting Office was changed to the U.S. Government Accountability Office. 


\section{References}

Chen, Qiuzi, W. Patrick Beaton, and H. Meghdir. 1995. Profile of employee transportation coordinators. Transportation Research Record 1496. Washington, DC: Transportation Research Board, National Research Council, National Academy Press, 123-130.

Georggi, Nevine L., Sara J. Hendricks, Liren Zhou, and Christopher Hagelin. 2006. National smart transportation archive researcher. Funded by the Florida Department of Transportation and the Federal Transit Administration through the National Center for Transit Research. Prepared by the Center for Urban Transportation Research, University of South Florida, Tampa, FL.

Hendricks, Sara J. 2005. Effectiveness of programs for work site trip reduction: The influence of organizational culture. Transportation Research Record 1924. Washington, DC: Transportation Research Board of the National Academies, pp. 207-214.

Hendricks, Sara J., and Ajay Joshi. 2004. Commuter choice program case study development and analysis. Funded by the Florida Department of Transportation and the Federal Transit Administration through the National Center for Transit Research. Prepared by the Center for Urban Transportation Research, University of South Florida, Tampa, FL.

Lopez-Aqueres, Waldo. 1993. Conceptual framework to study the effectiveness of employer trip-reduction programs. Transportation Research Record 1404. Washington, DC: Transportation Research Board, National Research Council, National Academy Press, pp. 55-63.

Martin, Joanne. 2002. Organizational culture: Mapping the terrain. Thousand Oaks, CA: Sage Publications.

United States General Accounting Office. 1990. Case study evaluations. GAO Program Evaluation and Methodology Division, GAO/PEMD-91-10.1.9. November.

Wachs, Martin, and Genevieve Giuliano. 1992. Employee transportation coordinators: A new profession in Southern California. Transportation Quarterly (July): 411-428.

Winters, Philip L., and Rafael A. Perez. 2004. Worksite trip reduction model and manual. Funded by the Florida Department of Transportation and the Fed- 
eral Transit Administration through the National Center for Transit Research. Prepared by the Center for Urban Transportation Research and the Computer Science and Engineering Department, University of South Florida, Tampa, FL. Yin, Robert K. 1981. The case study crisis: Some answers. Administrative Science Quarterly 26 (March): 58-65.

\section{About the Authors}

SARA J. Hendricks (hendricks@cutr.usf.edu) is a senior research associate at the Center for Urban Transportation Research, University of South Florida. She graduated with a Master of Regional Planning degree from the University of North Carolina at Chapel Hill. She formerly worked as a planner for Orth-Rodgers \& Associates in Philadelphia and Howard Needles Tammen Bergendoff in Raleigh, North Carolina.

NeVine LABIB GeORGG (georggi@cutr.usf.edu) is a senior research associate at the Center for Urban Transportation Research, University of South Florida. She graduated with a Master of Science in Civil Engineering degree from the University of South Florida. She formerly held positions as a transportation planner with DSA Group, Inc. in Tampa and as a transportation research engineer at the Energy Research Center at Cairo University, Egypt. 


\title{
User Perceptions of Private Paratransit Operation in Indonesia
}

\author{
Tri Basuki Joewono, Saitama University, Japan, \\ and Parahyangan Catholic University, Bandung, Indonesia \\ Hisashi Kubota, Saitama University
}

\begin{abstract}
In this article, public perception is expressed by user participation in rating the mode's condition and loyalty to it. The aim of this research is to explore user perceptions of paratransit (i.e., jitney) operation, a privately owned and operated mode of transport, regarding quality of service, frequency of negative experience, and loyalty. This article examines the condition of paratransit from the user's point of view to balance the judgment from other stakeholders. The findings from path analysis reveal the important determinants that influence overall satisfaction. Moreover, path analysis supports the hypothesis that this mode will still be relevant in the future, as there is a community base that uses this mode faithfully. Binomial regression analysis explores the characteristics of this loyal group of users. It can be concluded that the existence of paratransit in the future is still acceptable in developing countries such as Indonesia.
\end{abstract}

\section{Introduction}

In cities and megacities of developing countries, the need for mobility is increasing in sync with the growth of the cities themselves (Booth et al. 2000; Kaltheier 2002). On the other hand, mobility and accessibility are declining rapidly in most of the developing world, and even more so for public transport users (Gakenheimer 1999). Currently in developing countries, the real problem is not the high use of 
automobiles, but the poor service quality of public transit (Senbil et al. 2005). The Transport Research Laboratory has shown that public transport vehicles in African and Asian countries are frequently poorly maintained and often overloaded (Jacobs and Aeron-Thomas 2000). In the case of developing countries, the requirement first to fulfill the need for mobility with sufficient capacity and quality is constrained by the government's limitation to meet it. Then the real contribution of paratransit becomes significant. Paratransit is used extensively in almost all cities in Indonesia. The authors use the term paratransit in this article to refer to transport service that is owned and operated by private companies and individuals. In many Indonesian cities, paratransit uses its local name and employ various types of cars, vans, and minibuses. Cervero (1998) calls this mode jitney. Jitney service is available to everyone, which is different from the U.S. context that associates it with government subsidized elderly or handicapped transport.

Studies regarding paratransit in developing countries are mainly concerned with topics such as management of the mode; benefit of minibuses (e.g., Walters 1979); position of paratransit in the transport hierarchy (Cervero 1998); relationship with poverty in terms of supply, demand, cost, and consequences (e.g. Kaltheier 2002); relation with informality (World Bank 2002); and unregulated transit services (Vuchic 2005). To our knowledge, this study is the first attempt to use public perception to evaluate and explore paratransit operation. The authors' motive is to empower the citizen more, reveal their true expectations, and update the mode's suitability with the market, which used to be uncommon practice in developing countries. This motive bears similarity to the concept of mobility management (see e.g., Litman 2003), which emphasized a constant exchange between stakeholders (Desmedt 2000).

Moreover, traditionally, the exploration of transit is viewed from the perspective of technical performance (e.g., World Bank 1987, among others). The examination should also measure the dimensions of service quality perceived by passengers, current and potential, as stated by Hensher et al. (2003) to consider the heterogeneity of the users. Unfortunately, most studies about transit's performance measurement were conducted using data from developed countries (see, as an example, Transportation Research Board 1999, 2003; Friman and Gärling 2001; Winder 2005, among others). The literature traced in researching the service quality of public transit using public perceptions in developing cities is very limited (e.g., Jen and Hu 2003; Koushki et al. 2003; Kim et al. 2005; Zhang et al. 2005; Mori- 
yama 2005). The authors are not aware of any research studying the service quality of paratransit in developing cities.

This research explores user perceptions of paratransit operation, regarding quality of service, frequency of negative experience, and loyalty to balance the judgment from other stakeholders. The article corroborates the authors' hypothesis regarding the existence of user loyalty to paratransit as a mode of transport in the cities of developing countries, such as Indonesia.

This article begins by providing some brief information about private paratransit in Indonesia, followed by a concise explanation of the data collection and data description. Estimation results of the models, accompanied by the significance tests, are also presented. The article concludes with a discussion and findings of the study.

\section{Paratransit in Indonesia}

Paratransit represents the spectrum of vans, jitneys, shuttles, microbuses, and minibuses (Cervero 1998). Jitneys, privately operated minibuses under various degrees of coordination by a dispatcher, are used extensively in developing countries where labor costs are low and transit services do not offer adequate service (Vuchic 1999). Paratransit has become a vital mobility option in many developing countries, filling in gaps left unserved by public transit systems and providing efficient feeder connections (Cervero 1998). Paratransit in Indonesia is known as "Angkutan Kota," "jeepney" in the Philippines, "tuk-tuk" and "songtaew" in Thailand, and "mammy wagons" (converted trucks) and "matatu" (converted vans) in African cities.

Paratransit offers several advantages compared to other public transport modes, such as high accessibility and mobility, an operating cost that is more beneficial for short trips, easy and unimpeded lane movement, and relatively low maintenance costs (DLLAJ 2001). Paratransit supply is best in meeting the transport requirements of the poor in terms of fares and flexibility, and in some cases, a symbiosis of paratransit and the poor is assumed (Kaltheier 2002). This mode is an efficient road user, contributing only 18 percent of traffic flow while being able to transport more than 50 percent of passenger trips (DepKimPrasWil 2002). Beside its benefits, the price to be paid for the dominance of paratransit is obvious; there are high emission levels of pollutants, overcrowded innercity roads, revenue shortfalls, inhumane working conditions, and criminal-style structures (Kaltheier 2002). 
Paratransit is a public mode for passengers with a fixed route, but without a fixed schedule, and follows one route within the city's network. The paratransit crew (sometimes consisting of only the driver, but at other times the driver accompanied by a conductor) generally does not have a high level of education or even related training. Since there is no minimum requirement to enter this service, the driver and crew usually come from families with low economic ability. Although a license is required to drive, in practice, some of the drivers have no driving license or an unsuitable one. As for conductors, almost any person can get this job.

There are two types of crew, formal and informal. In the case of the former, the driver and/or conductor draws up an informal agreement with the car owner, and is obliged to pay a rental fee to the owner. The driver and conductor earn a salary as the surplus from the rental fee. Usually, the driver receives a larger share than the conductor. In the latter case, the informal crew takes the job as a substitute for the formal crew, which means the informal crew operates during the off-hours of the formal crew. The informal crew also pays a rental fee to the formal crew, where the salary comprises the surplus from the rental fee. In general, the driver pays the fuel cost, but the maintenance cost is borne by the car owner. Thus, the crew's only focus is to compete for collecting money, which makes them ignore both the traffic rules and other road users.

In paratransit operation, the role of government (performed by the related bureau at the city or municipal level with some coordination with the city or municipal authorities in charge) is to issue permission to operate on the selected designated route, and to decide the number of cars on each designated route. Although the related bureau issues the permission, in practice the owner should be a member of one of several available cooperations in the city/municipality to be appointed to a designated route. Each cooperation maintains an effective monopoly for its designated routes (DepKimPrasWil 2002).

Paratransit operates in mixed traffic without a fixed schedule (no particular time frame). Moreover, the infrastructure is insufficient to support paratransit operation. The impact of this includes waiting for passengers anywhere on the road, passengers having to wait for service in inconvenient places, or passengers getting on and off the vehicle in the middle of an intersection. The lack of widely available and accurate information regarding the paratransit service results in difficulties for new users to reach and use the service.

Paratransit uses various types of cars and vans with a capacity of 12-16 seats, but in fact, during rush hour, many passengers are crammed into the vehicle, even when 
seats are not available. Riders are forced to use vehicles that are in bad condition because of the operators' limited capability to maintain them. The operators' poor financial status results in reducing the priority of car maintenance, engine performance, and emissions. Although, there is a regulation calling for periodical checks of the vehicles' conditions, the law is not strictly enforced. Recently, many cities seem frustrated with the negative consequences of the paratransit sector. Thus, they are replacing this mode with bigger capacity, and more advanced technology, expressed as a symbol of modernization.

\section{Data Collection}

In this research, the sample size calculation was referred to the formula suggested by Israel (1992) and previous research by Joewono and Kubota (2005). With the population of passengers per day amounting to 174,907 , the sample size is 400 . Since this sample size reflects obtained responses, this number was increased to 1000 to compensate for nonresponses (Israel 1992).

\section{Questionnaire}

An 11-page questionnaire, divided into 4 main parts, was designed for this study. The first page of the questionnaire is an introduction that explains the purpose, the person in charge, and the contact address. The first part consists of 15 general questions. The second part addresses questions about service quality. Based on a long literature review regarding measurement in public transportation, the authors collected and selected attributes most applicable and useful in measuring and exploring the paratransit service. These selected attributes can be grouped into 9 important determinants with 54 attributes, in which each determinant factor has multiattributes in a range from 3-9. In all questions, respondents are asked to rate the aspects on a 5-point scale of satisfaction, ranging from very dissatisfied to very satisfied. Research indicates that a 5-point scale is just as good as any (Elmore and Beggs 1975; Sekaran 1992) and sufficient to stimulate a reasonably reliable indication of response direction (Frary 1996). The third part is a set of questions that asks the respondent to rate the frequency of negative experience while making use of paratransit. The rating is on a 5-point scale, ranging from very often to never. There are seven aspects: accessibility, reliability, crew treatment, information, design, customer service, and safety and security. Each aspect consists of one to two questions. The last part is a question regarding the respondent's 
loyalty. The respondent was asked whether he or she will make use of paratransit in the future and whether the respondent will recommend paratransit to others. For each question, the respondent was shown several conditions, such as when business is running as usual, when there is an improvement, and when a new kind of transportation mode will be operated with a higher standard of service quality and higher fares. The three conditions aim to capture requirements asked by the users when they become loyal.

\section{Method of Survey}

Data collection was conducted from December 15-22, 2005. Ten surveyors distributed the questionnaire on-board. Surveyors approached passengers personally to ask them to fill in the questionnaire. In most cases, surveys that were personally and courteously handed to customers during the service-delivery process yield higher response rates (Zimmerman et al. 1996). The personal approaches in the survey process could be shown by the willingness of surveyors to guide respondents when completing the questionnaires, reading questions to them in cases where respondents could not read, up to translating the questionnaire into a local language if respondents did not speak or read the national language (Bahasa Indonesia), since the questionnaire was written in Indonesian. After completing the questionnaire, respondents were rewarded with "thank you money." Some passengers were most willing to fill out the questionnaire, but others required more detailed explanation. Not all respondents accepted the "thank you money" for various reasons, including those who just wanted to help. Since it took approximately 20 minutes to fill out the form, this survey did not collect perceptions from short-trip users. In fact, users who spent more than 15 minutes in the car were supposed to have gained more experience and to have more reliable perceptions concerning all aspects of paratransit. On average, the success rate of gathering respondents willing to complete the questionnaire was 71.7 percent. This percentage was based on the number of efforts that surveyors made to ask passengers and the number of passengers who filled in the questionnaire. The percentage of success was quite high, and is evidenced by the large number of respondents who asked the surveyors about the follow-up to this questionnaire. They made a statement about their hope for better service in public transportation. 


\section{Descriptive Statistics}

Of the 1000 questionnaires returned, only 980 questionnaires could be used for further analysis. The descriptive statistics of the respondents are provided in Table 1. Note the high percentage of students as users of paratransit. Students and young users (younger than 20 years old) seem to dominate the users of paratransit, which is in line with previous and current research by the authors. The possible impact of this high percentage of the subsample is that the perception of young users and students possibly dominates the perception of the users as a whole. The authors believe that the possibility of bias is not the case, although further exploration for each subsample will be beneficial. The covariance, variance, and the mean of the significance aspects or determinants in the model are provided in Table 2.

\section{Table 1. General Characteristics of Respondents $(\mathbf{n}=980)$}

\section{Characteristics}

1. Sex

2. Marital status

3. Age

4. Place of living

5. Family members

6. Education

7. Job

8. Travel cost per trip (Indonesian Rupiah, IDR)

9. Income (IDR)

10. Car ownership

11. Reason for making use of paratransit

12. Trip purpose

13. Number of trips using

14. The way to reach stop

15. Overall satisfaction
Statistics

Male (58.3\%), Female (41.7\%)

Married (29.3), Single (70.7\%)

$<=20$-year-olds (44.8\%), 21-30-year-olds (32.4\%), 31-40-year-olds $(15.2 \%)$

City area (80\%), municipality area (20\%)

1 (9.8\%), 2 (11.9\%), 3 or more members (78.3\%)

Junior high school or less (19.9\%), senior high school (52.3\%), and diploma or higher (27.8\%)

Student (53.3\%), civil servant (2.7\%), entrepreneur (17.7\%), employed in the private sector (9.6\%), labor (6.2\%), housewife (4\%), other $(6.6 \%)$

$<2,500$ (25.3\%), 2,500-5,000 (50.1\%), 7,500-10,000 (18.4\%), > 10,000

(6.2\%)

$<1$ million (39.4\%), 1-2.5 million (36.5\%), $2.5-5$ million (14.7\%), more than 5 million (9.4\%)

Did not own any car (50\%), motorbike (32.9\%), automobile (14.2\%), other (3\%)

Did not own any car in their family (47.8\%), prefer to make use of paratransit (34.7\%), unable to drive (17.6\%)

Study (46.9\%), work (23.7\%), shopping (11.7\%), social activities (7.7\%), and other (10\%)

Once $(34.0 \%)$, twice (43.3\%), and three times or more per day paratransit per day (22.8\%)

Walking (81\%), others (19\%)

Very dissatisfied (7.2\%), dissatisfied (26.6\%), neutral $(50.7 \%)$,

satisfied (13.5\%), very satisfied (1.9\%) 


\section{Table 2. Covariance, Variance, and Means of the Significance Aspects in the Model}

\begin{tabular}{|c|c|c|c|c|c|c|c|}
\hline & Variable Names & 1 & 2 & 3 & 4 & 5 & 6 \\
\hline 1 & Availability & 0.42 & & & & & \\
\hline 2 & Accessibility & 0.16 & 0.62 & & & & \\
\hline 3 & Information & 0.12 & 0.31 & 0.83 & & & \\
\hline 4 & Customer service & 0.11 & 0.28 & 0.48 & 0.66 & & \\
\hline 5 & Fare & 0.13 & 0.10 & 0.23 & 0.28 & 0.57 & \\
\hline 6 & $\begin{array}{l}\text { Negative experience } \\
\text { with crew attitude }\end{array}$ & 0.12 & 0.18 & 0.21 & 0.27 & 0.21 & 0.97 \\
\hline & Mean & 3.07 & 2.70 & 2.42 & 2.46 & 2.68 & 2.68 \\
\hline
\end{tabular}

\section{Analysis}

In this article, path analysis was employed to reveal the relationship among variables, including testing the hypothesis concerning the existence of user loyalty. If the hypothesis was supported, then it is important to maintain this mode of transport in the future. The path analysis also examines the predictive power of several variables on overall satisfaction with paratransit. These statements are in line with Klem's findings (1995) regarding the major kinds of results from path analysis. Path analysis in this article refers to an explanation provided by Klem $(1995,2000)$, Arbuckle and Wothke (1999), Thompson (2000), Raykov and Marcoulides (2000), and Kline (2005). The model concerning the relationship between aspects of quality of service with loyalty is presented in Figure 1.

The $\chi^{2}$ of this model is 81.9729 with 13 degrees of freedom, resulting in the model being rejected at .05 . Since the sample size is big, this result is not surprising, as has been discussed by Kline (2005). This model has NC (normed chi-square) as much as 6.3056, which is slightly bigger than 5 for a reasonable fit. The RMR is .0208 , which is near to 0 as a perfect fit. The GFI is .9820, which is a value near 1 , meaning the model is a perfect fit. The values of the Bentler-Bonnet normed fix index (NFI), RFI, IFI, TLI, and CFI are $.9510, .8643, .9585, .8833$, and .9579, respectively, which means a reasonably good fit. The RMSEA is .0736 , where the value is in a range of .05 to .08 , meaning that the model shows a reasonable error of approximation. 


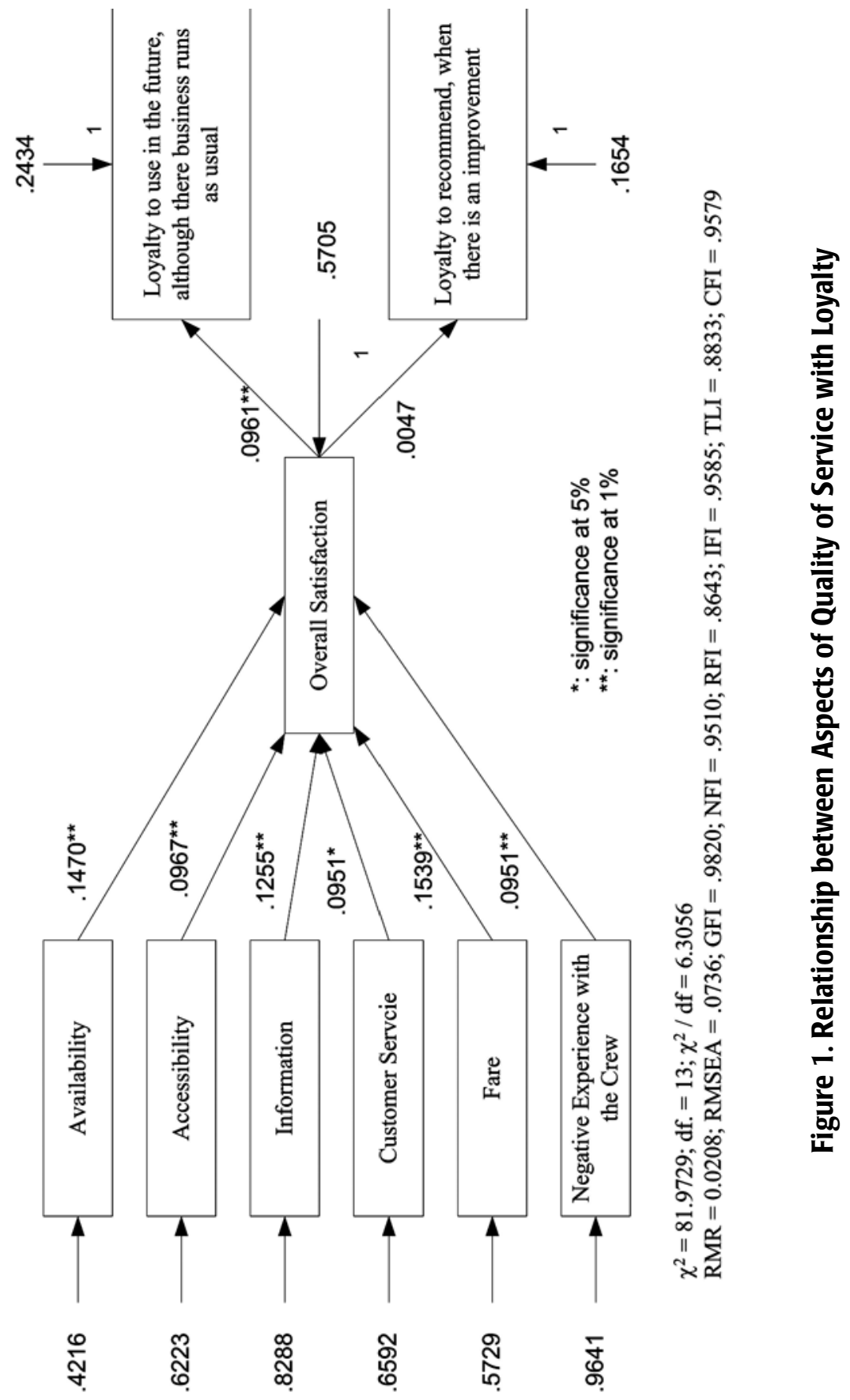


The values of NCP, AIC, CAIC, and ECVI were smaller compared to other models. According to these measures of fit, the model is a reasonably good approximation of the data.

As shown in Figure 1, only five from nine determinants of quality of service, and only one from seven determinants of negative experience, are significant in the model. Moreover, one from six determinants of loyalty is significant at .01 in the model as well. One determinant of loyalty, i.e. the loyalty to recommend to others when there is an improvement, is not significant at .05, but its existence creates the best fit of the model. Five determinants are significant at .01, except for the customer service's determinant being significant at .05 . The model explains these determinants as important factors in influencing the overall satisfaction. All determinants have positive signs, which means that the satisfaction in each determinant has a positive effect on overall satisfaction. In addition, the model reveals just the basic need among this group of users for fulfilling their mobility needs, which is shown by the lack of extra determinants, such as environmental impact and the like. The model explains around 43 percent of the variance in satisfaction or, in other words, around 57 percent of the variance is left unexplained. Another important finding from this model is the relationship between overall satisfaction and loyalty to use this mode in the future. The relationship between overall satisfaction and loyalty to use paratransit in the future when business runs as usual has a positive value. The positive sign means that the more they are satisfied, the more loyal the users prove to be to this mode. This group of users still wants to use it in the future and accepts the existing condition as it is. The findings support the hypothesis that this mode of transport is still relevant to future operation as there is a community group reliant on it. Moreover, the relationship between overall satisfaction and loyalty to recommend the use of paratransit to others when there is an improvement has a positive value. This finding emphasizes the requirement of improvement when users promote the mode to others.

The six binomial logistic models concerning the loyalty of the users are provided in Table 3. The aim of these models is to explore the important characteristics that explain the loyalty of users. Wright (1995) stated that in the logistic regression analysis for a dichotomous dependent variable, one attempts to predict the probability that an observation belongs to each of two groups. It becomes clear that the method is considered useful for exploring the user's choice of loyalty. Models I to III explain whether the user will use this mode in the future when business runs 
as usual, when there is an improvement, and when there is a new kind of public transport with a higher quality and fare. In addition, models IV and VI explain whether the user will recommend this mode to others in the future for the same three conditions. All six models have a significance value (model $\chi^{2}$ ) far below .05 , which means the rejection of the null hypothesis that the independents make no difference in predicting the loyalty. It shows that all models are well fitting; namely significantly different from the one with the constant only.

All six models have a Hosmer and Lemeshow goodness-of-fit value greater than .05 , which means the failure to reject the null hypothesis that there is no difference between observed and model-predicted values. It implies that all of the six models' estimates fit the data at an acceptable level. Although all models have low Cox and Snell $R^{2}$ and Nagelkerke $R^{2}$, the models can be accepted as well fitted as those $R^{2}$ are not actual percentages of variances explained. Garson (2006) said that $R^{2}$-like measures are not goodness-of-fit tests but rather attempts to measure strength of association. The result was strengthened by the value of percentages of correctness, in which all models yield medium percentages ranging between 58 and 83 . Finally, it can be concluded that all models are well fitting.

The models explain that the female users (including the married ones) seem to show more loyalty to paratransit. Users who reside in the city tend to be loyal ones. In addition, the models explain that young users are more loyal paratransit users in the future under all conditions. All these findings seem natural because that group of the community is more concerned with fulfilling the needs of mobility. That fact is supported by the variable of the number of family members, where it can be observed that the larger the family size, the more loyal they are. Large families seem to choose the mode of transport that may keep transport expenses as low as possible. The models reveal that users with an educational background of senior high school or higher seem more loyal to use paratransit in all situations. In these models, the job variables cannot clearly distinguish the loyal user since the values of the variables in the model spread to many jobs. 
Table 3. Binomial Logistic Regression Model for Loyalty

\begin{tabular}{|c|c|c|c|c|c|c|}
\hline Variables & $I$ & II & III & $I V$ & $\boldsymbol{V}$ & $V I$ \\
\hline Constant & .391 & $.750^{*}$ & -.338 & $\begin{array}{r}- \\
1.231 \\
* *\end{array}$ & $\begin{array}{r}1.700 \\
* *\end{array}$ & $.598^{*}$ \\
\hline Sex [1 if male, 0 otherwise] & $\begin{array}{r}- \\
.295^{*}\end{array}$ & -.079 & -.113 & .123 & -.078 & -.081 \\
\hline Status [1 if married, 0 otherwise] & .264 & -.215 & .061 & -.066 & .296 & .003 \\
\hline Place [ 1 if city, 0 otherwise] & -.104 & .421 & -.162 & .079 & .274 & .240 \\
\hline $\begin{array}{l}\text { Age } 1 \text { [ } 1 \text { if less than } 20 \text { years old, } \\
0 \text { otherwise] }\end{array}$ & & & .123 & & & \\
\hline $\begin{array}{l}\text { Age2 [1 if } 21-30 \text { years old, } 0 \\
\text { otherwise }]\end{array}$ & -.258 & & & -.312 & & -.163 \\
\hline $\begin{array}{l}\text { Age3 [1 if } 31-40 \text { years old, } 0 \\
\text { otherwise }]\end{array}$ & & -.231 & & & & \\
\hline $\begin{array}{l}\text { Age } 4 \text { [ } 1 \text { if } 41-50 \text { years old, } 0 \\
\text { otherwise }]\end{array}$ & & & & & -.512 & \\
\hline $\begin{array}{l}\text { Familynos1 [ } 1 \text { if } 1 \text { member, } 0 \\
\text { otherwise] }\end{array}$ & & .542 & -.111 & & & \\
\hline $\begin{array}{l}\text { Familynos2 [ } 1 \text { if } 2 \text { members, } 0 \\
\text { otherwise] }\end{array}$ & & & & & $\begin{array}{r}- \\
.530^{*}\end{array}$ & \\
\hline $\begin{array}{l}\text { Familynos } 3 \text { [ } 1 \text { if } 3 \text { or more } \\
\text { members, } 0 \text { otherwise] }\end{array}$ & .098 & & & .205 & & -.253 \\
\hline $\begin{array}{l}\text { Education1 [ } 1 \text { if junior high } \\
\text { school or less, } 0 \text { otherwise] }\end{array}$ & & & & $.536^{*}$ & $\begin{array}{r}- \\
.420^{*}\end{array}$ & \\
\hline $\begin{array}{l}\text { Education2 [ } 1 \text { if senior high } \\
\text { school, } 0 \text { otherwise] }\end{array}$ & & 216 & & $.439 *$ & & \\
\hline $\begin{array}{l}\text { Education3 [ } 1 \text { if diploma or more, } \\
0 \text { otherwise] }\end{array}$ & $\begin{array}{r}- \\
.374 *\end{array}$ & & .072 & & & .230 \\
\hline Job1 [1 if student, 0 otherwise] & $\begin{array}{r}- \\
.518^{*}\end{array}$ & & & -.442 & $\begin{array}{r}- \\
.690^{*}\end{array}$ & \\
\hline $\begin{array}{l}\text { Job2 [ } 1 \text { if civil servant, } 0 \\
\text { otherwise] }\end{array}$ & & & & & $\begin{array}{r}- \\
1.352 \\
*\end{array}$ & \\
\hline $\begin{array}{l}\text { Job3 [ } 1 \text { if private sector, } 0 \\
\text { otherwise] }\end{array}$ & & $\begin{array}{r}- \\
.668^{*}\end{array}$ & & & $\begin{array}{r}- \\
.947^{*}\end{array}$ & \\
\hline Job4 [1 if labor, 0 otherwise] & & & & & $\begin{array}{r}- \\
.920^{*}\end{array}$ & \\
\hline $\begin{array}{l}\text { Job5 [1 if entrepreneur, } 0 \\
\text { otherwise] }\end{array}$ & & & -.248 & & $\begin{array}{r}- \\
.995^{*} \\
*\end{array}$ & $\begin{array}{r}- \\
.547^{*} \\
*\end{array}$ \\
\hline $\begin{array}{l}\text { Car ownership1 [1 if car, } 0 \\
\text { otherwise] }\end{array}$ & & & & -.373 & & \\
\hline $\begin{array}{l}\text { Car ownership2 [1 if motorbike, } 0 \\
\text { otherwise] }\end{array}$ & -.159 & .385 & & & .258 & \\
\hline
\end{tabular}


Table 3. Binomial Logistic Regression Model for Loyalty (cont'd.)

\begin{tabular}{|c|c|c|c|c|c|c|}
\hline Variables & $I$ & II & III & $I V$ & $V$ & $V I$ \\
\hline $\begin{array}{l}\text { Car ownership } 3 \text { [ } 1 \text { if NMT or } \\
\text { others, } 0 \text { otherwise] }\end{array}$ & & & & & & -.515 \\
\hline $\begin{array}{l}\text { Car ownership4 [1 if not owned, } 0 \\
\text { otherwise] }\end{array}$ & & & $.306^{*}$ & & & \\
\hline $\begin{array}{l}\text { Reason } 1 \text { [ } 1 \text { if not able to drive, } 0 \\
\text { otherwise] }\end{array}$ & -.295 & .092 & $.397 *$ & & & \\
\hline $\begin{array}{l}\text { Reason2 [ } 1 \text { if not own a car, } 0 \\
\text { otherwise] }\end{array}$ & & & & $\begin{array}{r}.418 * \\
*\end{array}$ & & $\begin{array}{r}- \\
.376^{*} \\
*\end{array}$ \\
\hline $\begin{array}{l}\text { Reason3 [ } 1 \text { if more prefer to use } \\
\text { it, } 0 \text { otherwise] }\end{array}$ & & & & & .110 & \\
\hline $\begin{array}{l}\text { Trip purpose } 1 \text { [ } 1 \text { if studying, } 0 \\
\text { otherwise] }\end{array}$ & & & & .331 & & \\
\hline $\begin{array}{l}\text { Trip purpose } 2 \text { [ } 1 \text { if working, } 0 \\
\text { otherwise] }\end{array}$ & $\begin{array}{r}- \\
.632 * \\
*\end{array}$ & $.623^{*}$ & & & & \\
\hline $\begin{array}{l}\text { Trip purpose } 3 \text { [ } 1 \text { if shopping, } 0 \\
\text { otherwise] }\end{array}$ & $\begin{array}{r}- \\
.550^{*} \\
-\end{array}$ & & .361 & & & .208 \\
\hline $\begin{array}{l}\text { Trip purpose } 4 \text { [ } 1 \text { if social activity, } \\
0 \text { otherwise] }\end{array}$ & & & & & -.449 & \\
\hline $\begin{array}{l}\text { Trip number1 [ } 1 \text { if once, } 0 \\
\text { otherwise] }\end{array}$ & & & $.280^{-}$ & & & \\
\hline $\begin{array}{l}\text { Trip number } 2 \text { [ } 1 \text { if twice, } 0 \\
\text { otherwise] }\end{array}$ & & -.302 & & .036 & $\begin{array}{r}- \\
.613^{*} \\
*\end{array}$ & \\
\hline $\begin{array}{l}\text { Trip number } 3 \text { [ } 1 \text { if } 3 \text { times or } \\
\text { more, } 0 \text { otherwise] }\end{array}$ & -.235 & & & & & -.037 \\
\hline $\begin{array}{l}\text { Way to reach stop1 [ } 1 \text { if on foot, } \\
0 \text { otherwise] }\end{array}$ & .223 & & .241 & & & .185 \\
\hline $\begin{array}{l}\text { Way to reach stop } 2 \text { [ } 1 \text { if by NMT, } \\
0 \text { otherwise] }\end{array}$ & & $\begin{array}{r}- \\
1.485 \\
* * \\
\end{array}$ & & & $\begin{array}{r}- \\
1.423 \\
* *\end{array}$ & \\
\hline $\begin{array}{l}\text { Way to reach stop } 3 \text { [ } 1 \text { if park and } \\
\text { ride, } 0 \text { otherwise] }\end{array}$ & & & & $\begin{array}{r}1.121 \\
* *\end{array}$ & & \\
\hline $\begin{array}{l}\text { Expenses } 1 \text { [ } 1 \text { if less than } \\
2500 \text { IDR, } 0 \text { otherwise] }\end{array}$ & .075 & $\begin{array}{r}1.122 \\
* *\end{array}$ & & & $.811^{*}$ & \\
\hline $\begin{array}{l}\text { Expenses } 2 \text { [ } 1 \text { if } 2500-5000 \mathrm{IDR}, 0 \\
\text { otherwise] }\end{array}$ & & $\begin{array}{r}.906 * \\
* \\
\end{array}$ & & & $\begin{array}{r}.808^{*} \\
*\end{array}$ & \\
\hline $\begin{array}{l}\text { Expenses } 3 \text { [ } 1 \text { if } 7500-10000 I D R, \\
0 \text { otherwise] }\end{array}$ & & $\begin{array}{r}1.166 \\
* *\end{array}$ & & & $.867^{*}$ & \\
\hline $\begin{array}{l}\text { Expenses } 4 \text { [ } 1 \text { if more than } \\
10000 \text { IDR, } 0 \text { otherwise] }\end{array}$ & & & -.309 & -.353 & & -.129 \\
\hline $\begin{array}{l}\text { Satisfaction } 1 \text { [ } 1 \text { if very } \\
\text { dissatisfied, } 0 \text { otherwise] }\end{array}$ & & $\begin{array}{r}- \\
.744 * \\
*\end{array}$ & & & -.540 & \\
\hline
\end{tabular}


Table 3. Binomial Logistic Regression Model for Loyalty (cont'd.)

\begin{tabular}{|c|c|c|c|c|c|c|}
\hline Variables & $I$ & II & III & IV & $\boldsymbol{V}$ & $V I$ \\
\hline $\begin{array}{l}\text { Satisfaction2 [1 if dissatisfied, } 0 \\
\text { otherwise] }\end{array}$ & & & $\begin{array}{r}.712 * \\
*\end{array}$ & $\begin{array}{r}- \\
.457 * \\
*\end{array}$ & & \\
\hline $\begin{array}{l}\text { Satisfaction3 [1 if neutral, } 0 \\
\text { otherwise] }\end{array}$ & $\begin{array}{r}.380^{*} \\
*\end{array}$ & & $\begin{array}{r}.594 * \\
*\end{array}$ & & & \\
\hline $\begin{array}{l}\text { Satisfaction } 4 \text { [ } 1 \text { if satisfied, } 0 \\
\text { otherwise] }\end{array}$ & $\begin{array}{r}1.078 \\
* *\end{array}$ & & & & &.- \\
\hline $\begin{array}{l}\text { Income } 1 \text { [ } 1 \text { if less than } 1 \text { million } \\
\text { IDR, } 0 \text { otherwise] }\end{array}$ & & $\begin{array}{r}- \\
.387^{*}\end{array}$ & & $.380 *$ & & \\
\hline $\begin{array}{l}\text { Income } 2 \text { [ } 1 \text { if } 1-2.5 \text { million IDR, } \\
0 \text { otherwise] }\end{array}$ & $.427^{-}$ & & -.246 & & & -.244 \\
\hline $\begin{array}{l}\text { Income } 3 \text { [ } 1 \text { if } 2.5-5 \text { million IDR, } \\
0 \text { otherwise] }\end{array}$ & & & & & .524 & \\
\hline Omnibus Tests $\chi^{2}$, df., sig. & $\begin{array}{r}77.43 \\
6 ; 17 ; \\
.000 \\
\end{array}$ & $\begin{array}{r}68.81 \\
3 ; 17 ; \\
.000 \\
\end{array}$ & $\begin{array}{r}46.16 \\
1 ; 16 ; \\
.000 \\
\end{array}$ & $\begin{array}{r}85.67 \\
0 ; 16 ; \\
.000 \\
\end{array}$ & $\begin{array}{r}69.92 \\
5 ; 21 ; \\
.000 \\
\end{array}$ & $\begin{array}{r}38.15 \\
7 ; 15 ; \\
.001 \\
\end{array}$ \\
\hline$-2 L L$ & $\begin{array}{r}1281 . \\
116\end{array}$ & $\begin{array}{r}856.9 \\
36\end{array}$ & $\begin{array}{r}1310 . \\
248\end{array}$ & $\begin{array}{r}1197 . \\
540\end{array}$ & $\begin{array}{r}935.3 \\
06\end{array}$ & $\begin{array}{r}1312 . \\
855\end{array}$ \\
\hline Cox \& Snell $\mathrm{R}^{2}$ & .076 & .068 & .046 & .084 & .069 & .038 \\
\hline Nagelkerke $\mathrm{R}^{2}$ & .101 & .111 & .061 & .115 & .107 & .051 \\
\hline Hosmer \& Lemeshow $\chi^{2}$, df., sig. & $\begin{array}{r}7.841 ; \\
8 ; \\
.449\end{array}$ & $\begin{array}{r}3.521 ; \\
8 ; \\
.898\end{array}$ & $\begin{array}{r}13.86 \\
0 ; 8 ; \\
.086\end{array}$ & $\begin{array}{r}6.168 ; \\
8 ; \\
.628\end{array}$ & $\begin{array}{r}10.25 \\
8 ; 8 \\
.247\end{array}$ & $\begin{array}{r}7.447 ; \\
8 ; \\
.489\end{array}$ \\
\hline Percentage Correct & 60.6 & 82.6 & 58.1 & 65.4 & 79.3 & 59.2 \\
\hline
\end{tabular}

Note: $*$ significant at $5 \%, * *$ significant at $1 \%$.

Users whose families own a motorbike are loyal. This can be understood as the limitation of travel using a motorbike, since the number of motorbikes in a family is not sufficient for use by all family members. Usually the user of the motorbike is the father, or young family members, but not the mother or child. Loyal users are also characterized by the reason for choosing paratransit, such as not being able to drive and not owning a car. Trip purposes for loyal users are to study, to work, and to shop, while the number of trips per day is less than three. The typical way to reach the initial stop for this loyal user is by walking from the point of departure or residence. The group of users that spends less than 10,000 IDR per trip represents the loyal users of this mode. Loyal users are those who rate the existing service as somewhere in between dissatisfied and satisfied. In addition, the models explain that users with incomes of less than five million IDR per month are loyal ones. This finding is quite surprising because Indonesian families with incomes of 
approximately five million IDR can be categorized as being sufficiently prosperous, but somehow they still show this preference for being loyal to this particular mode. This finding shows considerable potential for the future of paratransit. It can be concluded that the existence of paratransit in the future is still important, although the need for improvement is an obligation to retain the ridership and improve the service.

\section{Discussion and Conclusion}

In this article, citizen perception was expressed by user participation in rating the mode's condition, including user expectations and loyalty. The distribution of the questionnaire to paratransit passengers took place in Bandung, Indonesia. Paratransit was chosen because of the dilemma in Indonesia and other developing cities regarding this privately operated and owned mode of public transport. On the one hand, some stakeholders (i.e., the government or transportation experts) want to replace this mode with a more advanced public transport mode. On the other hand, the real expectation from the community has never been considered thoroughly.

This research employs the path analysis and binomial regression method to reveal and explore the data. Five determinants of quality standards of service and one determinant of negative experience are significant in the model: availability, accessibility, information, customer service, fare, and negative experience with the crew's attitude. Two determinants of loyalty exist in the model: loyalty to use when the business is running as usual, and loyalty to recommend use to others when there is an improvement. All determinants of quality of service have positive signs, meaning that the satisfaction in each of them has a positive effect on overall satisfaction. Moreover, the findings from path analysis support the hypothesis that this mode is still relevant to operate in the future since a community group is relying on it. The analysis using the binomial logistic regression is able to distinguish the loyal users by exploring their characteristics. The analysis reveals that the number of students and young users is half of the overall users. This finding shows loyalty from a community group that clearly wants to keep using paratransit, which means that the future of paratransit shows considerable potential. It can be concluded that the existence of paratransit in the future is still important, although the need for improvement is an obligation to retain the ridership and attract new users. 
This article reports on a practice to reveal public perception and expectation and the mode's characteristics-factors that never seem to have received enough attention from decision-makers. The study underlines the need to focus on the needs and characteristics of the community regarding the operation of paratransit. This research also shows updated notions regarding the paratransit market in developing cities. Winder (2005) claims that national authorities should focus on the way the urban population perceives the outcome of their policies and measures as well. In other words, transport policy should confirm whether the public perceives something the government believes to be beneficial in the same manner, which is in line with mobility management. This article shows that public perception is useful to bridge the different perceptions with other stakeholders. Further research to explore the expectations and perception of stakeholders in weak positions is bound to become interesting and useful, especially in the context of developing countries. The hypothesis to be tested in future research is whether there is a difference in characteristics, expectations, and standards of the actual users of public transport in developing countries and developed countries.

\section{References}

Arbuckle, J. L., and W. Wothke. 1999. Amos 4.0 user's guide. Chicago, IL: Small Water Corporation.

Booth, D. L., L. E. Hanmer, and E. Lovell. 2000. Poverty and transport. Report prepared for the World Bank in collaboration with DFID. Chapter 4: Transport and Urban Poverty. pp. 53.

Cervero, R. 1998. The transit metropolis. A global inquiry. Washington, DC: Island Press.

DepKimPrasWil (Departemen Permukiman dan Prasarana Wilayah) (Department of Settlement and Regional Infrastructure of the Republic of Indonesia). 2002. Urban public transport policies in Bandung. Final Report, SURIP-1A, TF-25207, (Japanese Grant) and IBRD Loan No. 4054-IND. The Louis Berger Group Inc. and PT. Eskapindo Matra. (In Indonesian).

Desmedt, B. 2000. Toolbox for mobility management. Energy Efficient Transport Systems-Mobility Management. Session II / Lecture 3. Traject cv. Retrieved March 23, 2006, from www.p2pays.org/ref/17/16363.pdf 
DLLAJ (Traffic and Road Transport Agency). 2001. The guide of passenger public transportation price calculation with fixed routes in urban areas. West Java, Bandung. (In Indonesian).

Elmore, P. E., and D. L. Beggs. 1975. Salience of concepts and commitment to extreme judgments in response pattern of teachers. Education 95(4): 325334.

Frary, R. B. 1996. Hints for designing effective questionnaires. Practical Assessment, Research \& Evaluation 5(4). Retrieved October 31, 2005 from http://PAREonline.net/getvn.asp? $v=5 \& n=3$.

Friman, M., and T. Gärling. 2001. Satisfaction with public transport related to service performance. Travel Behavior Research, The Leading Edge, ed. D. Hensher. International Association for Travel Behavior Research. Oxford: Pergamon, Elsevier Science, Ltd., 845-854.

Gakenheimer, R. 1999. Urban mobility in the developing world. Transportation Research Part A 33: 671-689.

Garson, G. D. 2006. Logistic regression. Statnotes of PA 765: Quantitative Research in Public Administration. North Carolina State University, Raleigh, Retrieved February 20, 2006 from http://www2.chass.ncsu.edu/garson/pa765/logistic. htm.

Hensher, D. A., P. Stopher, and P. Bullock. 2003. Service quality-developing a service quality index in the provision of commercial bus contracts. Transportation Research Part A 37, 499-517.

Israel, G. D. 1992. Determining sample size. PEOD6. Agricultural Education and Communication Department. Florida Cooperative Extension Service. Institute of Food and Agricultural Sciences. University of Florida, Gainesville.

Jacobs, G., and A. Aeron-Thomas. 2000. Africa road safety review. Final Report, Project Report PR/INT/659/00. Washington, DC: U.S. Department of Transportation/Federal Highway Administration, Transport Research Laboratory.

Jen, W., and Hu, K-C. 2003. Application of perceived value model to identify factors affecting passenger's repurchase intentions on city bus: a case study of the Taipei metropolitan area. Transportation 30: 307-327. 
Joewono, T. B., and Kubota, H. 2005. The characteristics of paratransit and nonmotorized transport in Bandung, Indonesia. Journal of EASTS (Eastern Asia Society for Transportation Studies) 6: 262-277.

Kaltheier, R. M. 2002. Urban transport and poverty in developing countries. Analysis and options for transport policy and planning. Division 44 Environmental Management, Water, Energy, Transport. Deutsche Gesellschaft für Technische Zusammenarbeit (GTZ) GmbH. Eschborn.

Kim, N., C. Lee, J. Kim, and Y. Kwon. 2005. Critical measures of transit service quality in various city types. Proceedings of Eastern Asia Society for Transportation Studies 5: 414-427.

Klem, L. 1995. Path analysis. In Grimm, L.G., and P. R. Yarnold, P.R. Reading and Understanding Multivariate Statistics. Washington, DC: American Psychological Association.

Klem, L. 2000. Structural equation modeling. In Grimm, L. G. and P. R. Yarnold, Reading and Understanding More Multivariate Statistics. 4th printing. Washington, DC: American Psychological Association.

Kline, R. B. 2005. Principles and practice of structural equation modeling, 2 nd ed. New York: The Guilford Press.

Koushki, P. A., O. I. Al-Saleh, and M. Al-Lumaia. 2003. On management's awareness of transit passenger needs. Transport Policy 10: 17-26.

Litman, T. 2003. Mobility management, sustainable transport: a sourcebook for policy-makers in developing cities, Module 2, Deutsche Gesellschaft für Technische Zusammenarbeit (GTZ) GmbH, Division 44 Environmental Management, Water, Energy, Transport, Eschborn.

Moriyama, M., A. Fujiwara, and J. Zhang, J. 2005. Development of non-monetary indicators to evaluate public transport services in rural areas. Journal of Eastern Asia Society for Transportation Studies 6: 423-434.

Raykov, T. and G. A.Marcoulides. 2000. A first course in structural equation modeling. New Jersey: Lawrence Erlbaum Associates, Publishers.

Senbil, M., A. Fujiwara, J. Zhang, and D. U. Asri. 2005. Development of a choice model for evaluating sustainable urban form. Proceedings of the Eastern Asia Society for Transportation Studies 5: 2164-2178. 
Sekaran, U. 1992. Research methods for business, a skill building approach 2nd ed. New York: John Wiley \& Sons, Inc.

Thompson, B. 2000. Ten commandments of structural equation modeling. In Grimm, L. G., and P. R.Yarnold, Reading and Understanding More Multivariate Statistics. 4th printing. Washington, DC: American Psychological Association.

Transportation Research Board. 1999. A handbook for measuring customer satisfaction and service quality. Transit Cooperative Research Program. Report 47. Washington, DC: National Research Council.

Transportation Research Board. 2003. A guidebook for developing a transit performance-measurement system. Transit Cooperative Research Program Report 88. Washington, DC: National Research Council.

Vuchic, V. R. 1999. Transportation for livable cities. New Jersey: Center for Urban Policy Research, Rutgers, The State University of New Jersey.

Vuchic, V. R. 2005. Urban transit: Operations, planning, and economics. New Jersey: John Wiley \& Sons, Inc.

Walters, A. A. 1979. The benefits of minibuses. Journal of Transport Economics and Policy 13 (3): 320-334.

Winder, A., ed. 2005. Public perception of urban transport performance and policy. Survey Report for the EU-15, National Policy Frameworks (NPF) Urban Transport, Lyon.

World Bank. 1987. Bus services: Reducing costs, raising standards. World Bank Technical Paper No. 68, Urban Transport Series, Washington, DC.

World Bank. 2002. Cities on the move. A World Bank urban transport strategy review. Washington, DC.

Wright, R. E. 1995. Logistic regression. In Grimm, L. G., and P. R. Yarnold. Reading and Understanding Multivariate Statistics 9th printing. Washington, DC: American Psychological Association.

Zhang, S., W. Zhou, and C. Shao. 2005. Evaluation of urban passenger transport structure. Proceedings of Eastern Asia Society for Transportation Studies 5: 441-449. 
Zimmerman, R. E., L. Steinmann, and V. Schueler. 1996. Designing customer surveys that work. Quality Digest in http://www.qualitydigest.com/oct96/surveys.html downloaded on October 26, 2005.

\section{About the Authors}

TRI BASUKI JoewONO (vftribas@dp.civil.saitama-u.ac.jp) is a student in the Department of Civil and Environmental Engineering, Graduate School of Science and Engineering, Saitama University, Japan. He holds a bachelor's and a master's degree in civil engineering from Parahyangan Catholic University, as well as a master's degree in transportation from Bandung Institute of Technology. He is also a member of staff of the Department of Civil Engineering, Faculty of Engineering, Parahyangan Catholic University, Bandung, Indonesia.

Hisashi Kubota (hisashi@dp.civil.saitama-u.ac.jp) is a professor in the Department of Civil and Environmental Engineering, Graduate School of Science and Engineering, Saitama University, Japan. He holds a bachelor's degree from Yokohama National University, as well as a master's and a doctoral degree from the University of Tokyo. His research interest is in transportation planning and transportation demand management. 


\title{
Casual Carpooling-Enhanced
}

Kalon L. Kelley, Consultant

\begin{abstract}
Casual carpooling currently functions in environments where, because there is an HOV lane, riders and passengers join together to gain access to that lane. In this article, technology is introduced that will allow casual carpooling to function in areas without HOV lanes by providing an administrative system that records actual carpooling behavior so that incentives other than access to an HOV lane can be made available. This technology also addresses some of the current shortcomings associated with casual carpooling such as personal safety, the "free rider" problem, and the disincentive to maximize the number of passengers sharing a ride. The article concludes with comments on funding enhanced carpool programs including a hypothetical comparison of a program providing monetary incentives for carpooling to the alternative construction of new HOV lanes.
\end{abstract}

\section{Introduction}

Casual carpooling refers to the sharing of a ride with a driver and one or more passengers, where the ridesharing between the individuals is not established in advance but coordinated on the spot. While there may be a variety of motives for ridesharing, the expression refers primarily to commuting situations where the driver is incentivized to pick up passengers so as to allow for transit using a high occupancy vehicle (HOV) lane. This type of carpooling has been around for quite a number of years and is characterized by its informality and lack of governance. Meeting sites tend to evolve where there is reasonable parking (for passengers who may drive to the site and leave their cars) and proximity to major transportation corridors that provide HOV lanes. Casual carpooling has become a recognized 
cultural phenomena in places as diverse as Washington D.C., Pittsburgh, Houston, and San Francisco.

Casual carpooling is often considered a win-win activity. Drivers get access to transit lanes that reduce the length of their commute; passengers get a free commute to work. The community benefits by a reduction in vehicles on the road with its panoply of benefits. ${ }^{1}$

\section{Technology for Carpools}

Radio frequency identification devices (RFID) are now used in a variety of environments involving vehicles. An overview of toll collection systems is described by Saranow (2005), and the U.S. Border Patrol is now using automatic vehicle identification (AVI) technology to speed border crossings (U.S. Customs 2006). While these transponders identify a vehicle, that is all they do.

RFID devices are also used to identify people. For example, a major oil company makes available small keychain devices that can be waved by a gas pump to pay for a gasoline purchase; this technology is being extended to other retailers.

The proposal herein is to use a transponder that, physically comparable to the dashboard-positioned toll collection transponders, has the additional capability of reading and storing in memory individual RFID devices when they are passed in proximity to the transponder. Then, when interrogated, the transponder transmits its ID along with the individual IDs that were read and stored.

There is a one-time registration process where a potential driver registers with the administrator and receives an enhanced transponder. ${ }^{2}$ An individual participating in the program as a passenger will register and receive an individual RFID device.

The casual carpool begins when a driver enters his vehicle and turns on the transponder. At a collection point, any rider entering the vehicle passes his RFID device by the transponder, which beeps to indicate that the device was read and then records in memory the rider's ID. As the vehicle has occasion to travel by a reading station, the transponder will transmit its own ID along with IDs identifying the occupants. The reading station will periodically transfer its collected information to the central processing system. This allows for a historical record of carpooling events (who, where, and when) to be created effortlessly. This is the kind of information now manually collected by various carpooling systems to allow for reward- 
ing participants, with the implication that a framework for incentivizing people to form traditional carpools can apply as well to casual carpooling.

Identifying the transit corridors to be monitored is critical as it will not in general be possible to have transponder readers on all highways and surface streets that might be used for commuting. With multiple corridors and destinations, the placement of readers would need to be done with care, in particular to avoid situations where commuters are motivated to use a less efficient route simply to ensure that they pass through a transponder reader and get credit for their commute. Establishing a casual carpooling collection point would be subject to the same rationale as at present (density of drivers/riders, parking availability, public transit options), and it would probably be necessary to have a way of distinguishing "registered" passengers (those with RFID devices) from those without, ${ }^{3}$ as a driver will not get credit for providing a ride to the latter.

Two different contexts for casual carpooling exist. The traditional context is where an HOV or toll lane exist, and where a carpool is granted access or reduced-fee privileges on that lane. But casual carpools could exist in any transportation corridor if there was an incentive for drivers and passengers to participate; for ease of reference these will be called non-HOV carpools.

\section{Personal Security}

The caution "not to accept a ride from a stranger" is taught at an early age. While there are characteristics of casual carpooling that tend to ameliorate that concern (random nature of pick-ups; the typical requirement for there to be at least two passengers with a driver; and in some cases the restricted corridor, as for example, crossing of the San Francisco Bay Bridge), it clearly is a concern with a significant number of people in line choosing to decline an offered ride (Burris and Wynn 2006) or reporting that the accountability of the third person was a "major factor contributing to their sense of safety" (Gidal 2004). That there are websites that exist to report on wayward behavior of drivers and/or passengers is indicative of the concern. While the success of casual carpooling demonstrates that its participants have by and large adjusted to the security issue, the unanswered question is how many people presently do not participate but might choose this commuting model if security could be enhanced?

When a driver invites a rider to enter her vehicle with a transponder and the rider has an individual RFID device, both driver and rider can be comforted by know- 
ing that the other person's identity is on file and that the ridesharing activity will be recorded as the vehicle passes reading stations. In addition, the administrative system could be designed so as to allow a commuter to provide anonymous feedback. For example, suppose a passenger is picked up by someone who drives dangerously. The system could be set up so that later in the day the passenger could access the Internet, identify himself, and indicate that on that morning's commute the driver was not recommended because of their driving. Anonymity would be preserved as the passenger would not learn who the driver was. Similarly the driver could record passenger evaluations, again anonymously. ${ }^{4}$ If the system administrator established behavioral standards, participants with a pattern of inappropriate behavior reports could be warned or excluded from participation.

\section{Reporting of Carpool Events}

Self-reporting of carpooling events when required to obtain incentives is problematic. Underreporting happens due to laziness or forgetfulness, while overreporting can be a deliberate attempt to gain undeserved rewards. With the proposed technology, this reporting would be fully automated, with the only task required being the waving of an RFID device by the transponder when entering the carpool vehicle.

\section{How Many Passengers?}

The codified "rules of conduct" associated with casual carpooling serves to put boundaries on what drivers and passengers do when sharing rides (e.g., limited conversation and no cell phones). One of the constraints on drivers is not to pick up more than the minimum number of passengers needed to qualify for use of an HOV lane (with some exceptions such as late in the commute period when drivers are infrequent). From the viewpoint of the participants, this is a perfectly sound policy: it increases the liquidity of the system by "rewarding" more drivers with passengers. But the flip side is that it encourages low-volume ridesharing and hence more vehicles on the road.

In an HOV environment, it would be better to maintain liquidity with a dynamic definition of a qualifying carpool. Suppose there was at the carpool collection point a message board that defined the number of passengers needed to qualify for HOV access as of this point in time. During peak periods this number could be set high (4+) so as to provide an incentive for maximizing vehicle load. This 
would also serve to bring into equilibrium drivers and passengers, as a driver who regularly has difficulty finding a complement of passengers will have a diminishing incentive to leave home alone in hopes of being able to form a carpool. In nonpeak periods the number of passengers required to qualify might be reduced so as both to maintain system liquidity and to provide an incentive for drivers and passengers to shift to nonpeak-hour commuting.

In non-HOV carpools, both drivers and passengers can be incentivized to maximize vehicle occupancy, either by increasing the rewards to drivers for more passengers or, more likely, adjusting the program parameters so that rewards are available only for vehicles with a higher minimum number of passengers. Rewards could also be adjusted to favor nonpeak-hour commuting. There are endless permutations of reward structures with which to experiment. One of the more intriguing observations was made in an Atlanta program (Clean Air Campaign 2004) that showed a very substantial persistence (64\%) of alternative transportation use as long as nine months to a year after the subsidies were eliminated. This suggests a program design that provided financial incentives initially might not need to be forever wedded to maintaining them (see also Beroldo 1987).

\section{Haphazard Ride Matching}

In any casual carpooling arrangement, the ability to match rider destinations with driver destinations will be imperfect. In some situations this may not matter much (e.g., in San Francisco with crossing the Bay Bridge), but in others (Washington D.C. with its multiple collection points and often multiple destinations from each point) it may. In some meeting places riders self-segregate by destination, while in others the procedure is for the driver to call out his destination and then to have the first riders in line for whom that destination works step forward. When the queue is fairly small, this could be an aggravation for a driver who is unable to complete his carpool. Signage held by riders as to destination can also be useful. Some proposals and experiments use cellular phone technology to improve this "on-the-fly" matching function (Nelson/Nygaard Consulting Associates 2006), but there are not yet any successful implementations.

While building a database of actual commuting behavior has powerful implications for creation of traditional "match lists" and prearranged carpools, it can also be used with casual carpooling. For example, a transponder reader and a message board could be located at the pick-up site. When a vehicle pulls up, the transpon- 
der could be read and the destination displayed on the message board thereby facilitating decision making by those waiting. Similarly, if the passengers passed their RFID devices by a reader as they came into the pick-up area, there could be a message board for drivers indicating destinations and number of people waiting for that destination. Having this information available could be useful to both drivers and passengers (with no passengers there would be no reason to stop, and with too many heading to the same destination a passenger might anticipate an unacceptable waiting period).

\section{Enforceability of HOV Lane Restrictions}

There is quite a literature on enforceability of HOV restrictions and considerable diversity among communities and states in terms of the rigor with which the multioccupant requirement is enforced. That there have been efforts to recover Federal funding for HOV lanes where enforcement is poor (National Transportation Library 1993) attests to the problem. Ultimately it comes down to a law official peering into the window of a vehicle and trying to count occupants, a fairly difficult task to perform in the best of circumstances, and made problematic by reclining passengers, small children, dirty or tinted windows, or inclement weather.

Devices to read vehicle transponders can be positioned anywhere along a transit corridor and can be made part of the portable equipment of an enforcement official. When a vehicle passes a reading station, it is interrogated, and if the passenger count is inappropriate, a warning message or a signal to an enforcement official could follow. Vehicles without transponders (or with the transponder turned off) would be treated as violators. The system provides for a technical validation of occupancy rather than depending on sporadic visual observation. ${ }^{5}$

\section{Diffusion of Rewards}

HOV lanes are established to encourage behavioral change that would increase the number of occupants in a vehicle. ${ }^{6}$ To the extent that the lane becomes available to users who meet the occupancy requirement but for whom there has been no decision to trade off convenience for sharing a ride, the system gets degraded (Lehman et al. 1994). For example, a family on vacation has probably not decided to include an extra family member just to qualify for HOV access but may nonetheless enjoy this access. A mother driving her children to school has probably not made a carpooling decision, while another mother who drives her neighbor's chil- 
dren along with her own may well have. The inability of the system to distinguish among participants who should have access to the reward from those who should not results in bizarre results such as the family breadwinner who commutes to work accompanied by spouse (to qualify for HOV access), where after drop-off the spouse then returns home in the vehicle only to repeat the process at the end of the day. In this case the availability of the HOV lane has doubled the vehicle usage on the highway, resulting in two round-trips rather than one.

Minimizing "free riders" (vehicles that meet occupancy requirements and gain access to an HOV lane without any behavioral change to increase occupancy levels) should follow from the eligibility requirements established during registration. For example, a program might only register commuters who have an identified place of employment, thereby eliminating most of the fortuitous eligibility (examples cited above). Although some people will benefit without having changed their behavior (e.g., a neighborhood carpool that shifts to utilize a new HOV lane), and some people might benefit even when there is a questionable net societal gain (e.g., the bus rider who chooses to casually carpool because it is faster), a careful definition of eligibility should limit this.

\section{First and Last Miles}

One of the least tractable problems with casual carpooling is the "first mile" and "last mile"-the connections from home to the casual carpooling collection point and the connections from the drop-off point to work (with the directionality reversed on the way home). One approach to addressing this could be to adopt the transit center (or "hub-and-spokes") approach used in many municipal bus lines, wherein a passenger boards a bus and goes to the transit center and then shifts to another bus to complete the trip. While this would not fit all urban areas, in places where it was feasible the logistics are not difficult. Drivers and passengers would be identified both in the approach to the hub as well as when exiting, and any monetary reward programs could reflect what was happening. Drivers could be rewarded both for bringing passengers to the hub and for transporting a probably different group to their general area of employment. Message boards at the hub could be updated in real time to show how many vehicles were approaching (along with estimates as to time of arrival) that were bound for any particular destination.

In a non-HOV environment, the possibilities for fine-tuning the operation of an enhanced casual carpooling program are endless. If, for example, persons resid- 
ing in an area consistently failed to find rides, the formula for rewarding drivers could be adjusted so as to increase the incentive for picking up passengers in that area, and this could be done until a state of approximate equilibrium between passengers and drivers was reached. Conceptually, this could be viewed as a mini municipal bus system without fixed schedules and operating without exchange of money between riders and drivers, but operating with enough frequency that concerns about not getting a ride are minimal.

\section{Extending the Reach of Casual Carpooling}

As noted earlier, casual carpooling is, at present, closely tied to the incentive of HOV lane access, although there may be some ancillary incentives such as elimination of tolls. But the basic incentive from the driver's viewpoint is reduced transit time, and for passengers it is some mixture of reduced transit time and the savings associated with not having to drive. When access to an HOV lane is not available as an incentive, if an alternative incentive (such as cash or awards) were provided, it would free casual carpooling from its dependence on HOV lanes thereby greatly extending the environments in which casual carpooling could be effective.

Numerous employer-based programs reward carpoolers with economic benefits (free parking, monthly cash payments, and merchandise awards), and these programs do not depend on the existence of HOV lanes to make them work. Because they depend on self-reporting of carpool activities, the rewards are usually modest or temporary, and they usually work only within a company and not across a community.

Estimates of what it would cost to induce someone to commute using alternative transportation (other than an SOV) can be made using historic trip reduction tables (Victoria Transport Policy Institute 2005) projected to the current year as well as reports from actual employer-based programs (Clean Air Campaign 2004; National Transportation Library 1993; Victoria Transport Policy Institute 2006). The tables distinguish environments that differ by degree of transit infrastructure present as well as costs for parking, but the financial incentive needed to cause significant shifts from SOVs to alternative modalities is not large. Given the persistence of carpooling behavior once started, a program might start with relatively large incentives that are reduced over time. Endless opportunities exist for experimentation by a program manager, and data as to the relationship between amount of incentive and participation would accumulate over time. 


\section{Funding}

With the ability to monitor actual carpooling events, employers can incentivize their employees to carpool as an alternative to using an SOV, and the program need not be limited (as is typically the case now) to programs where all the participants are employed by the same company.

Further, the ability of the system to record carpooling events could help in motivating Congress to extend the Commuter Benefit Program to add carpools to the list of modalities (currently public transit or vanpools) that are eligible for tax benefits. That they have not been included has reflected the difficulty of verifying carpooling events, but in the proposed environment, the historical record is captured and available for audit.

But the largest source of funds should come from the Regional Transportation Boards and state and federal agencies that have as their mandate the construction and operation of transportation systems. The old paradigm of simply building more roads to accommodate ever-increasing traffic should no longer be the only game in town.

To illustrate the point, in the Regional Transportation Plan for Santa Barbara County (Parsons Brinckerhoff 2006), the estimates for construction of adding an HOV lane in both directions of a 12.8-mile section of Highway 101 (currently two lanes in each direction) came to $\$ 518$ million (2006 dollars), and this did not include the cost of additional infrastructure at freeway exits and entrances. After completion of some operational improvements (now scheduled to begin in 2008), the plan estimates that 600 vehicles per peak hour would need to be eliminated to improve traffic flow to a " $D$ " level of service (the minimum level of service acceptable in the Santa Barbara Congestion Management Program.)

If the number of riders (including the driver) to qualify for a financial incentive was set at 4+, this reduction could be achieved by moving 600 SOV drivers into qualifying carpools during each of two peak hours. If drivers were incentivized by a payment of $\$ 10 /$ day (to provide a carpool to Santa Barbara in the morning and then back home in the evening), and riders were incentivized by a payment of $\$ 4$ / day, the total cost for each peak hour would be 200 (drivers) $X \$ 10+600$ (former SOV drivers) $X \$ 4=\$ 4,400$. As the program would operate for two peak-hour periods per day and approximately 250 workdays/year, the annual cost would be $\$ 4400 \times 2 \times 250=\$ 2.2$ million. If operational costs were $\$ .5$ million/year, the total 
amount would be $\$ 2.7$ million. This is well under the $\$ 3.2$ million estimated annual maintenance cost of the proposed HOV lane.

The empirical justification for the incentive numbers used in this example is that (1) they are well in excess of what the trip reduction tables (Victoria Transport Policy Institute 2005) projected to 2007 from their base year suggest would be required to cause the needed percentage of drivers to shift from an SOV to alternative transportation, and (2) they also exceed the incentives actually used in a variety of carpooling programs (Transportation Demand Institute 1997; Victoria Transport Policy Institute 2007).

The comparison to HOV maintenance costs is imperfect (since the HOV lanes would provide benefits at nonpeak commuting hours, including the weekends when summer vacation traffic can cause congestion comparable to that of the workday week), and a more complete analysis would include projections for future years. ${ }^{7}$ However, the difference in capital $\operatorname{costs}^{8}$ is so large that it should cause planners to rethink their historical commitment to capacity building.

\section{Summary}

Over the years a number of proposals have addressed the automation of ridesharing (Niles and Tolliver 1992; Dickerson 2004). While from a systems architecture point of view the vision of dynamic carpool formation is fascinating, the complexity attending these proposals has made their adoption, even as pilot programs, problematic. In contrast, the technology proposed herein is simple to implement and easy for commuters to use. It holds the promise of extending the proven concept of casual carpooling to a larger regional audience. For regions with HOV lanes, performance can be enhanced, while for regions without HOV lanes, more traditional incentive-based programs become possible.

\section{Endnotes}

1 The computation of net reduction in vehicles due to carpooling is complicated by the fact that there can be mode displacements, for example persons choosing to carpool who might otherwise use a mass transit alternative (Beroldo 1990).

${ }^{2}$ Whether the driver also obtains a personal RFID might depend on whether the vehicle could have different operators on different days. If this were not the case, 
then the vehicle's transponder could also serve to identify the driver, and an RFID device for the driver would not be required.

${ }^{3}$ Perhaps by signage, "This line for registered riders only."

${ }^{4}$ This could be a bit tricky with multiple anonymous passengers as any evaluation by the driver would need to be attributed to the right passenger.

${ }^{5}$ Some enforcement issues remain (e.g., a driver potentially "borrowing" individual RFID devices without having the individuals present in the vehicle), but discussion of this topic goes beyond this article.

${ }^{6}$ Occasionally other objectives exist. For example, some venues encourage purchase of hybrid vehicles by opening HOV lanes to these vehicles apart from occupancy count.

7 The rate at which incentive program costs increase when traffic increases and more drivers need to become carpoolers may exceed the rate at which HOV maintenance costs increase.

${ }^{8}$ The capital cost to implement the carpooling program should be comfortably less than 1 percent of the $\$ 518$ million to construct the HOV lane.

\section{References}

Beroldo, S. J. 1987. Duration of carpool and vanpool usage by clients of rides. Transportation Research Record 1130.

Beroldo, S. J. 1990. Casual carpooling in the San Francisco Bay Area. Transportation Quarterly 44 (January 1990).

Burris, Mark W., and Justin Winn. 2006. Slugging in Houston: Casual carpool passenger characteristics. Transportation Research Board Annual Meeting Paper \#06-0061.

Clean Air Campaign. 2004. http://www.ewire.com/display.cfm/Wire_ID/2235.

Dickerson, Stephen L. 2004. U.S. Patent No. 6,697,730.

Gidal, Jessica W. M. 2004. Driving with the stranger. LoudPaperMag 4 (1).

Lehman, Christopher K., Preston L. Schiller, and Kristin Pauly. 1994. Re-thinking HOV - high occupancy vehicle facilities and the public interest. Institute for Transportation and the Environment. Chesapeake Bay Foundation. 
National Transportation Library. 1993. A guidance manual for implementing effective employer-based travel demand management programs. DOT, p.6 ff. http:// www.itsdocs.fhwa.dot.gov/JPODOC5/REPTS_TE/8383.pdf.

Nelson|Nygaard Consulting Associates. 2006. RideNow! Evaluation draft report. Alameda County Congestion Management Agency (September).

Niles, John S., and Paul A. Toliver. 1992. IVHS technology for improving ridesharing. Proceedings of the 1992 Annual Meeting of IVHS America.

Parsons Brinckerhoff Quade and Douglas, Inc. 2006. 101 in motion final report. Santa Barbara County Association of Governments (July). www.101inmotion. com/FileLib/SB-101\%20Final\%20Report\%20FINAL.pdf.

Saranow, Jennifer. 2005. Some new reasons to use high-tech tolls. Wall St. Journal (August 15), Section D1.

Transportation Demand Institute of the Association for Commuter Transportation. 2007. See case studies p. 11-70 (August). www.epa.gov/otaq/stateresources/rellinks/docs/tdmcases.pdf.

U. S. Customs. 2006. Website describes the Secure Electronic Network for Travelers Rapid Inspection (SENTRI). http://www.cbp.gov/xp/cgov/travel/frequent_ traveler/sentry.

Victoria Transport Policy Institute. 2005. Trip reduction tables. http://www.vtpi. org/tdm/tdm41.htm.

Victoria Transport Policy Institute. 2006. Ridesharing (see case studies and examples). http://www.vtpi.org/tdm/tdm34.htm.

Victoria Transport Policy Institute. 2007. Commuter financial incentives. http:// www.vtpi.org/tdm/tdm8.htm.

\section{About the Author}

KALON L. KeLLEY (kalon@mtnimage.com) is a retired computer software entrepreneur and college teacher. A member of the Association for Commuter Transportation, Dr. Kelley has published articles on computer science, linguistics, and transportation. He has been active in recent years in exploring transportation alternatives for Santa Barbara County, California. 


\title{
Guaranteed Ride Home Programs: A Study of Program Characteristics, Utilization, and Cost
}

\author{
William B. Menczer \\ Federal Transit Administration
}

\begin{abstract}
Guaranteed ride home programs play an important role in increasing public transportation ridership by providing a good reason to separate commuters from their single occupancy vehicles. Since they are inexpensive insurance policies, these programs provide a cost-effective way for a commuter to leave work in the event of a personal or family emergency or unexpected overtime. Research results show that usage rates and costs are quite low. As a possible incentive for commuters to leave their cars at home, these findings may make these programs attractive to communities that want to reduce congestion by increasing public transportation use. The research includes an examination of 55 such programs that serve the top 150 transit agencies in the United States.
\end{abstract}

\section{Introduction and Methodology}

As part of its effort to increase transit ridership and reduce congestion nationwide, the Federal Transit Administration (FTA) conducted research on guaranteed ride home $(\mathrm{GRH})$ programs that served 150 of the largest transit agencies in the United States. The overall goals of the research were to identify and describe key elements of the programs and performance measures to determine their use and cost effectiveness. The results of the research are intended to be used to convince communi- 
ties to adopt such programs where they presently do not exist and where they may help improve public transportation ridership.

According to a survey (Haas 2005) conducted on behalf of FTA by the Mineta Transportation Institute, 63 of the 150 largest transit agencies are covered by GRH programs. Of the 63 programs identified in the Mineta study, the study reported here is based on a review of 47 programs where complete data could be obtained. Data were also obtained for an additional 8 programs not included in the Mineta study that were in the top 150 largest transit agency list. A total of $55 \mathrm{GRH}$ programs were reviewed. The current study includes programs sponsored by transportation management associations (TMA), metropolitan planning organizations (MPO), municipal governments, and business associations.

Table 1 contains a complete list of organizations contacted over the course of conducting this study (see pages 146-148).

\section{Defining "Guaranteed Ride Home"}

Guaranteed Ride Home programs, also referred to as "emergency ride home" programs, are often described as an economical form of insurance. It reassures those commuters who do not drive alone that they have a timely and inexpensive way to leave work in the event of a personal or family emergency, illness, or unexpected employment-related delay, such as unscheduled overtime. These commuters include transit users, carpoolers, vanpoolers, pedestrians, and bicyclists (and in Santa Cruz Metro Transit District, roller bladers).

The purpose of the program is to increase transit use and ridesharing by removing the barrier of not having access to transportation in the event of an emergency. This lack of access prevents many from foregoing single occupant vehicle (SOV) travel to work.

\section{Eligibility}

Most GRH programs surveyed require that employees use alternative commuter modes such as public transportation, carpool, vanpool, walking, or biking for a minimum number of times per week. Tucson is an exception since walkers and bicyclists are not covered by the GRH program. In Monterey, California, employees must use alternate modes to commute to work at least once a week, while Sacramento requires three times a week, and Volusia County, Florida, four times a week. Other GRH programs require that the employee use an alternate commute 
mode on the day that a GRH is requested, such as Lane District Transit in Eugene, Oregon, and Clark County Transportation in Vancouver, Washington.

As shown in Figure 1, the majority of sponsors (54\%) require that to qualify for GRH benefits, commuters must travel using transit, van or carpools, walking, or bicycling. Twenty-two percent did not include walking or bicycling while 20 percent only covered the use of public transportation to the exclusion of all other modes in order for commuters to qualify for GRH benefits.

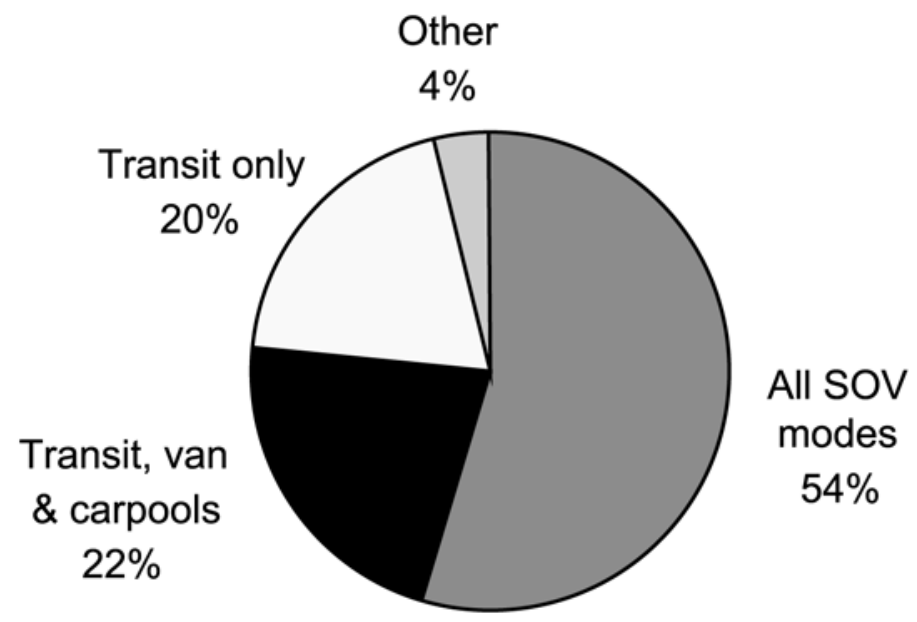

\section{Figure 1. Distribution of Non-SOV Modes Required for GRH Qualification}

\section{GRH Transportation Mode}

Most GRH programs have agreements with taxi companies, rental car companies, or both to provide service. Depending on the distance the employee must travel, some employees are allowed to rent cars, use employer vehicles, or be driven by another employee. The Transit Authority of Northern Kentucky provides rides only by agency road supervisors instead of rental cars or taxis. Central New York RTA in Syracuse, Niagara Frontier in Buffalo, Greater Cleveland, and Metro Tulsa Transit allow the use of either taxis or transit agency vehicles driven by agency supervisors. Madison Metro permits use of either taxis or employer fleet vehicles driven by the employee. San Francisco is the only GRH program that allows the use of a car-sharing company, City Car Share. 
As shown in Figure 2, a large majority of sponsors chose to offer a GRH only by taxi $(60 \%)$, followed by taxi or rental car (27\%). Transit agency vehicles are used either exclusively or in conjunction with taxis by 13 percent ( $9 \%$ with taxis and $4 \%$ exclusively agency-provided rides).

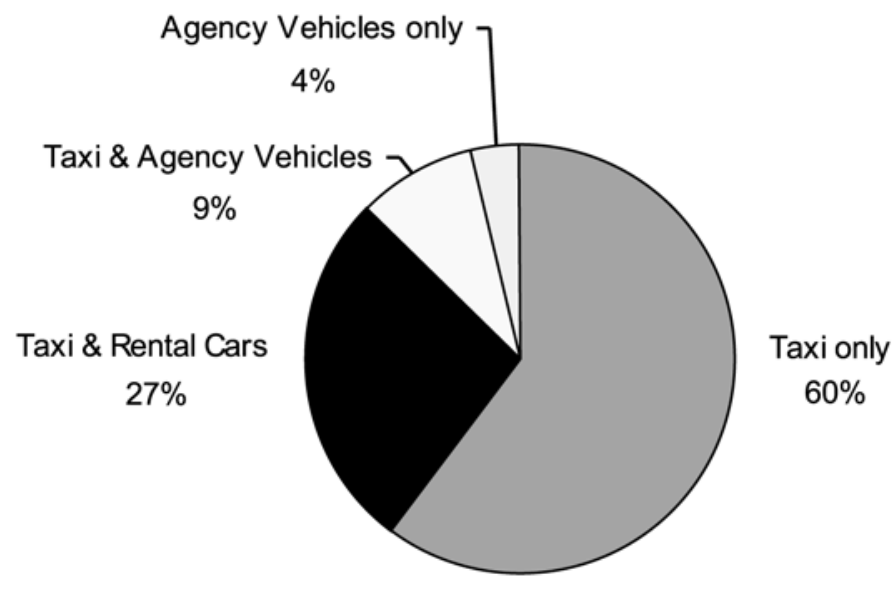

\section{Figure 2. Distribution of GRH Transportation Mode Allowed of $\mathbf{5 5}$ Transit Agencies in 2005}

Public transportation is often an integral part of a flexible, low-cost GRH program. GRH programs in areas with extensive transit systems often incorporate transit into their program design. Metropolitan Washington Council of Government's program in Washington, D.C. uses public transportation as one mode to get a commuter home quickly with minimal cost. When a commuter calls to request a ride, he or she may be instructed to take Metrorail or Metrobus to a distant station where a taxi will be waiting to complete the ride. Programs in Boston, Minneapolis/St. Paul, New York City, and Wilmington (Delaware) only approve an emergency ride for a transit rider when no transit service is available within 30 to 60 minutes.

Public transportation offers the potential to reduce the provider's cost of an emergency ride, but it may not serve every commuter's needs when a bona fide emergency occurs. Commuters who carpool or vanpool long distances or use transit periodically, particularly express buses and commuter rail, require GRH 
programs that supplement transit with more flexible and responsive services such as taxicabs or rental cars.

\section{Payment}

The two main methods of payment for the GRH program are vouchers issued to employees and reimbursement for direct payment by the employee to the vendor. With vouchers, only certain taxi companies can be used, which are arranged in advance by the program administrator. Vouchers may be used in some programs for rental cars. In the event of employee payment to the vendor, the employee may be restricted to choices of taxis and rental car companies. Vouchers are distributed to employees either when they register for the program or when requested from the on-site employee transportation coordinator (ETC) on the day of need.

As shown in Figure 3, the majority of sponsors (56\%) pay for the GRH costs through the use of vouchers, followed in equal portions (22\% each) by either direct payment by the sponsor to the transportation provider or by reimbursement to the traveler.

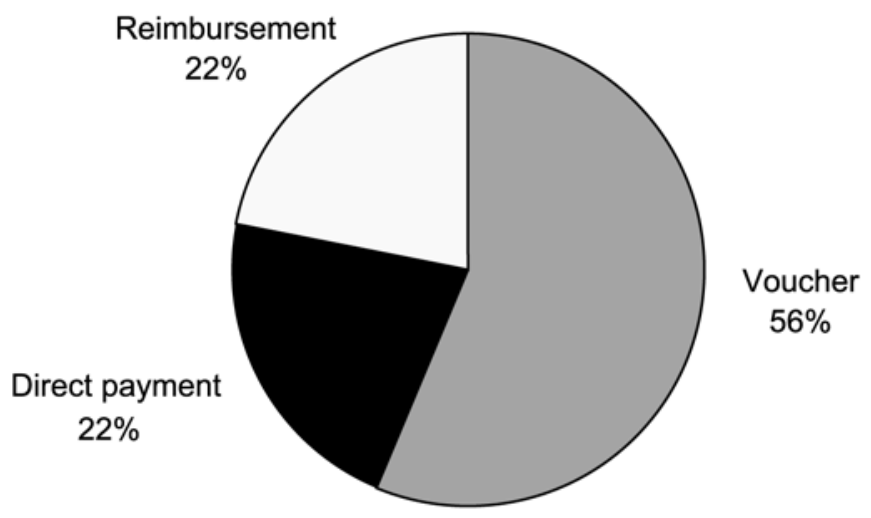

Figure 3. Distribution of GRH Payment Methods

\section{Destinations}

Most programs allow employees to travel to destinations other than their homes, such as a park-and-ride lot, an educational facility to pick up a dependant, a pharmacy to obtain a prescription, or a hospital to check on a family member. Program rules normally specify where and how many intermediate stops are permitted. For 
example, Sacramento allows 10-minute intermediate stops to a park-and-ride lot, home, or to a hospital. Lane Transit in Eugene allows a 15-minute stop to a location directly related to the emergency. Programs in Miami, Orlando, San Francisco, and Seattle permit multiple intermediate stops, while those in Kansas City, San Antonio, and Santa Cruz each allow only one stop.

\section{Distance and Cost}

Most programs specify limits on either the distance to be traveled or the amount of payment that may be incurred. Some restrict travel within specific geographic boundaries, such as within the city or county limits. For example, in San Antonio, taxi rides up to 60 miles within Bexar County are permitted. Clark County limits cab rides to 50 miles. Most programs permit taxi cab use for rides less than 20 miles or when the commuter is ill, does not have a license, or does not meet other requirements of using a rental car. An exception to the 20-mile rule is found in Denver where the program allows taxi rides up to 100 miles one way. San Francisco permits the use of City Car Share vehicles for trips up to 200 miles.

\section{Program Rules}

To minimize abuse of the program, most (89\%) place restrictions on the number of rides that may be claimed per a specified period. This study found the limits range from two per year to no limit at all. Those offering only two per year, representing 7 percent of those surveyed, are Hartford, Las Vegas, Phoenix, and Santa Cruz. Denver, Greater Richmond, Kitsap Transit, San Mateo, Santa Clara Valley, and Syracuse have no limits on the number of GRH requests a commuter can make either monthly or annually.

As shown in Figure 4, the most common GRH limit is four rides per year (offered by $37 \%$ of the transit agencies), followed by six rides per year (offered by $17 \%$ of the transit agencies). Eleven percent of the agencies surveyed have no annual limit on the number of rides permitted.

Most GRH programs do not place dollar limits on the cost of the trips, but those that do range from per-trip lows of $\$ 25$ in Minneapolis, $\$ 30$ in Oklahoma City, and $\$ 35$ in Cleveland, to highs of $\$ 100$ in Tampa, and $\$ 200$ in San Francisco (capped at $\$ 700$ per year).

Some programs require commuters to make copayments. These include San Diego (\$3), Central Ohio Transit Authority (10\% of the fare), Southwest Ohio Regional Transit (20\% of the fare), Dallas ( $\$ 10$ for vanpool users), Fort Worth $(\$ 5)$, and Richmond ( $\$ 5$ after the third claim). Phoenix provides the first ride free; subsequent 


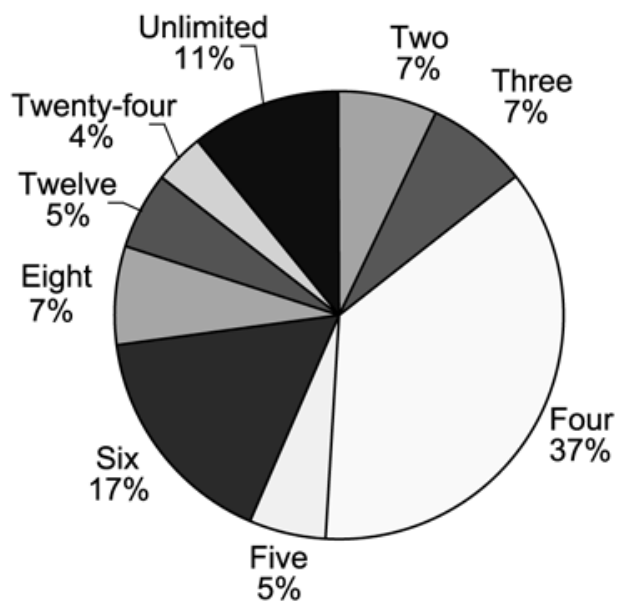

\section{Figure 4. Distribution of Maximum Annual Rides Allowed among GRH Agencies in 2005}

rides cost the user 50 percent of the total cost. Saint Louis requires a 20 percent copayment on rides costing up to $\$ 40$ and requires the user to pay 100 percent of the costs in excess of $\$ 40$.

Registration fees paid by commuters could constitute an impediment for the successful implementation of a GRH program. For example, the \$15 annual fee at San Antonio's VIA Metro entitles commuters to receive four vouchers for the year. Only two commuters are registered for this program despite an extensive marketing and outreach program. Austin's Capital Metro Transit imposes a \$5 annual fee for a GRH program covering vanpool and express bus riders. They receive up to four taxi rides per year, each for a maximum cost of $\$ 48.50$. Only 152 commuters are registered in this program.

Trip purposes are clearly defined in almost all programs. Common purposes include a personal or family illness or emergency, unscheduled overtime approved by a supervisor, and the unavailability of a rideshare partner due to his or her having to leave early or to stay late unexpectedly. Common prohibitions include preplanned events such medical or dental appointments, scheduled overtime, business-related travel, public transportation breakdowns, on-the-job injuries, claims on days when the commuter did not use an alternative to SOV travel, or 
severe weather. Unusual prohibitions include major area disasters in Bremerton, Washington, and employment terminations or layoffs in Tacoma, Washington.

\section{Cost and Use of GRH Programs}

$\mathrm{GRH}$ programs generally require minimal funding and staff time to operate. As indicated in Table 2, the cost of GRH claims is not significant. Comparisons of $\mathrm{GRH}$ program costs with overall rideshare program costs were not possible since complete financial data was not available from all programs studied.

\section{Table 2. Overall Cost of GRH Programs Surveyed}

\begin{tabular}{|l|l|l|l|l|l|}
\hline $\begin{array}{l}\text { Mean } \\
\text { Cost per } \\
\text { Claim }\end{array}$ & $\begin{array}{l}\text { Median } \\
\text { Cost per } \\
\text { Claim }\end{array}$ & $\begin{array}{l}\text { Range of Cost } \\
\text { per Claim }\end{array}$ & $\begin{array}{l}\text { Mean } \\
\text { Annual } \\
\text { Cost per } \\
\text { Registrant }\end{array}$ & $\begin{array}{l}\text { Median } \\
\text { Annual } \\
\text { Cost per } \\
\text { Registrant }\end{array}$ & $\begin{array}{l}\text { Range of } \\
\text { Annual Cost } \\
\text { per } \\
\text { Registrant }\end{array}$ \\
\hline$\$ 36.95$ & $\$ 29.96$ & $\$ 0-\$ 114.08$ & $\$ 1.69$ & $\$ .35$ & $\$ 0-\$ 15.78$ \\
\hline
\end{tabular}

The average cost per claim, in this survey, was $\$ 36.95$, with a median cost of $\$ 29.96$ and a range of no cost to $\$ 114.08$. Those with average costs per claim of less than \$20 were Albuquerque, Greater Richmond Minneapolis, Lane Transit, Madison Metro, and San Francisco. Grand Rapids, Monterey, San Antonio, and Volusia County (Florida) reported no claims during their most recent fiscal year. Syracuse, the Transit Authority of Northern Kentucky, and Tulsa used agency vehicles for rides home and therefore recorded no costs incurred during their last fiscal year. Those with average costs per claim over $\$ 75$ were Alameda, Birmingham, Boston Commuter Works, San Mateo, and Ventura. In 1993, a typical trip cost was estimated to be $\$ 30$ and average cost per employee was under $\$ 5$ per year (Comsis Corporation 1994). These costs are equivalent to $\$ 38.20$ and $\$ 6.37$ in 2005 dollars, respectively (Federal Reserve Bank of Saint Louis 2005), which are both higher than those found in this study.

Figure 5 shows the distribution of average (mean) costs per ride. It indicates that the most common cost categories are $\$ 20$ to $\$ 30$ (25\% of agencies surveyed) and $\$ 30$ to $\$ 40$ (20\%). No cost (13\%) and from $\$ 10$ to $\$ 20$ (11\%) represent the next most common cost categories. 


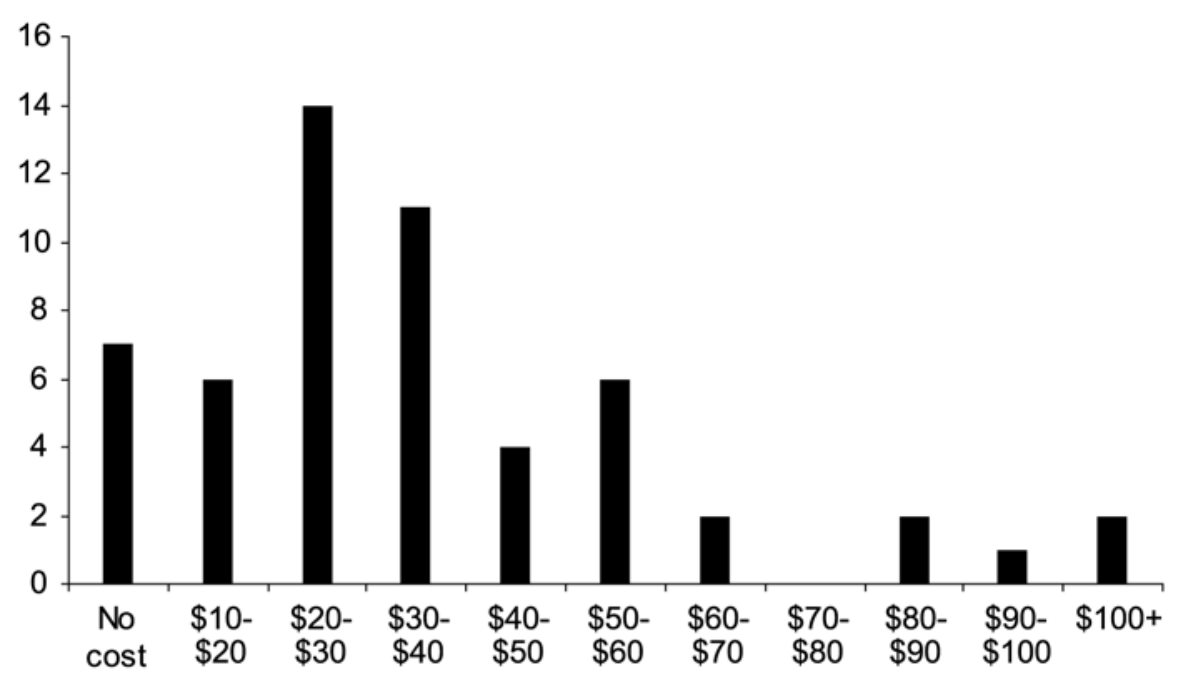

Figure 5. Distribution of Average Cost per Claim in 2005

The average (mean) annual cost per registered commuter was very low at only $\$ 1.69$ with a median cost of only $\$ .35$, and a range of no cost to $\$ 15.78$. Those with average costs per commuter of less than $\$ 0.30$ were Las Vegas, Pierce County, San Francisco (all at \$0.02), Albuquerque, Central Ohio, Clark County, Dallas, Delaware, Kansas City, Lane Transit, Milwaukee, River City, Rochester, Sacramento, Saint Louis, Santa Clara, Santa Rosa, Southwest Ohio, Tucson, and Utah. Those with average costs per registered commuter of more than $\$ 10$ were Contra Costa at $\$ 13.16$ and Fort Worth at $\$ 15.78$.

Figure 6 shows the distribution of the average annual costs per registered commuter. It indicates that the most common cost categories are less than $\$ 1$ (44\% of agencies surveyed), $\$ 1$ to $\$ 2(18 \%)$, and no cost (13\%).

Figure 7 shows that there does not appear to be a correlation between average cost per ride and the size of the service area. It would be reasonable to assume that costs would rise with the size of the area served by the GRH. The data shows, however, that this is not the case. Service area sizes in this study range from 22 square miles in Alameda County to 3,940 square miles in Orlando. The majority of the service areas are less than 600 square miles. 


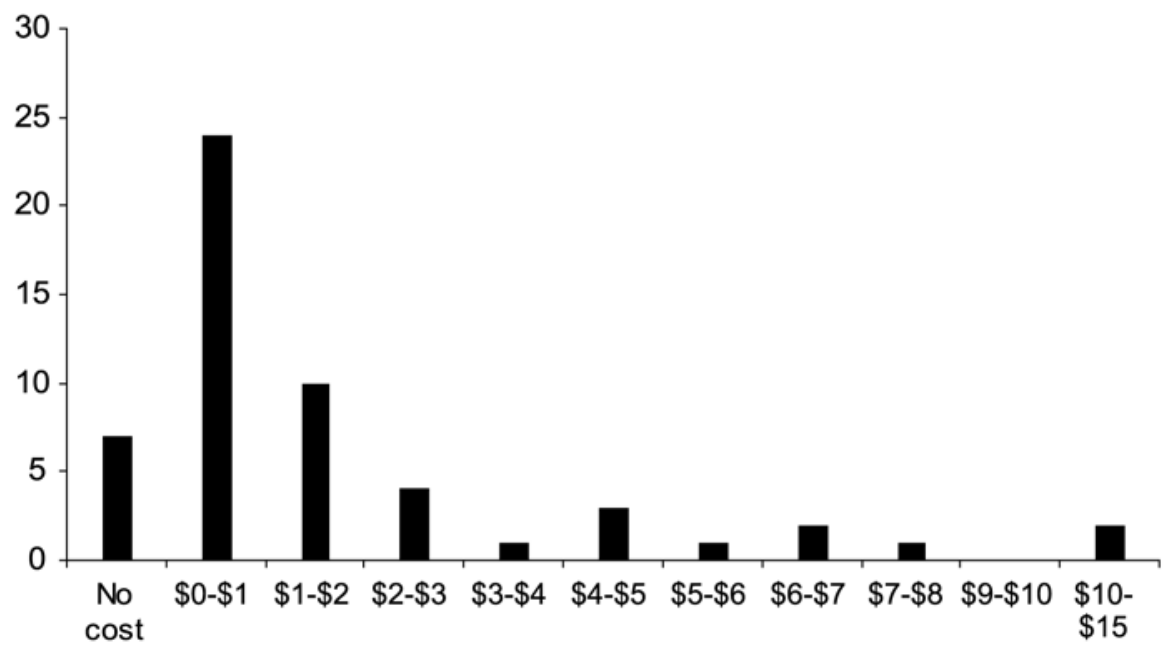

Figure 6. Distribution of Average Cost per Registrant in 2005

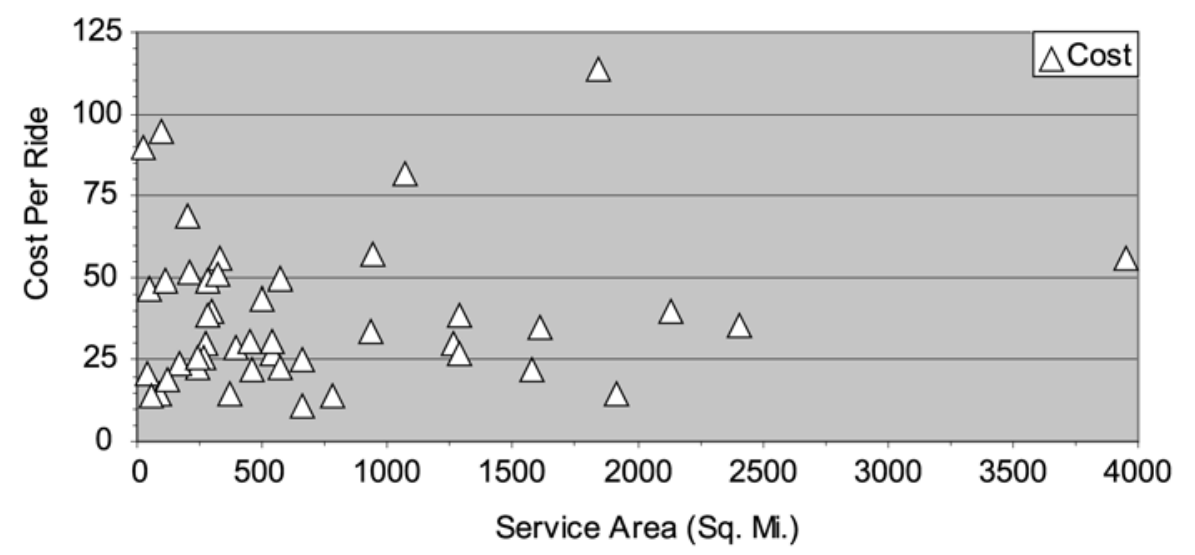

Figure 7. Correlation of Cost and Service Area

As indicated in Table 3, the overall use of GRH programs is not significant, as would be expected with any insurance program. The average use of the program in this survey, per registered commuter, was a very modest 4.57 percent, with a 
median use of 1.29 percent and a range from none to 30.87 percent. Those with usage rates of less than 1 percent during the last fiscal year were Cincinnati, Clark County, Columbus, Dallas, Delaware, Kansas City, Las Vegas, Milwaukee, Pierce County, River City, Sacramento, Saint Louis, San Francisco, Santa Clara, Santa Rosa, Tucson, and Utah. Those with usage rates more than 10 percent were Atlanta, Contra Costa, Fort Worth, Greater Richmond, Hillsborough, Miami, Minneapolis, Oklahoma City, Transit Authority of Northern Kentucky, and Washington, D.C.

\section{Table 3. Overall Use of GRH Programs Surveyed}

\begin{tabular}{|c|c|c|}
\hline $\begin{array}{c}\text { Mean Use per } \\
\text { Registrant }\end{array}$ & $\begin{array}{c}\text { Median Use per } \\
\text { Registrant }\end{array}$ & Range of Use per Registrant \\
\hline $4.57 \%$ & $1.29 \%$ & $0 \%$ to $30.87 \%$ \\
\hline
\end{tabular}

Figure 8 shows the distribution of the mean usage per registered GRH participant. The most common category is the average usage rate under 1 percent found among 31 percent of all agencies surveyed, followed by those over 10 percent, 1 to 2 percent, and those agencies with no usage.

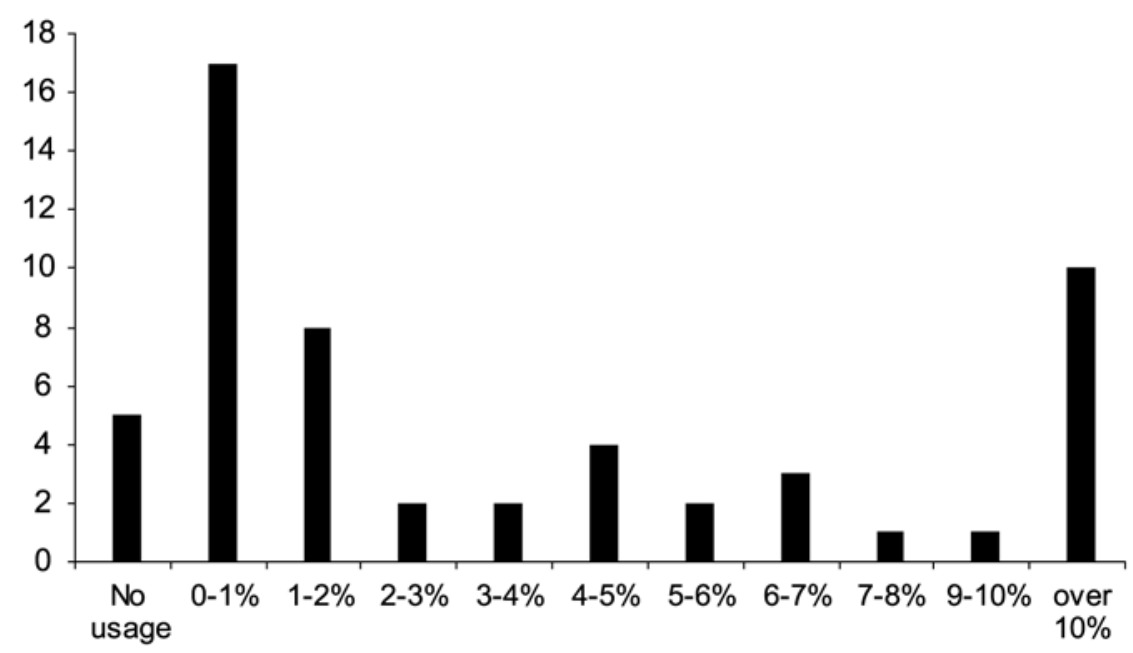

Figure 8. Distribution of Mean Usage per Registrant in 2005 
Figure 9 shows a negative correlation between average usage rates and the maximum number of rides allowed per year, but no statistically significant correlation. It would be reasonable to assume that usage would rise with the greater number of annual rides permitted. The data shows, however, that this is not the case. For the six agencies that permitted an unlimited number of rides per year, five agencies had usages rates under 6 percent. Greater Richmond Transit had a 26.11 percent usage rate. This high rate was due to geographic expansion of the program which attracted a large number of new registrants during the reporting year. According to the Richmond GRH program manager, new users in Richmond typically have higher claim rates in their first year until they become familiar with the program. Usage rates for the current fiscal year are considerably lower. For the two agencies with an annual limit of 24 , the usage rates were 1.47 percent and 6.67 percent.

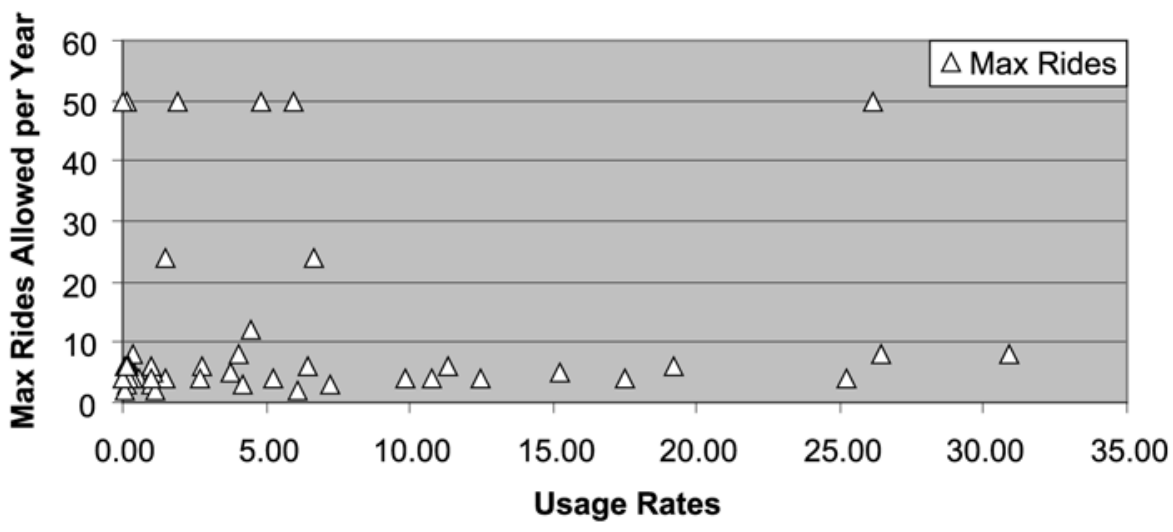

\section{Figure 9. Correlation of Usage with Maximum Number of Rides Permitted}

Figure 10 shows an apparent negative relationship between average usage rates and the size of the GRH service area. As the service areas of the GRH program decreases, the rates per registered user per year increases. As noted earlier, service area sizes in this study range from 22 square miles in Alameda County to 3,940 square miles in Orlando. The majority of the GRH programs surveyed serve areas that are less than 600 square miles in size. 


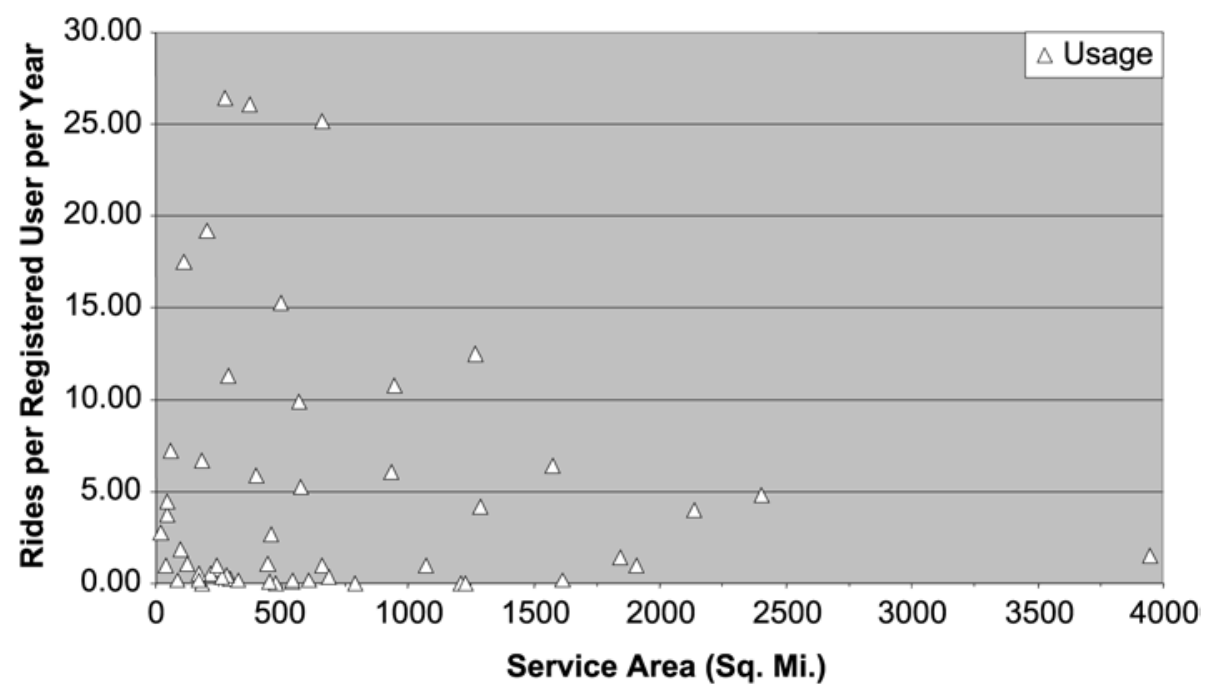

Figure 10. Correlation of Usage and Service Area

\section{Impact on SOV Commuting}

Most programs have anecdotal evidence from post-ride surveys and unsolicited commuter response regarding how offering GRH decreases SOV travel. These survey results show that offering GRH may contribute to some commuters shifting from driving alone to non-SOV commuting including public transportation.

In a 1999 survey of Tappan Zee (New York) express bus riders, 16 percent said they would definitely stop using the service without GRH.

A 2002 survey conducted by the Artery Business Committee in downtown Boston found that 9 percent of those responding to the survey switched from SOV commuting to an alternate mode of transportation due to the existence of a GRH program.

A 2002 survey of Haverstraw-Ossining Ferry riders in New York found 41 percent of those surveyed stated that the GRH was among the top reasons for taking the ferry instead of their previous mode of transportation. Four percent ranked GRH as their number one reason for taking the ferry. 
A 2003 study conducted for the Denver Regional Council of Governments found that a GRH program, at no cost to the user, would increase carpooling frequency by 17 percent for those who plan to join a carpool in the next year. Three percent of SOV commuters said they would carpool at least once a week if they found suitable partners and were covered by a GRH. The GRH would increase carpooling frequency for this group by 8 percent (Vantage Marketing Research 2003).

A program evaluation conducted in 2004 for the Alameda County Congestion Management Agency found that 47 percent of those surveyed would not use alternate modes of transportation without a GRH program. In 2003, the number was 41 percent (Nelson/Nygaard Consulting Associates 2005).

\section{Conclusion}

GRH program costs were found to be rather modest in this study. The average cost per claim of $\$ 36.95$ and average cost per registered participant of $\$ 1.69$ were quite low. Usage, comparable to other insurance programs, was equally low. Only an average of 4.57 percent of those registered in this study used the program during the most recent fiscal year. There did not appear to be a statistically significant correlation between average usage rates and the maximum number of rides permitted, between average cost and service area size, or between average usage and service area size. Therefore, agencies need not be parsimonious in setting the limit on the number of rides allowed per year for fear of high use and cost, or abuse.

There are more similarities than differences among the GRH programs surveyed in this study. Eligibility normally encompasses those who use alternative commuter modes and do not include SOV; the primary difference is in the number of days required for use of these modes. At least 60 percent of the programs use taxis to provide GRH services, which are often supplemented by rental cars. Payment for the service is either through reimbursement of the commuter or by the use of vouchers redeemable with specified providers. Most programs allow employees to travel to destinations other than their residences and many permit intermediate stops along the way. There is a large degree of consistency among the programs regarding the circumstances under which GRH can be provided and when it is not allowed. Most programs do not limit the cost of taxis or rental cars, and only some limit the total distance traveled. The vast majority of the programs limit the number of eligible claims per year, with a plurality allowing up to four rides per year. 
Although there are no recent national studies that assess the impact of these programs on SOV commuting, several local studies conducted in recent years indicate a positive impact on modal shift and on public transportation use.

Communities considering implementation of a GRH program should develop a written policy identifying how the program will serve them. The policy should show that emergency transportation will be fast, convenient, and at what cost, if any, to the user. Eligibility requirements, valid reasons for use of the service, registration requirements, and restrictions must all be addressed. The policy should identify the maximum number of trips permitted per year, any limitations on mileage, the transportation options available, and the maximum cost per trip. Requirements should not be overly restrictive to encourage maximum participation in the program. Some nonemergency trips should qualify for GRH to encourage more commuters to choose non-SOV modes. Potential users, which can be defined as all commuters, should be involved in the planning process to ensure a design that is most attractive to the largest number of commuters.

Every year, more communities realize that GRH programs may serve as an incentive for commuters to leave their cars at home and use public transportation and other non-SOV modes. This should continue to increase transit ridership and other non-SOV modes of commuting, and contribute to reduced levels of congestion. 


\begin{tabular}{|c|c|c|c|c|c|c|c|c|c|c|c|c|c|c|c|c|c|c|c|c|c|c|c|}
\hline 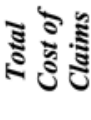 & & 空 & 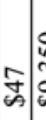 & 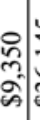 & 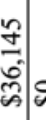 & \& & 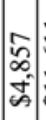 & $\overrightarrow{0}$ & & $\begin{array}{l}0 \\
\vdots \\
\vdots \\
\vdots \\
\leftrightarrow\end{array}$ & 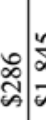 & 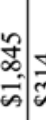 & 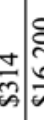 & 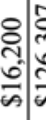 & \begin{tabular}{l}
$\infty$ \\
$\infty$ \\
\multirow{N}{*}{} \\
\multirow{\sim}{*}{}
\end{tabular} & în & 点 & ڤิ| & ભૂ & \& & $\mid \begin{array}{c}5 \\
\vdots \\
\vdots \\
a \\
\end{array}$ & 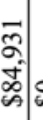 & \& \\
\hline 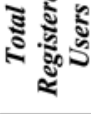 & 8 & సิ & $\vec{\beth}$ & $\begin{array}{l}\underset{N}{N} \\
\text { mis }\end{array}$ & ํํㄴ & 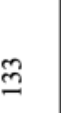 & 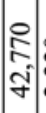 & సે & ही: & ㄱ. & 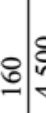 & 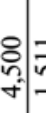 & $=$ & 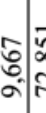 & : & $\mid \begin{array}{l}\overline{\hat{O}} \\
\hat{\mathrm{v}}\end{array}$ & त्र & 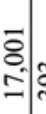 & ભૂ & $\widehat{b}$ & $\bar{a}$ & 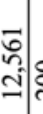 & હ્స \\
\hline 胥 & $m$ & $N$ & $\nabla$ & ○. & c. & 0 & (०). & $\nabla$ & $m:$ & & 큳 & $N$ & $+\lesssim$ & 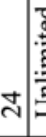 & N & 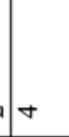 & + & ○. & + & $\nabla$ & $\infty$ & $n$ & F \\
\hline $\begin{array}{l}5 \\
5 \\
5 \\
5\end{array}$ & $\stackrel{\circ}{\circ}$ & ఫे & ○ุ & 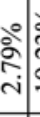 & ஸิ่ & 0 & ঐे & 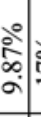 &  & 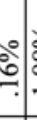 & 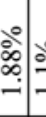 & ¿ْ & ลे & לें & $\frac{\circ}{6}$ & 家 & คిำ & : & i̊ & 0 & خे. & 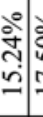 & مُ \\
\hline 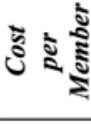 & $\begin{array}{l}\infty \\
\infty \\
\dot{\infty}\end{array}$ & के & $\frac{9}{4}$ &  & $\frac{0}{\mathrm{c}}$ & 0 & $=$ & 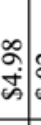 & 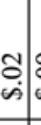 & sid & $\frac{2}{\dot{s}}$ & $\overrightarrow{0}$ & $\begin{array}{c}\overrightarrow{0} \\
\dot{\omega}\end{array}$ & 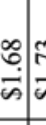 & 숑 & $\begin{array}{l}\infty \\
0 \\
0 \\
0\end{array}$ & શิ & $\begin{array}{c}n \\
\\
\\
\end{array}$ & $\begin{array}{l}\curvearrowright \\
\infty \\
\dot{\leftrightarrow}\end{array}$ & 0 & ڤ్ & 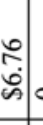 & 0 \\
\hline కั & 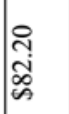 & 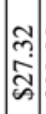 & $\begin{array}{l}\infty \\
\text { ñ. } \\
\\
\end{array}$ & ڤి. & $\begin{array}{ll}0 \\
+ \\
0 \\
0 \\
0 \\
0\end{array}$ & 0 & 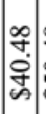 & \&. & $\begin{array}{l}\infty \\
\stackrel{\infty}{5} \\
\dot{\square}\end{array}$ & 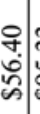 & 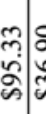 & 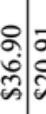 & $\bar{\sigma}$ & & ঠे & $\frac{a}{n}$ & 水 &  & $\begin{array}{l}\sqrt{n} \\
n \\
n \\
n\end{array}$ & 0 & $\begin{array}{l}\text { న. } \\
\text { స่ }\end{array}$ & के & \\
\hline 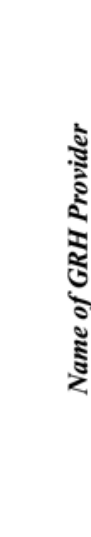 & 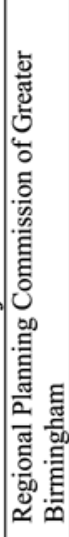 & 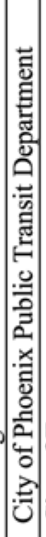 &  & 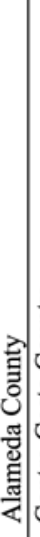 & | & 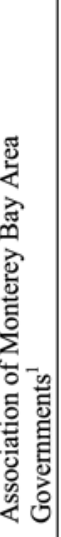 & 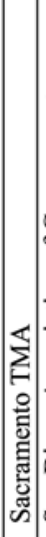 & 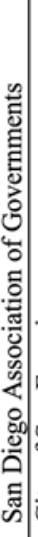 &  & 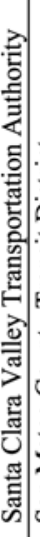 & 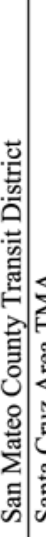 & 施 &  & 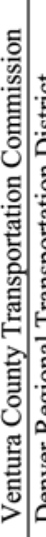 & 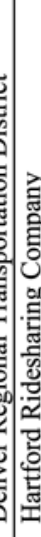 &  & $\mid$ & 苟 & 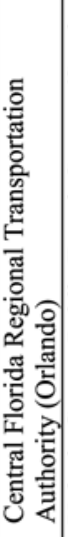 & 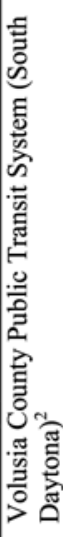 & 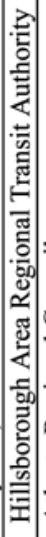 &  & 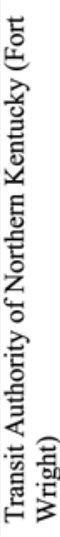 \\
\hline ฟัँ & $\frac{1}{4}$ & $\frac{N}{4}$ &  & & 0 & U & త & & & &  & & & తు & 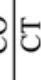 & Ua & 㭊 & 可边 & $\overrightarrow{|r|}$ & 至 & 실. & త্ & $\sqrt{2}$ \\
\hline
\end{tabular}




\begin{tabular}{|c|c|c|c|c|c|c|c|c|c|c|c|c|c|c|c|c|c|c|c|}
\hline ป气 & \& & 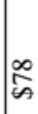 & $\begin{array}{l}\tilde{\infty} \\
\tilde{\infty} \\
\tilde{\kappa}\end{array}$ & 空 & \& & & & İ & $\frac{\infty}{\infty}$ &  & $\frac{8}{\infty}$ & \& & $\frac{d}{\infty}$ & 考? & $\begin{array}{c}\infty \\
\text { L } \\
\text { in }\end{array}$ & ల్ల & & బ, & $\frac{\mathscr{N}}{\stackrel{n}{A}}$ \\
\hline 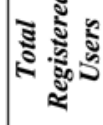 & స్. & $\mathscr{\sigma}$ & $\begin{array}{l}\tilde{N} \\
\infty \\
-\end{array}$ & নั & $\simeq$ & กิ| & ț & క. & : & ลू. & ৪্ণ & ¿̊ & ్ి & : & $\begin{array}{l}\text { స్ } \\
\text { తి }\end{array}$ & $\infty$ & & : 20 & $\stackrel{m}{\stackrel{m}{2}}$ \\
\hline 誌: & t & o & $\cong$ & $n$ & $\nabla$ & $\nabla$ & $\nabla \nabla$ & ton & $N$ & 0 & 0 & 畩 & $\nabla$ & + & $\nabla$ & \& & & $+\mid$ & $\infty$ \\
\hline : & مْ & 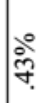 & 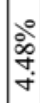 &  & & 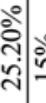 & ำ & مَ & : & 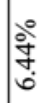 & $\varrho^{\circ}$ & 0 & लें & $\mid$ & & ִָ & & & :्ల \\
\hline
\end{tabular}

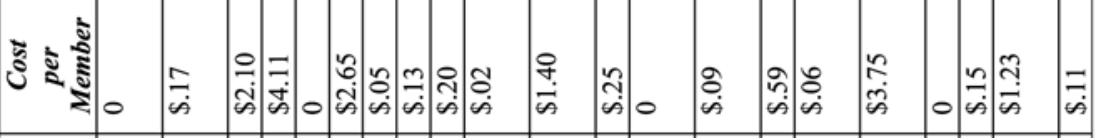



\begin{tabular}{|c|c|c|c|c|c|c|c|c|c|c|c|c|c|c|c|}
\hline  & 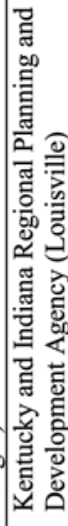 & \begin{tabular}{|c|c}
0 \\
0 \\
0 \\
0
\end{tabular} & 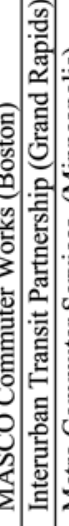 & 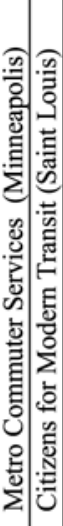 & \begin{tabular}{l|l}
3 & 0 \\
3 & 0 \\
0 \\
0
\end{tabular} & 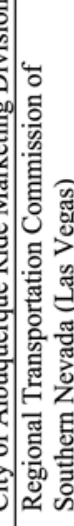 & 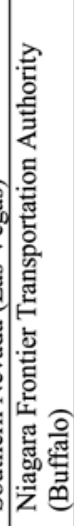 & 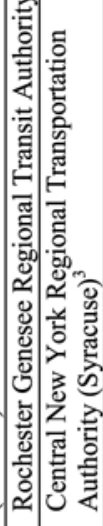 &  & & 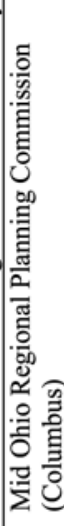 & 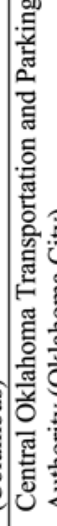 & $\frac{5}{5}$ & & 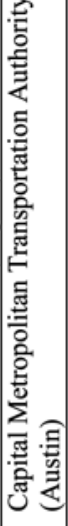 \\
\hline & & 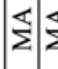 & $\Sigma|\Sigma|$ & $\sum \mid \stackrel{0}{\Sigma}$ & I0 & & z & そे| & 0 & & & & & & \\
\hline
\end{tabular}




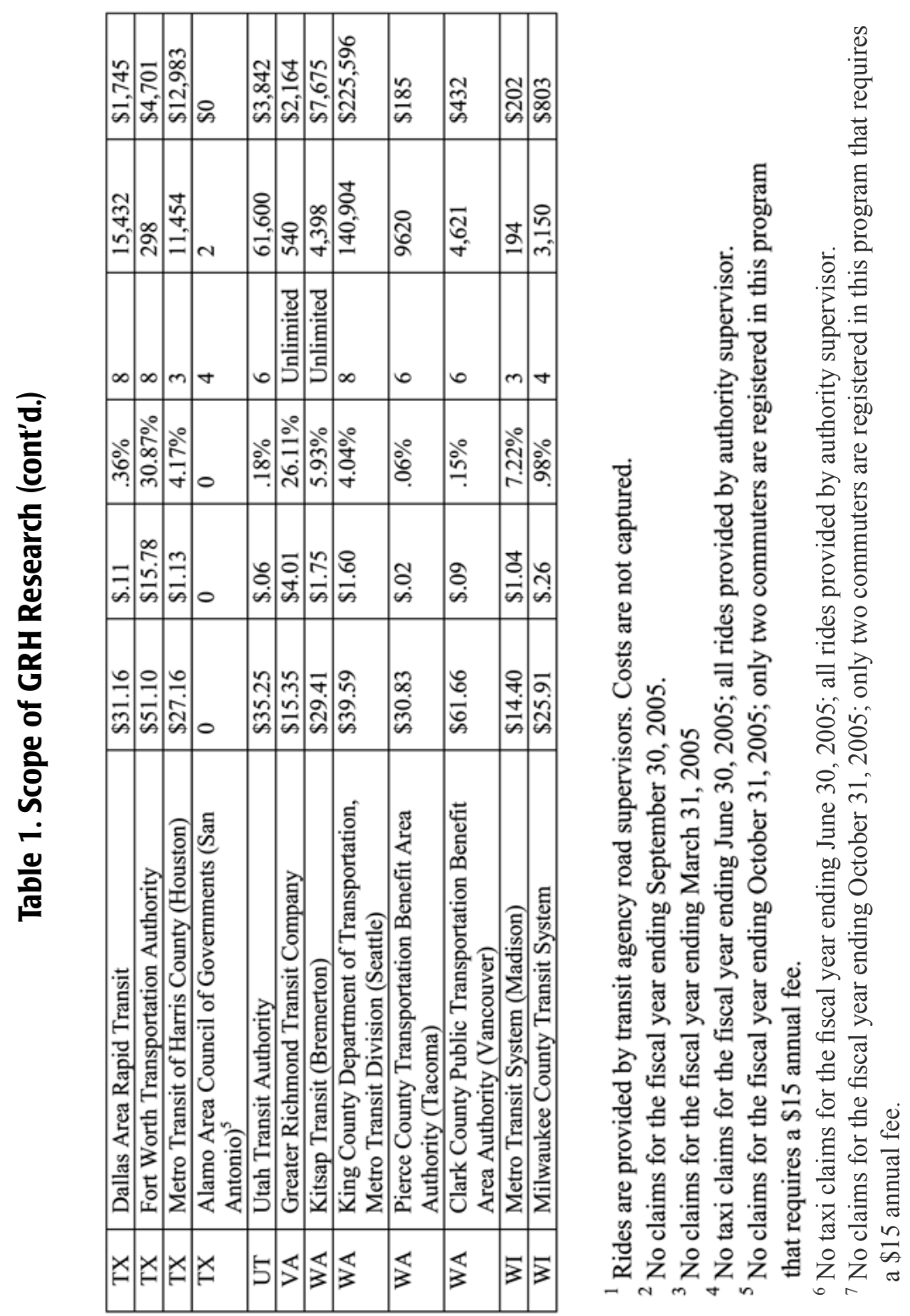




\section{References}

Comsis Corporation. 1994. A survey and analysis of employee responses to employer-sponsored trip reduction incentive programs. Sacramento, CA: California Air Resources Board.

Federal Reserve Bank of Saint Louis. 2005. Gross domestic product: Implicit price deflator.

Haas, Peter J. 2005. Ridership enhancement quick study. Washington, DC: Federal Transit Administration Report Number FTA-CA-26-7070-05.01.

Nelson/Nygaard Consulting Associates. 2005. Alameda County CMA guaranteed ride home program evaluation: Executive summary.

Vantage Marketing Research. 2003. Commuter transportation survey 2003. Denver, CO: Denver Regional Council of Governments RideArrangers.

\section{About the Author}

William B. MenCzer (William.Menczer@dot.gov) is the senior program analysis officer in the Office of Policy and Performance Management, Federal Transit Administration, U.S. Department of Transportation in Washington, DC. His previous management positions at FTA have included serving as the Acting Chief of the Performance Management Division, as the Director of the Office of Policy Development, and as the Director of the Office of Oversight. He received his Masters degree in public administration from the Maxwell School of Citizenship and Public Affairs at Syracuse University. His research has focused on internal and external factors that impact public transportation ridership, travel demand management, and qualified transportation fringe benefits. He has published numerous articles on these subjects in magazines, in international conference proceedings, and in the FTA website. 
Journal of Public Transportation, Vol. 10, No. 4, 2007 


\title{
Examining Incentives and Preferential Treatment of Carpools on Managed Lane Facilities
}

David Ungemah, Ginger Goodin, Casey Dusza, Texas Transportation Institute Mark Burris, Texas A\&M University

\begin{abstract}
As managed lanes $(M L)$ are considered throughout more than 25 North America cities, there is a need for guidance in defining the role of carpools in tolled ML and the trade-offs between carpool exemptions and other project objectives. Increasingly, project objectives are reflecting not only mobility concerns but the need to generate revenue as well. As a result, allowing exempt or discounted users, such as carpools on priced-ML requires an evaluation of revenue impacts as well as mobility interests such as person movements, operations, and emissions.

This article highlights the existing body of knowledge regarding carpooling, facilities, and incentives designed to encourage carpooling and carpooling's contributions to society. Following a review of literature, state and regional entities involved in either operating existing ML facilities or planning for new facilities were interviewed to determine the rationale for setting their carpool policies.
\end{abstract}

\section{Introduction}

The concept of tolling on managed lanes $(\mathrm{ML})$ has evolved since the first iterations in the early 1990s. Initially conceived as the allowance of previously prohibited vehicles to high occupancy vehicle (HOV) lanes in exchange for the payment of a 
fee, otherwise known as high occupancy/toll (HOT) lanes, ML have expanded in scope to include a variety of implementations, without any inherent policy regarding HOVs.

Of particular interest are those implementations that feature the collection of toll revenue in return for use of the ML facility. Originally perceived under one of two applications-HOT lanes or express toll lanes (ETL) - ML are studied and implemented with many operational variants. The broad definition of ML not only includes these variants, but any application that involves system-management techniques such as time-of-day restrictions, vehicle-type restrictions, and value pricing. In addition to HOT lanes and ETL facilities, common types of ML in the United States are HOV lanes, truck-designated lanes, and limited-access express lanes.

Of these, HOV lanes have a longer history of operations in North America than HOT lanes and ETL facilities. First implemented on Virginia's Shirley Highway (I$395)$ in 1969 as an exclusive busway, the concept of HOV lanes was born when four-or-more person carpools and vanpools were permitted access to the facility in 1973. Initiated during a time of high fuel costs, fuel shortages throughout the United States, and public concerns regarding mobility, HOV lanes provided yet another incentive to carpool or vanpool. Although the magnitude of travel-time savings offered by HOV lanes has been studied, the role of HOV-lane-related incentives relative to other incentives to carpool has rarely received the same attention. Nationally, since 1993, vehicle miles traveled (VMT) have increased 25 percent, while the percentage use and absolute number of carpools and vanpools for commute trips has declined to a 30-year low-10,057,000 trips in 2003, down from 11,852,000 in 1993 (Bureau of Transportation Statistics 2005). In the same 10-year time frame, $\mathrm{HOV}$-lane miles have more than doubled, from approximately 1,300 lane miles in 1995 to more than 2,500 in 2000, and 3,100 in 2005. The majority of these HOV-lane miles are located in California (1,000), Georgia (400), and Texas (300) (Fuhs and Obenberger 2002).

In many ways, HOV lanes are selling an uncongested carpool trip in the HOV facility against the possibility of recurring congestion in adjacent general-purpose lanes. The expectation, in return for accepting inconvenience associated with the trip, is that the use of the HOV lane will provide some travel-time savings. As a result, carpooling rates have increased significantly within HOV corridors (more than $100 \%$ ) even as carpool rates nationwide have declined (30\%) during the past two decades (Stockton 1999). However, severe congestion in the general-purpose lanes have tended to cause animosity on the part of the general public toward 
HOV lanes if they are underutilized (Fuhs and Obenberger 2002). As a means of mitigating the "empty lane syndrome," HOT lanes have been promoted as an effective way of utilizing the excess capacity without yielding the HOV lanes' travel time advantages (Swisher 2002).

In addition to HOT lanes, which imply maintenance of HOV operations, ETL concepts have also been promoted as a means of enhancing mobility within congested corridors and regions. First implemented in Orange County, California, as the privately built and operated State Route 91 (SR-91) express toll corridor, ETL facilities provide the same benefits of HOT lanes (exclusive right-of-way with congestion-free trips along the length of the corridor), but they do not carry the same implied benefit to carpools and vanpools. The SR-91 express toll facility has, at times, provided free use by three-or-more $(\mathrm{HOV}-3+)$ people, but has also at other times required partial toll payment by these users in the past eight years of operations. Although SR-91 is the only ETL facility currently in operation, ETL concepts are more attractive than HOT lanes for those transportation agencies seeking enhanced sources of revenue and ease of enforcement.

As $M L$ are considered throughout more than 25 North American cities, there is a need for research and guidance in defining the role of carpools in tolled $M L$ and the trade-offs between carpool exemptions and other project objectives. Increasingly, project objectives are reflecting not only mobility concerns but funding deficiencies and the need to generate revenue. As a result, allowing exempt users such as carpools requires an evaluation of revenue impacts as well as mobility interests such as person movement, operations, and emissions.

\section{Carpooling and HOV Lanes}

HOV lanes and carpooling have an overlapping purpose: Encourage greater person throughput through greater vehicle occupancies. By encouraging people to rideshare, particularly during peak periods, person throughput on congested corridors can increase without a corresponding significant increase in capacity. Since the 1970s, HOV lanes have been implemented with the explicit purpose of encouraging the formation of new carpools and enhancing the performance of transit through a significant, reliable travel-time incentive.

\section{Carpool Formation}

Although distinction is made between regular carpools (recurring, scheduled carpools) and occasional carpools (situational carpools only), the basics of carpooling 
has remained the same for 60 years - a minimum of two people with common commute patterns share one vehicle for their trip. Carpooling itself requires no public investment, as the decision to carpool remains a private one. However, advocates for governmental and commercial encouragements to carpool rationalize that, "Every person added to a carpool means another congestion- and pollution-causing car is taken off the road" (The Rideshare Company 1999). As practice holds, if commuters are presented a large enough incentive to switch from driving alone to carpooling, they may form a carpool either formally (through a matching service and/or agreement) or causally (through situational agreement).

Ridematching serves as the basis for formal carpooling and has been actively conducted for 30 years. Deployed at either regional or employer levels, formal programs may be administered by employers, transit organizations, or rideshare agencies, with overlap common. For example, a regional rideshare program may offer promotional activities and incentives through participating employers. Commuters provide information to the rideshare agency that assists in matching riders together, such as work hours, vehicle availability, location of residence, and location of employment if in the case of a nonemployer rideshare program. Typically, successful formal carpooling depends on a similar employment destination, so areas with high employment densities are more aptly suited to carpool promotions than those areas with dispersed employment (Turnbull, Turner, and Lindquist 1995; Department of Environmental Quality 2000; Best Workplace for Commuters 2005). Successful ridesharing occurs only when a variety of factors are met: potential riders should:

1. live near each other,

2. travel a sufficient distance to work so that the time required for pick up and drop off does not significantly add to the total commute time,

3. either work together or within a short distance of one another,

4. have agreeable working hours to carpool schedules, and

5. have consistency in use of carpools (Turnbull, Turner, and Lindquist 1995; Department of Environmental Quality 2000).

Casual or "slugging" carpool formations began in the late 1970s and have since emerged in Virginia, California, and Texas. Not officially administered or sanctioned by governmental entities, slugging involves drivers picking up a random carpool partner to access HOV lanes at preidentified locations (Burris and Winn 2006; Slug-Lines.com 2005). Casual carpooling avoids prearrangement and fixed 
schedule hassles of formal carpooling, but does add a layer of uncertainty and risk for drivers and riders alike (Environmental Defense 2002).

Studies have shown there are three main reasons commuters switch from driving alone to ridesharing (either carpools or vanpools):

- Travel time. Research indicates that commuters are likely to alter their commute choice if it reduces their commute time. As driving alone is typically the quickest means from home to work (or the reverse), total travel time is one factor that makes driving alone attractive to drivers (Turnbull, Turner, and Lindquist 1995; Crain and Associates 1978; Valdez and Arce 1990; Cervero and Griesenbeck 1998). HOV lanes have been shown to reduce travel time, thereby making carpooling more appealing and counteracting the disposition toward driving alone (Cervero and Griesenbeck 1998; Bullard 1991; Turnbull 1992a).

- Convenience. Studies have also confirmed convenience is a factor in determining mode choice. Driving alone is seen as the most convenient mode for many commuters. However, this can change if employers or municipalities have carpooling incentives in place, making carpooling more suitable for their needs, such as conveniently located parking spaces reserved for carpoolers (Turnbull, Turner, and Lindquist 1995; Crain and Associates 1978; Valdez and Arce 1990; Cervero and Griesenbeck 1998; Turnbull 1992b; Strgar-Roscoe-Fausch, Inc. 1995).

- Cost. Although many commuters do not use the most cost-effective commute choice, it is an influential factor. Cost savings can be realized simply through the sharing of costs between driver and passenger(s), although additional financial incentives and subsidies may be offered by governmental and/or employer entities. This is especially true with vanpool programs (Cervero and Griesenbeck 1998; Turnbull 1992b; Strgar-Roscoe-Fausch, Inc. 1995). Researchers note that free or low-cost parking tends to influence a greater use of single-occupant vehicles (SOV; Turnbull 1992b).

\section{Effectiveness of HOV Incentives}

\section{Benefits}

Benefits from carpooling, which HOV lanes endeavor to encourage, can be articulated for both users and society. 
User benefits include personal cost savings and perceived quality-of-life enhancements. Many commuters underestimate the true cost of driving alone to and from work. The cost of commuting may be significantly reduced when carpoolers or vanpoolers share the costs. This is especially true in situations with added costs, such as parking fees and tolls, in addition to fuel (Model Transportation Demand Management Program 1996; Littman 2005). Commutes are increasingly becoming too congested and stressful, which can be carried over into professional and social situations. Carpooling enables riders to relax and allows them to arrive at their destination without the stress of driving (Model Transportation Demand Management Program 1996; Pollution Probe 2001).

Societal benefits are most typically associated with reduction in vehicular use (and corresponding reduction in VMT) and a resulting improvement in air quality. In areas of serious air quality concerns, carpooling and HOV lanes together constitute important elements in achieving conformity with air quality targets (Committee for the Congestion Mitigation and Air Quality Improvement Program 2002). Coupled with the perception of HOV lanes and carpooling as enabling broader environmental objectives (including fuel consumption goals), a significant stakeholder community has been formed around their continued use and promotion (Fuhs and Obenberger 2002).

\section{Effectiveness of Incentives}

Although air quality benefits are the primary reason for regional and statewide financial investment in rideshare incentive programs (most notably, through the Congestion Mitigation and Air Quality [CMAQ] program), the benefits' estimation for conformity purposes lacks consistent application throughout the United States. Communities may directly model trip-reduction and VMT-reduction benefits of ridesharing and HOV lanes, produce estimates off-model, or directly measure the results of implemented programs (Committee for the Congestion Mitigation and Air Quality Improvement Program 2002). Altogether, the variety of estimation methodologies yields a noticeable lack of measurement of the direct benefits of ridesharing on air quality. Various research efforts have attempted to evaluate the pollutant and travel reduction effectiveness of HOV incentives (including HOV lanes), but this research has yet to provide solid evidence of the longitudinal impacts of these incentives either on a regional or sitewide scale-a factor which may be important in the consideration of HOV benefits for managed lanes. 
As evaluated within the literature, the effectiveness of rideshare incentives depends on the following factors:

- type and degree of incentive,

- affected area, and

- extent of concurrent supporting strategies.

The type and degree of incentive pertains to what strategy is deployed and how much resources are applied to that strategy. For the affected area factor, the effectiveness of a strategy will differ depending on the comparative scale-an extremely successful employer-based vehicular-reduction program may not even be measurable within a half-mile radius of the employer. As evaluated in the literature, almost all programs have less than a 1 percent affect on regional tripmaking (Cambridge Systematics, Inc. 2000; Ferguson 2000). In regard to the third factor, the effects of HOV incentive programs are not mutually exclusive from one another. Often, a combination of strategies is present when modal use is measured, complicating the isolation of strategies for effectiveness.

Two cross-cutting efforts serve as the principal body of knowledge regarding HOV incentive effectiveness-one in 1994 and the other in 2002 (Committee for the Congestion Mitigation and Air Quality Improvement Program 2002; Apogee Research, Inc. 1994).

The former study involved a bounty of data primarily accumulated by the State of California during a period of mandated trip reduction efforts. The results of this data analysis were used to create a post-process model for the Federal Highway Administration (FHWA), known as the TDM Model. To this day, the TDM Model remains the only official model for evaluating the regional impacts of various rideshare promotion and incentive activities, including HOV lanes (although subsequent models from the Environmental Protection Agency and Center for Urban Transportation Research have addressed work site and subarea evaluation of TDM). However, since the early 1990s, all states with the exception of Washington have eliminated the use of mandated commute trip reduction programs. As a result, the effectiveness of ridesharing programs has diminished with solely voluntary adoption.

Evaluating work-site-based and regional travel data, the 1994 study concluded that rideshare incentives could potentially eliminate up to 2 percent of regional VMT and 1 percent of regional trips (if applied regionally) or up to 3 percent of VMT and 4 percent of trips when promoted at employment sites. HOV lanes 
alone can provide up to 1 percent of regional VMT reduction and 0.5 percent of regional trip reduction (Apogee Research, Inc. 1994). At first glance, it appears that rideshare incentives are more effective than HOV lanes; however, it should be noted that:

- HOV lanes' regional impact is affected primarily within particular corridors (unlike rideshare programs, which have a regional scope); and

- additional studies have identified a synergistic relationship between rideshare programs and HOV lanes, in so much that the likelihood of carpooling as a result of an HOV incentive program increases with the availability of HOV lanes (Littman 2005; Ferguson 2000; Schreffler 2004).

The 2002 study pertained to a review of data submitted by regional and statewide entities currently participating in the CMAQ improvement program. For most very large and large metropolitan areas, and some medium-sized areas, CMAQ provides a significant amount of funding for rideshare programs. Examining evaluation studies of CMAQ programs where the methodology of evaluation was considered sufficiently robust, the 2002 Transportation Research Board (TRB) study of cost effectiveness from CMAQ projects found that rideshare and TDM programs (which provide the bulk of incentives for HOV use) tend to be among the more cost-effective of CMAQ projects, yet the extent of effectiveness is cautiously positioned (Committee for the Congestion Mitigation and Air Quality Improvement Program 2002).

In a parallel assessment of CMAQ projects using data provided in the 2002 TRB report, an Arizona Department of Transportation report identifies the comparative relationship between HOV facilities and other strategies for the cost of air quality improvement. In this analysis, carpool and vanpool promotion programs, including cost subsidies and other incentives, are shown to be far more cost effective in reducing pounds of volatile organic compounds (pollutants) than HOV facilities. However, as noted in the report, the effectiveness of those rideshare and TDM programs is enhanced with the availability of HOV facilities (Schreffler 2004).

\section{Challenges}

Since the 1980s, when earnest planning for HOV lanes was taking place throughout the country, carpooling itself has declined significantly, both in absolute numbers of commuters as well as in percentage of overall population (Bureau of 
Transportation Statistics 2005). As shown in Table 1, declines have occurred consistently as measured by the Bureau of Transportation Statistics.

\section{Table 1. National Principal Means of Transportation to Work (person trips, thousands)}

\begin{tabular}{|l|c|c|c|c|c|c|c|}
\hline & $\mathbf{1 9 8 5}$ & $\mathbf{1 9 8 9}$ & $\mathbf{1 9 9 3}$ & $\mathbf{1 9 9 7}$ & $\mathbf{1 9 9 9}$ & $\mathbf{2 0 0 1}$ & $\mathbf{2 0 0 3}$ \\
\hline $\begin{array}{l}\text { Drive } \\
\text { alone }\end{array}$ & $\begin{array}{c}72,137 \\
(72.4 \%)\end{array}$ & $\begin{array}{c}81,322 \\
(76.3 \%)\end{array}$ & $\begin{array}{c}79,449 \\
(76.6 \%)\end{array}$ & $\begin{array}{c}90,207 \\
(77.5 \%)\end{array}$ & $\begin{array}{c}92,363 \\
(78.2 \%)\end{array}$ & $\begin{array}{c}93,942 \\
(78.2 \%)\end{array}$ & $\begin{array}{c}91,607 \\
(79.4 \%)\end{array}$ \\
\hline HOV (all) & 14,011 & 12,621 & 11,852 & 11,701 & 11,104 & 11,644 & 10,057 \\
& $(14.0)$ & $(11.8)$ & $(11.4)$ & $(10.1)$ & $(9.4)$ & $(9.7)$ & $(8.7)$ \\
\hline HOV-2 & 10,381 & 9,708 & 9,105 & 9,294 & 8,705 & 9,036 & 7,866 \\
& $(10.4)$ & $(9.1)$ & $(8.8)$ & $(8.0)$ & $(7.4)$ & $(7.5)$ & $(6.8)$ \\
\hline HOV-3 & 2,024 & 1,748 & 1,684 & 1,526 & 1,454 & 1,635 & 1,351 \\
& $(2.0)$ & $(1.6)$ & $(1.6)$ & $(1.3)$ & $(1.2)$ & $(1.4)$ & $(1.2)$ \\
\hline HOV-4+ & 1,606 & 1,165 & 1,063 & 881 & 945 & 973 & 840 \\
& $(1.6)$ & $(1.1)$ & $(1.0)$ & $(0.8)$ & $(0.8)$ & $(0.8)$ & $(0.7)$ \\
\hline
\end{tabular}

Source: Bureau of Transportation Statistics 2005.

Critics of HOV lanes claim carpooling as a choice of mode of travel for work peaked at the time when HOV-lane planning hit its stride, thereby exacerbating the rationale for continuing to offer HOV-lane incentives to carpools. Potential reasons for the decline in carpooling may include an increase in disposable income, increase in car ownership, dispersed employment locations, trip-chaining, and availability of in-car entertainment (Poole and Balaker 2005).

This criticism is valid from the perspective of home-based-work (HBW) trips, which is the type of data provided by the Census. In a comprehensive side-byside analysis of Journey to Work (Census) and National Household Travel Survey (NTHS) data, however, one author identifies distinctions between HBW trips and what was called "work tour" trips, a term which attempts to aggregate trip chaining into one consolidated work trip (as the primary purpose). Using 2001 NHTS data, approximately 20 percent of work tours (trips that are not simply HBW trips, but rather also involves a pick-up or drop-off at some point between home and work) and only 12 percent of commute trips were by carpool (McGuckin and Srinivasan 2005). This indicates there is a greater percentage of the population that uses carpool modes for the work trip (meaning, these are not HBW trips, as the 
trip involves a pick-up or drop-off at some point between home and work). What this research does not indicate, however, is what proportion of the work trip is as a carpool. Further investigation into current carpooling trends indicates that the majority of carpools are family oriented, a type of carpooling termed "fam-pools" (Poole and Balaker 2005). Only 26 percent of all 2001 work tour carpools involved a nonhousehold member, compared to 74 percent involving a family member.

Critics have argued that the extensive amount of household-member-only carpooling for work trips belies the premise behind investments in HOV lanes-that it will encourage the formation of carpools between two drivers, explicitly to take advantage of the travel time savings in the HOV lanes:

That fampooling does not take cars off the street is particularly evident when HOV lanes are used by drivers whose passenger is someone who, for a variety of reasons, would not be driving anyhow. For example, it is certainly convenient for a parent driving with a son or daughter to use the carpool lane, but as long as the son or daughter is under the legal driving age, this sort of carpool does not spare the road from an extra car. (Poole and Balaker 2005)

Fam-pooling criticism implies that family members who carpool would do so with or without the presence of HOV lanes and other incentives. However, counterargument suggests that familial carpools (particularly involving two or more adults) are perfectly legitimate to the extent those family members would otherwise drive separately.

Regions with significant HOV facility investments have not been immune to declines in carpool rates. In Southern California, representing the greater Los Angeles metropolitan region, carpooling as a share of work trips declined from 14.3 percent to 11.4 percent since 2000, despite the availability of more than 350 route miles of HOV lanes (Chang 2005; Fuhs 2005). Similarly, the San Francisco Bay Area, with more than 150 route miles of HOV lanes, declined from a peak of 19 percent of commuters by carpool in 1995 to 14 percent in 2005 (Fuhs 2005; RIDES for Bay Area Commuters 1998; RIDES Associates 2005). Ideally, ML operators will evaluate HOV use effectiveness per facility (reflecting localized demand); however, the emerging context of regional policy making for $\mathrm{ML}$ (as evidenced by efforts in the Bay Area, Puget Sound region, Dallas/Ft. Worth area, and others) indicates that regional metrics will be as important as localized metrics. 


\section{The State of the Practice in Applying Carpool Incentives to $\mathbf{M L}$}

Given the evolution of HOV facilities to ML over the last decade and the level of activity in development of $M L$ projects nationally, there is still very little in the way of research and guidance defining the role of carpools and the trade-offs between carpool preference and other project objectives. A study of HOV treatments on toll facilities concluded that HOV pricing strategies and priority treatments are being utilized on a variety of toll facilities in the United States, although information on utilization levels and mode choice influences were very limited (Turnbull 1994). In examining the ML projects in operation today, decisions related to carpool preference have been based largely on policy decisions with little basis in quantitative analysis (Collier and Goodin 2004).

To obtain a current picture of HOV policies on ML facilities-both active and pending implementation-state and regional agencies involved with ML were contacted in January and February 2006 (Denver's project opened in June 2006, so it is reported as an "active" facility, although at the time of interview, it was still pending). Each responding entity, aggregated by region, compiled their communities' interests and pursuits regarding HOVs.

\section{Overview of Metropolitan Areas}

Figure 1 provides an overview of the various regions' approaches toward the tolling of HOVs on ML facilities. Note that the San Francisco Bay Area is different from the other implementations in that HOV discounts are applied on toll bridges with HOV lanes feeding the bridges. Although this is not a ML under conventional definitions, the resulting travel time and toll advantages on the HOV user proxies the effect of $M L$; hence, they are included in this analysis.

As shown in Figure 1, a few patterns emerge from the responses:

- All facilities toll or intend to toll SOVs. Houston has been the only community that has experimented with HOV-2 tolling, with no access to SOVs by toll. However, the reconstruction of the HOV facility on I-10 (opening 2008/2009) will provide sufficient capacity to permit tolled access to both HOV-2 and SOV.

- Most facilities provide free access to HOV-3+. The only exceptions to this policy are Orange County, California (where demand on the 91 Express Lanes is sufficiently high in the eastbound direction to require a discount toll in the PM peak period instead of free passage); Denver's (Colorado) C-470 


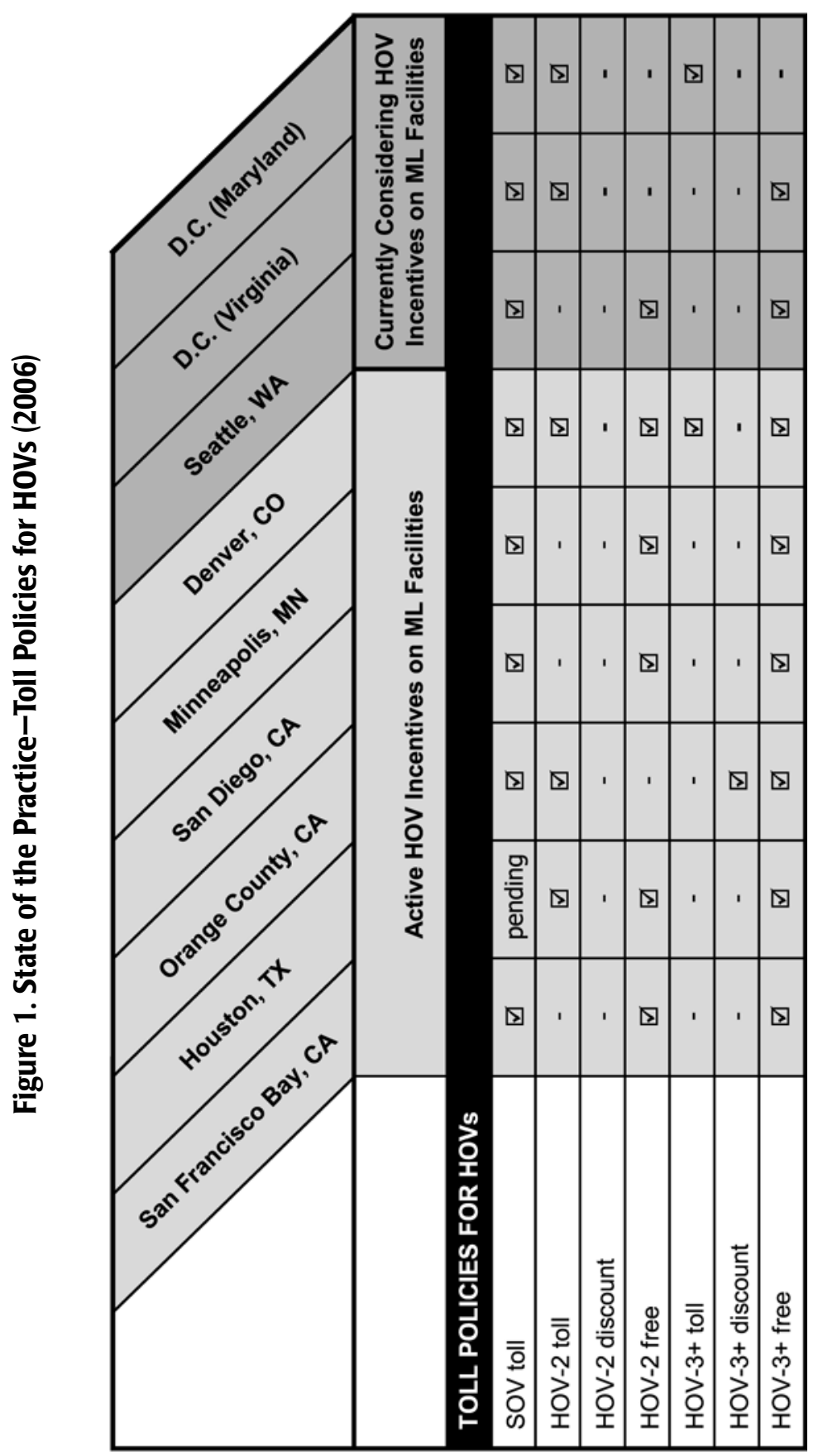


Express Lanes (for which HOV-3+ policies have not yet been finalized, but environmental documentation indicated all vehicles may be tolled regardless of occupancy); and Maryland (which intends to toll all vehicles on $\mathrm{ML}$ statewide without regard to occupancy).

- In general, HOVs either pay the full toll or travel toll free. Only one facility, the 91 Express Lanes, pursues a half-toll policy for HOVs. No other facility featured in the surveyed communities has adopted or intends to adopt a similar policy for either HOV-2 or HOV-3+.

- Most communities have a standard HOV toll policy. With the exception of the Denver area, where the $\mathrm{I}-25$ and $\mathrm{C}-470$ facilities provide differential rates and access to HOV-2 and HOV-3+, and the D.C. area, where Maryland and Virginia will have different HOV toll policies, all other communities generally have standardized their HOV toll policies across the region-either by intent or by default.

Figure 2 offers each region's responses to factors potentially impacting regional and/or corridor decisions for HOV-2 or HOV-3+ toll policies. These factors may be constituted in official transportation policy or may reflect prevailing concerns of agency stakeholders in the development of $M L$ facilities per region. The scale for each factor is rated simply as "high importance," "moderate importance," and "low importance" in terms of its effects on decision making in the region.

Unlike the toll policies, these results do not lend themselves easily to overall trends. Two principal findings include:

- No factor uniformly rates as a high or low importance in regional decision making. This finding confirms that each region is different and has its own core issues to address in setting ML policies. Furthermore, the different importance values assigned to each factor suggests that nationally standardized criteria regarding HOV toll policies not only do not exist but are also inappropriate, relative to regional issues.

- Factors that rate consistently high or moderate across all corridors and/or regions include: enforcement of carpool vehicles, maximizing vehicular throughput, and uniformity/equity issues. The first two factors are invariably linked to one another. Ensuring adequate enforcement of carpool policies without cumbersome geometric solutions may help fulfill the objective of maximizing vehicular throughput. With enforcement, pricing responds directly to prevailing demand; without adequate enforcement, pricing must 


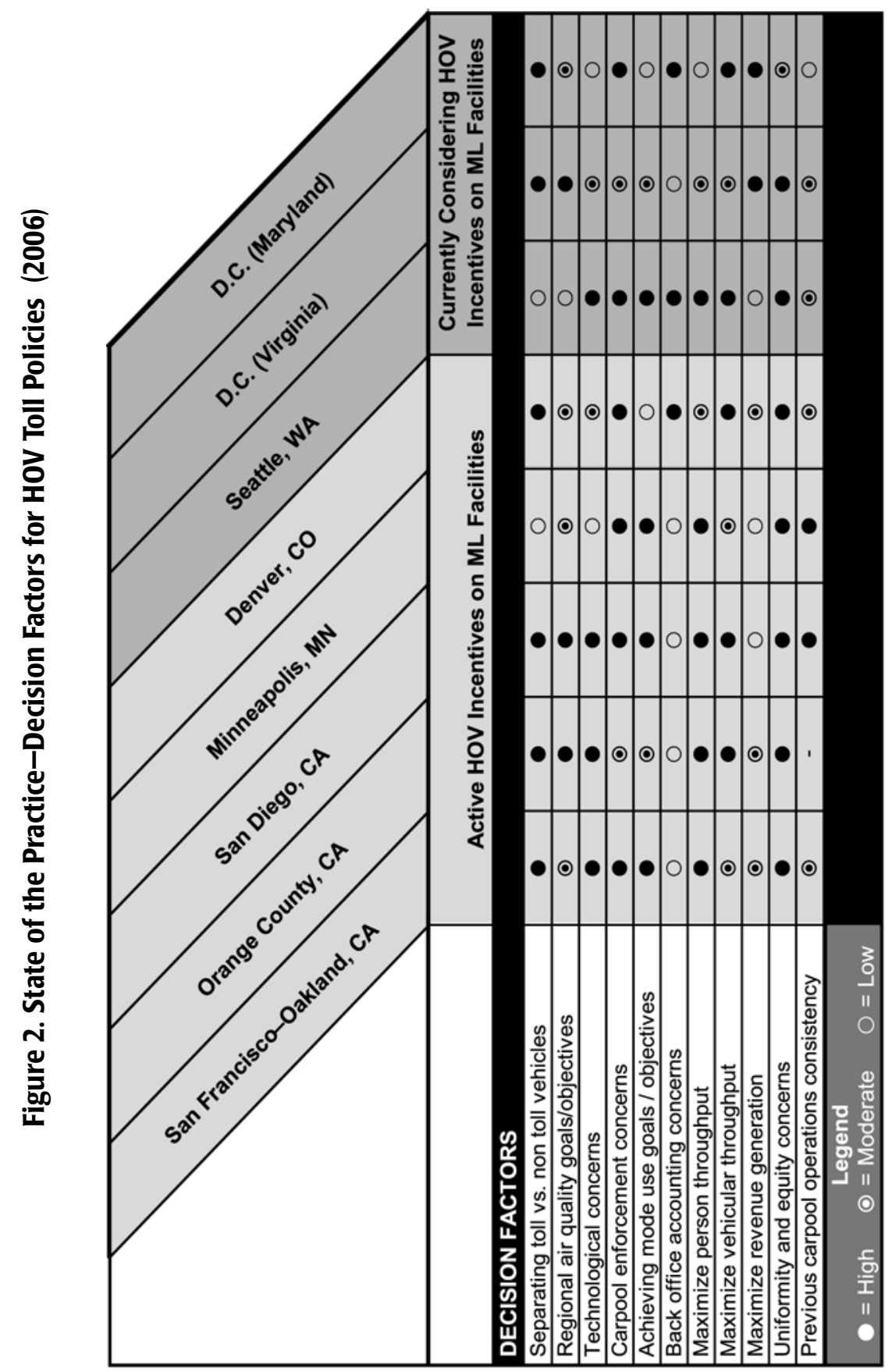


also account for violators, which distorts the price of entry. The final factors, uniformity and equity, suggest a policy issue that is rarely quantified in HOV preference: offering an HOV incentive not for air quality or modal use purposes, but rather to provide a toll-free alternative for potentially disadvantaged communities that is still consistent with regional transportation objectives.

\section{Conclusions}

Overall, the application and objectives of incentives for carpools in ML facilities differs widely across the United States. Although a nexus is found between the use of incentives (including cost incentives and other TDM activities) and HOV-lane usage, the evidence for priced $M L$ is less clear. Furthermore, when considering the effectiveness of carpool incentives relative to the decline in "acquaintance" carpools (as opposed to family carpools), policy-makers would be well advised to consider the overall contribution of incentives to the expressed objectives of the program.

The regional and state agencies interviewed for this research were consistent in rating high only a few guiding principles for carpool incentives: enforcement of carpool vehicles, maximizing vehicular throughput, and uniformity/equity issues. These three issues are generally considered outside the realm of consideration of TDM programs, whereby carpool incentives are initially set-these typically include air quality, person mobility, and accessibility to employment. This implies a disconnect between the expressed purpose of carpool programs on a regional basis, and, the application of carpool incentives on ML facilities. As regional planning processes consider the appropriate role of carpools on $M L$, efforts should be made to connect the objectives of regional demand management programs directly with policies as applied on ML.

\section{Acknowledgments}

The authors would like to thank the Texas Department of Transportation (TxDOT) for sponsorship of the research on which this article is based. The research was performed by the Texas Transportation Institute of the Texas A\&M University System and the University of Texas at Arlington. The contents of this article reflect the views of the authors, who are responsible for the facts and the accuracy of the 
data presented herein. The contents do not necessarily reflect the official views or polices of the Federal Highway Administration or TxDOT.

\section{References}

Apogee Research, Inc. 1994. Cost and effectiveness of transportation control measures (TCMs): A review and analysis of the literature. (January).

Best Workplace for Commuters. 2005. Carpool incentive programs: Implementing commuter benefits as one of the nation's best workplaces for commuters. U.S. Environmental Protection Agency, Office of Air and Radiation. (March). http://www.bwc.gov/pdf/carpool.pdf.

Bullard, D. L. 1991. An assessment of carpool utilization of the Katy high-occupancy vehicle lane and the characteristics of Houston's HOV lane users and nonusers. College Station, TX: Texas Transportation Institute.

Bureau of Transportation Statistics. 2005. National transportation statistics: 2005. U.S. Department of Transportation, 2005. http://www.bts.dot.gov/publications/national_transportation_statistics/2005/.

Burris, M. W., and J. R. Winn. 2006. Slugging in Houston-Casual carpool passenger characteristics. Journal of Public Transportation 9 (5).

Cambridge Systematics, Inc. 2000. Quantifying air quality and other benefits and costs of transportation control measures. Final Report. NCHRP Project 8-33.

Cervero, R., and B. Griesenbeck. 1998. Factors influencing commuting choices in suburban labor markets: A case study of Pleasanton, California. Transportation Researcher 22A (3): 151-161.

Chang, P. 2005. State of the region 2005: Measuring regional progress. Southern California Association of Governments. (December). http://www.scag.ca.gov/ publications/pdf/2006/SOTR05/SOTR05_FullReport.pdf.

Collier, T., and G. Goodin. 2004. Managed lanes: A cross cutting study. FHWA-HOP05-037. McLean, VA: Federal Highway Administration. (November).

Committee for the Congestion Mitigation and Air Quality Improvement Program. 2002. The congestion mitigation and air quality improvement program: Assessing 10 years of experience. Special Report 264. Transportation Research Board, National Academy Press. 
Crain and Associates.1978. San Bernardino freeway busway evaluation of mixedmode operations. Los Angeles, CA: California Department of Transportation.

Department of Environmental Quality. 2000. Guidance for estimating trip reductions from commute options. http://www.deq.state.or.us/NWR/ECO/checklst.pdf.

Environmental Defense. 2002. What are casual carpools? (February 11). http:// www.environmentaldefense.org/article.cfm?ContentID $=1363$.

Ferguson, E. 2000. Travel demand management and public policy. Burlington, VT: Ashgate Publishing Co.

Fuhs, C. 2005. Operational characteristics of selected freeway/expressway HOV facilities. Transportation Research Board HOV Systems Committee. (December). http://www.hovworld.com/hovinventory_assets/Hov\%20Operations\%201121-05.pdf.

Fuhs, C., and J. Obenberger.2002. HOV facility development: A review of national trends. Transportation Research Board HOV Systems Committee. (January). http://www.hovworld.com/PDFs/Fuhs_Obenberger-final\%20paper.pdf.

Littman, T. 2005. TDM encyclopedia: Ridesharing. Victoria Transport Policy Institute.(December 14). http://www.vtpi.org/tdm/tdm34.htm.

McGuckin, N., and N. Srinivasan. 2005. Journey to work in the context of daily travel. Transportation Research Board, Census Data for Transportation Planning Conference (May). http://www.trb.org/conferences/censusdata/ResourceJourney-to-Work.pdf.

Model Transportation Demand Management Program. 1996. Explore your commute options: It's the SMART thing to do. Detailed Program Description and Policy Guidelines. Washington State Department of Transportation. (June). http://www.wsdot.wa.gov/tdm/tripreduction/download/CTR_Manual.pdf.

Pollution Probe. 2001. SMART movement: Save money and air by reducing trips. Trip Reduction Manual. http://www.pollutionprobe.org/Reports/SMART.pdf.

Poole, R., and T. Balaker. 2005. Virtual exclusive busways: Improving urban transit while relieving congestion. Reason Foundation, Policy Study 337 (September). http://www.reason.org/ps337.pdf.

RIDES Associates. 2005. Commuter profiles 2005: Regional report. Metropolitan Transportation Commission (June). http://www.mtc.ca.gov/library/commute_profile/commuteprofile_2005.pdf. 
RIDES for Bay Area Commuters. 1998. Commuter profile 1998. Metropolitan Transportation Commission. http://www.mtc.ca.gov/library/commute_profile/commuteprofile_1998.pdf.

The Rideshare Company. 1999. Carpools a simple way to save time, money and the environment. http://www.commutersregister.com/ct/articles/9905/rslocal. htm.

Schreffler, E. 2004. Alternative modes as an air quality mitigation strategy. Report No. FHWA-AZ-04-566. (June). http://ntl.bts.gov/lib/24000/24800/24853/ AZ566.pdf.

Slug-Lines.com. 2005. About slugging. http://www.slug-lines.com/Slugging/ About_slugging.asp.

Stockton, W. R., G. Daniels (Goodin), D. Skowronek, and D. Fenno. 1999. The ABC's of HOV: The Texas experience. Texas Transportation Institute, Texas A\&M University. (September). http://www.hovworld.com/PDFs/1353-I.pdf.

Strgar-Roscoe-Fausch, Inc. 1995. I-394 phase III evaluation-final report. Minneapolis, MN: Minnesota Department of Transportation.

Swisher, M., W. Eisele, D. Ungemah, and G. D. Goodin. 2002. Life cycle graphical representation of managed HOV lane evolution. Committee on High Occupancy Vehicle Systems, 11th International HOV Conference. (October). http:// www.hovworld.com/PDFs/TRB2003-002138.pdf.

Turnbull, K. F. 1992a. An assessment of high-occupancy vehicle facilities in North America: executive report. College Station, TX: Texas Transportation Institute.

Turnbull, K. F. 1992b. High-occupancy vehicle project case studies: Historical trends and project experience. College Station, TX: Texas Transportation Institute.

Turnbull, K. F. 1994. High-occupancy vehicle (HOV) treatments on toll facilities. Transportation Research Record 1446.

Turnbull, K. F., P. A. Turner, and N. F. Lindquist. 1995. Investigation of land use, development, and parking policies to support the use of high-occupancy vehicles in Texas. College Station, TX: Texas Transportation Institute.

Valdez, R., and C. Arce. 1990. Comparison of travel behavior and attitudes of rideshare, solo drivers, and the general commuter population. Transportation Research Record 1285: 105-108. 


\section{About the Authors}

David Ungemah (d-ungemah@tamu.edu) has 13 years of experience in TDM and ML. Prior to joining the Texas Transportation Institute in 2005, Mr. Ungemah cofounded UrbanTrans Consultants, a firm specializing in TDM services. He received his undergraduate degree in political science from the University of Colorado and master of planning from the University of Minnesota. Mr. Ungemah is an active member of the TDM and Congestion Pricing committees of the Transportation Research Board, and currently chairs the HOV/HOT Council for the Association for Commuter Transportation.

GiNGer Goodin (g-goodin@tamu.edu) has more than 20 years of experience in transportation engineering and planning, with specialty in HOV and ML systems. She received both her undergraduate and graduate degrees in civil engineering from Texas A\&M University. Ms. Goodin currently serves as chair of the HOV Systems committee of the Transportation Research Board.

MARK BURRIS (mburris@tamu.edu) is an assistant professor in the Department of Civil Engineering at Texas A\&M University, and an assistant research scientist at the Texas Transportation Institute. He received his bachelor of engineering, co-op program, degree in 1993 from the Technical University of Nova Scotia, his master of science in engineering in 1995 from the University of New Brunswick, and his doctorate in civil engineering in 2001 from the University of South Florida. Prior to joining Texas A\&M in August 2001, he was a senior research associate at the Center for Urban Transportation Research (CUTR) in Tampa, Florida.

CASEy Dusza (c-dusza@tamu.edu) has served as an assistant transportation researcher at the Texas Transportation Institute for five years. She received her undergraduate degree in community and regional planning from lowa State University and her graduate degree in community and regional planning from the University of Texas. Mrs. Dusza is active in a variety of research projects including those focusing on TDM, ML, and bicycle issues. 
Journal of Public Transportation, Vol. 10, No. 4, 2007 


\title{
Employer Perceptions and Implementation of Commute Alternatives Strategies
}

Kai Zuehlke and Randall Guensler, Georgia Institute of Technology

\begin{abstract}
Employer-based trip reduction (EBTR) strategies are the transportation demand management elements of commute options programs that target commute travel. This article reports the results of two surveys conducted in the Atlanta metropolitan area of implementation of EBTR strategies and employer perceptions of associated costs and benefits. On average, less than a quarter of the employers surveyed utilized EBTR strategies. Survey results indicate that employers commonly perceive that EBTR strategies provide minimal benefits for the company, that employers believe their employees lack interest in such measures, and that upper management does not provide support. Employers regard the distance between work location and transit as a significant barrier to implementing EBTR programs, and onsite sale of transit passes is associated with cost, equity, and operational concerns. However, members of transportation management associations and Atlanta's Clean Air Campaign report higher levels of implementation.
\end{abstract}

\section{Introduction}

Transportation demand management (TDM) can mitigate congestion and improve air quality by reducing the impact of individual travel decisions. Many TDM strategies do this by causing commuters to utilize alternatives instead of driving alone during peak periods. TDM organizations can urge individuals to par- 
ticipate in TDM programs via mass media campaigns and encourage employers to adopt TDM strategies through employer outreach.

This article examines the implementation of various employer-based trip reduction (EBTR) strategies among a sample of employers in the Atlanta metropolitan area. The Atlanta Clean Air Campaign (CAC) manages and publicizes various TDM programs and local transportation management associations (TMAs) support EBTR strategies. A large portion of employer membership in either of these organizations could indicate a high degree of employer outreach in the region. Employer promotion of TDM programs could indicate a degree of employer commitment to EBTR. Employers making alternative work modes available and offering commute benefits to employees would indicate a high degree of EBTR strategy implementation.

Approximately 15 percent of employers surveyed are members of either the CAC or a TMA, and at least 20 percent of employers promote commute programs at least rarely. Almost 80 percent of employers have a 40 -hour workweek available to all employees, about 25 percent of employers make flexible scheduling available to all employees, and other work modes are less available. On average, less than 15 percent of employers offer commute benefits.

This article addresses whether employer outreach actually leads to implementation of EBTR strategies. Members of CAC/TMAs achieve higher levels of implementation and have more positive employer perception of employer trip reduction programs than nonmembers. Noting this success, but acknowledging the potential influence of other factors, this article further explores barriers employers perceive as impeding implementation of EBTR strategies.

Survey results indicate that employers commonly perceive minimal benefits of, believe their employees lack interest in, and feel that upper management do not provide support for employer trip reduction programs. Employers regard the distance between their work location and transit as a significant barrier to implementing trip reduction programs. Implementation of onsite sales of transit passes is also associated with increased employer perception of conflict with organization operations, high cost, and concerns regarding equity across types of employees.

To understand the implications of these general results, the next section chronicles the history of employer-based TDM in the United States, and then discusses the local context of TDM and EBTR in Atlanta. The conceptual framework section defines the scope of this article; the methodology section covers the survey design, 
response rates, and analytical approach. Next, the levels of implementation of a wide set of EBTR strategies are presented, followed by the effect of CAC/TMA membership on EBTR strategy implementation. The barriers section uncovers obstacles employers perceive as impeding EBTR strategy implementation. The conclusions drawn are presented in the final section.

\section{Employer Transportation Demand Management}

TDM seeks to reduce congestion and improve overall mobility by influencing individual travel behavior. Various elements of U.S. transportation planning and policy have served this function. Following the major freeway construction boom of the 1950s and 1960s, transportation planning efforts turned in the 1970s toward increasing effective highway vehicle-carrying capacity and transit system performance without large federal capital expenditures. Parallel concerns sparked by the series of Clean Air Act Amendments and the oil price hikes led to efforts to manage transportation systems in the interest of air quality and energy efficiency and security, respectively (Meyer 1999). Thus, TDM incorporates aspects of congestion mitigation, air quality, and energy conservation. Rye (1999b) also points out the important roles employer-specific TDM can play in growth management, business development, and employee recruitment and retention.

A primary means of managing transportation demand is reducing the proportion of trips made by single occupancy vehicle, which would be measurable by a reduction in vehicle miles traveled (VMT). Work commute trips by automobile represent 20-25 percent of all trips made in the United States, are concentrated in the congested peak periods, and tend to be predominantly single occupant (Horner 2004). Given significant average geographic separation between home and work, influencing the travel demand of commuting employees could have the potential to greatly reduce VMT in the critical periods. Engaging employers is a primary means of achieving this reduction in commute travel.

TDM initiatives directed at employers have many different labels. Starting with aspects of early traffic management and transportation system management, more recent terms include employer-based TDM, employer trip reduction programs, EBTR strategies, employer commute options programs, employer-based travel plans, employer transport plans, mobility management, green commuter plans, and green transport plans (Meyer 1999; Rye 1999a, 1999b). Regardless of the moniker, EBTR strategies utilize employers as "mediating institutions" for public 
policy (Dehart-Davis and Guensler 2005). EBTR strategies can be similarly viewed as social marketing (McGovern 2005) specifically targeting employers. More can be found on EBTR strategies in Institute of Transportation Engineers and COMSIS Corporation (1993), Meyer (1997, 1999), Hendricks and Joshi (2004), and Henry and Gordon (2003).

Given the societal importance and costs of work-related travel, the goal of EBTR strategies may be "to encourage more employers to take responsibility for the congestion and pollution generated by their employees' trips to, from, and at work" (Rye 1999b). That is, EBTR strategies urge employers to internalize the externalities of commute travel. This is no easy task, given bureaucratic, corporate, and organizational tendencies for self-interest.

Serious challenges confront the acceptance, implementation, and success of EBTR strategies (Higgins 1996; Meyer 1999; Rye 1999a, 1999b). Limited success of early, mandatory EBTR programs has underscored the importance of inclusive planning processes in formulating EBTR strategies and implementation goals (Guensler 1998; Dill 1998). Automobile reliance, low-density suburban land-use patterns, and modest transit service have the potential to discourage U.S. employers from accepting EBTR strategies. Yet one recent study has shown that EBTR strategies can benefit employers' bottom line, requiring only a change of mindset and a commitment (Winters, Hendricks, and Stutts 2003).

When employers do embrace EBTR strategies, researchers are challenged with determining program effectiveness. Reduction in the drive-alone rate relative to a pretest or control group is one measure of program effectiveness (Higgins 1996). However, such data are rarely collected. A "performance measure continuum" that captures both the social acceptance of and quantifiable change in travel behavior has been proposed to evaluate EBTR project and program effectiveness (Finke and Schreffler 2004) and has been applied to Atlanta (Center for Transportation and the Environment 2003).

\section{Atlanta Context}

Atlanta has faced increasing transportation and air quality problems in recent decades, culminating in noncompliance with federal Clean Air Act standards. Public interest group reports gave the perception that Atlanta's traffic congestion and air quality issues were negative quality-of-life indicators, which could discourage businesses and employees from locating in the region. In this environment, business leaders and policy-makers were eager to employ innovative measures 
to address transportation issues. A major initiative started during this time is the Atlanta Framework for Cooperation to Reduce Traffic Congestion and Improve Air Quality, a collaboration among planning agencies, business groups, and transportation management associations (Clean Air Campaign 1999).

The Atlanta Framework envisions a multifaceted campaign to "improve the Atlanta Region's Air Quality and Mobility through the coordinated programs of public and private organizations designed to change individual and employer behaviors" (Clean Air Campaign 1999). Employer-based strategies and mass media publicity supplement commute services to individuals. Programs available to individuals include 1-87-RIDEFIND, which matches interested carpoolers, and guaranteed ride home (GRH), which guarantees ridesharing employees a trip home under emergency circumstances. The CAC coordinates TDM efforts regionally in conjunction with local TMAs and serves the public relations function of the Atlanta Framework by encouraging employers to adopt trip reduction strategies (see http://www.cleanaircampaign.com/ - July 2007). The Atlanta Framework utilizes many EBTR strategies, including carpools, vanpools, sales and subsidies of transit passes, GRH, flexible and compressed scheduling, and telework.

Results presented in this article afford unique insight into employer participation in and perception of EBTR strategies among a sample of Atlanta employers. The goal of this research is neither to determine the effectiveness of the Atlanta Framework in recruiting employers nor to gauge the resulting amount of travel reduction. The performance of the Atlanta Framework has been evaluated previously for an earlier time period (Center for Transportation and the Environment 2003) and is currently being evaluated again. Instead, this article examines the level of implementation of a variety of EBTR strategies across time. Using employer mail surveys, EBTR strategy implementation rates are assessed and barriers are identified. Before presenting an overview of the methodology of this study, the next section frames the scope of analysis.

\section{Conceptual Framework}

A major thrust of the Atlanta TDM Framework is to urge commuters to choose commute alternatives instead of driving alone during peak periods. Efforts in individual and employer outreach can be conceptualized according to Figure 1. "Awareness" indicates knowledge of TDM strategies and "participation" means commute benefit utilization, alternative work mode selection, and/or TDM program enrollment. 




Figure 1. Employer Role in TDM

Sometimes simply informing individuals is sufficient to induce program participation. Assuming complete information dissemination, individuals would evaluate their commute choice set considering factors such as proximity to transit and service attributes through the filter of personal bias or predisposed disinclination. A subset of aware individuals would choose to participate in TDM programs. Participation in TDM programs would entail use of commute alternatives, which would then result in some travel and emissions changes (presumably reductions). On this "individual" branch of the TDM tree, other possible outcomes are awareness without participation and media publicity without awareness.

To capture commuters not recruited to TDM program participation by individual outreach, regional TDM organizations engage in employer outreach. The added mediation and social marketing provided by employers are presumed to increase the likelihood of individual commuters participating in TDM programs. Employers could balance factors such as transit proximity to their location, work-site operations, and employee characteristics through the lens of institutional bias. Employers engaged by the CAC/TMAs might choose to promote employees to ongoing regional programs and systems, such as transit, rideshare matching service, GRH, or financial incentives. This added marketing could cause awareness in commuters 
not reached by mass media marketing. A subset of such aware individuals might choose to participate.

Still, informational awareness would only induce a certain percentage of commuters to modify their travel behavior. Capturing more intrepid drivers would require tougher measures, such as not merely promoting existing regional TDM programs but implementing onsite TDM strategies. This could include actual coordination/facilitation of work-site programs, additional incentives, and modification of work schedules. Except for possibly during the brief stint of mandatory EBTR programs (Guensler 1998; Dill 1998), even employer implementation of TDM strategies would not result in 100 percent employee participation. To summarize the "employer" tree, the additional options include employer program implementation without employee participation, employer program promotion without employee awareness, employee awareness without employee participation, and complete employer nonparticipation. ${ }^{1,2}$

This article primarily assesses employer TDM strategy implementation and the impact of effective employer outreach, as measured by membership in the CAC/ TMAs, on strategy implementation. Given the challenges of inducing employers to CAC/TMA membership and EBTR strategy implementation, employer-perceived barriers are examined.

\section{Methodology}

\section{Survey Design}

This article presents data from the Atlanta Employer Commute Options (ECO) Survey, which was conduced in 2003 and 2005 as a part of the Commute Atlanta project (see http://commuteatlanta.ce.gatech.edu/ - July 2007). Commute Atlanta is an ongoing congestion pricing research project that uses GPS-instrumented vehicles to study driver behavior and consumer response to mileage-based and real-time congestion pricing ( $\mathrm{Li}$ et al. 2004; Ogle 2005). The employer survey element was designed to control for changes in employer policies and practices that might impact trip-making behavior during the Commute Atlanta study period. The survey data provide insight into employer perception and implementation of EBTR strategies across two phases: 2003 and 2005. This time period was selected due to the Commute Atlanta project schedule and not due to any specific treatment presumed to have particular impact. 
The survey design and strategies included in the survey were developed in consultation with an expert survey advisory panel (Dehart-Davis and Guensler 2005; Dehart-Davis, Feng, and Guensler 2004; Feng, Dehart-Davis, and Guensler 2005). The original survey sample was drawn from 207 employers of Commute Atlanta households, a random selection of 300 members of the Metro Atlanta Chamber of Commerce (MACOC), and a random selection of 300 employers of 4,000 household participants in the Strategies for Metropolitan Atlanta's Regional Transportation and Air Quality (SMARTRAQ) regional travel diary study (Dehart-Davis, Feng, and Guensler 2004; Feng, Dehart-Davis, and Guensler 2005). The ECO survey was mailed to the human resources director of each employer, as the director was believed to be the best person within the organization to know the employee transportation policies of the organization. An alert letter preceded the printed survey, cover letter, postage-paid return envelope, and a small monetary incentive. If, after a follow-up postcard, there was still no response, a second survey was sent with a new cover letter and return envelope. For businesses that were members of the chamber of commerce, a third mailing was addressed to the CEO with a cover letter from the MACOC president. Employer identification numbers enabled positive employer identification and tracking of all employers across phases.

Scrutiny of the mail survey returns warranted exclusion of 44 employers believed to have never received any survey mailing in either phase. Of employers that completed a survey in Phase 1, 34 either relocated or went out of business between phases and were consequently excluded from the Phase 2 potential sample pool. After the analysis was completed, it was discovered that accidental multiple polling of several work sites yielded cases of multiple returned surveys for a single employer. The same employer was coded in separate records due to redundancy across the data sources. Most duplication appeared in pairs, with two cases of three records representing a single employer. Cleaning the dataset resulted in removing 19 records; 10 cases of two-phase nonresponse (no data lost), 7 cases of one-phase nonresponse (one phase of results lost), and 1 case of two-phase response (both records deleted). ${ }^{3}$

\section{Response Rates}

After data cleaning, in Phase 1 (2003), 35 employers declined to participate (5\%), 297 employers did not respond (40\%), and 406 employers completed the survey (55\%), resulting in a response rate of 58 percent. In Phase 2 (2005), 24 employers declined to participate (3\%), 338 did not respond (48\%), and 343 employers completed the survey (49\%), yielding a 59 percent response rate. The sample of com- 
pleted surveys consisted of 172 employers that responded only in Phase 1 (34\%), 109 only in Phase 2 (22\%), and 225 that responded in both phases (44\%).

Figure 2 maps the locations of the ECO survey employers. The geographic distribution of employers was determined by categorization of geocoded addresses into three location types. Employers were assumed to be located in a high-density "rail core" if they were within a 0.25 -mile radius of a heavy rail station $(n=89,12 \%)$. Employers within 0.25 straight miles of any transit line (heavy rail, express bus, and local bus) were considered within a "transit zone" ( $n=431,58 \%)$. Other employers in the sample were labeled "non-transit zone" ( $n=222,30 \%)$. The results are used in the analysis of barriers to EBTR implementation below.



Transit Accessibility Classification Zones

Rail Core:

0.25 miles of rail stations

Transit Zone:

0.25 miles of transit routes

Non-Transit Zone:

Other urbanized and

non-urbanized area

Service Providers:

MARTA

Clayton County Transit

Cobb Community Transit

GRTA Xpress

Gwinnett County Transit

Figure 2. Surveyed Employer Locations

Individual respondents and/or organizations with a higher regard for EBTR strategies might have more readily returned surveys, resulting in self-selection bias. However, given the relatively low frequency of EBTR implementation reported, this seems 
unlikely to have had much impact. Because the Atlanta ECO survey targeted more than 700 employers from three randomized sources and achieved response rates of 50 percent or better, the survey sample is considered reasonably representative of Atlanta employers. See a discussion on potential sample bias in Feng, Dehart-Davis, and Guensler (2005).

Analytical Approach The survey contains nearly 200 different data elements. Subquestion nonresponse was resolved by filtering out records that contain blank values in any field directly relevant to each analysis. Survey questions include binary, categorical, ordinal, and numeric data types on employer characteristics, opinion, metrics, and EBTR strategy implementation. Comparison of binary variables allow for chi-square $\left(\chi^{2}\right)$ testing of statistical significance using $2 \times 2$ contingency tables. With these one degree-of-freedom tables and $\alpha=0.05$, the critical $\chi^{2}=3.841$.

\section{Longitudinal Frequencies}

No statistically significant change in CAC/TMA membership, EBTR strategy promotion, or EBTR strategy implementation was detected between the surveys.

\section{CAC and TMA Membership}

Figure 3 illustrates that membership in the CAC and TMAs averages less than 15 percent of employers. Membership in "either" organization is used in the membership-benefit analysis below. Employer outreach as measured by CAC or TMA membership has not engaged a large portion of the survey sample.

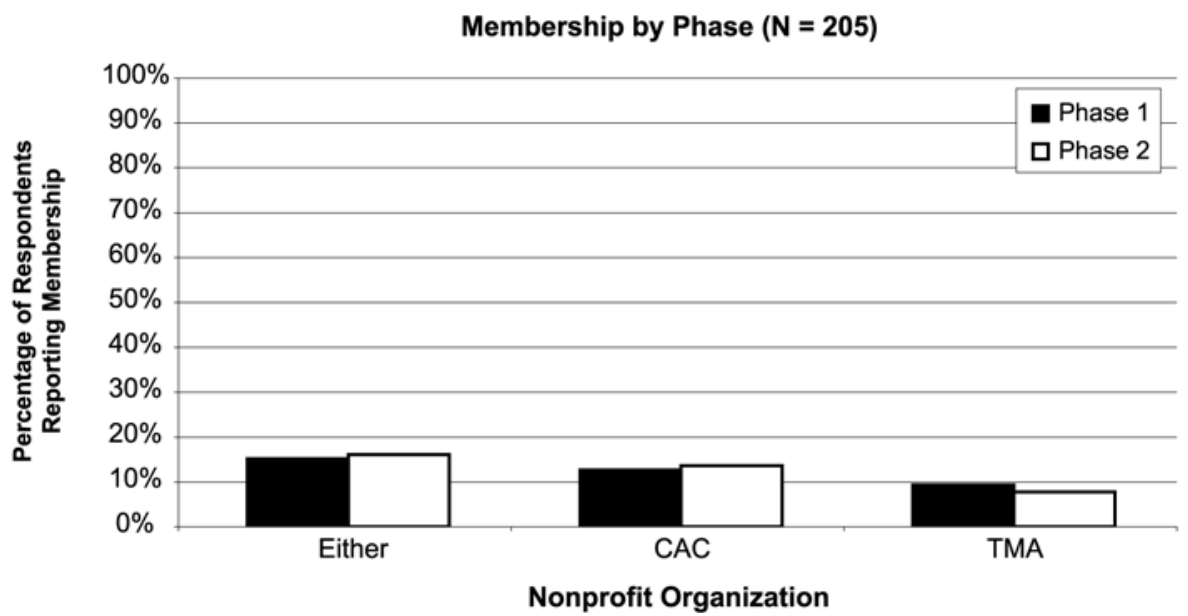

Figure 3. Membership by Phase 


\section{Program Promotion}

Frequency of commute options program promotion serves as an indicator of EBTR prevalence. Promoting programs could enable employers to support ongoing regional EBTR strategies without necessarily bearing direct responsibility. These more "hands-off" approaches include providing information about public transit routes and fares, GRH, and 1-87-RIDEFIND (see Figures $4 a$ and $4 b$ ). Less than 30 percent of surveyed employers promote each of the three programs referenced below.

Frequency of Program Promotion in Phase $1(\mathrm{~N}=\mathbf{2 3 1})$

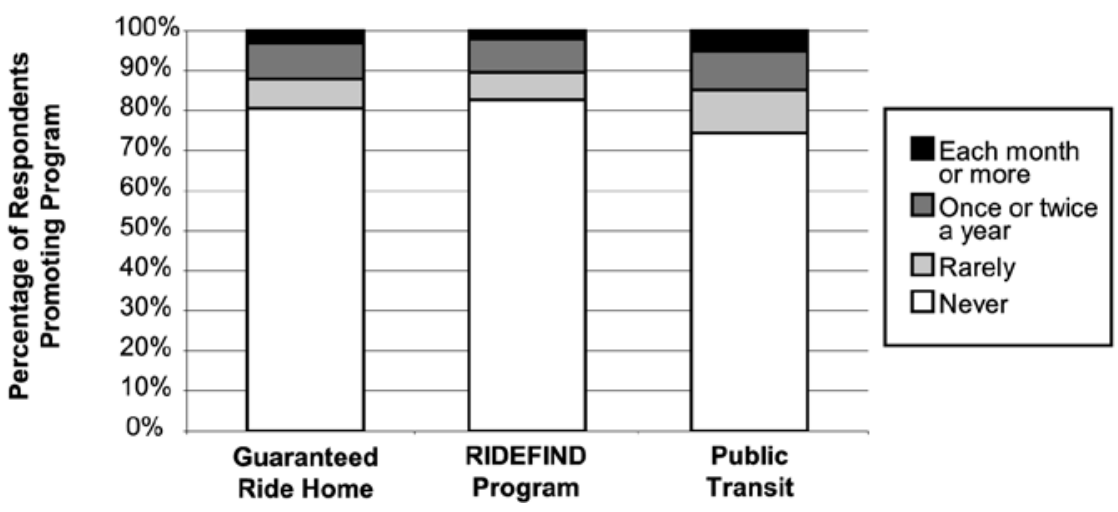

Figure 4a. Program Promotion in Phase 1

Frequency of Program Promotion in Phase $2(\mathrm{~N}=\mathbf{2 3 1})$

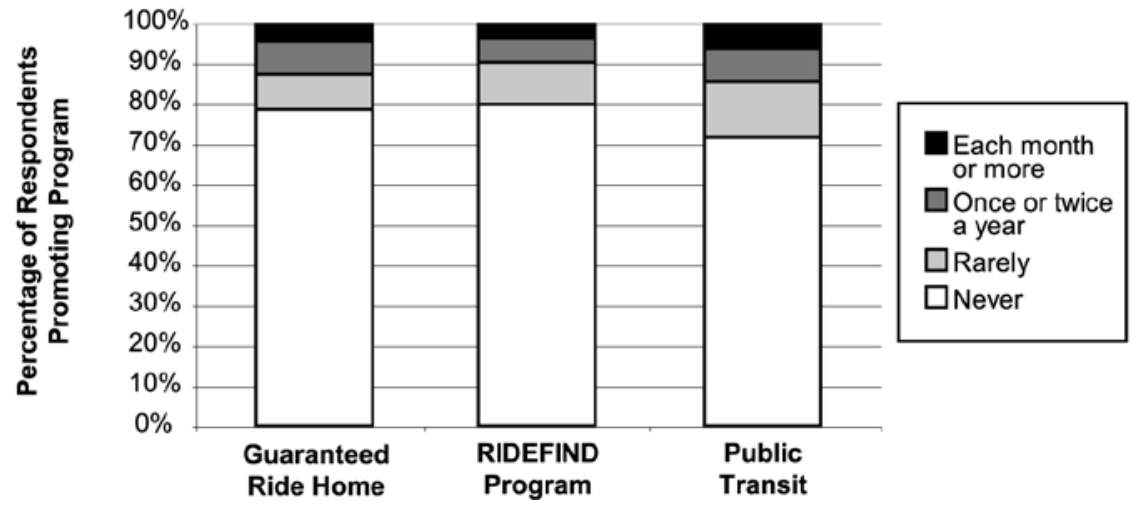

Figure 4b. Program Promotion in Phase 2 


\section{Work Mode Availability}

Offering alternative work modes, though dependent in part on the type of employment, indicates a significant commitment by the employer and represents another key EBTR variable. These include: traditional 40-hour onsite workweek, compressed workweek, multiple work shifts, flexible arrival/departure times, and working from home (see Figures $5 a$ and $5 b$ ).

Clearly, the traditional 40 -hour workweek is the dominant work mode, with flexible arrival and departure times the second most available.

\section{Benefits Offering}

Both in 2003 and in 2005, employers were asked if they offered the following commute benefits:

- Participation in GRH

- Onsite sales of transit passes or tokens

- Employer-subsidized bus, rail, or vanpool passes

- Deductions of carpool, vanpool, or transit expenses from employee pretax income

- Deductions of parking expenses from employee pretax income

- Brokering of discount bus, rail, or vanpool passes

- Bicycle lockers

- Showers for employees biking or walking to work

- Satellite offices from which employees can work

$\mathrm{GRH}$ indicates an employer's estimate of employee participation in the regional program. Bicycle lockers, showers, and satellite offices represent investments committed by employers that could benefit employees choosing commute alternatives. The remaining benefits represent TDM strategies implemented by the employer. 
Work Mode Availability in Phase 1 ( $N=199)$

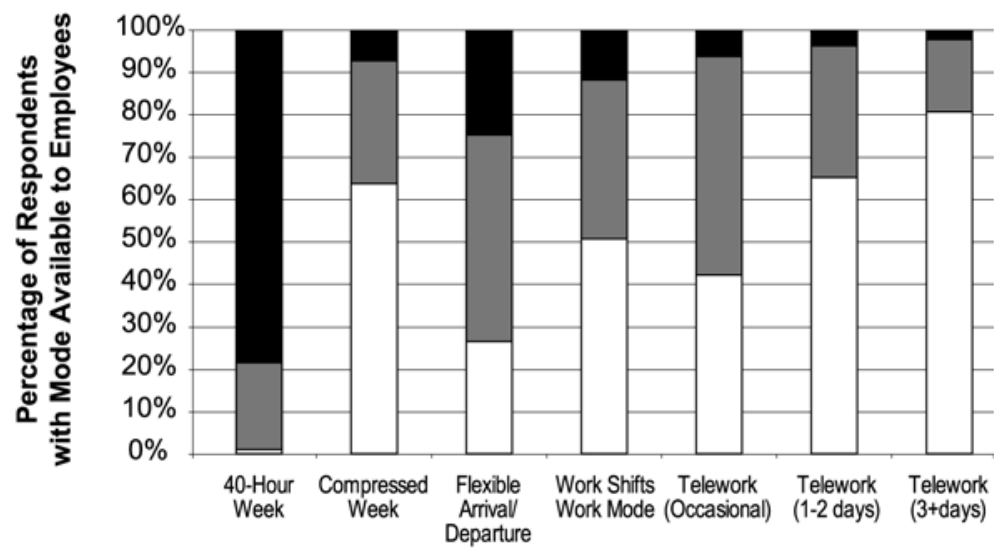

all

$\square$ Some

$\square$ Not

\section{Work Mode}

Figure 5a. Work Mode Availability in Phase 1

Work Mode Availability in Phase 2 ( $\mathrm{N}=199)$
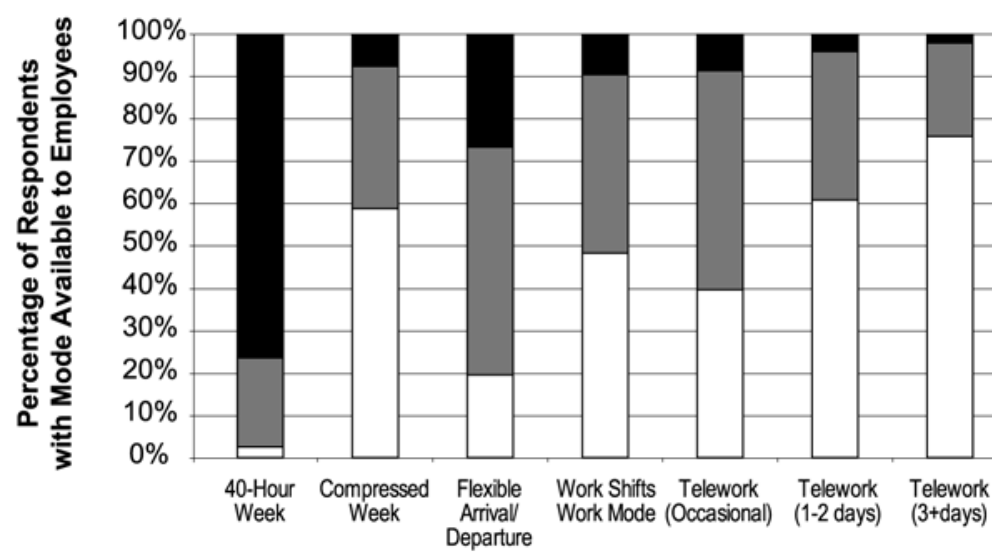

Work Mode

Figure 5b. Work Mode Availability in Phase 2 
Figure 6 charts percentages of respondents offering the benefit in each phase. Most commute benefits are offered by 5 to 15 percent of respondents.



Figure 6. Benefits Offered by Phase

The longitudinal analysis indicates the implementation penetration rates for EBTR strategies by surveyed Atlanta employers may not have changed significantly between survey years. A further key question, however, pertains to whether employer outreach actually leads to employer implementation of TDM strategies.

\section{CAC and TMA Membership}

Figure 7 charts the respective percentages of respondents offering commute benefits by member or nonmember status along with 95 percent confidence intervals. Members of the CAC/TMA are more likely to offer every commute benefit in both phases, except for satellite offices in Phase 1. Also, members are more likely to offer onsite sales of transit passes ( $56 \%$ in Phase $1,54 \%$ in Phase 2 ) than parking deductions ( $25 \%, 26 \%$, respectively) and satellite offices ( $15 \%, 24 \%$, respectively). 


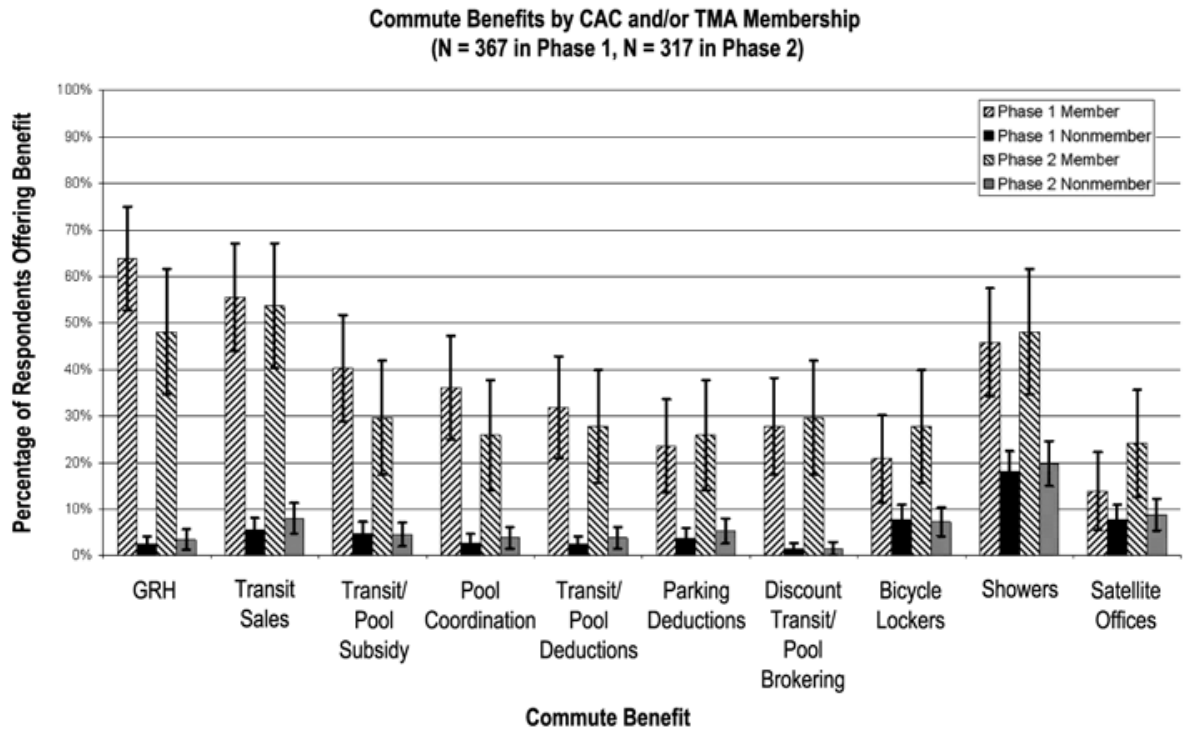

Figure 7. Benefits by CAC/TMA Membership

As further indication of the strength of CAC/TMA EBTR programs, members are more likely to offer transit passes than pretax deductions of parking expenses.

That members of the CAC/TMAs implement EBTR strategies so much more than nonmembers is not necessarily a given and is encouraging to verify. Self-selection is inherent in the very nature of voluntary TDM program participation. However, recruiting more employers to the CAC and TMAs could enhance EBTR program implementation in the region. CAC employees are meeting with strategically targeted employers in a recent aggressive recruitment effort.

Despite the high level of EBTR strategy implementation by CAC/TMA members, most employers surveyed are not members and do not implement EBTR strategies. The next section analyzes employer trepidation to EBTR strategy implementation in terms of perceived barriers. 


\section{Strategy Implementation Barriers}

The survey asked employers the general question, "How influential have the following factors been in preventing your organization from implementing more employee commute options?"

- Insufficient employee interest

- Minimal perceived benefits to organization

- Lack of upper management interest

- Potential regulatory or legal barriers

- Potential conflicts with organization operations

- Potential union opposition or conflicts

- High cost to the organization

- Equity issues across types of employees

- Lack of commute options information

- The office's distance to public transit

- Lack of government incentives

- Potential paperwork requirements

The key question was, "If a company did not offer a commute benefit, what was the potential barrier?" The discussion below focuses on the three major findings: (1) the most commonly perceived barriers, (2) the strength of perceived distance to transit as a barrier, and (3) barriers to onsite sale of transit passes.

\section{Influential Barriers}

For each commute benefit, the percentages of employers not offering the benefit and also considering each barrier as influential were calculated. Each barrier's percentages were averaged across all commute benefits. Under such consideration, the most influential barriers are:

- Insufficient employee interest (62\% in Phase 1,60\% in Phase 2)

- Minimal perceived benefits to organization (54\%,58\%)

- Lack of upper management support $(52 \%, 49 \%)$

- Office's distance to public transit $(51 \%, 43 \%)$

Survey respondents indicate significant resistance to implementing EBTR strategies when they report lack of employee interest from below, lack of upper manage- 
ment support from above, and minimal perceived benefits across the organization.

\section{Distance to Transit}

The second major finding is the strength of distance to transit as a barrier to major EBTR commute benefits in both phases: GRH, transit sales, transit/vanpool/carpool subsidy, deductions of transit/pool and parking expenses, and brokering of discount transit/pool passes. Table 1 indicates $\chi^{2}$ statistical difference for influence of distance to transit on not offering these commute benefits. Two other statistics demonstrate the importance of this barrier: difference and consistency factors. The difference factor, $\delta$ percent, indicates the raw difference between the percentage of respondents who do not offer the commute benefit that report the barrier as influential and the percentage of respondents who do offer the commute benefit that report the barrier as influential. A large positive value for the difference factor for barriers indicates the potential presence of a persuasive and preventative barrier. The "consistency factor," c, is one additional dispersion statistic that relates the total number of employers who indicate barrier influence to how many end up not offering the benefit. Low values of this percentage would indicate a high level of consistency and a strong explanatory value. Employer perception of distance to transit impedes implementation of onsite sales of transit passes or tokens, transit/pool subsidies, both parking and transit/pool deductions, and discount brokering of transit passes.

\section{Table 1. Distance to Public Transit as a Barrier to Offering Commute Benefits}

\begin{tabular}{lrrr|lrrr}
\hline \multicolumn{2}{c}{ Phase 1 } & & & \multicolumn{4}{c}{ Phase 2 } \\
\hline Commute Benefit & \multicolumn{1}{c}{$\chi^{2}$} & $\delta \%$ & c & Commute Benefit & $\chi^{2}$ & $\delta \%$ & c \\
\hline GRH & 6.790 & $20 \%$ & $9 \%$ & GRH & 9.630 & $27 \%$ & $6 \%$ \\
Transit Sales & 23.258 & $36 \%$ & $6 \%$ & Transit Sales & 15.194 & $29 \%$ & $8 \%$ \\
T/P Subsidy & 24.752 & $40 \%$ & $3 \%$ & T/P Subsidy & 6.411 & $24 \%$ & $5 \%$ \\
T/P Deductions & 4.946 & $22 \%$ & $5 \%$ & T/P Deductions & 8.062 & $29 \%$ & $3 \%$ \\
Parking Deductions & 16.553 & $41 \%$ & $2 \%$ & Parking Deductions & 8.062 & $29 \%$ & $3 \%$ \\
Discount T/P & 8.762 & $33 \%$ & $2 \%$ & Discount T/P & 6.944 & $29 \%$ & $2 \%$ \\
Brokering & & & & Brokering & & & \\
\hline Average & 14.177 & $32 \%$ & $4 \%$ & Average & 9.051 & $28 \%$ & $4 \%$ \\
\hline
\end{tabular}


To assess employer concern of distance to transit, perception of this barrier was cross-tabulated with actual employer geographic location (see Tables $2 \mathrm{a}$ and $2 \mathrm{~b}$ ). A map of Phase 2 results is given in Figure 8.

\section{Table 2a. Perceived and Actual Distance to Transit in Phase 1}

Geographic Location \& Perceived Distance toTransit as Barrier, Phase 1

\begin{tabular}{|lll|r|r|r|r|}
\hline & & & \multicolumn{3}{|c|}{ Transit Barrier P1 } & \\
\cline { 4 - 7 } & & $\begin{array}{c}\text { No } \\
\text { Influence }\end{array}$ & $\begin{array}{c}\text { Some } \\
\text { Influence }\end{array}$ & $\begin{array}{c}\text { Strong } \\
\text { Influence }\end{array}$ & Total \\
\hline Geographic Location & Rail Core & $\mathrm{n}$ & 47 & 9 & 2 & 58 \\
& & $\%$ & $81.0 \%$ & $15.5 \%$ & $3.4 \%$ & $100.0 \%$ \\
\cline { 2 - 7 } & Transit Zone & $\mathrm{n}$ & 126 & 46 & 54 & 226 \\
& & $\%$ & $55.8 \%$ & $20.4 \%$ & $23.9 \%$ & $100.0 \%$ \\
\cline { 2 - 6 } & Non-Transit Zone & $\mathrm{n}$ & 32 & 23 & 49 & 104 \\
& & $\%$ & $30.8 \%$ & $22.1 \%$ & $47.1 \%$ & $100.0 \%$ \\
\cline { 3 - 7 } Total & & $\mathrm{n}$ & 205 & 78 & 105 & 388 \\
& & $\%$ & $52.8 \%$ & $20.1 \%$ & $27.1 \%$ & $100.0 \%$ \\
\hline
\end{tabular}

Table 2b. Perceived and Actual Distance to Transit in Phase 2

Geographic Location \& Perceived Distance toTransit as Barrier, Phase 2

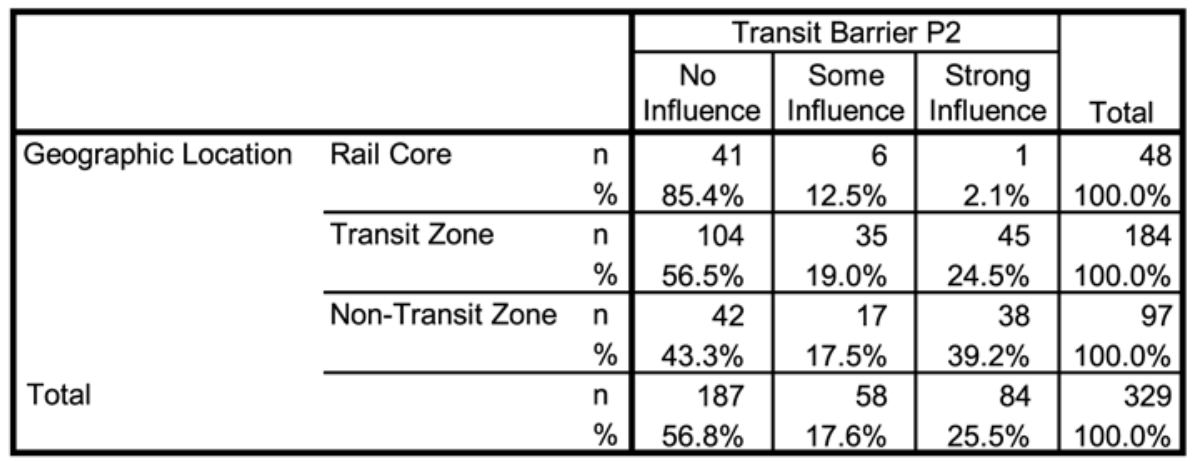






Figure 8. Perceived and Actual Distance to Transit

Generally, employers located near transit report no influence of distance to transit as a barrier. However, many employers who appear to have good access to transit claim not to. This finding is the subject of ongoing research that will treat accessibility to transit in more detail. Employers located outside the transit service area who report no influence might dismiss transit altogether. A policy implication here is to target transit-related EBTR strategies in transit service areas, which is already underway.

\section{Onsite Transit Sales}

The third finding involves barriers to offering onsite sales of transit passes or tokens. Specifically, these barriers are "potential conflicts with organization operations," "high cost to our organization," "equity issues across types of employees," and "lack of government incentives." Table 3 indicates that all four barriers were significant in both phases by the $\chi^{2}$ test. 
The negative difference factor $(\delta \%)$ indicates that employers who do offer transit sales are more likely to regard these barriers as influential than employers who do not offer this benefit. That is, employer implementation of onsite transit sales appears to increase employer perception of conflict with organization operations, high cost, and concerns regarding equity across types of employees. Development of government and transit agency strategies designed to reduce the burden on employers associated with offering onsite sales of transit passes should probably be a high priority.

Table 3. Barriers to Onsite Transit Sales

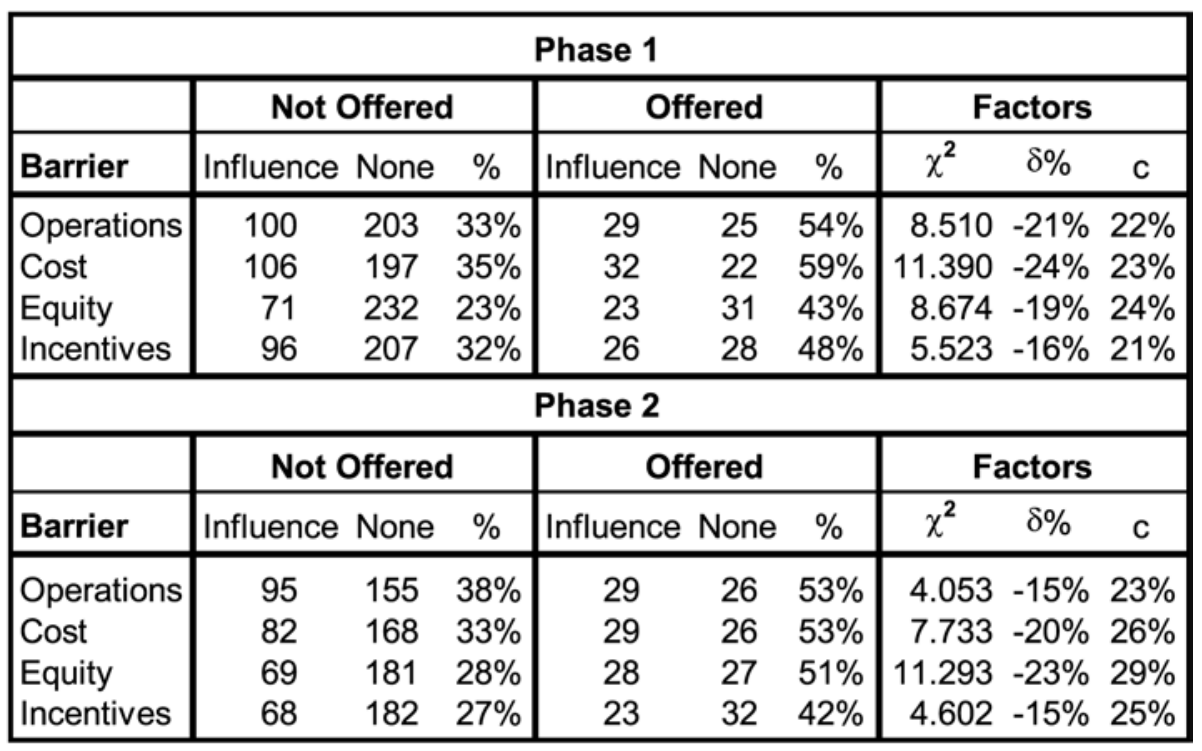

Also noteworthy, in both phases, high regard for the preventative influence of "equity issues across types of employees" is correlated with low levels of offering "employer-subsidized bus, rail or vanpool passes."

\section{Conclusions}

The survey results reported in this article indicate that the promotion, coordination, and service efforts of the CAC and TMAs to member employers are cor- 
related with higher levels of strategy implementation among members. Whether these employers are self-selected into organizational membership remains somewhat uncertain. However, these results are very encouraging.

Internal employer barriers, however, still appear to be significant with respect to implementing incentives. Employers commonly perceive that strategies yield minimal benefits, that their employees lack participation interest, and that upper management will not provide support for employer trip reduction programs.

Employers also regard the distance of their work location to transit as a significant barrier to implementing trip reduction programs. On average, only 4 percent of companies that regard distance to transit as a barrier offer any transit-related benefit. Implementation of onsite sales of transit passes is associated with increased employer perception of conflict with organization operations, high cost, and concerns regarding equity across types of employees. Development of government and transit agency strategies designed to reduce the burden on employers associated with offering onsite sales of transit passes should probably be a high priority.

Given these transit results, additional research efforts should better define acceptable distances to transit and the relationship between employer-perceived and actual distance to transit. Educational initiatives on transit accessibility should be directed toward employers within acceptable transit zones. In addition, employers located an unacceptable distance from transit should not be encouraged to offer transit-related benefits. Such work would also be useful in the planning of future regional transit. Employer-specific choice set analysis, such as that underway in the Commute Atlanta project, would provide a better picture of transit accessibility. Research into the equity impacts associated with employer commute options strategies appears warranted based on the stated concerns of industry in the 2003 and 2005 surveys. Further research is needed to assess trends in employer perception of subsidies on potential conflict with organization operations.

Given that there was no significant change in CAC membership in the samples, advertising campaigns may not have increased employee and employer interest in commute options programs between 2003 and 2005. It is acknowledged that the ECO survey sample may not have captured effects of recent recruitment efforts by CAC contract employees that target sector- and location-specific employers. Nevertheless, as these programs continue to expand in Atlanta, it will become paramount to implement monitoring and survey efforts designed to assess the actual effect of implemented incentives on employee travel behavior. 


\section{Endnotes}

1 This assumes where an employer implements a program, all employees are aware.

${ }^{2}$ Another possibility is employer awareness.

${ }^{3}$ Some of the analysis in this article contains the 19 records identified and deleted in 2006. The calculations were not rerun after the cleaning process in the interest of time, because the impact of these records is negligible given the sample size for each analysis.

\section{References}

Clean Air Campaign. 1999. A framework for cooperation to reduce traffic congestion and improve air quality.

Center for Transportation and the Environment. 2003. Evaluation of the effectiveness of programs contained in the "framework for cooperation to reduce traffic congestion and improve air quality." Phase Three, FY2002 Atlanta TDM Framework Final Report.

Dehart-Davis, Leisha, Chunxia Feng, and Randall Guensler. 2004. Atlanta employer commute options survey report of final results: For GDOT and FHWA.

Dehart-Davis, Leisha, and Randall Guensler. 2005. Employers as mediating institutions for public policy: The case of commute options programs. Policy Studies Journal 33 (4):675-697.

Dill, Jennifer. 1998. Mandatory employer-based trip reduction: What happened? Transportation Research Record: Journal of the Transportation Research Board (1618):103-110.

Feng, Chunxia, Leisha Dehart-Davis, and Randall Guensler. 2005. Survey design and preliminary results for Atlanta employer commute options survey. Paper read at 98th Annual Meeting CD-ROM, June 2005, Pittsburgh, PA.

Finke, Timo, and Eric Schreffler. 2004. Using multiple assessment levels for evaluating transportation demand management projects: Monitoring and evaluation toolkit. Transportation Research Record: Journal of the Transportation Research Board (1864):135-143. 
Guensler, Randall. 1998. Increasing vehicle occupancy in the United States. Paper read at L'Avenir Des Deplacements en Ville (The Future of Urban Travel), Lyon, France.

Hendricks, Sara J., and Ajay Joshi. 2004. Commuter choice program case study development and analysis. Tampa, FL: Center for Urban Transportation Research. University of South Florida.

Henry, Gary T., and Craig S. Gordon. 2003. Driving less for better air: Impacts of a public information campaign. Journal of Policy Analysis and Management 22 (1):45-63.

Higgins, Thomas J. 1996. How do we know employer-based transportation demand management works? The need for experimental design. Transportation Research Record: Journal of the Transportation Research Board (1564).

Horner, Mark W. 2004. Spatial dimensions of urban commuting: A review of major issues and their implications for future geographic research. The Professional Geographer 56 (2):160-173.

Institute of Transportation Engineers and COMSIS Corporation. 1993. Implementing effective employer-based travel demand management programs. Washington, D.C.

Li, Hainan, Randall Guensler, Jennifer Ogle, and J. Wang. 2004. Using global positioning system data to understand day-to-day dynamics of morning commute behavior. Transportation Research Record: Journal of the Transportation Research Board (1895).

McGovern, Enda. 2005. Social marketing applications and transportation demand management: An information instrument for the 21st Century. Journal of Public Transportation 8 (5):1-24.

Meyer, Michael D. 1997. A toolbox for alleviating traffic congestion and enhancing mobility. Washington, DC: Institute of Transportation Engineers.

- - - 1999. Demand management as an element of transportation policy: Using carrots and sticks to influence travel behavior. Transportation Research Part A 33:575-599.

Ogle, Jennifer. 2005. Quantitative assessment of driver speeding behavior using instrumented vehicles. Atlanta, GA: Civil and Environmental Engineering, Georgia Institute of Technology. 
Rye, Tom. 1999a. Employer attitudes to employer transport plans: A comparison of UK and Dutch experience. Transport Policy 6:183-196.

- - . 1999b. Employer transport plans-A case for regulation? Transport Reviews 19 (1):13-31.

Winters, Philip L., Sara J. Hendricks, and Elizabeth Stutts. 2003. Quantifying the business benefits of TDM. Tampa, FL: National Center for Transit Research.

\section{About the Authors}

KAI ZUEHLKE (kai@gatech.edu) is a graduate research assistant in the School of Civil and Environmental Engineering at the Georgia Institute of Technology. He is studying urban transportation planning, and working toward dual M.S. in civil engineering and city and regional planning degrees. His research focuses on employer incentives, commute mode choice, and individual travel behavior. Prior to attending Georgia Tech, Mr. Zuehlke earned a B.S. in engineering science and mechanics from Virginia Polytechnic Institute and State University.

RANDALL GUENSLER (randall.guensler@ce.gatech.edu) is a professor in the School of Civil and Environmental Engineering at the Georgia Institute of Technology. Since arriving at Georgia Tech in 1994, Dr. Guensler's main research focus has been the development of new monitoring and modeling tools to assess the air quality impacts of transportation policies.

Dr. Guensler is the director of Commute Atlanta, a joint value pricing initiative sponsored by the Federal Highway Administration and Georgia Department of Transportation. In addition to allowing study of consumer response to road pricing experiments, Commute Atlanta's second-by-second vehicle speed, position, and engine operating data have led to research on analysis of speeding, journey-to-work route choice, trip chaining, activity-based demand, household trip-making variability, household and vehicle range of travel, long-distance travel, freeway operations, engine load, start and soak distributions, and transit bus operations.

Dr. Guensler was the chairman of the Transportation Research Board committee on Transportation and Air Quality from 1997 to 2002. From 1995 to 2001, he served on the Environmental Protection Agency's Mobile Source Technical Advisory Subcommittee. Over the past 10 years, he has served on various National Academy of Sciences committees and panels charged with the assessment of vehicle emissions impacts and identification of research needs. 